\title{
DEVELOPMENT OF LATTICED TOWERS USING ADVANCED COMPOSITE MATERIALS
}

BY

\section{ANDREW OCHONSKI}

\author{
A Thesis \\ Submitted to the Faculty of Graduate Studies \\ In Partial Fulfillment of the Requirements for the Degree of
}

Doctor of Philosophy

Department of Civil Engineering

The University of Manitoba

Winnipeg, Manitoba

Canada

(C) March 2009 
THE UNIVERSITY OF MANITOBA

FACULTY OF GRADUATE STUDIES

$\div * \div * *$

COPYRIGHT PERMISSION

Development of Latticed Towers Using Advanced Composite Materials

BY

Andrew Ochonski

A Thesis/Practicum submitted to the Faculty of Graduate Studies of The University of Manitoba in partial fulfillment of the requirement of the degree

Of

Doctor of Philosophy

Andrew Ochonski $(\mathcal{C} 2009$

Permission has been granted to the University of Manitoba Libraries to lend a copy of this thesis/practicum, to Library and Archives Canada (LAC) to lend a copy of this thesis/practicum, and to LAC's agent (UMI/ProQuest) to microfilm, sell copies and to publish an abstract of this thesis/practicum.

This reproduction or copy of this thesis has been made available by authority of the copyright owner solely for the purpose of private study and research, and may only be reproduced and copied as permitted by copyright laws or with express written authorization from the copyright owner. 


\section{ABSTRACT}

Due to the need for maintenance and corrosion protection, the use of galvanized steel in the fabrication of latticed structures has become an expensive process. To avoid these problems Advanced Composite Materials (ACM), such as FibreReinforced Polymers (FRP) have been introduced. A new technology developed by Cormorant Composites and University of Manitoba was used to fabricate tower segments using a specially constructed collapsible mandrel and a continuous multiple roving filament winding process. The ANSYS Finite Element Analysis Program was used to design the optimal cross sectional properties. A non - linear finite element analysis of a full scale guyed tower prototype was performed using wind loads outlined in CSA-S37-01. The dynamic response of the wind was included by using a gust factor method in which a gust factor was applied to the wind pressure of a static loading. The finite element results were

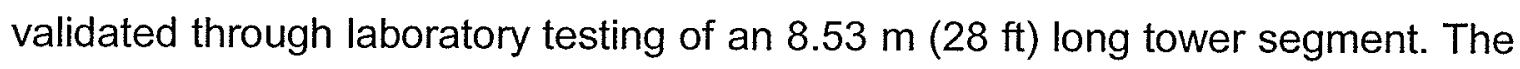
test conditions were created to resemble actual restraints and loading conditions

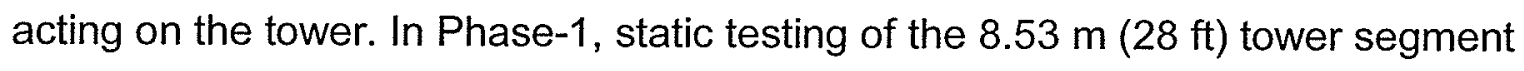
was conducted, using a "Whiffle Tree" arrangement, to simulate a uniformly distributed wind loading. Static testing in Phase-1 provided insight into the FRP connection performance, which was significantly improved for the dynamic testing. In Phase-2, dynamic testing of $8.53 \mathrm{~m}(28 \mathrm{ft})$ tower segment in an upright position was conducted to obtain natural frequencies of vibrations, which were confirmed through a mathematical model and through ANSYS Modal and 
Harmonic analyses. The dynamic test results showed that the undamped natural frequency of the vibrating tower segment was $4.31 \mathrm{~Hz}$. Also, the modal analysis of a full scale model was carried out in order to compare its dynamic findings with the results obtained through testing of the $8.53 \mathrm{~m}(28 \mathrm{ft})$ tower segment. The first natural frequency of vibration of full scale tower was $0.219 \mathrm{~Hz}$ which was lower than the natural frequency of the tested FRP tower segment by the factor of 20 .

A full dynamic analysis of the FRP tower was also conducted using the patch load method, recommended by CSA-S37-01 (CSA, 2001). Twelve different patch load cases were used in the FEM ANSYS 8.1 (ANSYS, 2004) program. After the dynamic analysis using the patch load method it was concluded that the gust factor method and the patch load method with the detailed scaling predict the peak response of the FRP tower well. Finally, design considerations for FRP towers were developed. The effect of fibre volume fraction on the mechanical properties of the FRP tower was illustrated through an example. It was found that by increasing the fibre volume fraction of lamina by $28.2 \%$ resulted in a reduction in the tip deflection of the FRP tower by $7.5 \%$. The strength performance of the FRP tower was also evaluated using the Maximum Stress non interactive criterion and the Tsai-Wu interactive criterion. The maximum combined stress from static analysis was $-68.22 \mathrm{MPa}(-9.89 \mathrm{ksi})$ which was well below the compressive strength of FRP material. An estimation of the compressive buckling strength of the chord members, based on the model developed by Rosen (1964) for unidirectional composites, was obtained. The result showed that local buckling of chord members was not the critical mode of failure. 


\section{ACKNOWLEDGEMENTS}

The author wishes to express his sincere gratitude and appreciation to the following individuals without whom this project would not have been possible:

- Dr. Dimos Polyzois, P.Eng., Advisor

- Dr. Nipon Rattanawangcharoen, P.Eng., Advisory committee member

- Dr. Raghavan Jayaraman, P.Eng., Advisory committee member

- Dr. Murty K.S. Madugula, P.Eng., External Examiner

- Mr. Greg Friesen, P.Eng., Manitoba Hydro

- Mr. Nibong Ungkurapinan, PhD Candidate, University of Manitoba

- Dr. Vladimir Burachynsky, Cormorant Advanced Composites

- Mr. Morey McVey, Technician, University of Manitoba

- Mr. Dino Philopulos, Research Associate, University of Manitoba

- Mr. Grant Whiteside, Technician, University of Manitoba

- Mr. Jeremy Pinkos, Research Assistant

The project was funded by Manitoba Hydro and Collaborative Research and Development Program of The Natural Science and Engineering Research Council of Canada-Collaborative Research and Development (NSERC-CRD). 


\section{TABLE OF CONTENTS}

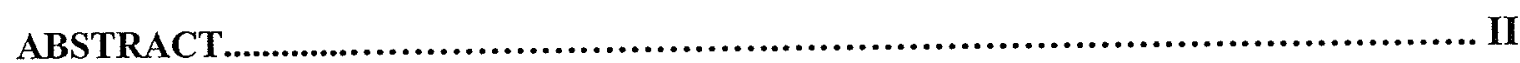

ACKNOWLEDGEMENTS..............................................................

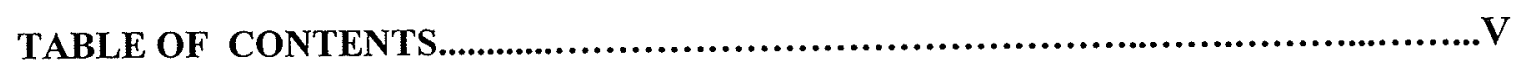

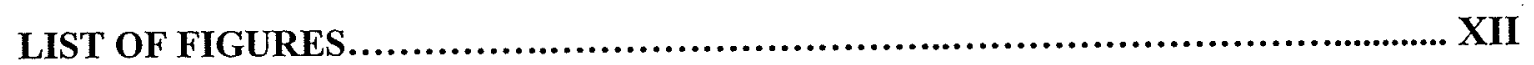

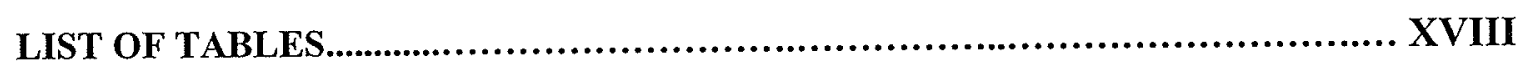

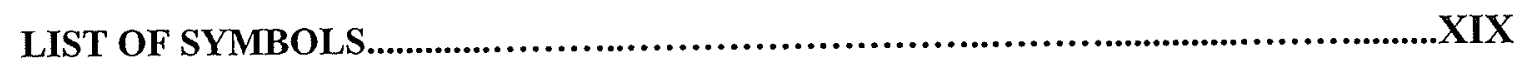

CHAPTER 1: INTRODUCTION...............................................30

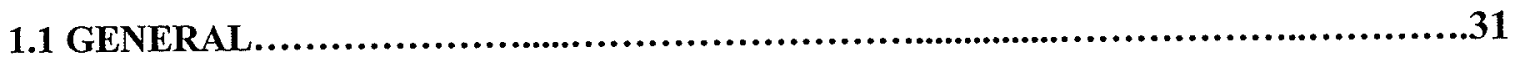

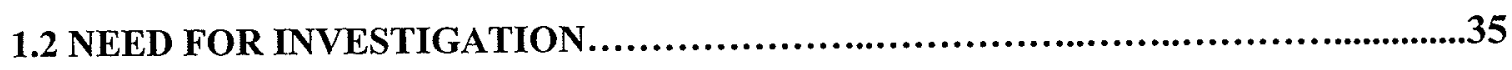

1.3 OBJECTIVES OF THE PRESENT RESEARCH PROGRAM...................................37

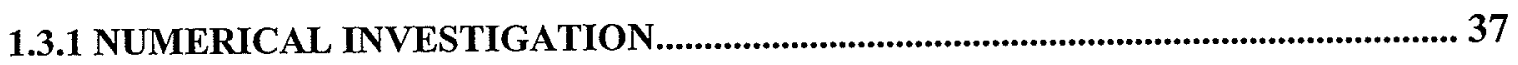

1.3.2 MANUFACTURING OF PROTOTYPES................................................................... 37

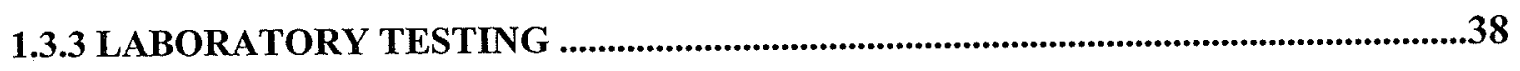

\subsubsection{DISCUSSIONS OF RESULTS AND RECOMMENDATIONS FOR THE DESIGN}

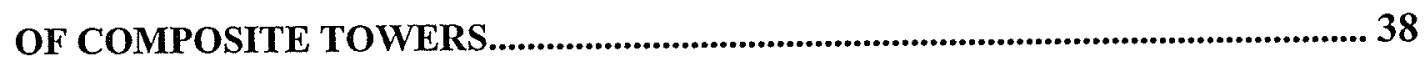


CHAPTER 2: LITERATURE REVIEW.

41

2.1 METHODS OF ANALYSIS OF GUYED TOWERS -BRIEF HISTORY. .42

2.2 BRIEF HISTORY OF FILAMENT WINDING.

2.2 REVIEW OF CURRENT DESIGN STANDARDS AND SPECIFICATIONS . .48

CHAPTER 3: NUMERICAL INVESTIGATION

3.1 GEOMETRIC PROPERTIES OF TOWER.................................................52

3.2 PHYSICAL AND MECHANICAL PROPERTIES OF TOWER.........................54

3.3 PROPERTIES OF GUY CABLES AND TOWER BASE........................................56

3.4 THEORIES OF FAILURE FOR UNIDIRECTIONAL LAMINA.........................57

3.4.1 LONGITUDINAL MODULUS..................................................................................57

3.4.2 TRANSVERSE MODULUS...................................................................................58

3.4.3 MAJOR POISSONS'S RATIO................................................................60

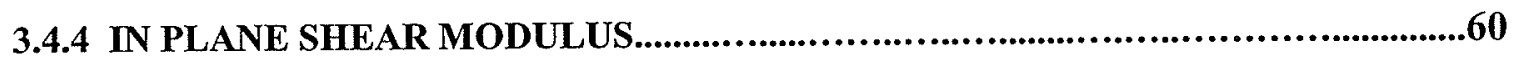

3.4.5 LONGITUDINAL TENSILE AND COMPRESSIVE STRENGTH...............................61

3.4.6 TRANSVERSE TENSILE AND COMPRESSIVE STRENGTH ...................................62 


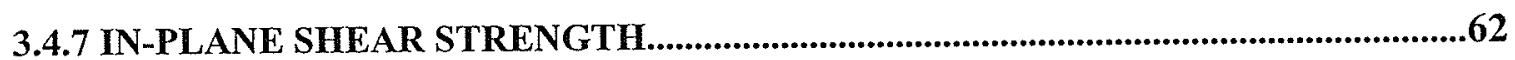

3.4.8 FAILURE MECHANISM OF UNIDIRECTIONAL COMPOSITES..........................63

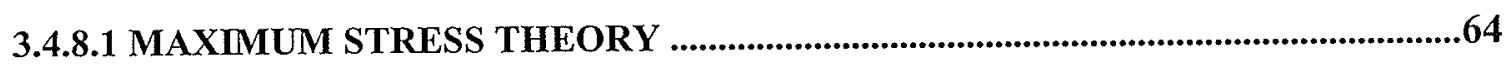

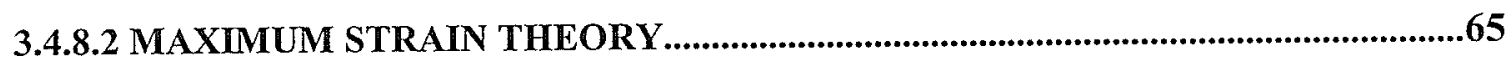

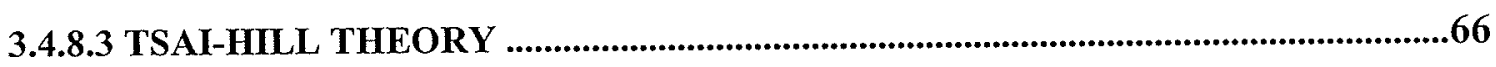

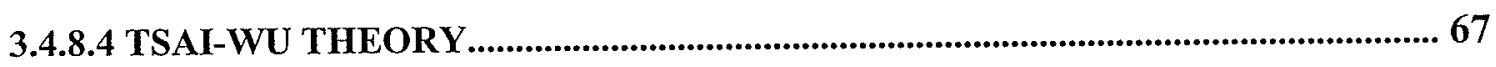

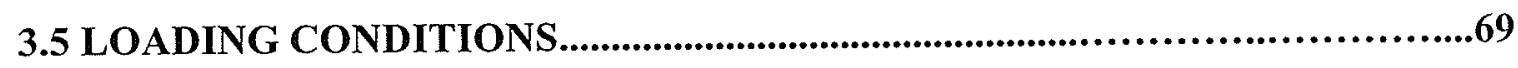

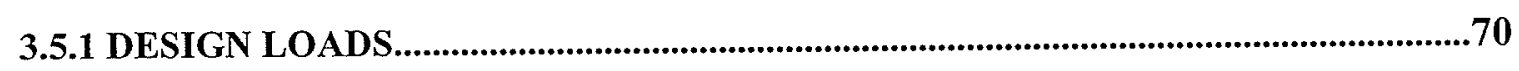

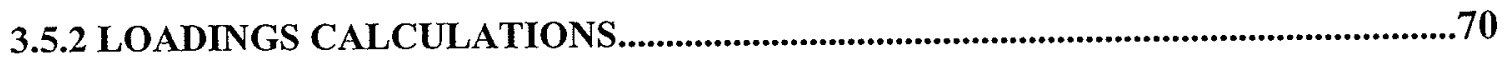

3.5.3 CALCULATION OF DESIGN WIND PRESSURE...................................................73

3.5.4 CALCULATION OF DESIGN WIND AND ICE LOADINGS...................................75

3.5.5 DESIGN WIND AND ICE LOADS FOR CASE 2 ....................................................79

3.5.6 DESIGN WIND LOADS FOR PARABOLIC ANTENNA...........................................80

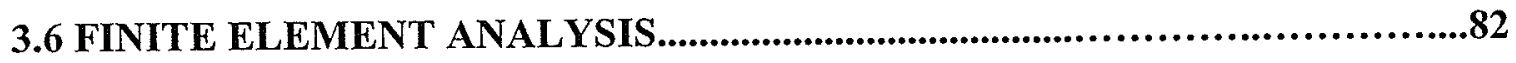

3.6.1 STATIC FEA OF THE 8.53 M (28 FT) FRP TOWER SEGMENT..........................82

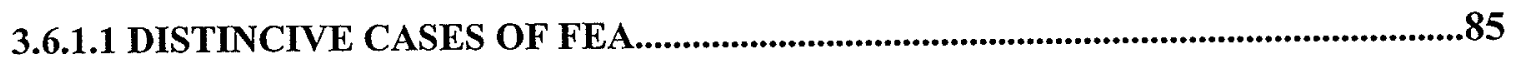

3.6.2 NON LINEAR STRUCTURAL BEHAVIOUR OF GUYED TOWERS.......................87

3.6.3 STATIC FEA OF 45 M (147 FT) FRP GUYED TOWER.........................................91 


\subsubsection{DEFLECTION COMPARISON BETWEEN FEA OF TOWER SEGMENT AND}

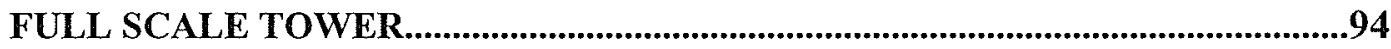

3.6.3.2 FINAL STATIC FEM ANALYSIS OF THE 45 M (147 FT) FRP TOWER........97

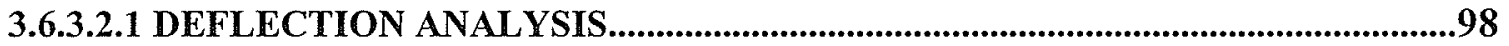

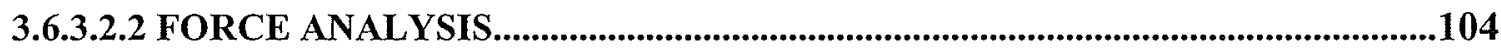

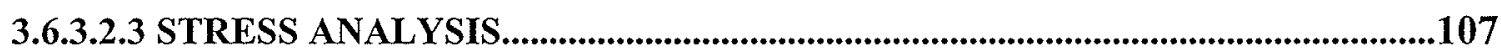

3.6.4 PRELIMINARY CONCLUSION FROM FEA OF 45 M (147 FT) TOWER..........117

3.6.5 DEVELOPMENT OF SLEEVE MODEL ...................................................................118

3.6.6 DYNAMIC FEA OF 8.53 M (28 FT) FRP TOWER SEGMENT..................122

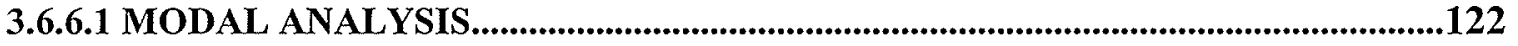

3.6.6.2 MODAL ANALYSIS OF TOWER SEGMENT BY ANSYS..................................124

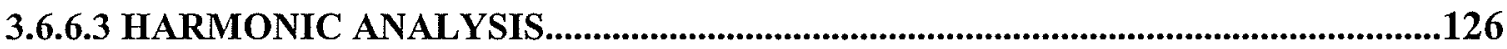

3.6.6.4 HARMONIC ANALYSIS OF TOWER SEGMENT BY ANSYS.............................128

3.6.7 DYNAMIC FEA OF 45 M (147 FT) FRP TOWER......................................130

3.6.7.1 MODAL FEA OF 45M (147 FT) FRP TOWER ........................................................130

3.6.7.2 NUMERICAL MODEL FOR DYNAMIC ANALYSIS OF 8.53 M (28 FT) FRP

TOWER SEGMENT

3.6.8 DYNAMIC ANALYSIS OF 45 M (147 FT) FRP TOWER ACCORDING

viii 
TO CSA-S37-01 STANDARD 136

3.6.8.1 ANALYSIS OF DYNAMIC RESPONSE OF 45 M (147 FT) FRP TOWER USING PATCH LOAD METHOD 139

CHAPTER 4: EXPERIMENTAL PROGRAM. .157

4.1 INTRODUCTION 158

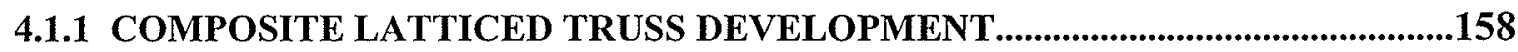

4.1.2 INITIAL SELECTION OF CROSS SECTION 159

4.2 STATIC TESTING OF FRP TOWER SEGMENT TEST SET-UP.. 159

4.2.1 DESIGN AND MANUFACTURING OF TOWER BASE. 163

4.2.2 DESIGN AND MANUFACTURING OF TOWER CONNECTIONS. .164

4.2.3 TEST PROCEDURE .166

4.3 DYNAMING TESTING OF FRP TOWER SEGMENT TEST

SET-UP. 168

4.3.1 IMPROVEMENTS TO TOWER SLEEVE CONNECTIONS. 173

4.3.2 NEW TOWER BASE. 174

4.3.3 VIBRATION TEST PROCEDURE. . .175 
5.1 GENERAL . .178

5.2 ANALYSIS OF STATIC TESTING RESULTS. 178

5.3 STRAIN DISTRIBUTION ANALYSIS. 183

5.4 ANALYSIS OF EXPERIMENTAL RESULTS FROM DYNAMIC TESTS. .195

5.5 THEORETICAL BACKGROUND OF THE DYNAMIC ANALYSIS .201

5.6 CALCULATION OF DYNAMIC PROPERTIES FROM TEST DATA. .205

5.7 COMPARISON OF FEM MODEL AND TEST DEFLECTION UNDER SERVICE LOADS 209

CHAPTER 6: RECOMMENDATIONS FOR THE DESIGN OF COMPOSITE TOWERS. .210

6.1 GENERAL.

6.2 EFFECT OF THE FIBRE VOLUME FRACTION ON MECHANICAL PROPERTIES

OF FRP TOWERS .211

6.3 STRENGTH FAILURE EVALUATION OF THE FRP TOWER .218

6.4 BUCKLING OF UNDIRECTIONAL LAMINA .224

6.5 PREDICTION OF MAXIMUM COMPRESSIVE LOAD BASED ON EULER

FORMULA .225 
CHAPTER 7: SUMMARY AND CONCLUSIONS .228

7.1 SUMMARY AND CONCLUSIONS. .229

7.2 RECOMMENDATION FOR FUTURE RESEARCH .234

REFERENCES. .236

APPENDIX-A: ANSYS INPUT FILES.............................................................242

A.1 INPUT FLE FOR 8.53 M (28FT) FRP TOWER SEGMENT.. .247

A.2 INPUT FILE FOR 45 M (147 FT) FRP TOWER .243

APPENDIX-B: COMPARISON BETWEEN A COMPOSITE AND

STEEL TOWER .273

B.1 FEM MODELLING OF STEEL TOWER .274 


\section{LIST OF FIGURES}

Fig.1.1 Self supporting radio and telecommunication towers............................................31

Fig.1.2 Self supporting transmission towers ....................................................................... 32

Fig.1.3 Guyed telecommunication towers ........................................................................

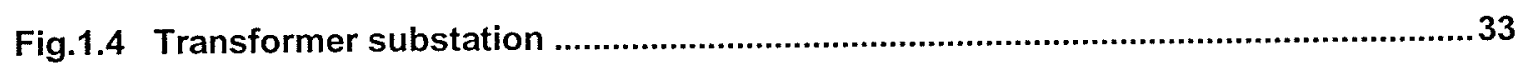

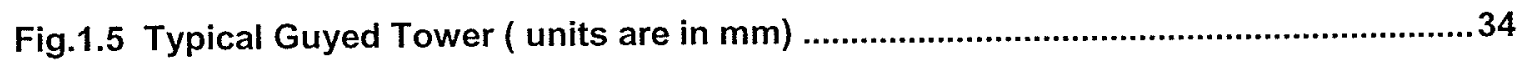

Fig. 3.1 Proposed tower arrangement (units are in $\mathrm{mm}$ )...............................................52

Fig. 3.2 Tower Segment Elevation and Section (units are in $\mathrm{mm}$ ) .....................................53

Fig. 3.3 Maximum Stress Theory failure envelope..............................................................65

Fig. 3.4 Maximum Strain Theory failure envelope .............................................................66

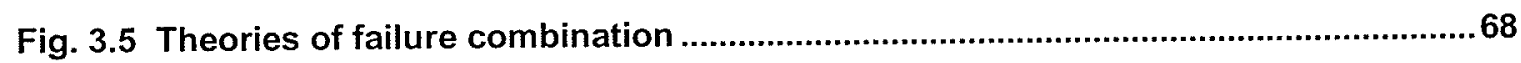

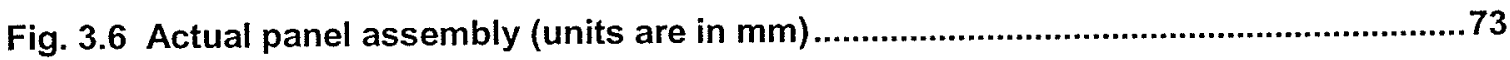

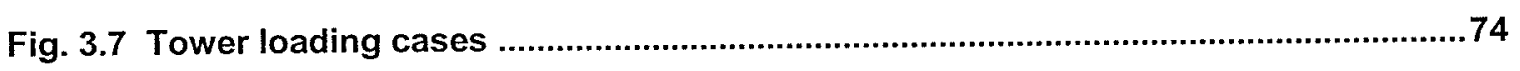

Fig. 3.8 Factored and unfactored loads along the tower ..................................................79

Fig. 3.9 Wind forces on paraboloid antennas with radomes ..............................................81

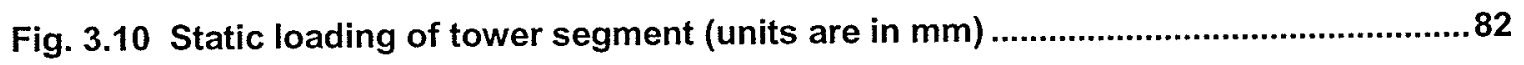

Fig. 3.11 Section of trial tower segment (Global axes; all dimensions in $\mathrm{mm}$ )....................83

Fig. 3.12 Local coordinate system adjustment for chords (units are in $\mathrm{mm}$ ) .......................84

Fig. 3.13 Case A- Cable stiffness $=1751.52 \mathrm{kN} / \mathrm{m}$ (short cables) ......................................... 86

Fig. 3.14 Case B- Cable stiffness $=47.82$ kN/m (long cables) ..............................................8

Fig. 3.15 Load displacement for non linear structure (ANSYS, 2004) .................................. 89

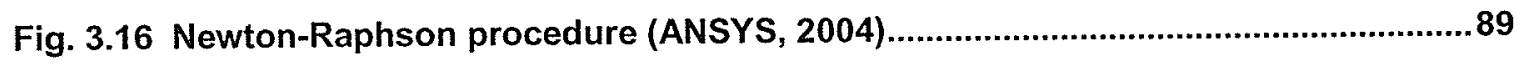

Fig. 3.17 Newton-Raphson iteration-one step (ANSYS, 2004) ...............................................90

Fig. 3.18 Newton-Raphson iteration-up to equilibrium (ANSYS, 2004)................................90

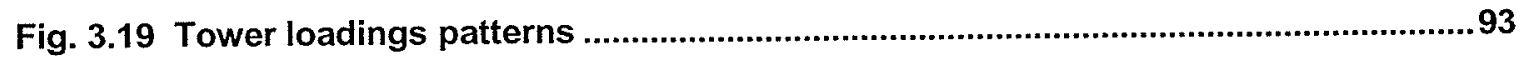

Fig. 3.20 Deflections (in inches) of $45 \mathrm{~m}$ (147 ft) tower for wind load CASE-1 ....................93 
Fig. 3.21 Deflections (in inches) of the bottom of $8.53 \mathrm{~m}(28 \mathrm{ft}$ ) segment of .......................94

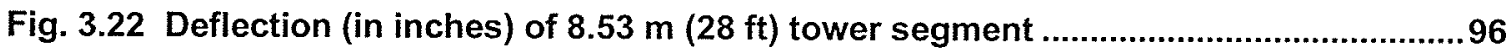

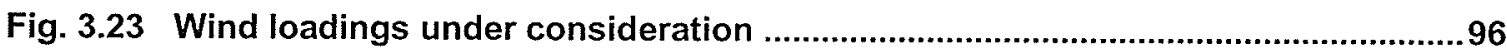

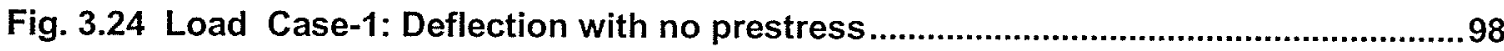

Fig. 3.25 Load Case-1: Deflection with a prestress ..........................................................99

Fig. 3.26 Load Case-1: Tower deflections with and without cable prestress .....................100

Fig. 3.27 Load Case-1: Deflection of the tower with no prestress .....................................102

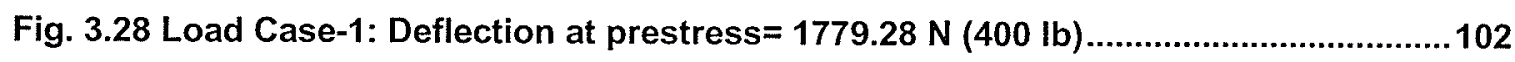

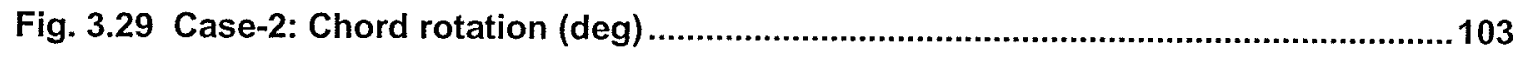

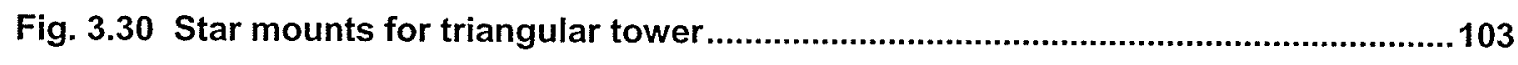

Fig. 3.31 Maximum chord forces* for load Case-1 ..........................................................105

Fig. 3.32 Maximum chord forces ${ }^{*}$ for Case-2 ............................................................106

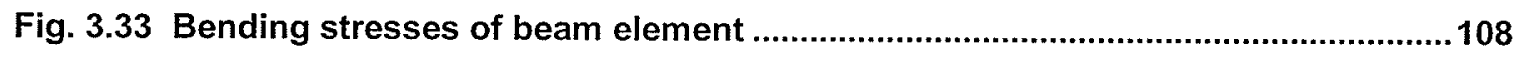

Fig. 3.34 Max bending stresses SMAXI and SMINJ for beam element .............................110

Fig. 3.35 Maximum stresses SMAXI and SMINJ for chord members...............................110

Fig. 3.36 Tower chords annotation for Load Case-1 and Case-2 ….................................111

Fig. 3.37 Combined stresses ${ }^{\star}$ SMAXI and SMINJ for load Case-1 ..................................111

Fig. 3.38 Combined stresses ${ }^{\star}$ SMAXI and SMINJ for load Case-1 ....................................112

Fig. 3.39 Combined stresses* SMAXI and SMINJ for load CASE-2 .................................113

Fig. 3.40 Direct axial stress for load Case-1 ................................................................115

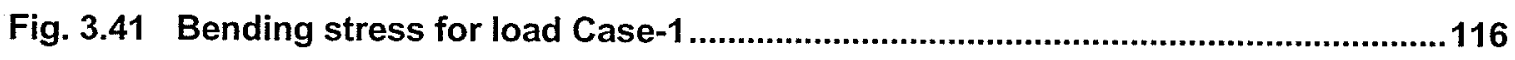

Fig. 3.42 Steel brace for guyed cables connection .........................................................117

Fig. 3.43 Sectional properties of sleeves at segments splices (units are in $\mathrm{mm}$ ) .............120

Fig. 3.44 FEM sleeve model loading condition ..............................................................121

Fig. 3.45 Deflections along the $8.53 \mathrm{~m}(28 \mathrm{ft})$ tower segment..........................................121

Fig. 3.46 Modal analysis of $8.53 \mathrm{~m}(28 \mathrm{ft})$ tower segment, mode ......................................125

Fig. 3.47 Modal analysis of $8.53 \mathrm{~m}(28 \mathrm{ft})$ tower segment, mode ......................................125

Fig. 3.48 Modal analysis of $8.53 \mathrm{~m}(28 \mathrm{ft})$ tower segment, mode .....................................126 


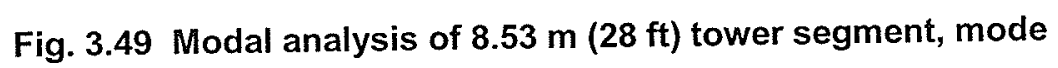
126

Fig. 3.50 Harmonic analysis of tower segment

Fig. 3.51 Mode shape -2 at $0.219 \mathrm{~Hz}$ 131

Fig. 3.52 Mode shape -4 at $0.265 \mathrm{~Hz}$ 131

Fig. 3.53 Mode shape -7 at $0.319 \mathrm{~Hz}$ 132

Fig. 3.54 Mode shape -11 at $0.468 \mathrm{~Hz}$ .132

Fig. 3.55 Mode shape -13 at $0.6128 \mathrm{~Hz}$ 132

Fig. 3.56 Mode shape -20 at $1.101 \mathrm{~Hz}$ 133

Fig. 3.57 Mode shape -26 at $1.654 \mathrm{~Hz}$ .133

Fig. 3.58 Mode shape -35 at $2.438 \mathrm{~Hz}$ .133

Fig. 3.59 Mode shape -90 at $3.507 \mathrm{~Hz}$ .134

Fig. 3.60 Deflected shape of $8.53 \mathrm{~m}(28 \mathrm{ft})$ tower segment under .135

Fig. 3.61 SMIN I, Combined windward chord stress under men wind (MPa). 142

Fig. 3.62 Required patch wind loading cases 143

Fig. 3.63 SMIN I, Combined windward chord stress no wind loading 146

Fig. 3.64 SMIN I, Combined windward chord stress Patch Load. 147

Fig. 3.65 SMIN I, Combined windward chord stress Patch Load 147

Fig. 3.66 SMIN I, Combined windward chord stress Patch Load 148

Fig. 3.67 SMIN I, Combined windward chord stress Patch Load 148

Fig. 3.68 SMIN I, Combined windward chord stress Patch Load 149

Fig. 3.69 SMIN I, Combined windward chord stress Patch Load 149

Fig. 3.70 SMIN I, Combined windward chord stress Patch Load 150

Fig. 3.71 SMIN 1, Combined windward chord stress Patch Load 150

Fig. 3.72 SMIN I, Combined windward chord stress Patch Load 151

Fig. 3.73 SMIN I, Combined windward chord stress Patch Load 151

Fig. 3.74 SMIN I, Combined windward chord stress Patch Load 152

Fig. 3.75 SMIN I, Combined windward chord stress Patch Load 152 
Fig. 3.76 SMINI, for Patch Load Case1-6

Fig. 3.77 SMINI, for Patch Load Case 7-12 153

Fig. 3.78 Resultant patch load response Fig. 3.79 Peak response simple scaling ........154

Fig. 3.80 Peak response simple and detailed scaling 156

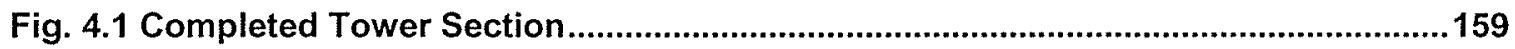

Fig. 4.2 Tower segment configuration for testing (units are in $\mathrm{mm}$ ) ...............................160

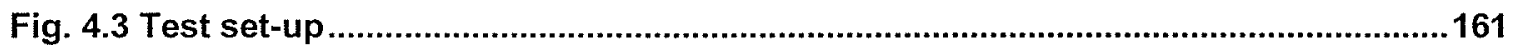

Fig. 4.4 Schematic drawing of scaled test set-up (units are in $\mathrm{mm}$ ) ...................................161

Fig. 4.5 Loading applied to "wiffle tree system" ..............................................................162

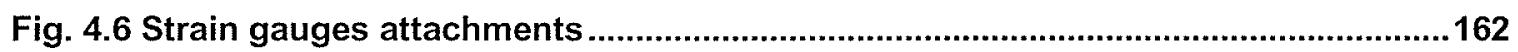

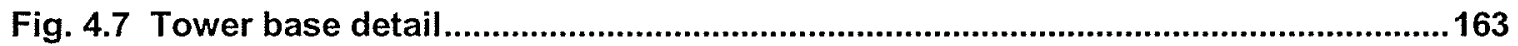

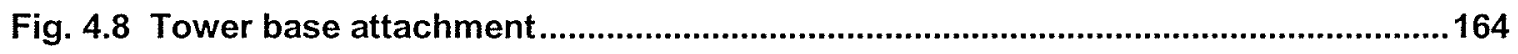

Fig. 4.9 Bracket for joining segments together (units are in $\mathrm{mm}$ ) ..................................164

Fig. 4.10 Sleeve bracket connection (units are in $\mathrm{mm}$ ) ......................................................165

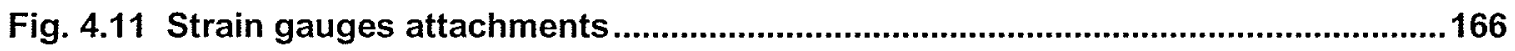

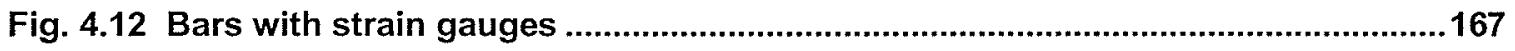

Fig. 4.13 Tower segment configuration for dynamic testing-elevation ..............................168

Fig. 4.14 Tower segment configuration for dynamic testing-plan (units are in $\mathrm{mm}$ ) .........169

Fig. 4.15 Test set-up, north -south configuration ...............................................................170

Fig. 4.16 Test set-up, west -east configuration .................................................................171

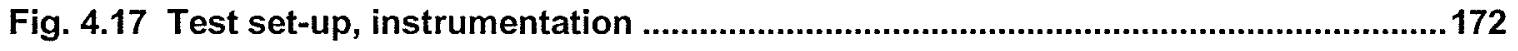

Fig. 4.18 Sleeve bracket connection for dynamic testing .................................................173

Fig. 4.19 Sleeve bracket connection for dynamic testing ...............................................173

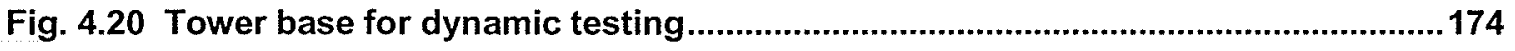

Fig. 4.21 Load cell calibration .......................................................................................175

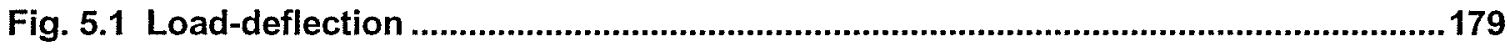


Fig. 5.2 Deflection along the tower segment at the maximum load. 179

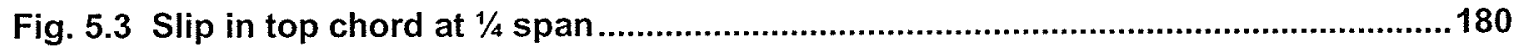

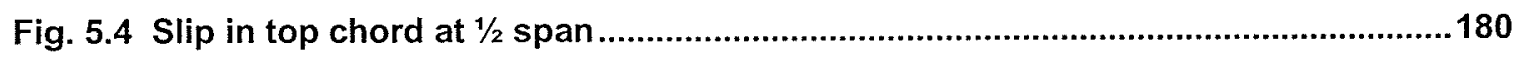

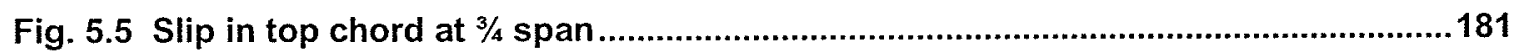

Fig. 5.6 Deflection along the $8.53 \mathrm{~m}(28 \mathrm{ft})$ tower segment..........................................182

Fig. 5.7 Load deflection curves at the midspan ............................................................. 182

Fig. 5.8 Sleeve bracket connection for static testing .....................................................183

Fig. 5.9 Strain gauges location along one side of the tower segment ..............................184

Fig. 5.10 Shear and bending moment diagrams for tower segment ................................184

Fig. 5.11 SDIR, direct axial stress (psi) along the tower segment ...................................185

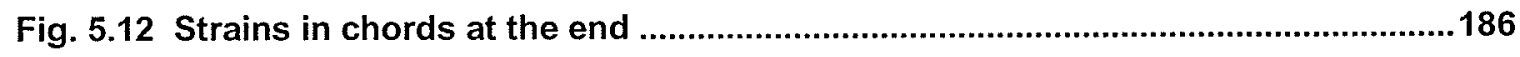

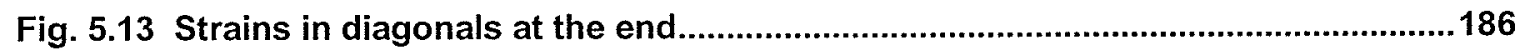

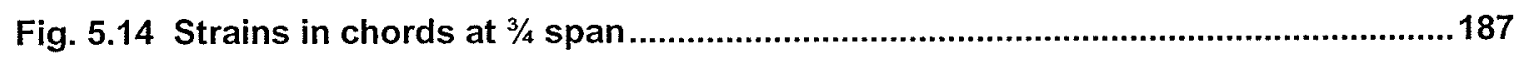

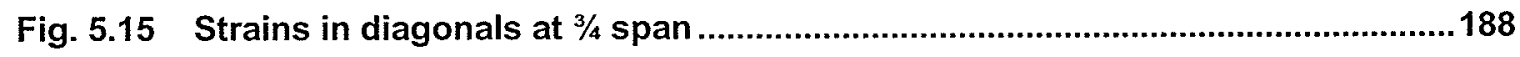

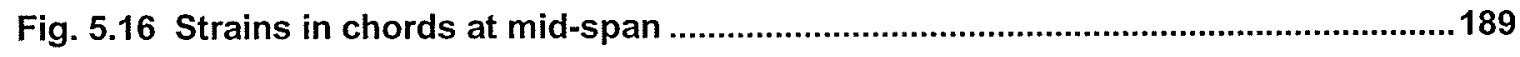

Fig. 5.17 SMINI minimum stress (psi) at joints $i$ of the tower segment .............................189

Fig. 5.18 SMAXI maximum stress (psi) at joints $i$ of the tower segment ..........................190

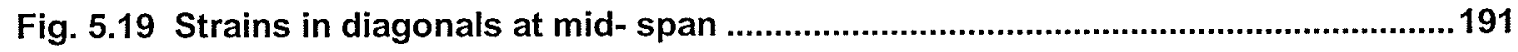

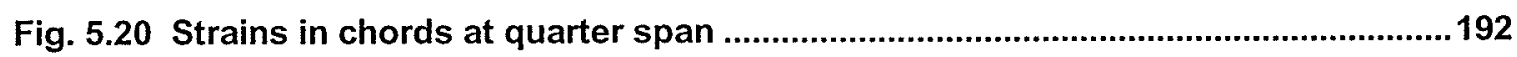

Fig. 5.21 Strains in diagonals at quarter span .............................................................. 192

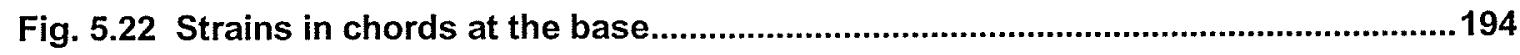

Fig. 5.23 Strains in diagonals at the base ..................................................................... 194

Fig. 5.24 Deflections along the tower prior the load release .............................................196

Fig. 5.25 Vibration Test Time History for Test-16 ...........................................................196

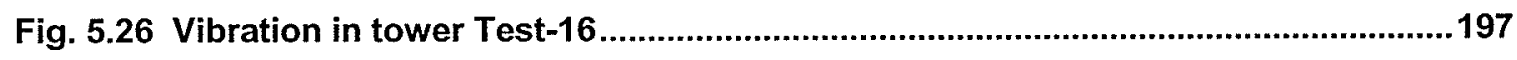

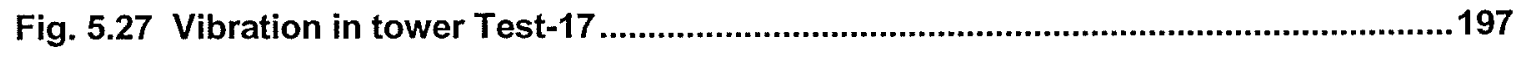

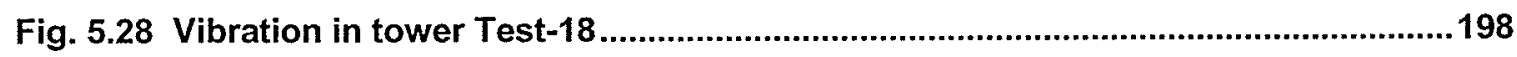

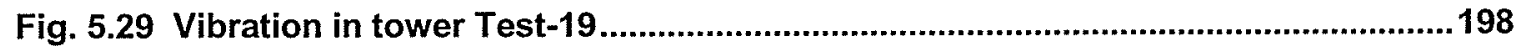




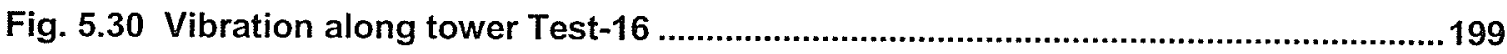

Fig. 5.31 Mode shapes for 3 full cycles Test-16 ..........................................................200

Fig. 5.32 3-D mechanical model of tested tower segment ............................................201

Fig. 5.33 2-D mechanical model of tested tower segment ............................................202

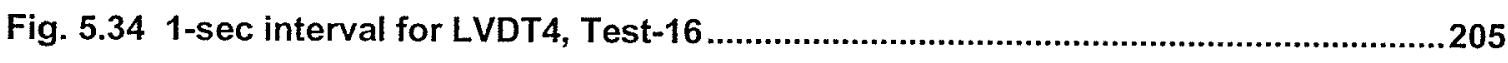

Fig. 5.35 Comparison of FEM model and Test deflection under service loads ..................209

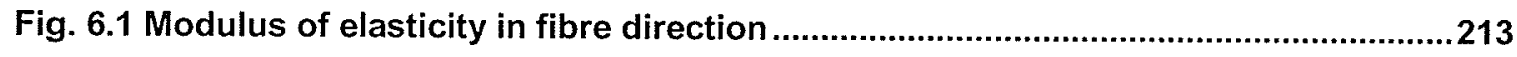

Fig. 6.2 Modulus of elasticity in the direction perpendicular to the fibres.........................214

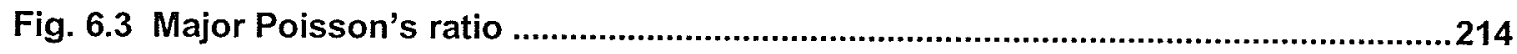

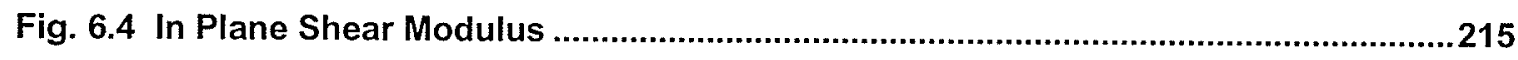

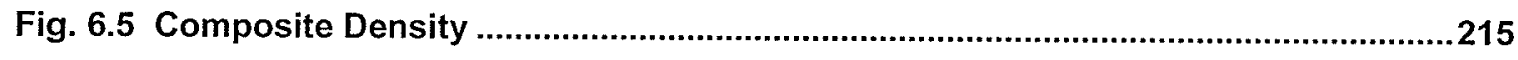

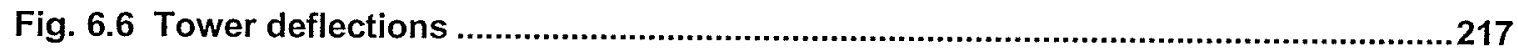

Fig. 6.7 Failure envelope based on Maximum Stress and Tsai-Wu Theories ....................219

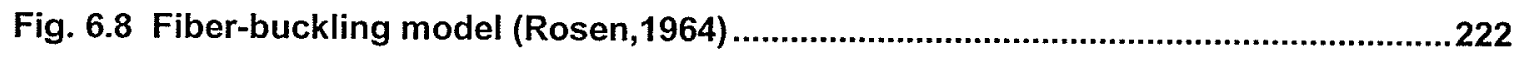

Fig. 6.9 Extension mode (Kaw, 1997) Fig. 6.10 Shearing mode (Kaw, 1997)................... 222

Fig. 6.11 Critical buckling stress for extension and shear modes of failure ......................224

Fig. 6.12 Tower chord geometry for Euler Load calculations (units are in $\mathrm{mm}$ ) ................226

Fig. B.31 Steel tower cross section (all dimensions in $\mathrm{mm}$ )..........................................274

Fig. B.3 2 Steel tower typical panel (all dimensions in $\mathrm{mm}$ ) ...........................................275

Fig. B.3 3 Maximum deflection of Steel tower (units are in inches) ..................................277

Fig. B.3 4 Maximum deflection of FRP tower (units are in inches) ....................................277

Fig. B.3 5 Deflection comparison between Steel and FRP towers …................................278

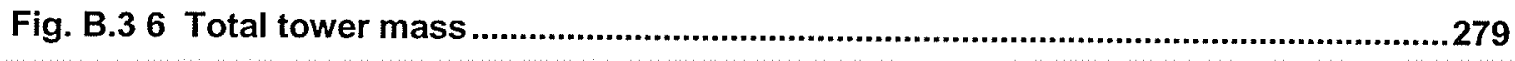




\section{LIST OF TABLES}

Table 3.1 Tower service load no ice, Case-1 ...................................................................75

Table 3.2 Tower service load with ice, Case-1 .....................................................................77

Table 3.3 Factored wind tower loads with and without ice for Case-1 ................................78

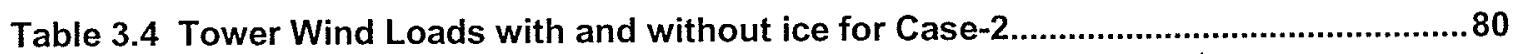

Table 3.5 Maximum factored guy forces ..........................................................................107

Table 3.6 Strength values from unidirectional test coupons............................................114

Table 3.7 Typical mean wind loading per node .................................................................141

Table 3.8 Patch Wind Load Cases Part- a......................................................................... 144

Table 3.9 Patch Wind Load Cases Part-b........................................................................145

Table 5. 1 Dynamic Properties of Tower Segment..............................................................208

Table 6.1 Properties of constituencies for unidirectional lamina ....................................211

Table 6.2 Typical fibre volume fractions (Kaw, 1997) ......................................................212

Table 6.3 Mechanical properties for unidirectional lamina ................................................216

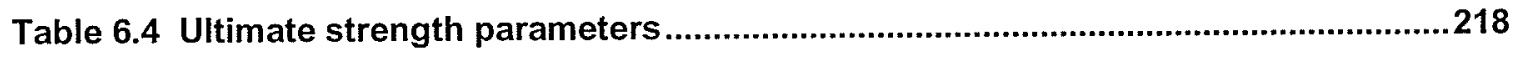

Table 6.5 Maximum tower stresses from the static FEM analysis under ..........................220

Table 6.6 Euler load and critical stresses for a single leg in the tower chord....................227

Table B.3 1 Typical loading per node for steel tower .........................................................276

Table B.3 2 Mass comparison FRP vs steel tower..............................................................279

Table B.3 3 Cost comparison FRP vs steel tower.............................................................280 


\section{LIST OF SYMBOLS}

$A \quad$ Area of the cross section

$A_{f} \quad$ Face area of flat members, bare

$A_{r} \quad$ Face area of round bare members

$A_{s} \quad$ Net projected area of flat member $A_{f}$

$A_{g} \quad$ Gross area of the panel

$A_{i} \quad$ Face area of radial ice

B/S Both sides

$C_{c} \quad$ Critical damping constant

c Damping constant

$[C]$ Structure viscous damping matrix

$C_{e} \quad$ Height factor

$C_{\text {exp }} \quad$ Exposure factor

$C_{d f} \quad$ Drag factor for flat members

$C_{d r} \quad$ Drag factor for round bare members

C/W Connected with

$C_{g} \quad$ Gust factor

d Fibre diameter 
DMX Maximum deflection

D Dead Loads

$E_{1} \quad$ Modulus of elasticity in the fibre direction

$E_{2} \quad$ Modulus of elasticity in the direction perpendicular to the fibres

$E_{f} \quad$ Elastic modulus of fibre

$E_{m} \quad$ Modulus of elasticity of matrix

$f_{i} \quad$ Vibrating frequency of the system

$f_{n} \quad$ Natural frequency

$F_{a} \quad$ Force normal to the antenna

$F_{c} \quad$ Force being taken by composite

$F_{D} \quad$ Damping force

$F_{f} \quad$ Force being taken by fibre

$f_{d} \quad$ Damped frequency of oscillation

$F_{1}^{t h} \quad$ Longitudinal tensile strength in fibre direction

$F_{1}^{c t} \quad$ Longitudinal compressive strength in fibre direction

$F_{2}^{t h} \quad$ Transverse tensile strength in direction perpendicular to the fibres

$F_{2}^{c u} \quad$ Transverse compressive strength in direction perpendicular to the fibres

$F^{s t} \quad$ In-plane shear strength (in-plane 1,2)

FX Axial force in $\mathrm{x}$ direction

$F_{x, j} \quad$ Axial force in $\mathrm{x}$ direction 
$F_{1}^{t l} \quad$ Axial or longitudinal strength in tension

$F_{2}^{l u} \quad$ Transverse strength in tension

$F_{1}^{c u} \quad$ Axial or longitudinal strength in compression

$F_{2}^{c u} \quad$ Transverse strength in compression

$F^{s u} \quad$ Shear strength (in-plane and through - thickness)

$\{F(t)\} \quad$ Structure external load vector matrix

$\left\{F_{C}\right\} \quad$ Complex force vector

$\{F\} \quad$ External load vector

$\left\{F^{n r}\right\} \quad$ Internal force vector

$F_{0} \quad$ Maximum force

$F_{I} \quad$ Inertia force

$F_{S} \quad$ Spring force

$F_{s} \quad$ Force tangential to the antenna

g Peak factor

GA Shear stiffness

$G_{f} \quad$ Shear modulus of fibre

$G_{m} \quad$ Shear modulus of matrix

$G_{12} \quad$ In plane shear modulus of lamina 
$G_{x y} \quad$ Shear modulus in XY plane

$G_{y z} \quad$ Shear modulus in $Y Z$ plane

$G_{x z} \quad$ Shear modulus in XZ plane

$H_{x} \quad$ Height above the ground

I Ice Loads

$I_{z z} \quad$ Moment of inertia about $\mathrm{z}$ axis

$I_{y y} \quad$ Moment of inertia about $y$ axis

$i \quad$ Intensity of turbulence

$j \quad$ Square root of -1

$k \quad$ Spring constant

$[K] \quad$ Structure stiffness matrix

$\left[K_{C}\right]$ Complex matrix

$\left[K_{T}\right] \quad$ Tangent stiffness matrix

$l \quad$ Length

$L_{e} \quad$ Effective length

LMT Linear Motion Transducer

LVDT Linear Variable Displacement Transducer

$m \quad$ mass

M Moment 
$[M]$ Structure mass matrix

MTS Hydraulic Press

$M_{y, i} \quad$ Moment about the element y axis at end $\mathrm{i}$

$M_{z, i} \quad$ Moment about the element $\mathrm{z}$ axis at end $\mathrm{i}$

MFRX Axial force in $\mathrm{x}$ direction

NMISC Non-Summable miscellaneous items variables

n Number of degree of freedom

n Total number of patch load cases.

$P \quad$ Design wind pressure

$P \quad$ Pressure of undisturbed flow

$P \quad$ Critical buckling force

$P_{E} \quad$ Euler load

$P_{P L} \quad$ Patch load wind pressure

$\bar{P} \quad$ Mean wind pressure

$q \quad$ Reference wind velocity pressure

$q_{h} \quad$ Average value of wind pressure per one span

$\{R\} \quad$ Residual value

$R_{s} \quad$ Solidity ratio

$r \quad$ Radius of gyration

$\hat{r} \quad$ Design peak response 
$\bar{r} \quad$ Mean response component

$\tilde{r}_{P L} \quad$ Peak fluctuating response

$\tilde{r}_{P L i} \quad$ Value of the response in question for the $\mathrm{i}$-th patch load case

$\{R\} \quad$ Residual value

s $\quad$ Fibre spacing ratio

SBZ Bending in $x$ direction in $+z$ side of beam at end $i$

SBY Bending in $x$ direction in $-y$ side of beam at end $i$

SMAXI Maximum combined stress at end $\mathrm{i}$

SMINJ Minimum combined stress at end $\mathrm{j}$

SDIR Direct axial stress

SI International System of units

$t \quad$ Time

$t_{z} \quad$ Thickness of beam element in $\mathrm{z}$ direction

$t_{y} \quad$ Thickness of beam element in y direction

$T_{d} \quad$ Damped period

TKY Thickness of the section in $\mathrm{Y}$ direction

TKZ Thickness of the section in Z direction

U Amplitude of displacement vector

\{u\} Displacement vector

$\{i i\} \quad$ Structure acceleration vector 
$\{\dot{u}\} \quad$ Structure velocity vector

$\{u\} \quad$ Structure displacement vector

$\{u\}_{i} \quad$ Eigenvectors, the mode shapes shown by displacements

of the structure

$u_{0} \quad$ Maximum displacement

$V_{f} \quad$ Fibre volume fraction

$V_{m} \quad$ Matrix volume fraction

W Wind Loads 


\section{GREEK SYMBOLS}

$\gamma_{12} \quad$ Shear strain in the plane 1,2

$\gamma_{12}^{u} \quad$ In plane ultimate shear strain (in plane 1,2)

$\left(\gamma_{12}\right)_{u l t} \quad$ Ultimate shear strain of matrix

$\gamma \quad$ Density of composite

$\delta \quad$ Logarithmic decrement

$\{\Delta u\} \quad$ Displacement increment

$\{\triangle F\} \quad$ Load increment

$\{\Delta u\} \quad$ Displacement increment

$\varepsilon_{1} \quad$ Strain for uniaxial loading in the fibre direction

$\varepsilon_{2} \quad$ Strain for transverse loading in the direction perpendicular

to the fibres

$\varepsilon_{1}^{t u} \quad$ Ultimate longitudinal tensile strain in fibre direction

$\varepsilon_{1}^{c u} \quad$ Ultimate longitudinal compressive strain in fibre direction

$\left(\varepsilon_{f}\right)_{u l t} \quad$ Ultimate strain in fibre

$\left(\varepsilon_{2}\right)^{c} \quad$ Ult $\quad$ Ulimate compressive failure strain of matrix

$\varepsilon_{2}^{t t} \quad$ Ultimate transverse tensile strain in direction perpendicular to the fibres 
$\varepsilon_{2}^{c h} \quad$ Ultimate transverse compressive strain in direction perpendicular to the fibres

$\varepsilon_{\text {intial }} \quad$ Initial cable prestress

$\zeta \quad$ Damping factor or damping ratio

$\eta \quad$ Multiplying factor

$\theta \quad$ Rotation angle

$\lambda \quad$ Slenderness ratio

$\lambda_{\text {crit }} \quad$ Critical value of slenderness ratio

$\lambda_{B} \quad$ Background scaling factor

$\lambda_{R} \quad$ Resonant scaling factor

$\lambda_{T L} \quad$ Turbulent length scale factor

$v_{X Y} \quad$ Poisson's ratio in $\mathrm{XY}$ plane

$v_{Y Z} \quad$ Poisson's ratio in $\mathrm{YZ}$ plane

$v_{Y Z} \quad$ Poisson's ratio in $\mathrm{XZ}$ plane

$\xi \quad$ Reinforcing factor

$\sigma_{1} \quad$ Stress for uniaxial loading in the fibre direction

$\sigma_{2} \quad$ Stress for transverse loading in the direction perpendicular

to the fibres

$\left(\sigma_{1}\right)_{\text {ult }}^{t} \quad$ Ultimate longitudinal tensile strength of composite

$\left(\sigma_{f}\right)_{u l t} \quad$ Ultimate tensile strength of fibre 
$\sigma_{i}^{\max } \quad$ Maximum combined stress in $\mathrm{x}$ direction at end $\mathrm{i}$

$\sigma_{i}^{\min } \quad$ Minimum combined stress in $\mathrm{x}$ direction at end $\mathrm{i}$

$\left(\sigma_{2}\right)_{u l t}^{t} \quad$ Ultimate transverse tensile strength of composite

$\left(\sigma_{2}\right)^{c} \quad$ Ultimate transverse compressive strength of composite

$\sigma_{C R E} \quad$ Critical stress for extension mode

$\sigma_{C R B} \quad$ Critical stress for buckling mode

$\sigma_{i}^{\text {dir }} \quad$ Centroidal stress

$\sigma_{z, i}^{b n d} \quad$ Bending stress in element $\mathrm{x}$ direction on the element $+z$ side of the beam at end $i$

$\sigma_{y, i}^{b n d} \quad$ Bending stress in element $\mathrm{x}$ direction on the element $-\mathrm{y}$ side

of the beam at end $i$

$\tau_{12} \quad$ Shear stress in the plane 1,2

$\left(\tau_{12}\right)_{\text {ult }} \quad$ Ultimate compressive failure strain of matrix

$\left(\tau_{m}\right)_{u l t} \quad$ Ultimate tensile strain of matrix

$v_{f} \quad$ Poisson's ratio of the fibre

$v_{m} \quad$ Poisson's ratio of the matrix

$\phi \quad$ Displacement phase shift

$\left\{x_{C}\right\} \quad$ Complex displacement vector

$\psi \quad$ Force phase shift 
$\omega$

$\omega_{n} \quad$ Natural circular frequency

$\omega_{d} \quad$ Damped frequency of oscillation

$\omega_{i}^{2} \quad$ Eigenvalues, natural frequencies of a system

$\omega_{i} \quad$ The structure natural circular frequencies

$\Omega \quad$ Excitation frequency of loading 
CHAPTER 1

\section{INTRODUCTION}




\subsection{GENERAL}

Latticed towers are mainly used as supporting structures for transmission of radio and telecommunication antennas and to support transmission lines that transmit and distribute electricity. Latticed towers can be further classified into two categories: self-supporting towers: which can be either radio and telecommunication towers, Fig.1.1, or transmission towers, Fig.1.2, or guyed towers, Fig.1.3. The guyed towers are commonly used to support communication equipment such as microwave antennas.
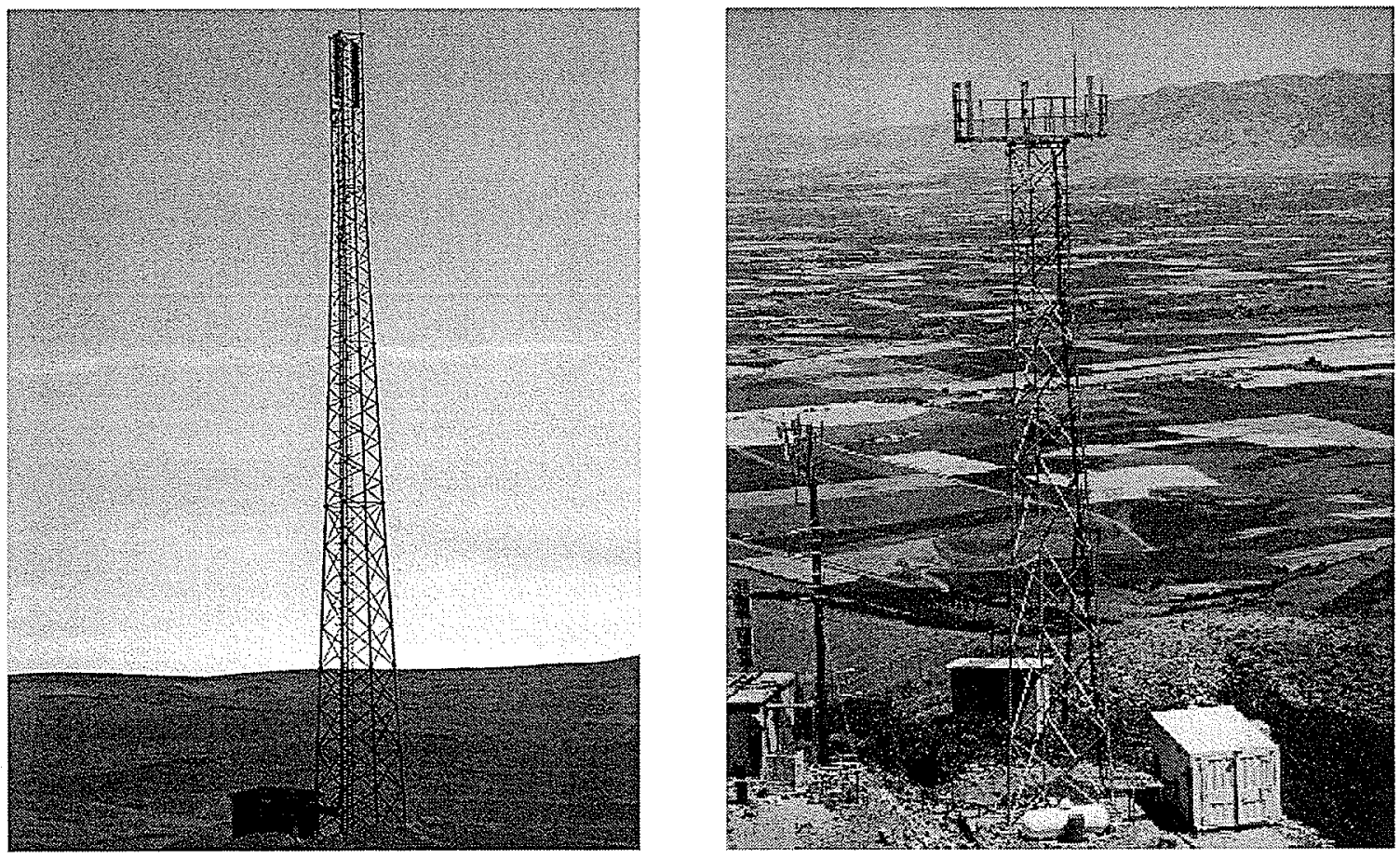

Fig.1.1 Self supporting radio and telecommunication towers (photo courtesy of WIBE Mast and Tower Systems, Harstad, Norway and Storuman, Sweden)

Latticed structures are also used in transformer substation structures, Fig.1.4.

In this case they are used as supporting beams for electrical insulators distributing power. 

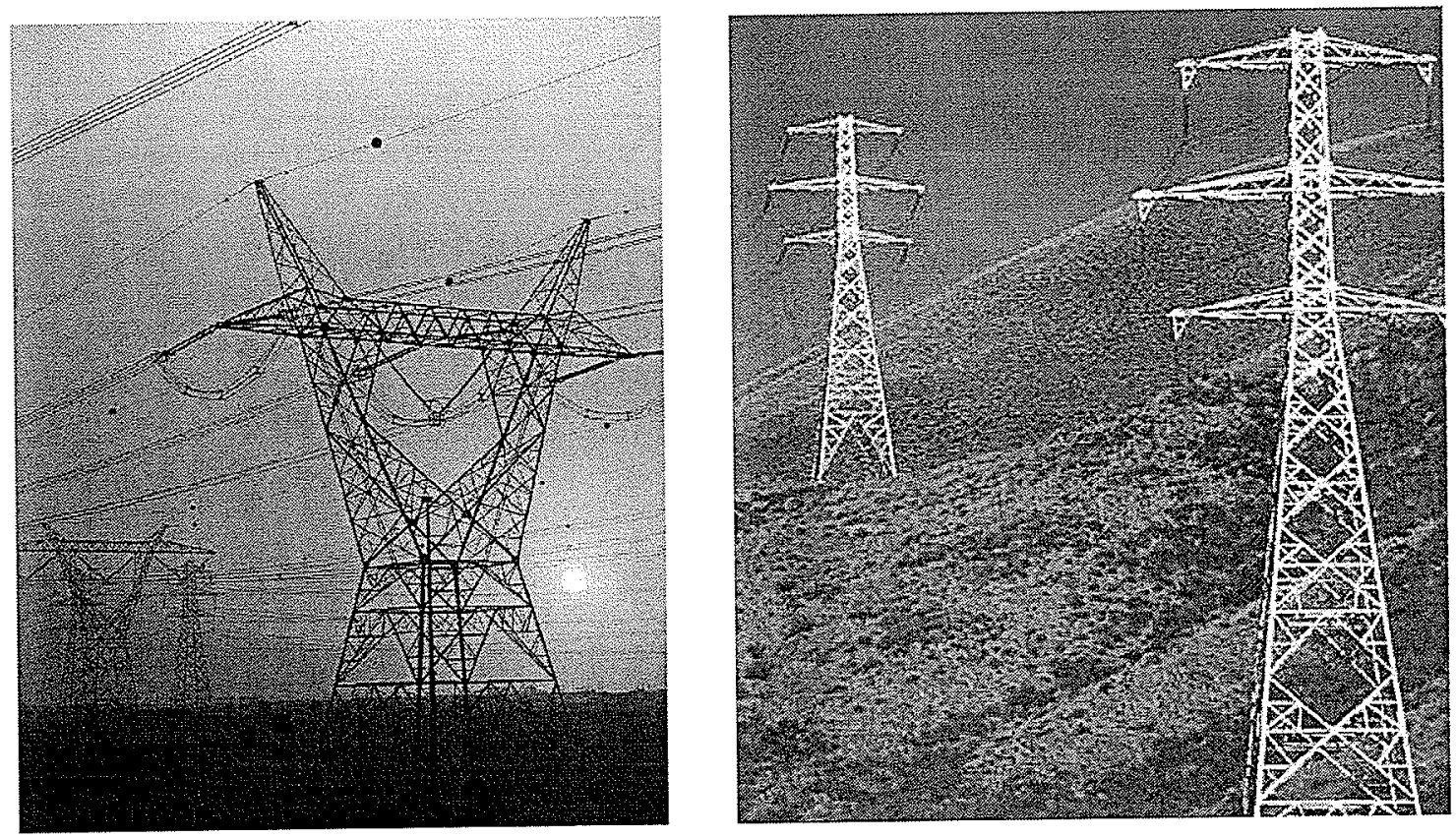

Fig.1.2 Self supporting transmission towers (photo courtesy of www.answers.com/topic/ electric-power-transmission, Little Rock, Arkansas)
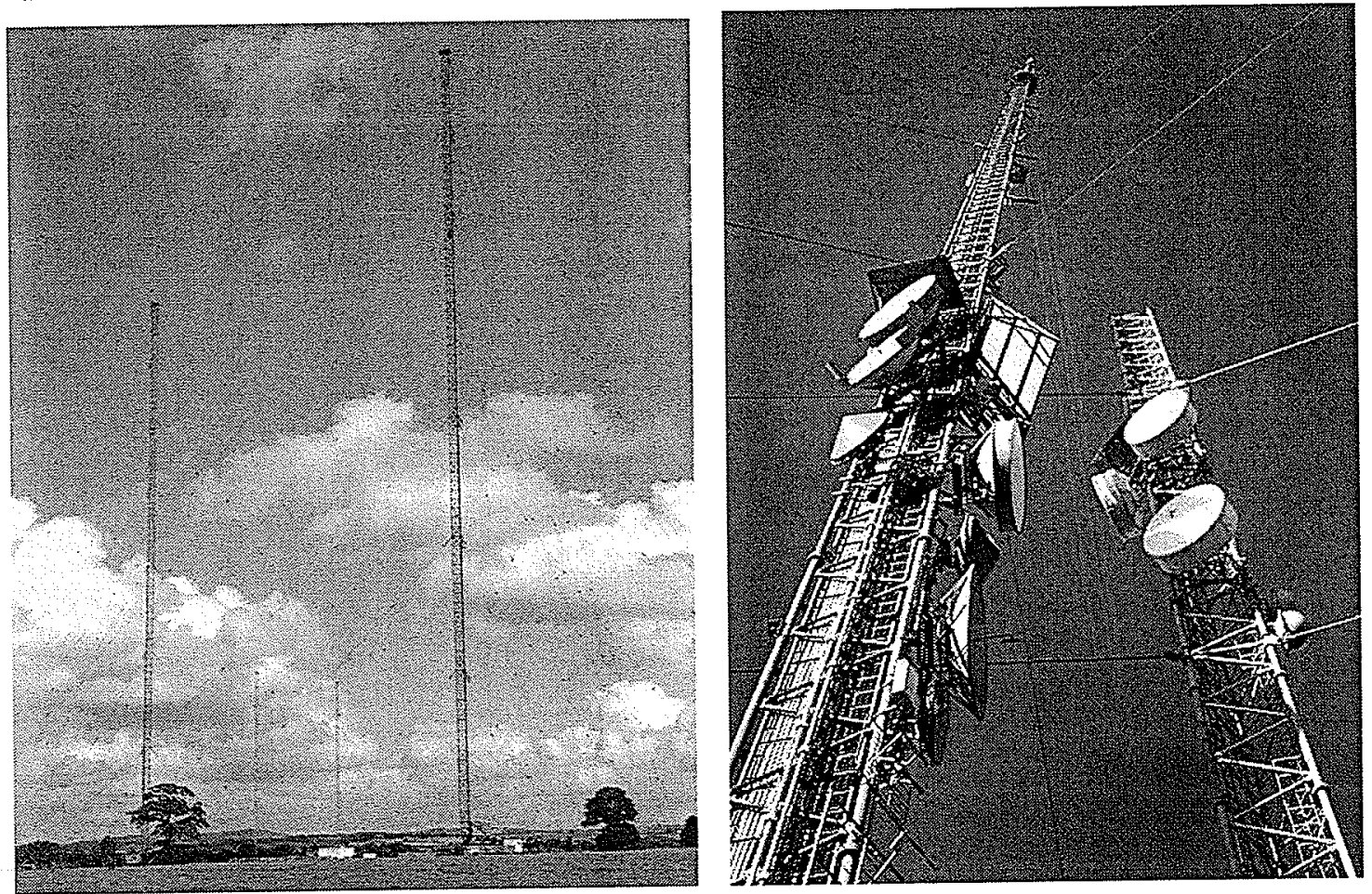

Fig.1.3 Guyed telecommunication towers (photo courtesy of WIBE Mast and Tower Systems, Falun, Sweden) 


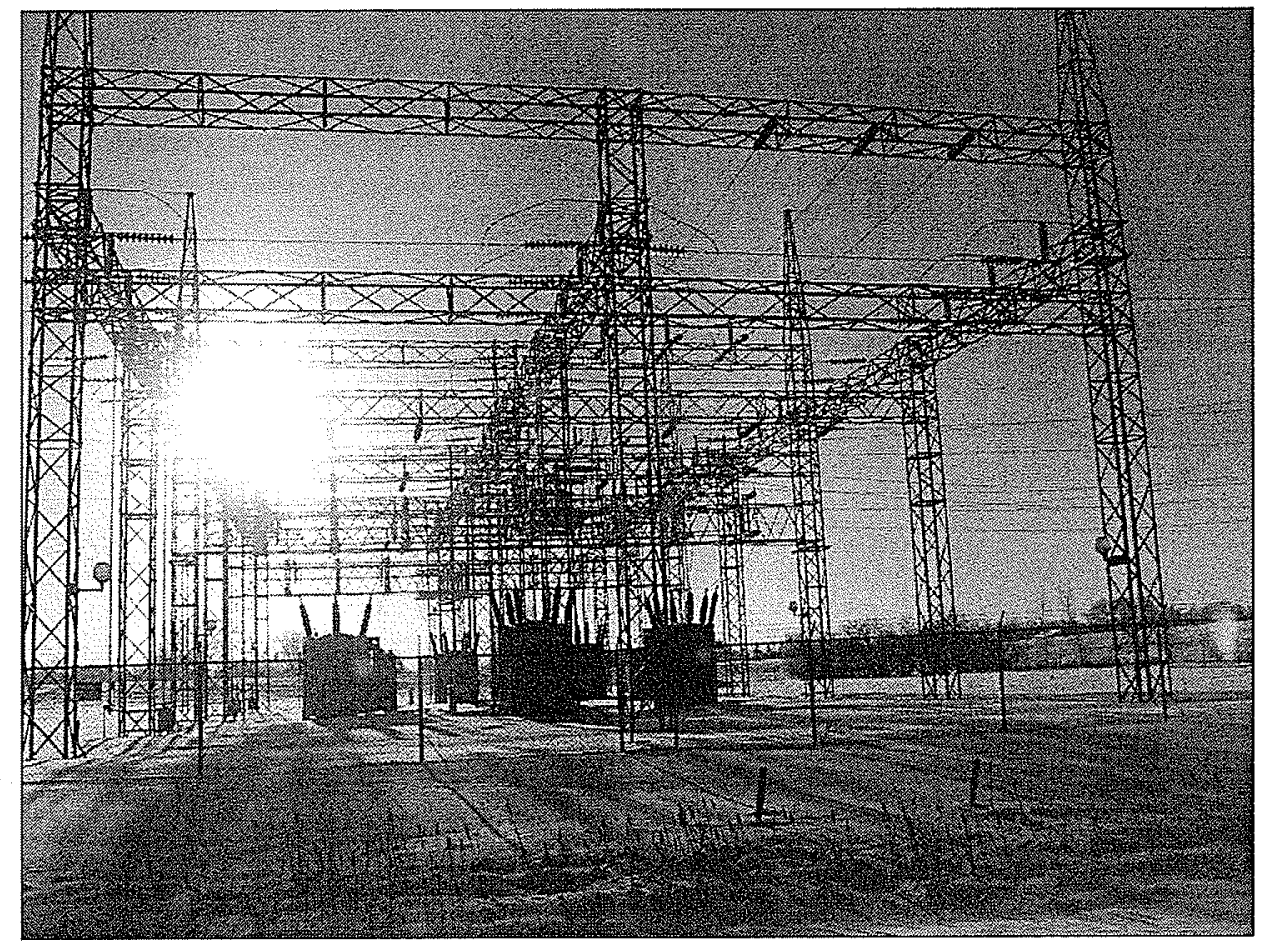

Fig.1.4 Transformer substation

(photo courtesy, Dino Philopulos, Winnipeg, Manitoba)

Self-supporting telecommunication towers are usually three legged or four-legged space-trussed structures, with a heights up to $120 \mathrm{~m}$ (394 ft). The legs of the mast are usually composed of 90 deg. angles (in four legged towers) and $60 \mathrm{deg}$. schifflerized or cold formed angles (in three legged towers). Tubular or round solid sections are also very common. The web system by which the legs are connected can be with and without horizontals. The web system may consist of single diagonals, diagonals with midspan horizontals and tension - compression diagonals (cross - braced diagonals). Self supporting transmission towers usually have a square body configuration and are constructed with asymmetric angle sections that are eccentrically connected. Guyed telecommunication towers consist of a single mast of constant triangular or square cross section. The legs are made similarly to self-supporting towers and are usually bolted with 
horizontal and diagonal braces to form a 3-D truss structure. The tower is supported laterally along its span by a system of pretensioned inclined guy cables connected to concrete foundations buried in soil, as shown in Fig.1.5.

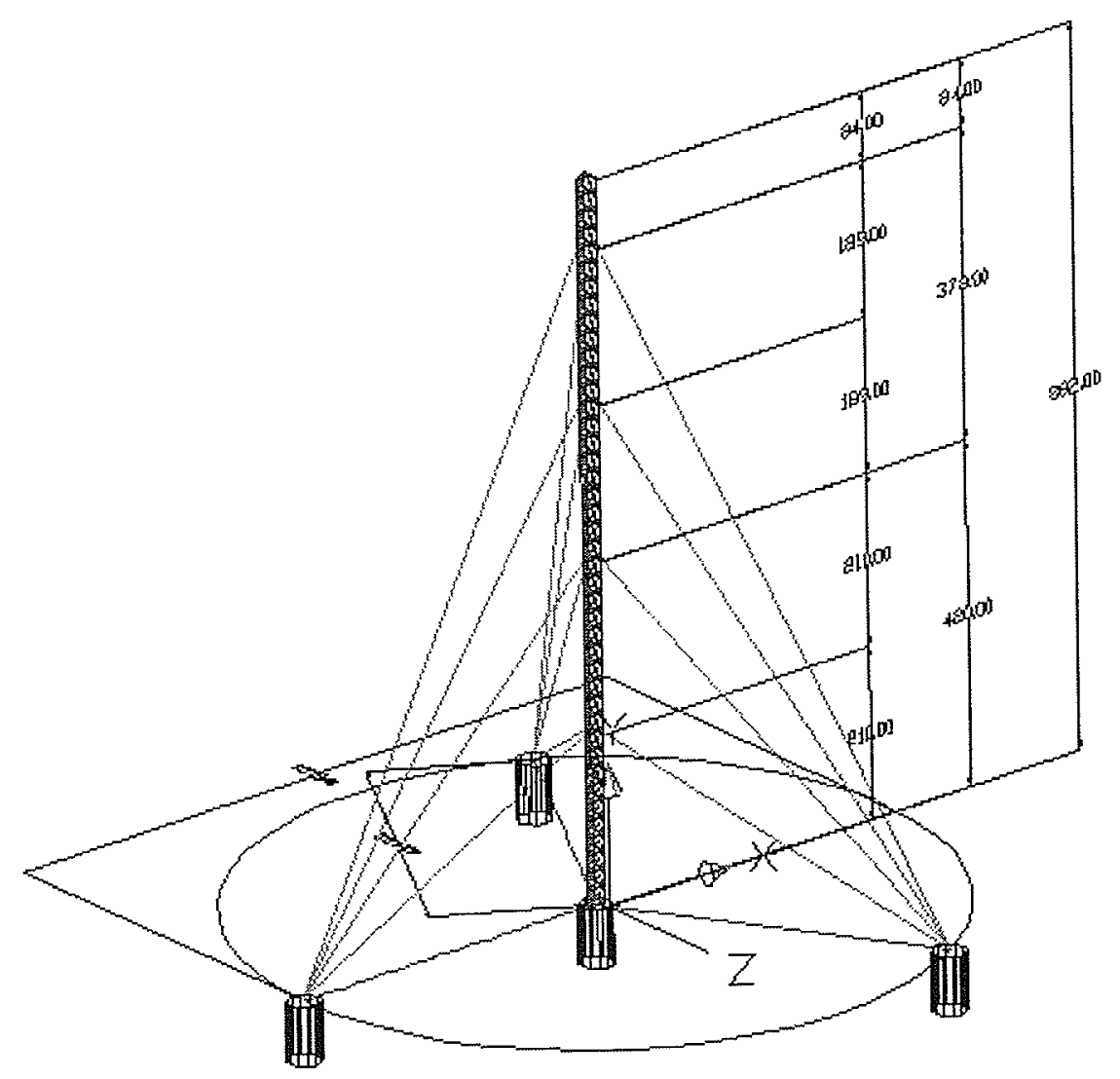

Fig.1.5 Typical Guyed Tower ( units are in $\mathrm{mm}$ )

To decrease the lateral deflections of the tower, supporting cables can be prestressed to $10 \%$ of their breaking strength. To limit the tower twist at the location of microwave antennas, star mounts are installed. The guyed towers are lighter than free standing towers of the same height. Therefore, they have smaller cross sections and smaller members. They are more economical to transport, easy to assemble on site, and require smaller foundations. 


\subsection{NEED FOR INVESTIGATION}

The use of steel for the fabrication of latticed structures has its drawback due to the need for maintenance and corrosion protection. The hot galvanizing process used to coat steel members has its limits since the size of galvanized members is restricted by the size of the galvanic bath available. Latticed structures have shown significant deterioration of the galvanized coating caused by weathering. Such deterioration exposes the steel area to weather and triggers a decrease of cross sectional area of the members over time. A decreased area means decreased load carrying ability that could potentially lead to structural failure. Canadian (CSA, 2001) and American (TIA-222F, 2003) codes of practice require additional corrosion preventing measures such as: galvanizing, epoxy coating, electric isolation and cathodic protection.

A research program was initiated at the University of Manitoba under the sponsorship of Manitoba Hydro and NSERC-CRD to develop a latticed tower fabricated from fibre-reinforced polymers (FRP) using the filament winding process. The search for an alternative material for constructing latticed towers was prompted by the need to eliminate such problems as corrosion and to provide a maintenance-free system. By eliminating the need for galvanizing and corrosion protection over the life span of a tower structure, significant overall cost reduction could be achieved. Also the ease of transportation and erection of the FRP towers could lead to additional savings in the early stages of the construction. 
From several new technologies in composite latticed tower applications available today, the composite truss tower made by Iso-Truss (Przybyla, 2008) and Composite Tower Solutions (CTS, 2008) seem to be the most advanced.

The Iso-Truss is a three dimensional truss structures composed of series of interconnecting triangles, forming outward-pointing pyramids along the length of the tower. The lattice elements are unidirectional fibre rovings wound on specially designed collapsible metallic mandrel. The Iso-Truss technology provides excellent strength-to-weight ratio with an ultra low weight.

Composite Tower Solutions (CTS) introduced recently the world's first composite lattice tilt-up-tower. CTS towers are built on lattice pattern composed of 8 FRP longitudinal rods, running axially and interconnected with octagonal cross-section members and helical rods of smaller diameter making the lattice faces.

The longitudinal members carry $95 \%$ of structural load, while helical members provide stiffness to them. CTS towers are being fabricated in sections as single parts using a specially designed winding machine. CTS technology provides supreme weight-to-strength characteristics, resistance to hardest weather conditions and excellent UV and corrosion resistance. They are easy to erect and cost affordable.

The tower concept presented in this research will have the same advantages as Iso-Truss and CTS towers. The extra advantage from our tower concept lies in simplification of lattice arrangement for tower faces and flexibility in the size of the individual members which result in further weight reduction. 


\subsection{OBJECTIVES OF THE PRESENT RESEARCH PROGRAM}

The primary objective of the research program reported here was to develop the technology needed for the design and fabrication of filament wound latticed tower segments which can easily be transported and assembled on site. To achieve this objective the following four major steps were followed: Numerical analysis; manufacturing of prototypes; laboratory testing; and, development of design guidelines.

\subsubsection{Numerical analysis}

Prior to commencing the experimental component of the research program, a numerical analysis was carried out. It included:

a) A review of the current design standards and specifications;

b) the determination of loads according to the Canadian Standard CSA-S37-01(CSA, 2001);

c) the modeling of the tower taking into account the basic tower characteristics, material properties, and the joint attachments;

d) defining the tower characteristics (size, configuration, cross section, etc.);

e) choosing the materials, the fibre orientation and the layer thickness; and,

f) carrying out a finite element analysis (FEA).

\subsubsection{Manufacturing of prototypes}

The manufacturing process included:

a) The construction of a collapsible mandrel; 
b) the fabrication of prototype tower segments;

c) the design and fabrication of lap joints; and,

d) the assembly of parts for testing.

\subsubsection{Laboratory testing}

The tower segment fabricated for testing consisted of four identical parts interconnected by lap joints. Both static and dynamic tests were carried out.

\subsubsection{Discussions of results and recommendations for the design of composite towers}

This phase of the research investigation followed the experimental stage and involved:

a) The review of current design standards and specifications;

b) the static and dynamic FEA; and,

c) an evaluation of the results from the FEA and testing.

\subsection{SCOPE}

The thesis consists of seven chapters.

Chapter 1: Introduction. This chapter includes a brief introduction to the project, followed by the objectives and scope of the research and acknowledgement. 
Chapter 2: Literature review. This chapter includes a review of the literature related to the design and analysis of guyed towers, as well as a brief history of the filament winding process.

Chapter 3: Numerical investigation. The particulars about the tower geometry, FRP material properties and guy cables characteristics are presented. The mechanical properties of unidirectional lamina obtained trough the Strength of Material Approach as well as a number of theories describing failure criteria of composite materials are also discussed in this chapter. FEA Static modeling of both the tested tower segment and the full-scale tower are included. The Dynamic modal and harmonic analysis of the tower segment and the modal analysis of the full-scale tower together with the Dynamic analysis of the full scale tower according to CSA-S37-01 are also discussed here.

Chapter 4: Experimental program. Details of the experimental investigation of the tower segment tested under static and dynamic loading are presented in this chapter.

Chapter 5: Discussion of Results The experimental results are analyzed and compared to the theoretical results in this chapter. 


\section{Chapter 6: Recommendations for the design of Composite Towers}

Design Recommendations for the design of latticed composite towers are presented here. These are based on both the experimental and theoretical investigations.

Chapter 7: Summary and conclusions

This chapter provides a summary of the work carried out along with recommendations and conclusions reached. 
CHAPTER 2

\section{LITERATURE REVIEW}




\subsection{METHODS OF ANALYSIS OF GUYED TOWERS - BRIEF HISTORY}

The first most comprehensive investigation of guyed towers has been carried out by Cohen and Perrin (1957a and 1957b). In the first paper (1957a), the authors dealt with wind and ice loads acting on towers and provide a variety of charts that could be used to select drag and lift coefficients for different tower cross sections and guy arrangements. The work also included formulae to calculate design wind loadings acting on towers. The second paper (1957b) provided a structural analysis of multi-level guyed towers, using a mathematical model. In this model, the mast of the tower was treated as a continuous beam-column resting on nonlinear elastic supports (guys), where spring constants were provided by the lateral stiffness of the guys. A solution method based on linearized slopedeflection equations is included in this paper. Using the moment distribution method the final moments are computed by superposition of moments obtained from the analysis of the shaft on rigid supports, the moments due to elastic deflections, and the moment due to the eccentricity of the vertical component of the guy forces resultant.

Rowe (1958) developed a theoretical model in which guy cables were treated as bars and amplification charts were presented for stress and displacements in guyed towers. These charts were intended to point out when advanced methods of structural analysis were required in the design and what modification could be made to classical method to obtain adequate results. 
Dean (1961) presented a catenary equation for the static guy cable. The dynamic guy modulus was not included in the elastic stretch of the cable.

Hull (1962) provided a stability analysis of guyed towers leading to the formulation of the critical moment of inertia corresponding to a critical buckling wind load. The author concluded that the most efficient way of increasing the buckling capacity of a tower is by increasing the stiffness of the guys. The author also stated that this method is limited and that the only way to further increase the buckling capacity of the tower was by means of increasing the moment of inertia of the mast itself.

Goldberg and Myers (1965) presented a method of analysis for guyed towers that considered the non- linear behaviour end effect of wind on guy cable stiffness.

They pointed out the importance of including the wind effects on guy cables and concluded that not including the wind effect would result in serious discrepancies in the end moments, shears, guy tensions and lateral displacements.

Odley (1966) presented an iterative method of analysis of high guyed towers and may be the first time that such an analysis was implemented in computer programming. The analysis started with assuming the value for the deflection of the shaft at each guy level to be used in determining the moments and reactions. After the reactions were established, deflections were computed and compared to those previously assumed. The iteration process stopped when these two values are in agreement with an allowable range and after that guy spring 
constants were evaluated and equations for the tower bending, shear and deflection diagrams were formulated and solved.

Miklofsky and Abegg (1966) developed a method for the design of guyed towers by interaction diagrams. In this method the tower was analyzed as a continuous beam on elastic supports and secondary effects such as the effect of ice and insulators located on guys, shear deformation, and initial imperfection of the shaft are included in the analysis. The tower was then reanalyzed with the inclusion of amplification stresses arising from axial loads.

Williamson and Margolin (1966) stressed the fact that including the shear deformations in the analysis of guyed tower in order to achieve safe design was very important. They also showed the way of modifying the conventional moment distribution factors when the axial thrust and web flexibility were considered and included an equation for computing the thickness of a fictious solid web which has the same rigidity as flexible trussed web.

Goldberg and Gaunt (1973) presented a method for determining the lateral loading due to an increased wind pressure at which a multi-level guyed tower becomes unstable. The authors used linearized slope-deflection equations to analyze a multi level guyed tower. In their analysis they also included secondary effect due to bending and axial thrust. They concluded that instability of guyed towers may result from large lateral deformations even at small increases in the applied load. The effect of independent varying parameters of the tower system, 
such as the moment of inertia of the shaft and the pretensioning of the guy system, on the critical load on the tower were examined.

The effect of icing on tall communication towers was examined by Williamson (1973). This study involved the design and analysis of a $457.2 \mathrm{~m}$ (1500 ft) tall tower guyed at 7 levels with a signal transmitter on the top. As a result of this study, the critical ice thickness which can lead to instability of the tower was formulated. The author also recommended design modifications which can account for tower icing, such as increasing initial guy tension, stiffening of the web and guy system, and increasing the face width of the tower shaft.

Peyrot and Goulois $(1978,1979)$ developed an efficient method for calculating the complex geometry of guy cables along with its end forces and its tangent stiffness matrix. These methods, together with the developed computer program were successfully used to analyse three dimensional guyed structures.

Rosenthal and Skop (1980) developed a new method for the static analysis of guyed towers. With the tower guy cables loaded by arbitrary distributed or concentrated forces, or both, and with derived by hypothesis assumptions about cable shape (catenary) and including the effect of axial forces as well as shear deformation in the tower, integration algorithms for the nonlinear beam-column equations were demonstrated in this paper. Cables were analysed by the Method of Imaginary Reactions.

Issa and Avent (1991) treated guyed towers as trusses. Three truss tower configurations were considered in which the three tower legs form the peaks of 


\section{Literature Review}

an equilateral triangle and the truss configuration on the faces of the tower were either X-braced, Warren, or Vierendeel. The tower modeling was combined with an algorithm to include the effects of the nonlinear cable/tower interaction. The analysis was programmed for use on a personal computer. As a demonstrative example, a $214 \mathrm{~m}(700 \mathrm{ft})$ tower was comparatively analyzed with an X-braced, Warren, and Vierendeel configuration. It was found that the Warren configuration was superior to the X-braced in terms of material efficiency, while direct comparisons with the Vierendeel could not be made without completing the detail design for each truss configuration.

Kahla (1993) studied the behaviour of a single guy cable under both leeward and windward wind pressure. By using a computer algorithm the author determined the natural frequencies and mode shapes of guy cable. The findings were validated using the developed analytical formulae.

Ekhande and Madagula (1998) included geometrical nonlinearities in their analysis of guyed towers employing an equivalent reduced modulus of elasticity for cables instead of continuous catenary. They also treated the tower as a geometrically non linear element.

The dynamic analysis of guyed cables under turbulent winds was examined by Sparling and Davenport (1998). Using a turbulent wind simulation, the authors found that the fluctuating response in the across-wind direction was similar in magnitude to that in the along-wind direction. The result was a significant 
increase in the bending moment across the tower shaft, leading to larger peaks in leg loads with less significant increases in the shear and displacements peaks.

The literature review presented here gave the insight in to the static and mechanics of guyed tower behaviour necessary for mathematical modelling.

It provided over 50 years development of theoretical methods being used to analyse the guyed towers.

The literature available in the area specific to guyed FRP towers analysis and design is presently either extremely rare or not available. Presented research is intended to fill this gap.

\subsection{BRIEF HISTORY OF FILAMENT WINDING}

The first ancient winding of molten glass around a soluble mandrel and a wrapping of mummies with bandages soaked with resin took place in $1370 \mathrm{BC}$ in Egypt. From then it took almost 3000 years to develop useful resin and glass fibres which happened in the 1930's (Peters at al., 1991). Filament winding is a process, particularly, characterized by production of strong light weight parts, which have better corrosion and electrical resistance. Filament winding process was first introduced by R.E. Young and M.W. Kellog in 1947 (Peters at al., 1991). The equipment they designed was very basic, performing simplest tasks using only 2- axis of motion (mandrel rotation, and horizontal carriage). The filament winding machine they used consisted of a beam, a few legs, and a horizontal 
carriage. The simplistic design was sufficient to create the first filament wound parts: fibreglass-polyester rocket engine cases.

The first recorded commercial use of filament winding was the production of lightweight FRP hoops for the Manhattan project in 1954 (Murphy, 1998).The first commercial filament winding machines were designed and produced by McClean and Andreson in the 1960's. The first six-axis winding machine was designed and built by Goldsworthy Engineering for the United States Army Aviation System Command in 1965. The first book on filament winding authored by D.V Rosato and C.S. Grove, titled "Filament Winding: Its Development Manufacture, Application and Design", was published in 1964 by John Willy and Sons (Murphy, 1998).

In the mid 1970's advancement in servo-mechanism technology and high speed computers to filament winding machines took place. This resulted in smoother motion and greater fibre placement accuracy. During the 1980's and 1990's there was an introduction of programmable motion cards, and pattern generation software which allowed winding more complex configuration parts, such as tapered shafts, $T$ shaped parts and non-axisymmetric parts. Because the winding process is controlled electronically by servo mechanisms it allows for improved accuracy of roving placements when compared to hand lay-up, Resin Transfer Molding (RTM) and press forming.

Filament winding is well suited for pressure vessels. Therefore, it has primary applicability for both intercontinental and tactical missile cases. Helicopter rotor 
blades and large wind turbine blades with drive shafts are now being manufactured using this technology. As reported recently by the Society of Plastic Industry (SPI, 2008), the largest market for filament winding is still in transportation (13\%), followed by construction (19.7\%), marine $(12.4 \%)$, electrical and electronic equipment (9.97\%), consumer (5.58\%) and aircraft and aerospace $(0.8 \%)$. The filament winding process of latticed tower segments presented in this thesis is a new technology which relies on the use of a collapsible winding machine ${ }^{1}$. A prototype FRP tower was fabricated for testing at the University of Manitoba McQuade Structural Laboratory under static and dynamic testing.

As of today the two most advanced FRP latticed tower systems for guyed towers applications are: Iso-Truss (Iso-Truss, 2008) and Composite Tower Solution (CTS, 2008), three dimensional composite truss structures.

\subsection{REVIEW OF CURRENT DESIGN STANDARDS AND SPECIFICATIONS}

The design of steel latticed towers is governed by the Canadian Standards CSAS37-01 and the American Specifications TIA-222-F. Both codes of practice provide guidelines regarding the wind and ice loads calculations. In addition the American Specifications provide guidelines for earthquake load calculations.

\footnotetext{
${ }^{1}$ Patent is pending through Cormorant Advanced Composites.
} 
Both standards outline design and analysis of guy cables as well as tower foundations. The limit state design approach is adopted as a method for structural analysis and design in both codes. The reference wind velocity pressure in Canadian code has a probability of being exceeded 1 in 30 years while the reference wind speed from which the velocity pressure is calculated in American Code has the probability of being exceeded 1 in 50 years.

Both American and Canadian Standards used so called "Gust Factor" which is applied to wind pressure for static analysis. As both Standards deal with only steel structures, they present strength for compression members as a function of slenderness ratio for the member. The tensile strength for the tower members is a function of net cross sectional area. The strength of guy wires is generally given by manufacturer as a braking strength modified by safety factors. 
CHAPTER 3

\section{NUMERICAL INVESTIGATION}




\subsection{GEOMETRIC PROPERTIES OF FRP TOWER}

The current research investigation focused on a medium size tower, typical of those used to support microwave equipment .The tower, shown in Fig. 3.1a, consisted of five $8534 \mathrm{~mm}$ segments and one extra section of $2134 \mathrm{~mm}$ at the top. The total length of tower was $44804 \mathrm{~mm}$.

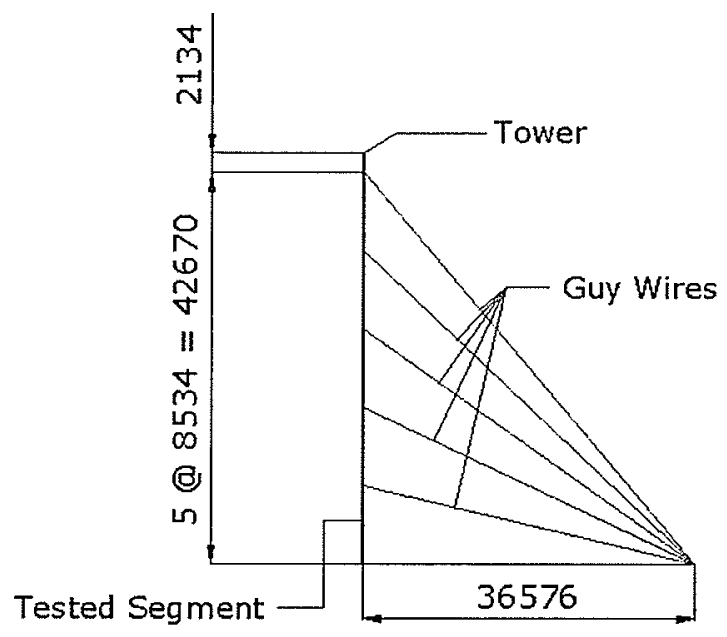

(a) Elevation

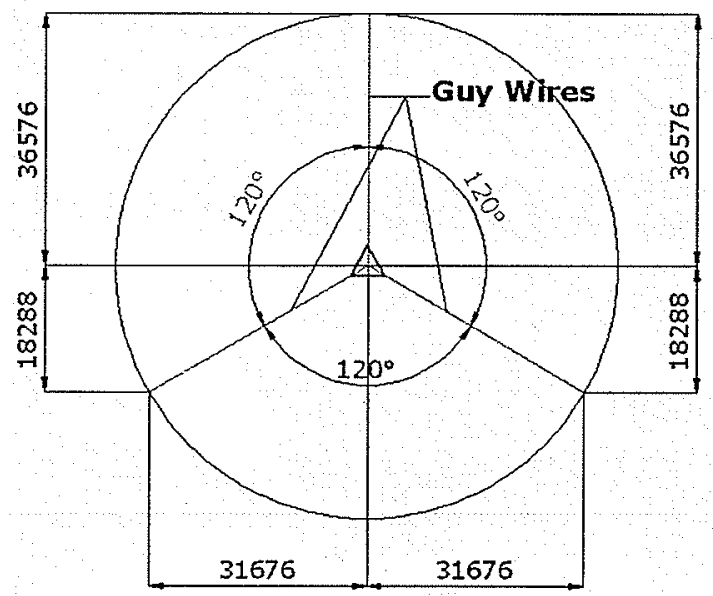

(b) Plan

Fig. 3.1 Proposed tower arrangement (units are in $\mathrm{mm}$ ) 
The tower was supported by three sets of cables spread at 120 deg, as indicated on Fig. 3.1b. There were five guy wire cables in each set. Each cable was connected on one anchor located on a radius of $36576 \mathrm{~mm}$. At the other end the cables were attached to the top of each of the $8534 \mathrm{~mm}$ tower segments. As indicated on Fig. 3.1a, the bottom segment of the tower was selected as the test specimen. It consisted of four separate parts, $2134 \mathrm{~mm}$ in length each. Each part, shown in Fig. 3.2 consisted of six vertical chord members and twenty four bracing members.
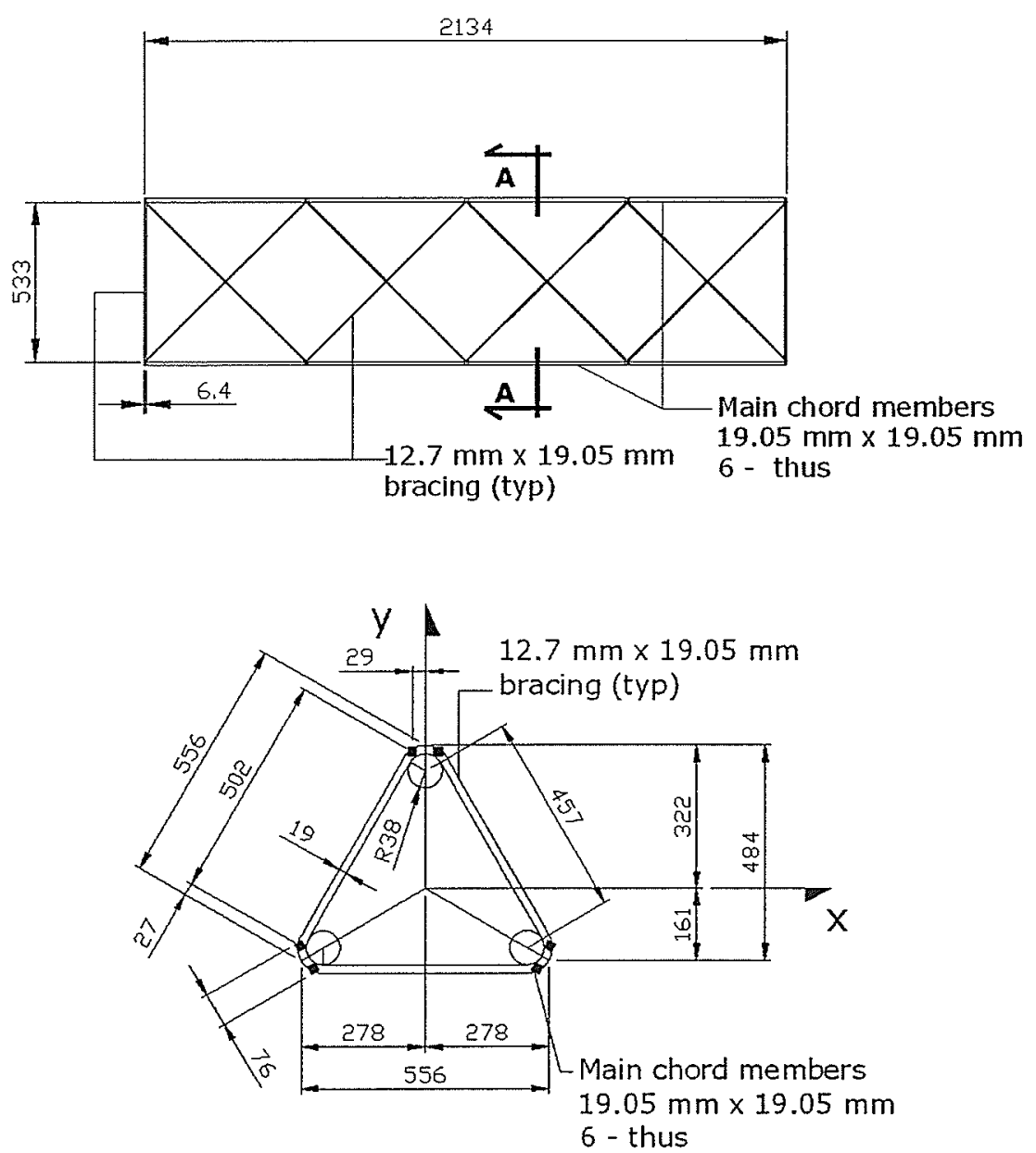

Section A-A

Fig. 3.2 Tower Segment Elevation and Section (units are in $\mathrm{mm}$ ) 
All these members were fabricated through a continuous filament winding process.

Each of the main chord members, shown in Fig. 3.2, had cross sectional dimensions: $19.05 \mathrm{~mm} \times 19.05 \mathrm{~mm}$ (0.75 in $\times 0.75 \mathrm{in})$. The diagonal braces were $12.7 \mathrm{~mm} \times 19.05 \mathrm{~mm}$ (0.5 in $\times 0.75$ in) while the vertical braces were $12.7 \mathrm{~mm} \times$ $19.05 \mathrm{~mm}(0.5 \mathrm{in} \times 0.75 \mathrm{in})$. The sizes and the arrangements of the tower members were initially selected on the basis of the maximum dimensions of a collapsible mandrel which could be fabricated and could be manually operated. The cost of manufacturing the mandrel, the cost of the fibres and the resin limited the size of the tower segments that could be fabricated. The guy cables were assumed to be $4.76 \mathrm{~mm}$ (3/16 in) dia. Galvanized Guy Cables, designed as "Left Hand Lay" (LHL) with 1 in 7 construction (Nello Corporation, 2006). The base of the tower was assumed to be pin supported.

\subsection{PHYSICAL AND MECHANICAL PROPERTIES OF FRP TOWER}

The continuous loop winding process was used to fabricate the tower segments. Strings of 12 fibres were placed in the grooves of the mandrel. Because there was no distinction of individual layers, the whole member can be described as an unidirectional composite. This unidirectional composite member has exceptional mechanical properties in the direction of the reinforcing fibres but has lower strength in the direction perpendicular to the fibres. Because latticed members are mainly two force members and bending stresses are marginal compared to 
direct axial stresses, unidirectional composites are ideal for FRP tower applications. The following two groups of lamina properties were used for both the analysis and design of the FRP latticed tower segment and the full scale tower:

a) Physical properties:

Density $\rho=0.0021 \mathrm{~g} / \mathrm{mm}^{3}(0.076 \mathrm{lb} / \mathrm{in})$ and Fibre volume fraction $V_{f}=36.8 \%$;

b) Mechanical properties:

$$
\begin{aligned}
& E_{1}=25.44 \mathrm{GPa}\left(3.69 \times 10^{6} \mathrm{psi}\right), E_{2}=4.24 \mathrm{GPa}\left(0.615 \times 10^{6} \mathrm{psi}\right), v_{12}=0.35, v_{21}=0.06, \\
& G_{12}=2.76 \mathrm{GPa}\left(0.4 \times 10^{6} \mathrm{psi}\right) .
\end{aligned}
$$

The physical and mechanical properties were taken from tests performed by Ungkurapinan (2005) and Burachynsky (2006). Physical properties were established from the burn out test, while mechanical properties were determined by coupon testing.

The testing of coupons is governed by ASTM Standards. Tension Tests are outlined in D 3039/ D3039 M (2005) Standards; Compression Tests in D 3410/D 3410M-03 (2005) Standards and Shear Tests in D 5379/D 5379M-05 (2005) Standards. Specimens tested by Ungkurapinan (2005) and Burachynsky (2006) were fabricated using a Slab Winding Machine, built by Cormorant Composites. The 1100 Tex Glass roving was used. The rectangular box-shaped section, was removed from the mandrel of and sawed into four flat panels 12 in (304.8 mm) by 36 in $(914 \mathrm{~mm})$. Test coupons were than cut to the dimensions outlined in the 
Standards and four grip stocks were also cut and added to each end of the specimens. All test coupons were arranged with unidirectional parallel fibres consolidated in resin. The coupons were fabricated using Type 30, 1100 Tex Roving E-Glass and 105 Epoxy Resin with 205 Fast hardener manufactured by West System Inc. The mixing ratio was (5:1). The FRP tower segments were fabricated using the same materials as the coupons. The fibres arrangement was also unidirectional due to filament winding procedure. The test coupons for FRP tower segments in this study would have been identical to the test coupons tested before. Therefore, the material properties from previous tests were used in the FE modeling of the latticed tower.

\subsection{PROPERTIES OF GUY CABLES AND TOWER BASE}

The modulus of elasticity of guy cables was assumed to be $200 \mathrm{GPa}(29000 \mathrm{ksi})$ and the diameter of the individual wire strand was $1.83 \mathrm{~mm}(0.072 \mathrm{in})$ giving a total cross sectional area of $18.39 \mathrm{~mm}^{2}\left(0.0285 \mathrm{in}^{2}\right)$ per cable. The braking strength of each cable is listed by the supplier (Nello Corporation, 2006) as 17.75 kN (3990 lbs). Each cable weights $1.06 \mathrm{~N} / \mathrm{m}$ or $72.9 \mathrm{lbs}$ per 1000 feet. Tower base was made from steel pipes and angles with modulus of elasticity of 200 GPa (29000 ksi). 


\subsection{THEORIES OF FAILURE FOR UNIDIRECTIONAL LAMINA}

The mechanical properties of unidirectional lamina can be obtained from laboratory experiments which are often expensive and time consuming (Kaw, 1997). The alternative way of deriving the mechanical properties of lamina are through theoretical methods. The most basic method for predicting the strength and stiffness of lamina is the Strength of Materials Approach which is a primary method in Micromechanics of composite materials. The assumptions made in the Strength of Material Approach are as follows:

- Good matrix - fibre bonding

- Uniform spacing between fibres

- Fibres are continuous and parallel

- The fibres and matrix are linearly elastic following Hooke's law

- Uniform strength of fibres

- The composite is free of voids and is residual stress free

The Strength of Material Approach is based on simple mechanical deformation and force equilibrium. The modulus obtained from experimental results tends to be of lower value due to voids and fiber misalignment.

\subsubsection{Longitudinal Modulus}

For unidirectional composites the longitudinal modulus can be obtained by using the rule-of-mixture defined by Eq. 3.1.

$$
E_{1}=E_{f} V_{f}+E_{m} V_{m} \quad \text { or } \quad E_{1}=E_{f} V_{f}+\left(1-V_{f}\right) E_{m}
$$


where:

$E_{1}=$ Modulus of elasticity of the composite in the fibre direction

$E_{f}=$ Elastic modulus of the fibre

$V_{f}=$ Fibre volume fraction

$V_{m}=$ Matrix volume fraction

$E_{m}=$ Modulus of elasticity of the matrix

The ratio of the load taken by the fibres to the load taken by composite is an indicator of how much of the applied load is shared by fibres. Thus,

$$
\frac{F_{f}}{F_{c}}=\frac{E_{f}}{E_{1}} V_{f}
$$

where:

$F_{f}=$ force acting in the fibres

$F_{c}=$ force acting in by the composite

According to Eq. 3.2, the amount of load in the fibres is directly proportional to fibre volume fraction $V_{f}$.

\subsubsection{Transverse Modulus}

The transverse modulus of the unidirectional composite can be obtained from the inverse rule-of -mixture as follows:

$\frac{1}{E_{2}}=\frac{V_{f}}{E_{f}}+\frac{V_{m}}{E_{m}}$ or $\quad \frac{1}{E_{2}}=\frac{V_{f}}{E_{f}}+\frac{\left(1-V_{m}\right)}{E_{m}}$

where: 
$E_{2}=$ modulus of elasticity of the composite in the direction perpendicular to the fibre

The value of the transverse stiffness obtained from Eq. 3.3 compare poorly with experimental data. Hopkins and Chamis (1988) studied this problem and refined the Strength of Material Approach model by introducing the method of subregions. They converted a representative volume element (RVE) with a circular fibre to an equivalent RVE having square fibres. Then, they divided the representative volume element into sub-regions using square fibres. The modified expression for the transverse stiffness is given by Eq. 3.4.

$$
E_{2}=E_{m}\left[\left(1-V_{f}\right)+\frac{\sqrt{V_{f}}}{1-\sqrt{V_{f}} \times\left(1-E_{m} / E_{f}\right)}\right]
$$

Alternatively, the value of the transverse stiffness can be obtained from the Halpin-Tsai (Kaw, 1997) semi empirical equation:

$$
E_{2}=E_{m} \frac{1+\xi \eta V_{f}}{1-\eta V_{f}}
$$

where:

$$
\eta=\frac{\left(E_{f} / E_{m}\right)-1}{\left(E_{f} / E_{m}\right)+\xi}
$$

The term $\xi$ is called the reinforcing factor and for circular fibres in square packing geometry, $\xi=2$. 


\subsubsection{Major Poisson's ratio}

The major Poisson's ratio for unidirectional lamina can be obtained from the following equation:

$v_{12}=v_{f} V_{f}+v_{m} V_{m}$

where:

$v_{f}=$ Poisson's ratio of the fibre

$v_{m}=$ Poisson's ratio of the matrix

\subsubsection{In Plane Shear Modulus}

In plane shear modulus can be calculated from the following formula:

$$
\frac{1}{G_{12}}=\frac{V_{f}}{G_{f}}+\frac{V_{m}}{G_{m}} \quad \text { or } \quad G_{12}=\frac{G_{m} G_{f}}{V_{m} G_{f}+V_{f} G_{m}}
$$

where:

$G_{f}=\frac{E_{f}}{2\left(1+v_{f}\right)}$ is the shear modulus of the fibre

$G_{m}=\frac{E_{m}}{2\left(1+v_{m}\right)}$ is the shear modulus of matrix

As in the case of the transverse stiffness, the formula for in-plane shear modulus was improved by introducing the method of sub-regions (Kaw, 1997) and is given by the following equation : 


$$
G_{12}=G_{m}\left[\left(1-V_{f}\right)+\frac{\sqrt{V_{f}}}{1-\sqrt{V_{f}} \times\left(1-G_{m} / G_{f}\right)}\right]
$$

As before, the in-plane shear modulus can be obtained alternatively from the Halpin-Tsai semi empirical equation:

$$
G_{12}=G_{m} \frac{1+\xi \eta V_{f}}{1-\eta V_{f}}
$$

where:

$$
\eta=\frac{\left(G_{f} / G_{m}\right)-1}{\left(G_{f} / G_{m}\right)+\xi}
$$

The term $\xi$ for circular fibres in square packing geometry is $\xi=1$ (Swanson,1997).

\subsubsection{Longitudinal Tensile and Compressive Strength}

The longitudinal tensile strength using the Strength of Materials Approach is:

$$
\left(\sigma_{1}\right)_{u l t}^{t}=\left(\sigma_{f}\right)_{u l t} V_{f}+\left(\varepsilon_{f}\right)_{u l t} E_{m}\left(1-V_{m}\right)
$$

where:

$\left(\sigma_{f}\right)_{n t h}=$ ultimate tensile strength of fibre

$E_{m} \quad=$ Elastic modulus of matrix

$$
\left(\varepsilon_{f}\right)_{u l t}=\text { ultimate strain in fibre }
$$

This is assuming that this failure is the first one to occur.

The longitudinal compressive strength can be calculated from the formula: 


$$
\left(\sigma_{1}\right)_{u l t}^{c}=2\left[\left(\tau_{f}\right)_{u t t} V_{f}+\left(\tau_{m}\right)_{u l t} V_{m}\right]
$$

where:

$\left(\tau_{f}\right)_{u t}=$ ultimate tensile strain of fibre

$\left(\tau_{m}\right)_{u l t}=$ ultimate tensile strain of matrix

\subsubsection{Transverse Tensile and Compressive Strength}

The transverse tensile strength is given by the equation:

$$
\left(\sigma_{2}\right)_{u l t}^{t}=E_{2}\left(\varepsilon_{2}\right)_{u t t}^{t}
$$

where:

$\left(\varepsilon_{2}\right)_{u l t}^{t}=$ ultimate tensile failure strain of matrix

$E_{2} \quad=$ Elastic modulus of lamina in the transverse direction

Transverse compressive strength is given by the equation:

$$
\left(\sigma_{2}\right)^{c}{ }_{u l t}=E_{2}\left(\varepsilon_{2}\right)_{u l t}^{c}
$$

where

$$
\left(\varepsilon_{2}\right)_{u l t}^{c}=\text { ultimate compressive failure strain of matrix }
$$

\subsubsection{In-Plane Shear Strength}

Ultimate in-pane shear strength can be calculated from the following equation:

$$
\left(\tau_{12}\right)_{u l t}=G_{12}\left[\frac{d}{s} \frac{G_{m}}{G_{f}}+\left(1-\frac{d}{s}\right)\right]\left(\gamma_{12}\right)_{u l t}
$$


where:

$G_{12}=$ in-plane shear modulus of lamina

$\left(\gamma_{12}\right)_{u l t}=$ ultimate shear strain of matrix

$\mathrm{d}$ and $\mathrm{s}=$ the fiber diameter and fiber spacing ratio, respectively.

Knowing the stifnesses and strengths, failure mechanism theories for unidirectional laminated composites can be derived.

\subsubsection{Failure Mechanism in Unidirectional Composites}

Extensive research has been conducted to study the failure mechanism of composites from the micromechanical and macromechanical points of view (Swanson,1997). On the micromechanical level the failure varies widely depending on fibre type, matrix or interface, statistical variation in strength of fibre, matrix and interface, and local nature of failure initiation (Daniel and Ishai, 1994). Failure predictions based on micromechanics, even when they are accurate with regard to failure initiation at critical points, are only approximate with regard to global failure of a lamina. Because of that, a macromechanical approach to failure analysis is widely preferred. Several failure theories have been proposed and are available to asses the ultimate strength of the unidirectional lamina. They are classified into two main groups, limit or noninteractive theories (maximum stress, maximum strain) and interactive theories (Tsai-Hill,Tsai-Wu). These are discussed briefly in the following sections. 


\subsubsection{Maximum Stress Theory}

According to the Maximum Stress Theory for 2D lamina, no failure occurs when the following relations are satisfied:

$F_{1}^{c u t} \leq \sigma_{1} \leq F_{1}^{l t}$

$F_{2}^{c u} \leq \sigma_{2} \leq F_{2}^{t l u}$

$F^{s t} \leq \tau_{12} \leq F^{s t}$

where:

$F_{1}^{t n}=$ longitudinal tensile strength in the fibre direction

$F_{1}^{c t}=$ longitudinal compressive strength in the fibre direction

$F_{2}^{t u}=$ transverse tensile strength in the direction perpendicular to the fibres

$F_{2}^{c l t}=$ transverse compressive strength in direction perpendicular to the fibres

$F^{s u}=$ in plane shear strength in plane 1,2 (Fig. 3.3)

$\sigma_{1}=$ stress for uniaxial loading in the fibre direction

$\sigma_{2}=$ stress for transverse loading in the direction perpendicular to the fibres

$\tau_{12}=$ shear stress in the plane 1,2 (Fig. 3.3)

The Maximum Stress Theory failure envelope is shown in Fig. 3.3. 


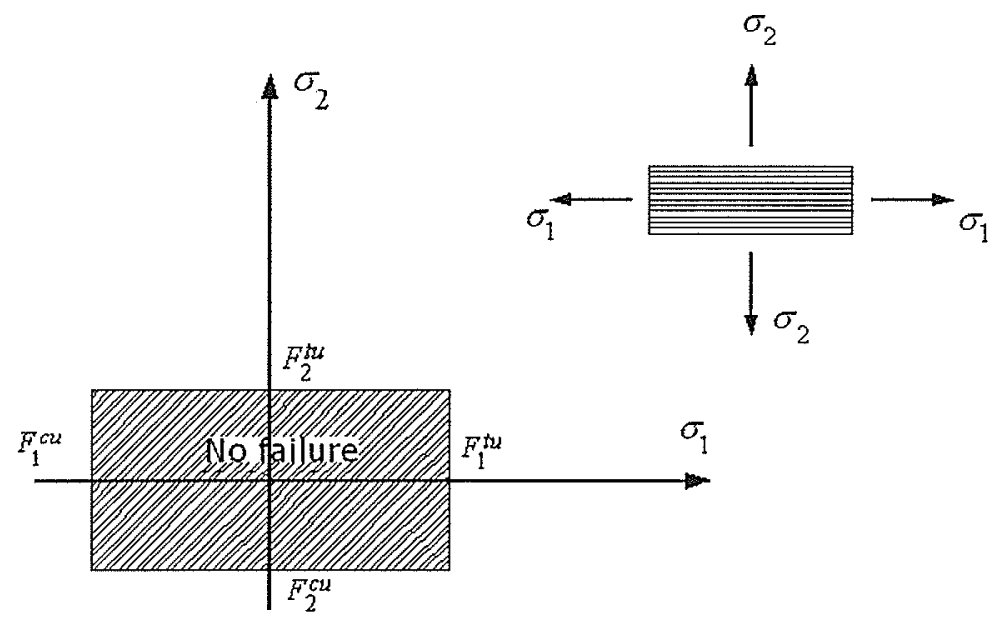

Fig. 3.3 Maximum Stress Theory failure envelope

\subsubsection{Maximum Strain Theory}

According to the Maximum Strain Theory for 2D lamina, no failure occurs when the following conditions are satisfied:

$\varepsilon_{1}^{c u t} \leq \varepsilon_{1} \leq \varepsilon_{1}^{t h t}$

$\varepsilon_{2}^{c u} \leq \varepsilon_{2} \leq \varepsilon_{2}^{t u}$

$\left|\gamma_{12}\right|<\gamma_{12}^{u}$

where:

$\varepsilon_{1}^{i t}=$ ultimate longitudinal tensile strain in the fibre direction

$\varepsilon_{1}^{c t}=$ ultimate longitudinal compressive strain in the fibre direction

$\varepsilon_{2}^{t t}=$ ultimate transverse tensile strain in the direction perpendicular to the fibres

$\varepsilon_{2}^{c l}=$ ultimate transverse compressive strain in the direction perpendicular to the fibres 
$\gamma_{12}^{n}=$ in plane ultimate shear strain (in plane 1,2) (Fig. 3.4)

$\varepsilon_{1}=$ strain for uniaxial loading in the fibre direction

$\varepsilon_{2}=$ stress for transverse loading in the direction perpendicular to the fibres

$\gamma_{12}=$ shear strain in ( plane 1,2) (Fig. 3.4)

The Maximum Strain Theory failure envelope is shown in Fig. 3.4.

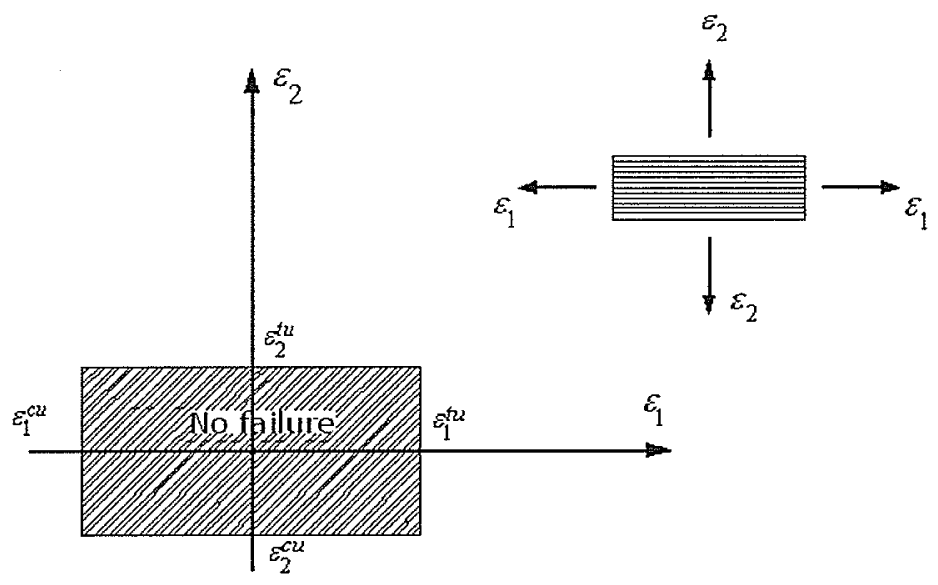

Fig. 3.4 Maximum Strain Theory failure envelope

\subsubsection{Tsai-Hill Theory}

According to the Tsai-Hill theory (Tsai, 1984) for 2D lamina, failure occurs when the following equation is not satisfied.

$$
\frac{\sigma_{1}^{2}}{\left(F_{1}^{c u}\right)^{2}}+\frac{\sigma_{2}^{2}}{\left(F_{2}^{c u}\right)^{2}}-\frac{\sigma_{1} \sigma_{2}}{\left(F_{1}^{c l}\right)^{2}}+\frac{\tau_{12}^{2}}{\left(F_{S}^{u}\right)^{2}} \leq 1
$$

where: 
$\sigma_{1}=$ stress for uniaxial loading in the fibre direction

$\sigma_{2}=$ stress for transverse loading in the direction perpendicular to the fibres

$\tau_{12}=$ shear stress in the plane 1,2

$F_{1}^{c u}=$ longitudinal compressive or tensile strength in the fibre direction

$F_{2}^{c u}=$ transverse compressive or tensile strength in the direction perpendicular to the fibre

$F^{s \prime}=$ in plane shear strength (in plane 1,2)

Normal stress and strength in any direction must be either tensile or compressive for this criterion.

\subsubsection{Tsai-Wu Theory}

Tsai and Wu (1971) proposed a strength criterion in which there exist a failure surface in stress-space. The criterion takes the following form:

$f_{1} \sigma_{1}+f_{2} \sigma_{2}+f_{11} \sigma_{1}^{2}+f_{22} \sigma_{2}^{2}+f_{66} \tau_{6}^{2}+2 f_{12} \sigma_{1} \sigma_{2} \leq 1$

All six constants in this equation are evaluated by tests using the following formulae:

$$
\begin{aligned}
& f_{1}=\frac{1}{F_{1}^{t u}}-\frac{1}{F_{1}^{c t}} \\
& f_{11}=\frac{1}{F_{1}^{t t} F_{2}^{c t}} \\
& f_{2}=\frac{1}{F_{2}^{t h}}-\frac{1}{F_{2}^{c u}}
\end{aligned}
$$




$$
\begin{gathered}
f_{22}=\frac{1}{F_{2}^{t u} F_{2}^{c u}} \\
f_{66}=\frac{1}{\left(F^{s u}\right)^{2}}
\end{gathered}
$$

$f_{12} \cong-\frac{1}{2} \sqrt{f_{11} f_{22}}$ or $f_{12} \cong-\frac{1}{2} \sqrt{\frac{1}{F_{1}^{t u} F_{1}^{c u} F_{2}^{t u} F_{2}^{c u}}}$

These are determined by longitudinal and transverse tension and compression tests as well as a shear test. The Tsai-Hill theory requires only one strength as input (either compressive or tensile), while the Tsai-Wu theory requires both the compressive and the tensile strength data as input.

The safe envelope for design of unidirectional composites, based on criteria discussed above is shown in Fig. 3.5.

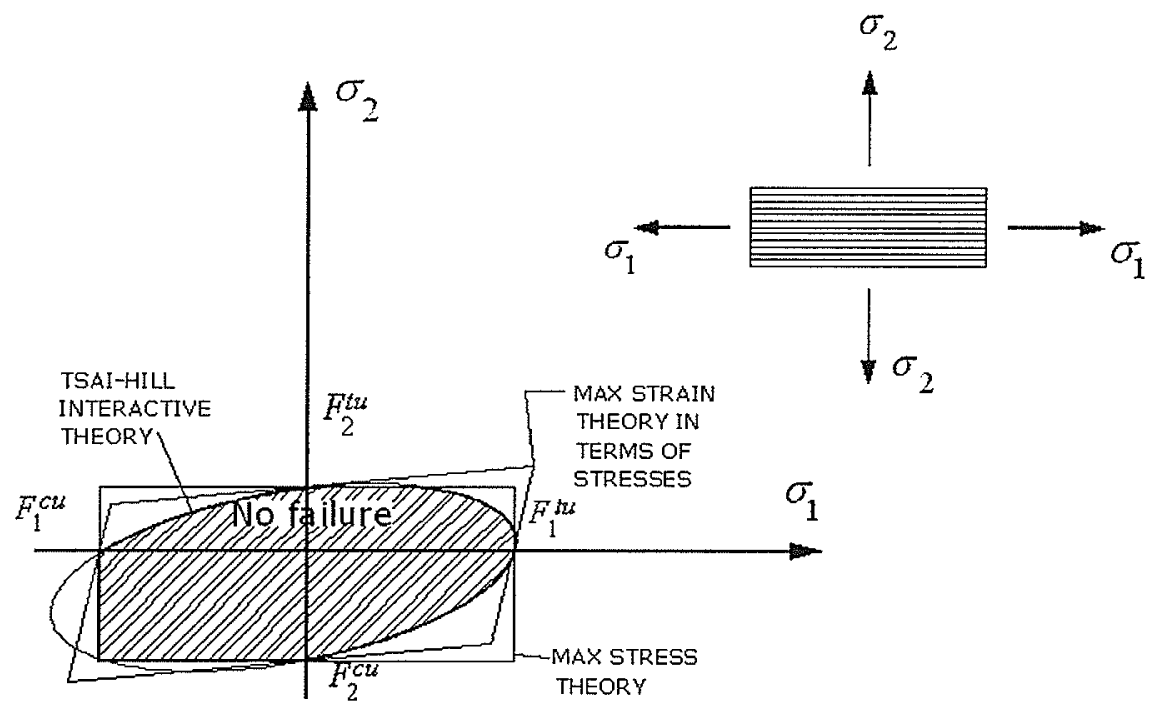

Fig. 3.5 Theories of failure combination 
All of the above theories hypothesise the failure based on certain failure mechanisms. In fibre-reinforced composites the principal mechanisms of failure are:

- Matrix cracking

- (Fibre-Matrix) debonding

- (Inter-Layer) delamination

- Fibre fracture

- Fibre pullout

- Microbuckling

- Kink bands (most predominant mode of failure in compression for most FRP composites)

The non interactive theory (Maximum Strength) and the interactive theory (Tsai $\mathrm{Wu}$ ) were used in this thesis to evaluate the strength of the FRP latticed tower components.

\subsection{LOADING CONDITIONS}

The calculation of loadings acting on latticed towers in Canada is governed by the current CSA Standard CSA-S37-01 (CSA, 2001). This Standard requires that towers are designed to be serviceable and safe from structural failure during their useful life and provides serviceability and ultimate limit states criteria for design. Serviceability limit states require that the structure possesses sufficient rigidity to 
ensure that the specified limits of tilt and twist, or combinations of these, are not exceeded under the action of service loads. Ultimate limit states require that the structure has sufficient strength and stability to ensure that the factored resistance of its members equals or exceeds the stress due to factored loads.

\subsubsection{Design Loads}

The design loads required according to CSA Standard are grouped in three categories: Dead Loads (D), Ice Loads (I), and Wind Loads (W). In addition, a soil report, and antenna loading requirements have to be provided. The service loads are the actual loads acting on the structure without a load factor, while the factored loads are the service loads multiplied by an appropriate load factor (NBCC, 2005). The soil report details the soil conditions present at the site and helps determine what type of foundation is required. Antenna loadings cover anything added to the tower, initially or in the future, that will be exposed to wind.

\subsubsection{Loadings Calculations}

According to CSA-S37 Standard, Clause 4.8.1, the wind load on lattice structures with round, flat or a combination of round and flat members, without the presence of ice, shall be calculated according to formula:

$$
W=P \times\left(C_{d f} \times A_{f}+C_{d r} \times A_{r}\right)
$$

where, 
$W=$ wind load $\left[\frac{k N}{m^{2}}\right]$

$P=$ design wind pressure $[\mathrm{Pa}]$

$C_{d f}=$ drag factor for flat members

$A_{f}=$ face area of flat members, bare $\left[\mathrm{m}^{2}\right]$

$C_{d r}=$ drag factor for round bare members

$A_{r}=$ face area of round bare members $\left[\mathrm{m}^{2}\right]$

In this research project, the design wind pressure was calculated according to

Clause 4.3 .1 of the CSA-S37 Standard using the formula:

$$
P=q_{h} \times C_{g} \times C_{a}
$$

where:

$P$ is the pressure of undisturbed flow, $[P a]$,independent of drag factor, and

$$
q_{h}=q \times C_{e}
$$

$q=$ the reference velocity pressure, given in the NBCC.

For Winnipeg, Manitoba, Class A terrain,

$$
\begin{aligned}
q & =450\left(\mathrm{~Pa} \text { or } \mathrm{N} / \mathrm{m}^{2}\right) \\
C_{e} & =\text { the height factor defined as, } \\
C_{e} & =\left(\frac{H_{x}}{10}\right)^{0.2} \text { and } 0.9 \leq C_{e} \leq 2.0
\end{aligned}
$$

where,

$$
H_{x}=\text { the height in }(\mathrm{m}) \text { above grade }
$$


According to Clause 4.5 .2 of the CSA-S37 Standard, the average value of $q_{h}$ for one span may be used for the full span between guy levels.

In the tower investigated here, the height factor $C_{e}$ was calculated for each panel separately. Also, $C_{g}$ is a gust factor and its value is given by Clause 4.6 .1 of the CSA-S37 Standard as $C_{g}=2.0$, for latticed structures and their attachments. $C_{a}$ is a wind speed factor and, according to Clause 4.7 .1 , it is equal to 1.0.

Because the tower being investigated consists only of flat members, as shown in Fig. 3.6, the drag factor $C_{d f}$ can be calculated according to Clause 4.9.1.1 of the Standard, as follows:

$C_{d f}=3.4 \times\left(R_{s}\right)^{2}-4.7 \times\left(R_{s}\right)+3.4$

where:

$R_{s}=$ solidity ratio defined as:

$R_{s}=\frac{A_{S}}{A_{g}}$

where:

$A_{s}=$ net projected area of flat member,

$A_{g}=$ gross area of a panel.

Using the dimensions shown in Fig. 3.6, 


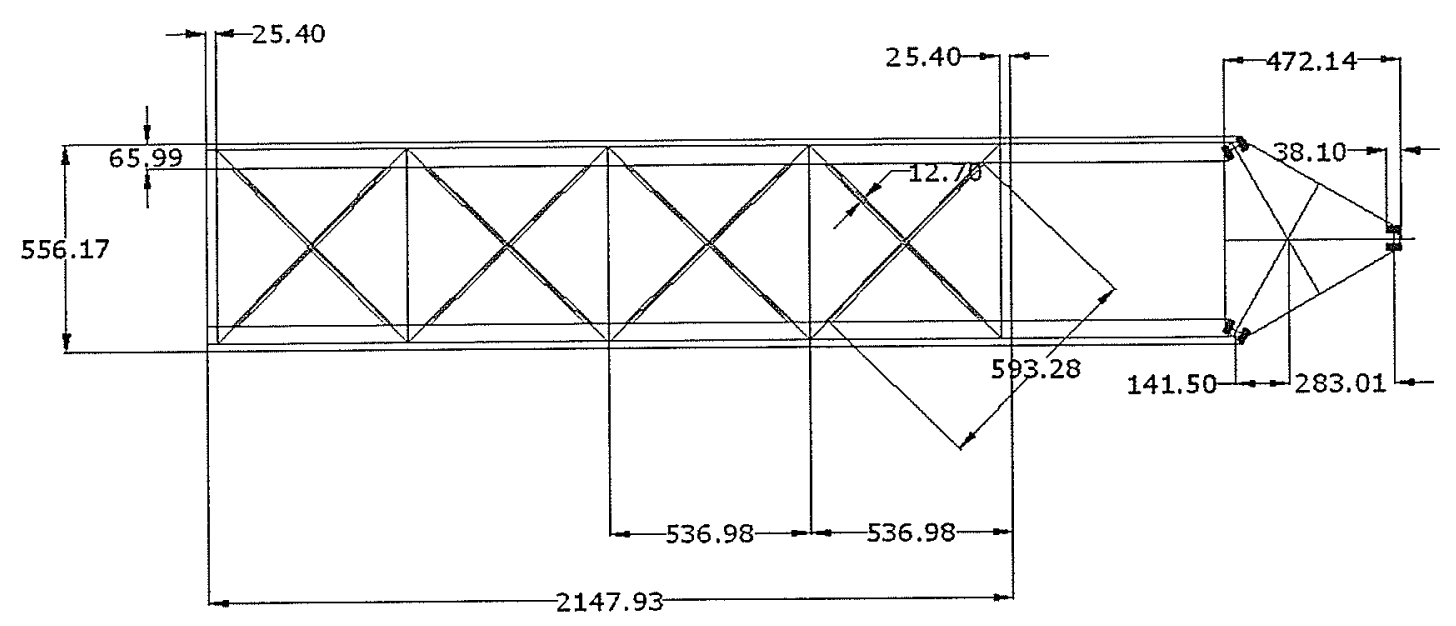

Fig. 3.6 Actual panel assembly (units are in $\mathrm{mm}$ )

$A_{s}=(593.28 \times 12.7 \times 8)+(2147.93 \times 131.98)+(556.17 \times 25.4 \times 2)=372014.5 \mathrm{~mm}^{2}$

$A_{g}=(556.17 \times 2147.93)=1194614.2 \mathrm{~mm}^{2}$

Thus, $R_{s}=0.311$, and $C_{d f}=2.267$.

\subsubsection{Calculation of Design Wind Pressure}

The tower was assumed to be located in Winnipeg, Manitoba, and initially the ice loads were neglected in the analysis. According to NBCC, the reference velocity pressure, $q$, is equal to $450 \mathrm{~Pa}$. The reference velocity pressure, $q$, for a 50 year return period was selected. This is referring to the mean hourly wind pressure at $10 \mathrm{~m}$ above the ground level, as appropriate for the site selected. The height factor $C_{e}$ varies with distance above ground and was calculated according to Eq. 3.27. The uniform gust factor $C_{g}=2.0$ was applied to wind 
pressure to account for the dynamic response, as stipulated by Clause 4.6 .1 of the CSA-S37 Standard. A panel was defined as a tower segment having a width equal to $556.17 \mathrm{~mm}(21.89 \mathrm{in})$ and height equal to $2147.93 \mathrm{~mm}$ (84.56 in). Two loading cases were investigated. Load normal to the side, shown in Fig. 3.7 (a) and load parallel to the side, as shown in Fig. 3.7 (b). Loading normal to the side, was assumed as the critical condition for determining the lateral deflections.

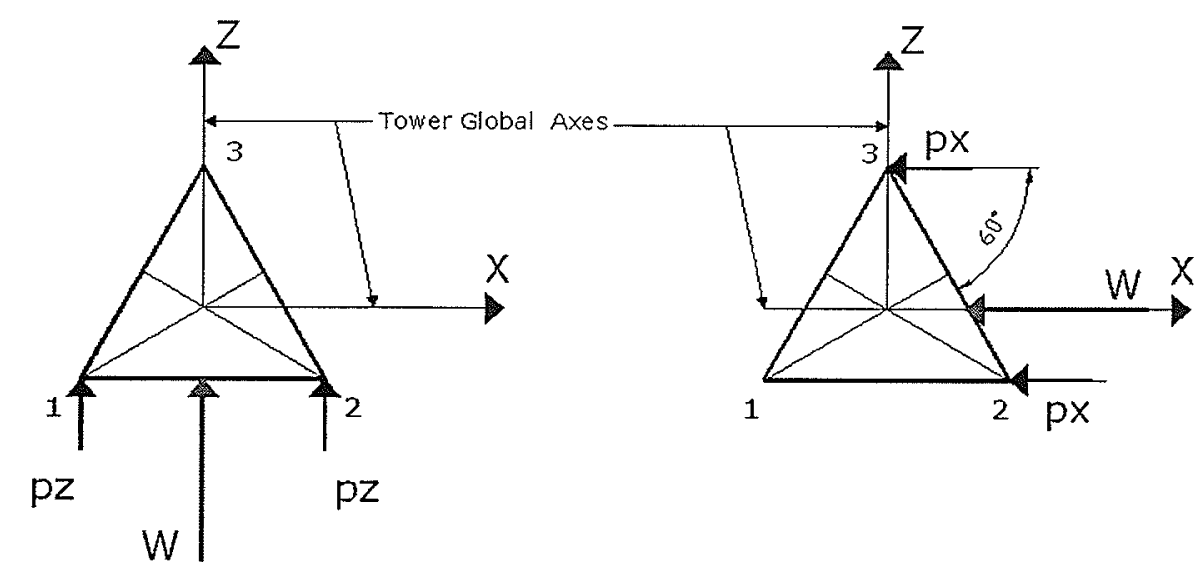

(a) Load Case-1

Perpendicular wind (b) Load Case-2

Side wind

Fig. 3.7 Tower loading cases

Loading parallel to the side of the tower was considered to be critical for tower twist. The FEA requires that loading per node be computed. In this case, the loading per node refers to the portion of loading equivalent to a tributary area equal to $1 / 8$ of the panel load. For the $45 \mathrm{~m}(147 \mathrm{ft}$ ) tower, the wind loads for Case-1 are listed in Table 3.1 
Table 3.1 Tower service load no ice, Case-1

\begin{tabular}{|c|c|c|}
\hline \multicolumn{3}{|c|}{ Tower Service Loads } \\
\hline Distance above the ground ( $\mathrm{mm}$ ) & $\begin{array}{c}P \\
\text { per panel } \\
(\mathrm{N})\end{array}$ & $\begin{array}{c}P \\
\text { per node } \\
\text { (N) }\end{array}$ \\
\hline $42672-44806$ & 1023.36 & 127.93 \\
\hline $40538-42672$ & 1013.44 & 126.69 \\
\hline $38405-40538$ & 1003.12 & 125.40 \\
\hline $36271-38405$ & 992.31 & 124.02 \\
\hline $34138-36271$ & 981.01 & 122.64 \\
\hline $32004-34138$ & 969.22 & 121.17 \\
\hline $29870-32004$ & 956.77 & 119.61 \\
\hline $27737-29870$ & 943.65 & 117.97 \\
\hline $25603-27737$ & 929.77 & 116.23 \\
\hline $23470-25603$ & 915.00 & 114.36 \\
\hline $21336-23470$ & 899.25 & 112.41 \\
\hline $19202-21336$ & 882.26 & 110.27 \\
\hline $17069-19202$ & 863.84 & 108.00 \\
\hline $14935-17069$ & 843.74 & 105.47 \\
\hline $12802-14935$ & 821.50 & 102.71 \\
\hline $10668-12802$ & 796.59 & 99.55 \\
\hline 8534-10668 & 768.03 & 95.99 \\
\hline $6401-8534$ & 734.53 & 91.81 \\
\hline $4267-6401$ & 693.43 & 86.70 \\
\hline $2134-4267$ & 639.43 & 79.93 \\
\hline $0-2134$ & 556.65 & 69.57 \\
\hline
\end{tabular}

\subsubsection{Calculation of Design Wind and Ice Loading}

The provisions in the CSA-S37 Standard for radial ice thickness of $25 \mathrm{~mm}$ were used to calculate wind loadings acting along the tower. The wind loads were obtained with the help of Eq. 3.30. 
$W=P \times\left(C_{d f} \times A_{f}+C_{d r} \times A_{r}+C_{d r} \times A_{i}\right)$

where,

$A_{i}$ - refers to the face area of radial ice and is determined according to CSAS37-01 Standard. Other symbols in Eq. 3.30 are similar to those used in Eq.

\subsection{4 .}

The calculations were performed with the help of a Microsoft Excel spread sheet. The service wind loads for this case are listed in Table 3.2. The factored wind loads for the tower with and without ice are listed in Table 3.3. A factor of 1.5 was used to determine the factored wind loads ${ }^{2}$.

${ }^{2}$ Load factor for wind loads was used according to NBCC (2005) as a principal load factor for live loads specified in Division B, Part 4, sentence 4.1.3.2.(5). 
Table 3.2 Tower service load with ice, Case-1

\begin{tabular}{|c|c|c|}
\hline \multicolumn{3}{|c|}{ Tower Service loads } \\
\hline $\begin{array}{l}\text { Distance above the ground } \\
\qquad(\mathrm{mm})\end{array}$ & $\begin{array}{c}P \\
\text { Per panel } \\
\text { (N) }\end{array}$ & $\begin{array}{c}P \\
\text { per node } \\
(\mathrm{N})\end{array}$ \\
\hline $42672-44806$ & 1920.30 & 240.03 \\
\hline $40538-42672$ & 1901.66 & 237.71 \\
\hline $38405-40538$ & 1882.27 & 235.27 \\
\hline $36271-38405$ & 1862.03 & 232.73 \\
\hline $34138-36271$ & 1840.85 & 230.11 \\
\hline $32004-34138$ & 1818.66 & 227.35 \\
\hline $29870-32004$ & 1795.35 & 224.41 \\
\hline $27737-29870$ & 1770.75 & 221.34 \\
\hline $25603-27737$ & 1744.68 & 218.10 \\
\hline $23470-25603$ & 1716.97 & 214.63 \\
\hline $21336-23470$ & 1687.34 & 210.93 \\
\hline $19202-21336$ & 1655.49 & 206.93 \\
\hline $17069-19202$ & 1620.98 & 202.62 \\
\hline $14935-17069$ & 1583.26 & 197.90 \\
\hline $12802-14935$ & 1541.53 & 192.70 \\
\hline $10668-12802$ & 1494.74 & 186.83 \\
\hline $8534-10668$ & 1441.18 & 180.15 \\
\hline $6401-8534$ & 1378.28 & 172.28 \\
\hline 4267-6401 & 1301.24 & 162.67 \\
\hline $2134-4267$ & 1199.86 & 149.99 \\
\hline $0-2134$ & 1044.53 & 130.56 \\
\hline
\end{tabular}


Table 3.3 Factored wind tower loads with and without ice for Case-1

\begin{tabular}{|c|c|c|}
\hline \multicolumn{3}{|c|}{ Tower factored loads } \\
\hline $\begin{array}{l}\text { Distance above the ground } \\
(\mathrm{mm})\end{array}$ & $\begin{array}{c}P \\
\text { per panel } \\
\text { (N) } \\
\text { No ice }\end{array}$ & $\begin{array}{c}P \\
\text { per node } \\
(\mathbb{N}) \\
\text { With ice }\end{array}$ \\
\hline $42672-44806$ & 191.90 & 360.04 \\
\hline $40538-42672$ & 190.03 & 356.57 \\
\hline $38405-40538$ & 188.07 & 352.92 \\
\hline $36271-38405$ & 186.07 & 349.14 \\
\hline $34138-36271$ & 183.93 & 345.14 \\
\hline $32004-34138$ & 181.71 & 341.00 \\
\hline $29870-32004$ & 179.40 & 336.64 \\
\hline $27737-29870$ & 176.95 & 332.02 \\
\hline $25603-27737$ & 174.33 & 327.12 \\
\hline $23470-25603$ & 171.57 & 321.92 \\
\hline $21336-23470$ & 168.59 & 316.36 \\
\hline $19202-21336$ & 165.43 & 310.40 \\
\hline $17069-19202$ & 161.96 & 303.95 \\
\hline $14935-17069$ & 158.22 & 296.87 \\
\hline $12802-14935$ & 154.04 & 289.05 \\
\hline $10668-12802$ & 149.37 & 280.24 \\
\hline $8534-10668$ & 143.99 & 270.23 \\
\hline $6401-8534$ & 137.72 & 258.44 \\
\hline $4267-6401$ & 130.02 & 243.98 \\
\hline $2134-4267$ & 119.88 & 224.99 \\
\hline $0-2134$ & 104.36 & 195.86 \\
\hline
\end{tabular}

The factored and non factored loadings acting along the tower are shown in

Fig. 3.8. 


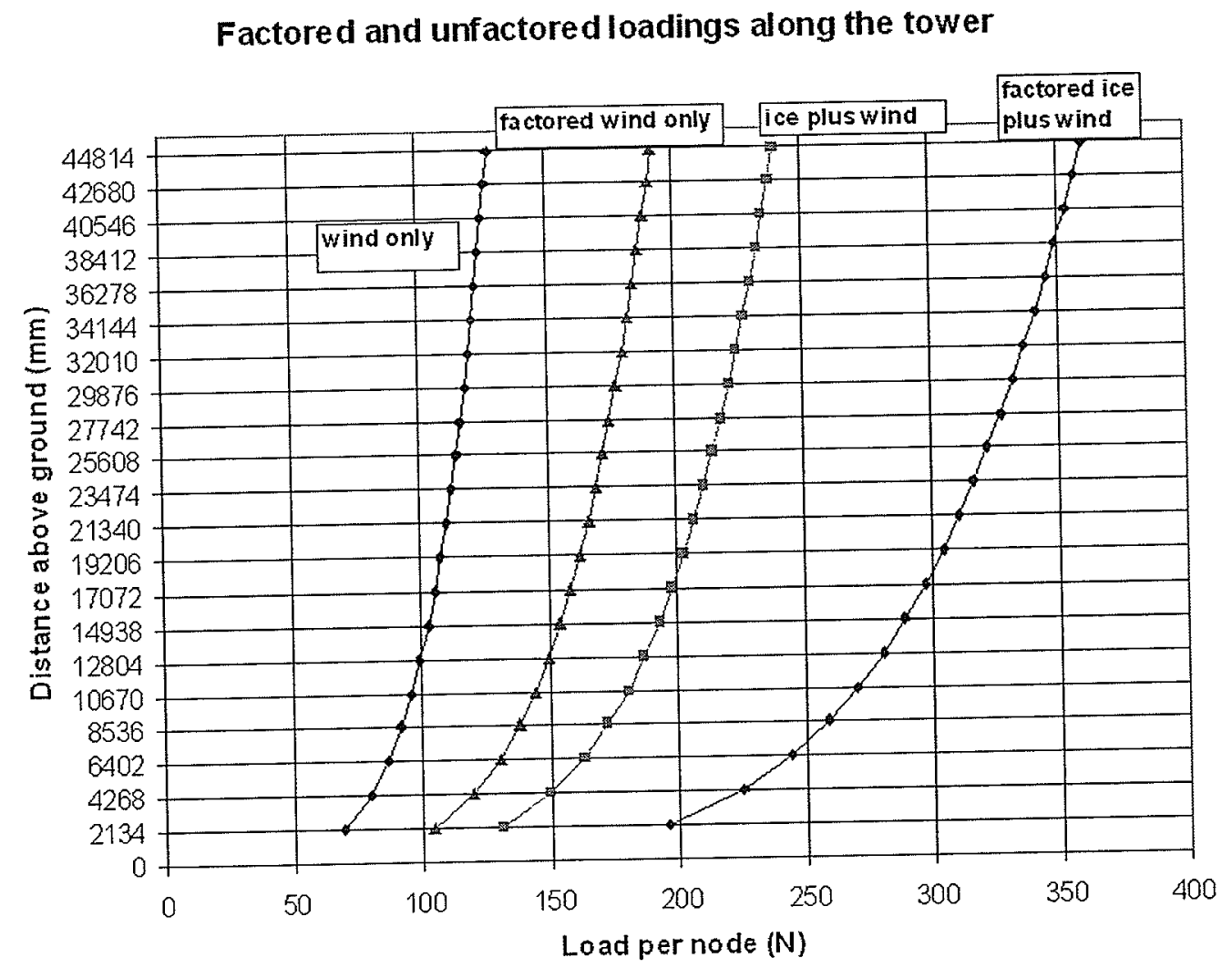

Fig. 3.8 Factored and unfactored loads along the tower

\subsubsection{Design Wind and Ice Loads for Case-2}

Load Case-2, shown in Fig. 3.7, was included in the analysis of the tower. This load case accounts for side wind, which is critical for tower twist. Calculations of the tower wind loads for Case-2 with and without ice were performed using a Microsoft Excel spread sheets and are included in Table 3.4. 
Numerical Investigations

Table 3.4 Tower Wind Loads with and without ice for Case-2

\begin{tabular}{|c|c|c|c|c|c|c|c|c|}
\hline \multirow{3}{*}{$\begin{array}{l}\text { Distance } \\
\text { above } \\
\text { ground } \\
(\mathrm{mm})\end{array}$} & \multicolumn{4}{|c|}{$\begin{array}{c}\text { Tower wind loads without } \\
\text { ice }(N)\end{array}$} & \multicolumn{4}{|c|}{$\begin{array}{l}\text { Tower wind loads with } \\
\text { ice (N) }\end{array}$} \\
\hline & \multicolumn{2}{|c|}{ Service } & \multicolumn{2}{|c|}{ Factored } & \multicolumn{2}{|c|}{ Service } & \multicolumn{2}{|c|}{ Factored } \\
\hline & $\begin{array}{c}\mathrm{pz}^{*} \\
\text { per } \\
\text { node }\end{array}$ & $\begin{array}{c}\text { px } \\
\text { per } \\
\text { node }\end{array}$ & $\begin{array}{c}\mathrm{pz}^{*} \\
\text { per } \\
\text { node }\end{array}$ & $\begin{array}{c}\text { px* } \\
\text { per } \\
\text { node }\end{array}$ & $\begin{array}{c}\mathrm{pz}^{*} \\
\text { per } \\
\text { node }\end{array}$ & $\begin{array}{c}\text { px* } \\
\text { per } \\
\text { node }\end{array}$ & $\begin{array}{c}\mathrm{pz}^{*} \\
\text { per } \\
\text { node }\end{array}$ & $\begin{array}{c}\text { px }^{*} \\
\text { per } \\
\text { node }\end{array}$ \\
\hline $42672-44806$ & 0 & 127.93 & 0 & 191.90 & 0 & 240.03 & 0 & 360.04 \\
\hline $40538-42672$ & 0 & 126.69 & 0 & 190.03 & 0 & 237.71 & 0 & 356.57 \\
\hline $38405-40538$ & 0 & 125.40 & 0 & 188.07 & 0 & 235.27 & 0 & 352.92 \\
\hline $36271-38405$ & 0 & 124.02 & 0 & 186.07 & 0 & 232.73 & 0 & 349.14 \\
\hline $34138-36271$ & 0 & 122.64 & 0 & 183.93 & 0 & 230.11 & 0 & 345.14 \\
\hline $32004-34138$ & 0 & 121.17 & 0 & 181.71 & 0 & 227.35 & 0 & 341.00 \\
\hline $29870-32004$ & 0 & 119.61 & 0 & 179.40 & 0 & 224.41 & 0 & 336.64 \\
\hline $27737-29870$ & 0 & 117.97 & 0 & 176.95 & 0 & 221.34 & 0 & 332.02 \\
\hline $25603-27737$ & 0 & 116.23 & 0 & 174.33 & 0 & 218.10 & 0 & 327.12 \\
\hline $23470-25603$ & 0 & 114.36 & 0 & 171.57 & 0 & 214.63 & 0 & 321.92 \\
\hline $21336-23470$ & 0 & 112.41 & 0 & 168.59 & 0 & 210.93 & 0 & 316.36 \\
\hline $19202-21336$ & 0 & 110.27 & 0 & 165.43 & 0 & 206.93 & 0 & 310.40 \\
\hline 17069-19202 & 0 & 108.00 & 0 & 161.96 & 0 & 202.62 & 0 & 303.95 \\
\hline $14935-17069$ & 0 & 105.47 & 0 & 158.22 & 0 & 197.90 & 0 & 296.87 \\
\hline $12802-14935$ & 0 & 102.71 & 0 & 154.04 & 0 & 192.70 & 0 & 289.05 \\
\hline $10668-12802$ & 0 & 99.55 & 0 & 149.37 & 0 & 186.83 & 0 & 280.24 \\
\hline $8534-10668$ & 0 & 95.99 & 0 & 143.99 & 0 & 180.15 & 0 & 270.23 \\
\hline $6401-8534$ & 0 & 91.81 & 0 & 137.72 & 0 & \begin{tabular}{|l|}
172.28 \\
\end{tabular} & 0 & 258.44 \\
\hline $4267-6401$ & 0 & 86.70 & 0 & 130.02 & 0 & 162.67 & 0 & 243.98 \\
\hline $2134-4267$ & 0 & 79.93 & 0 & 119.88 & 0 & 149.99 & 0 & 224.99 \\
\hline $0-2134$ & 0 & 69.57 & 0 & 104.36 & 0 & 130.56 & 0 & 195.86 \\
\hline
\end{tabular}

* pz and px are shown in Fig. 3.7

\subsubsection{Design Wind Loads for Parabolic Antenna}

According to Structural Standards for Steel Antenna Towers and Antenna Supporting Structures (TIA-222-F, 2003), the three basic forces caused by wind acting on an antenna are: axial force $F_{a}$, side force $F_{s}$ and twisting moment 
$M$, as shown in Fig. 3.9. The values of these forces are determined from formulae and tables in Annex B, of the American Standard TIA/EIA-222F (TIA 222F, 2003).

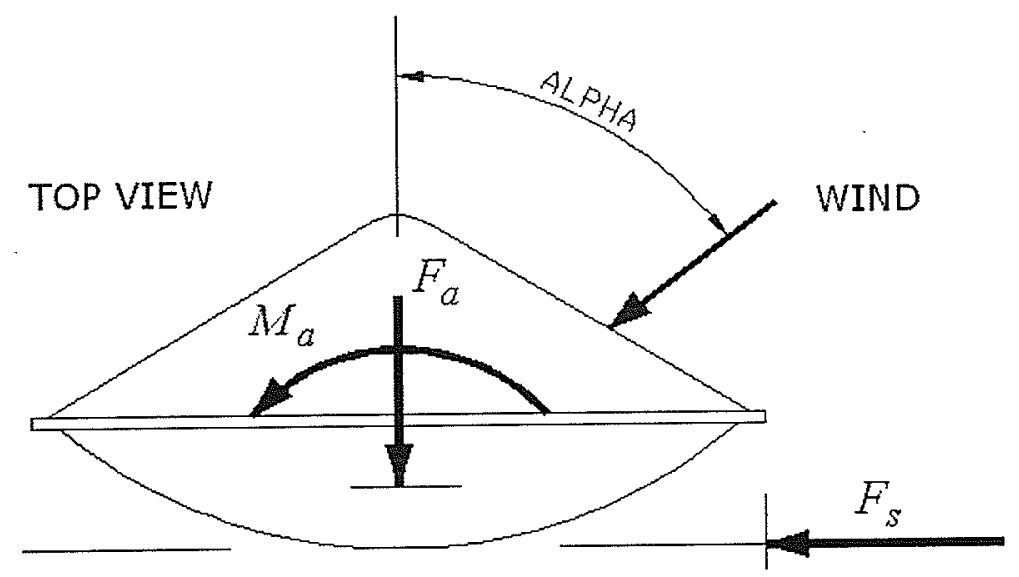

Positive Sign Convention for Windloads

Fig. 3.9 Wind forces on paraboloid antennas with radomes

For the purpose of the present project, a $600 \mathrm{~mm}(2.0 \mathrm{ft})$ standard industry antenna with radome was selected. According to Nello Corporation Manual (Nello Corp., 2006) and a wind direction, alpha, varying from 0 to 180 deg the factored forces due to a $200 \mathrm{~km} / \mathrm{h} \quad(125 \mathrm{mph})$ wind, are as follows: $F_{a}=725.06 \mathrm{~N}(163 \mathrm{lb}), F_{s}=448.82(100 \mathrm{lb})$ and $M=114 \mathrm{~N}-m(76 \mathrm{lb}-f t)$. The service loads computed for a wind speed of $95 \mathrm{~km} / \mathrm{h}$ (59 mph) are: $F_{a}=346.96 \mathrm{~N}(78 \mathrm{lb}), F_{s}=213.51(48 \mathrm{lb})$ and $M=54 \mathrm{~N}-m(36 \mathrm{lb}-f t)$.

These factored forces were used for the FEA of the full scale $45 \mathrm{~m}(147 \mathrm{ft})$ tower. 


\subsection{FINITE ELEMENT ANALYSIS}

The finite element program ANSYS Version.8.1 (ANSYS, 2004) was used for modeling of the $8.53 \mathrm{~m}(28 \mathrm{ft})$ FRP tower segment as well as the $45 \mathrm{~m}(147 \mathrm{ft})$ tower. A Beam4 element was used to model all latticed members and a Link10 element or Combin14 element was used to model all guy cables. The tower base was modelled using Pipe16 element.

\subsubsection{Static FEA of the $8.53 \mathrm{~m}(28 \mathrm{ft})$ FRP Tower Segment}

For the purpose of obtaining lateral deflections and strains of the tower segment tested, the Finite Element ANSYS 8.1 program (ANSYS, 2004) was used. The tower segment model, with static loading $\mathrm{P}$, applied at 8 locations representing a uniformly distributed wind loading, is shown in Fig. 3.10.

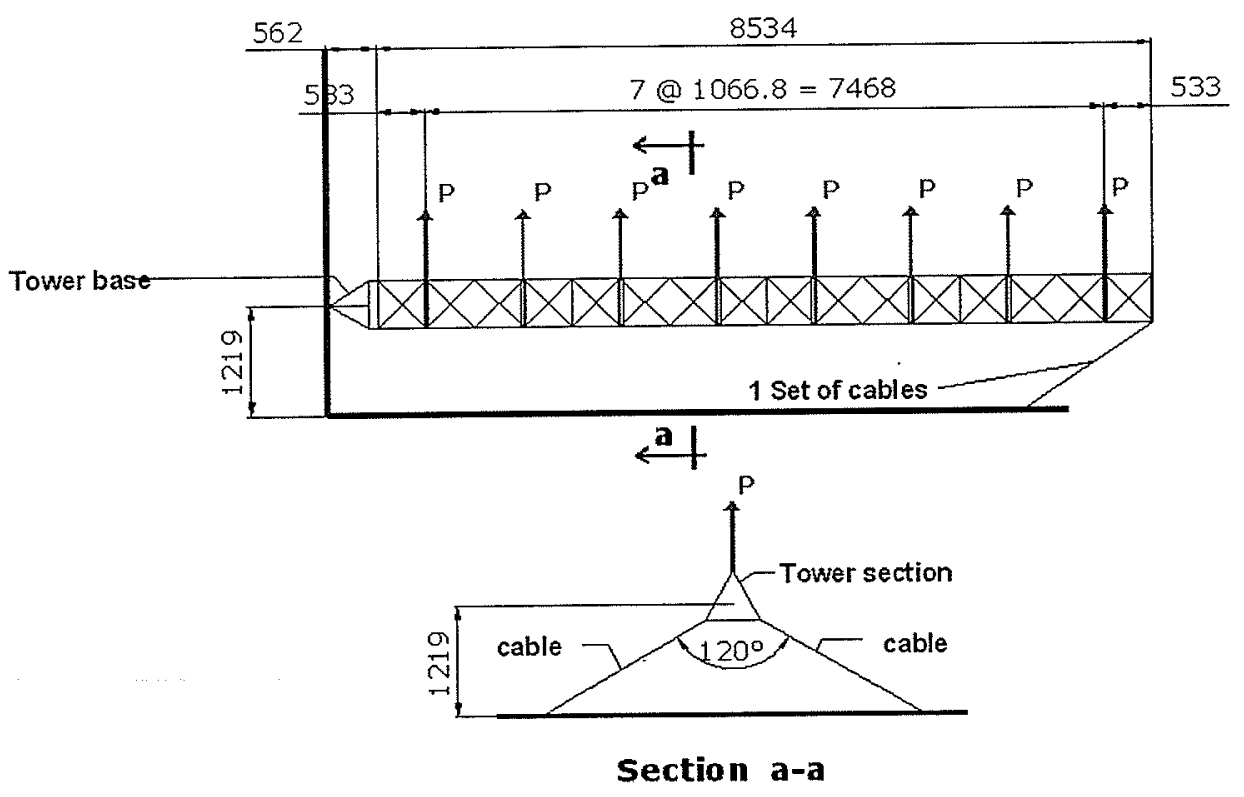

Fig. 3.10 Static loading of tower segment (units are in $\mathrm{mm}$ ) 


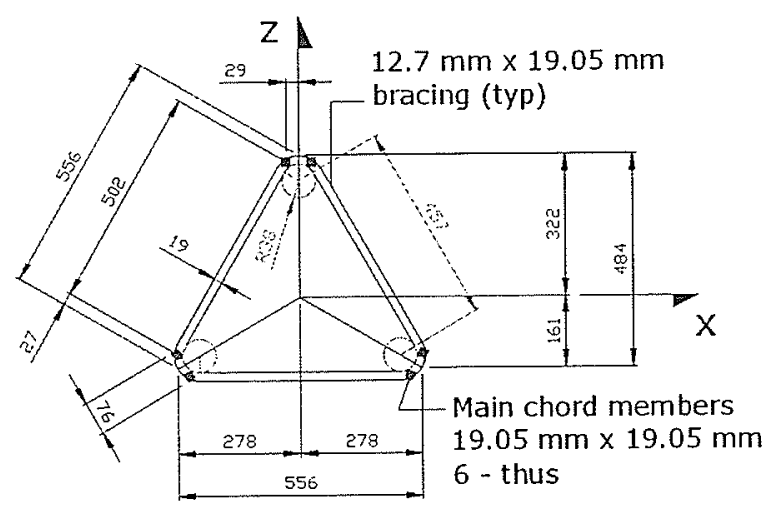

Fig. 3.11 Section of trial tower segment (Global axes; all dimensions in $\mathrm{mm}$ )

For the purpose of modeling, the double chords at each corner of the tower, shown in Fig. 3.11, were represented by a single member with sectional properties $I_{x x}, I_{y y}$ and $A$ calculated using the double chord sectional dimensions shown in Fig. 3.11. The Continuous FEM Model was used, in which tower sections were assumed to be fully connected. The three chord members were modelled as BEAM4 - elements from the ANSYS library. Both the diagonal and the vertical bracing members were modeled using BEAM4 elements. The guy cables were represented by LINK10 elements with the tension-only option, for which the stiffness was removed each time the element went into compression, simulating a hanging loosely or slack cable condition. This feature was adopted here for static guy-wire applications where the entire guy wire was modelled as single element. The base of the tower was modelled as a pin connection with full moment release. The cables were also connected to pinned supports. All 
members of the tower were assumed to have orthotropic material properties which were established through material testing (Burachynsky, 2006).

The entire program was written entirely in ANSYS command language and its input batch file is given in Appendix A.

The tower segment was loaded at eight locations with eight equal forces $P$. These values were calculated based on wind loading determined according to the CSA-S37-01 (CSA, 2001). Forces $P$ are referenced to a Wind Loading Case1, included in Table 3.1, and are unfactored (service loads). Detailed calculations of wind loadings and loading cases were included in Section 3.5. To account for the variation of the moment of inertia between global and local element coordinate systems, a rotation angle $\theta$ was introduced to the three distinctive chord member orientations shown in Fig. 3.12.
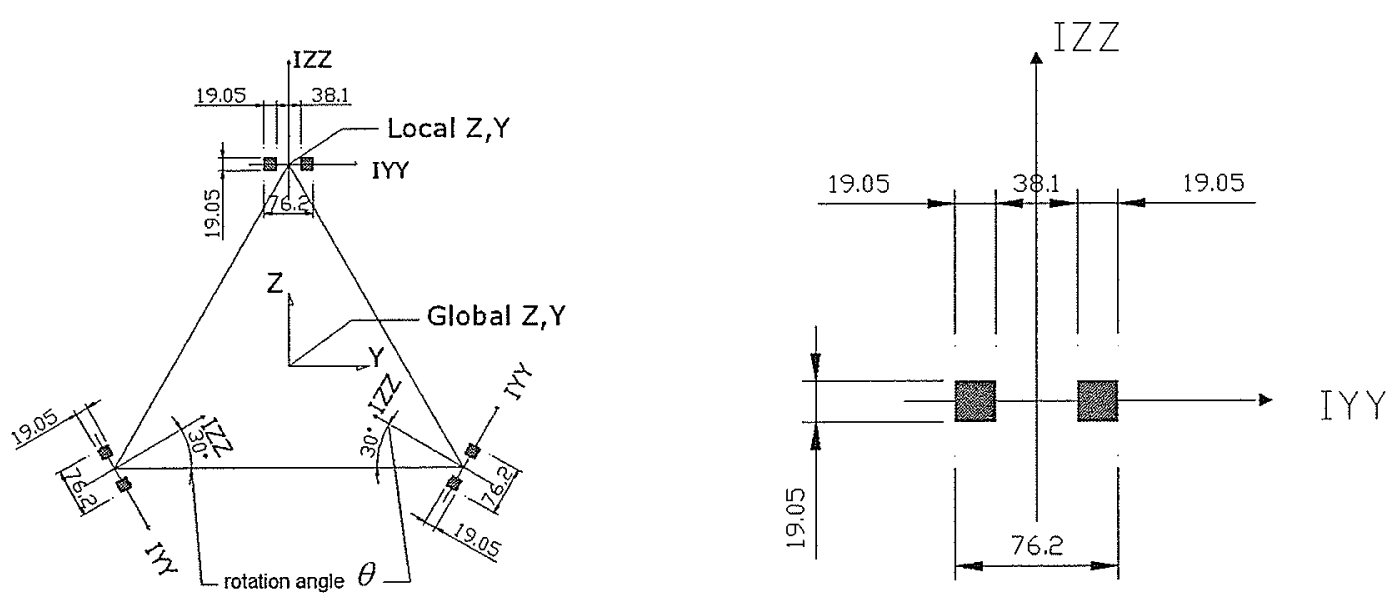

Fig. 3.12 Local coordinate system adjustment for chords (units are in $\mathrm{mm}$ ) 


\subsubsection{Distinctive Cases of Finite Element Analysis}

The tower segment investigated was designed to resemble the conditions experienced by the bottom section of a full scale tower, as shown in Fig. 3.1a.

To be able to compare the deflections of the tower segment under investigation to the bottom segment of the full scale tower, two distinctive cases were examined, according to the stiffness of the guy cables:

- Case A: short cables length $=2.09 \mathrm{~m}(6.88 \mathrm{ft})$ for tower segment tested in lab. This resulted in stiffness in cables $k=A E / L=1751.52 \mathrm{kN} / \mathrm{m}(10003$ Ibs/in).

- Case B: long cables length $=37.56 \mathrm{~m}(123.22 \mathrm{ft})$ used in full scale tower. This resulted in stiffness in cables $k=A E / L=97.82 \mathrm{kN} / \mathrm{m}(558.67 \mathrm{lbs} / \mathrm{in})$.

The cables stiffnesses for both cases were calculated based on cross sectional area and modulus of elasticity taken from manufacturer specifications (Nello Corporation, 2006).

In Case $A$, the wind loads acting on the bottom section of the full scale tower were averaged and converted to point loads applied at each node. These loads were calculated to be $P=328 \mathrm{~N}(73.74 \mathrm{lbs})$, giving a total load of $8 \times 328 \mathrm{~N}(73.74$ lbs $)=2634 \mathrm{~N}(589.92 \mathrm{lbs})$ for the $8.53 \mathrm{~m}(28 \mathrm{ft})$ long segment. With wind loads of $P=328 \mathrm{~N}(73.74 \mathrm{lbs})$, and $4.76 \mathrm{~mm}(3 / 16 \mathrm{in})$ dia. cables of length $2.09 \mathrm{~m}(6.88$ $\mathrm{ft}$ ), the tower segment was analysed to determine the deflected shape. The cables were spread at $120 \mathrm{deg}$, as shown in Fig. 3.10. The length of cables was limited by the lab space available. 
The cables in Case A were modelled as Link10 elements found in the ANSYS element library. The results of analysis for Case A are shown in Fig. 3.13. The maximum deflection was $11.35 \mathrm{~mm}$ (0.447 in).

By examining the results shown in Fig. 3.13, it is observed that the deflected shape resembles the deflections of a simply supported beam with a maximum deflection at mid span.

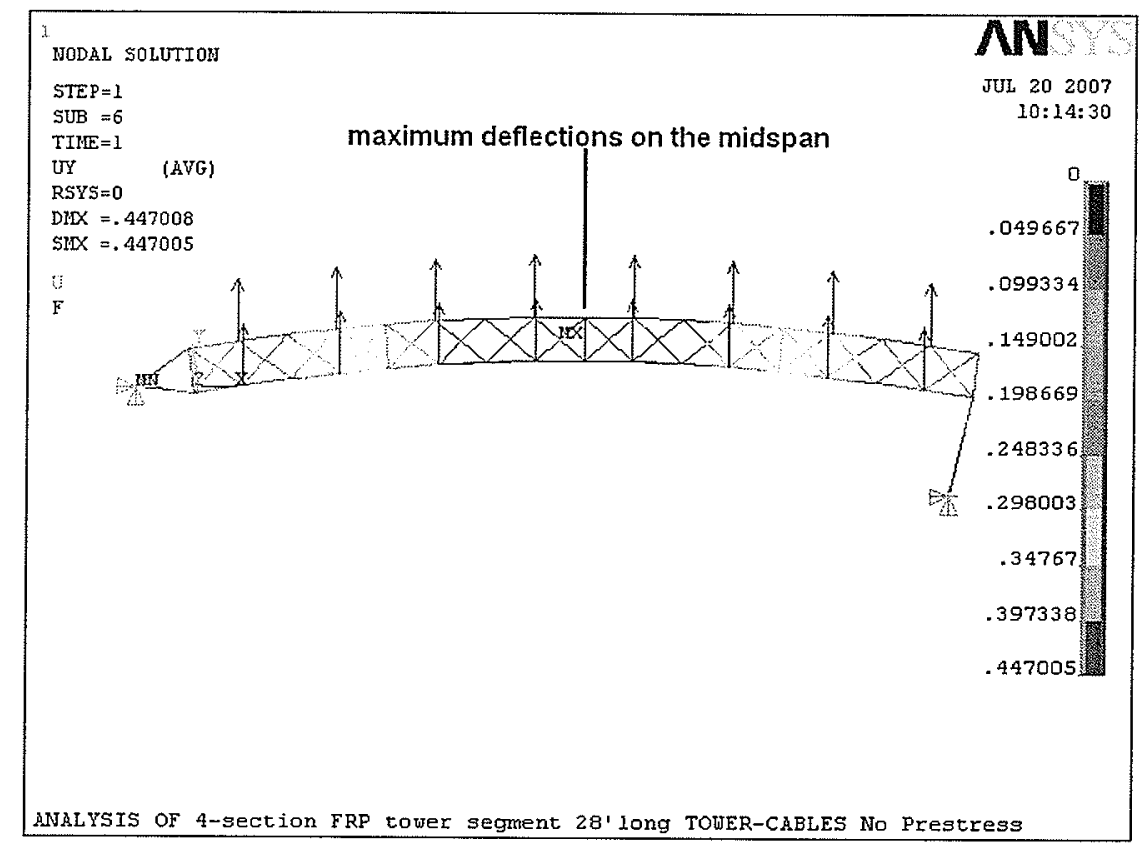

Fig. 3.13 Case A- Cable stiffness $=1751.52 \mathrm{kN} / \mathrm{m}$ (short cables)

Since the length of the cables used for the analysis in Case A is much smaller than that used in a full scale tower, an equivalent spring constant value equal to a $\mathrm{k}=\mathrm{AE} / \mathrm{L}=97.82 \mathrm{kN} / \mathrm{m}(558.67 \mathrm{lbs} / \mathrm{in})$ corresponding to the actual length of cables in full scale tower was used in the analysis. The cables in Case B were modelled using a new element Combin14, from the ANSYS element library. Using the same loading condition as before, the ANSYS FEA was carried out for CASE B. 
The results are shown in Fig. 3.14. The deflected shape shown in Fig. 3.14 resembles the deflection of a cantilever beam with maximum deflection $U Y=$ $30.22 \mathrm{~mm}$ (1.19 in) occurring at the end. This deflection shape is compared in Chapter-5 to the deflected shape of the bottom segment of the full scale model.

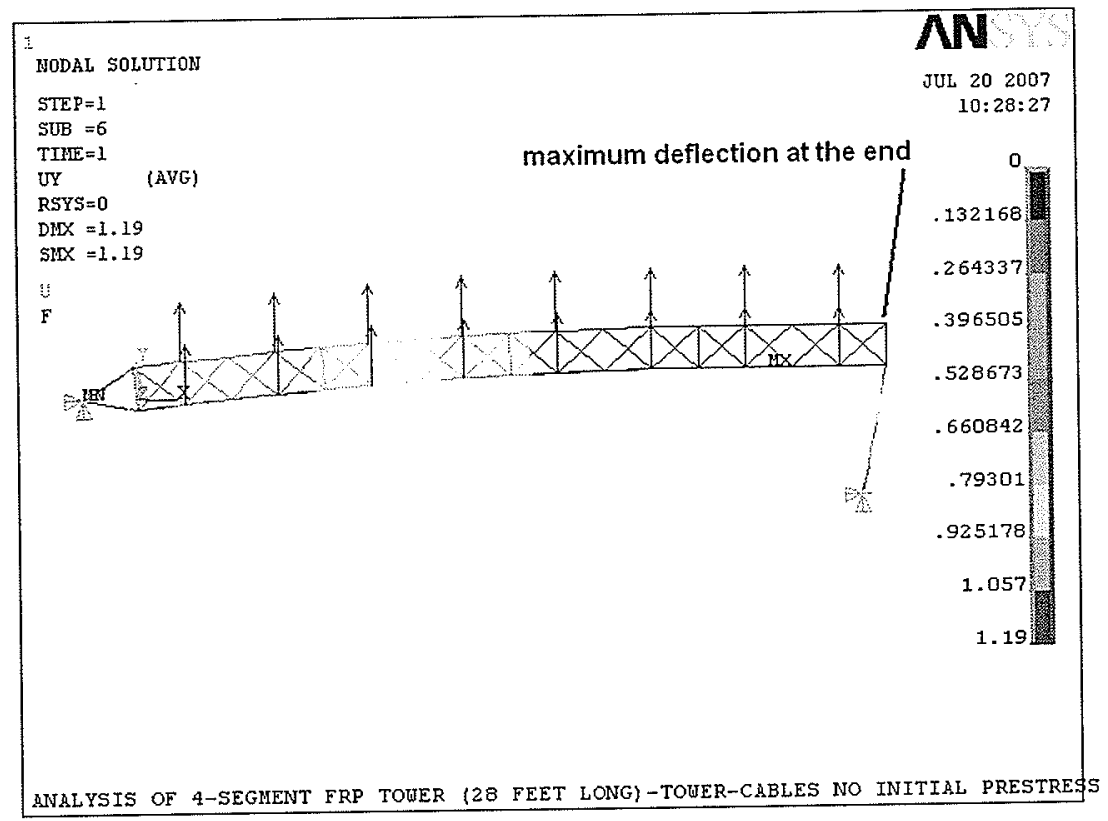

Fig. 3.14 Case B- Cable stiffness $=47.82 \mathrm{kN} / \mathrm{m}$ (long cables)

\subsubsection{Non Linear Structural Behaviour of Guyed Towers}

The structural behaviour of guyed towers is quite complex, primarily due to the geometric nonlinearities arising from the sagging cables and also the slenderness of the mast itself ( $p$-delta effect). The non linear structural behaviour arises from three primary causes: changing status, geometric nonlinearity and 
material nonlinearity. For example, guy cables are both status dependent and subjected to geometric nonlinearity, because they can be either slack or taut and at the same time they sag due to gravity. Generally, in modelling linear elastic structures, the response between applied loads and displacements can be obtained in one step. However, one step solution cannot be achieved in the case of guyed towers. A non linear finite element analysis (ANSYS, 2004), with several linear steps, has to be employed with incrementation scheme. In a non linear structure the relation between loads and response is not linear. This means that the principle of superposition is not applicable. The major characteristic of a non linear structure is that during loading, changes in geometries (deformation, displacements) will have an effect on the load displacement response. This means that with changes in the load, the structure stiffness changes, making the load-deflection curve nonlinear, as shown in Fig. 3.15. Given a nonlinear loaddisplacement relationship, the objective is to find the response $\{u\}$ from the relation: $\{F\}=[K(u)]\{u\}$. To obtain the displacement vector $\{u\}$ for nonlinear analysis, ANSYS uses the Newton-Raphson algorithm demonstrated in Fig. 3.16. In this iterative procedure the load was applied gradually in increments, and at each load increments equilibrium iteration was done to drive the differences between the external force vector (applied loads) and the internal force vector (the loads corresponding to the element stresses) to required minimum. 


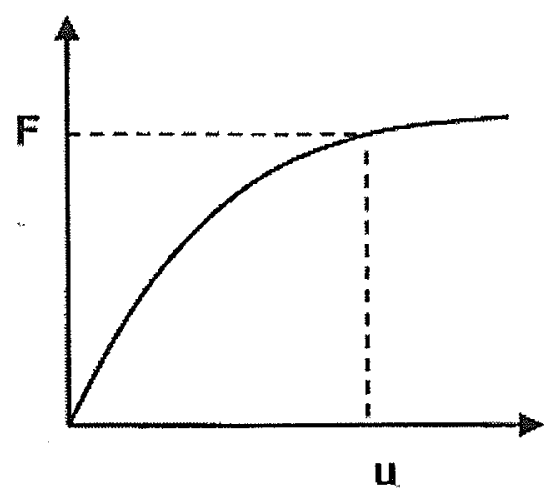

Fig. 3.15 Load displacement for non linear structure (ANSYS, 2004)

As an example, the four step Newton-Raphson procedure shown in Fig. 3.16 would be explained in detail.

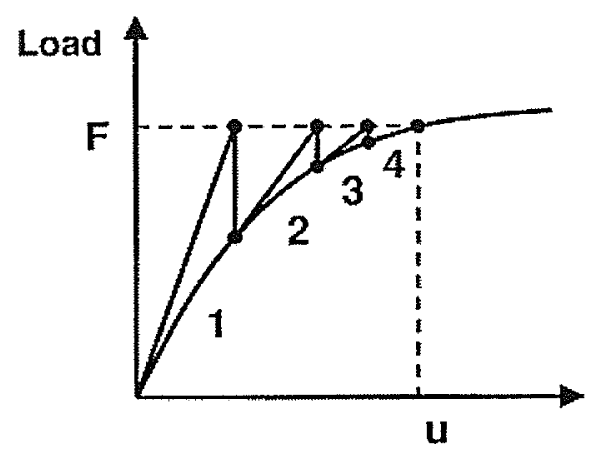

Fig. 3.16 Newton-Raphson procedure (ANSYS, 2004)

Based on the configuration of the structure depicted in Fig. 3.17 at initial displacement $u 0$, the tangent stiffness $\left[K_{T}\right]$ is computed. The displacement increment $\{\Delta u\}$ is computed after that, based on the load increment $\{\Delta F\}$, and the configuration is updated to $u 1$. The internal forces (element forces) are then computed in the updated configuration. The residual value is then calculated $\{R\}=\{F\}-\left\{F^{n r}\right\}$. When the residual value $\{R\}$ becomes small, within a 
predetermined tolerance, the Newton-Raphson iterations are terminated and an equilibrium solution is obtained

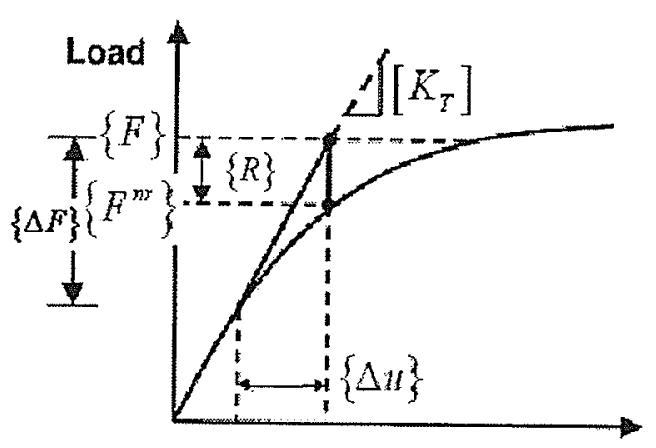

u0 u1

Fig. 3.17 Newton-Raphson iteration-one step (ANSYS, 2004)

Fig. 3.18 describes the Newton-Raphson iteration up to equilibrium being taken in four steps.

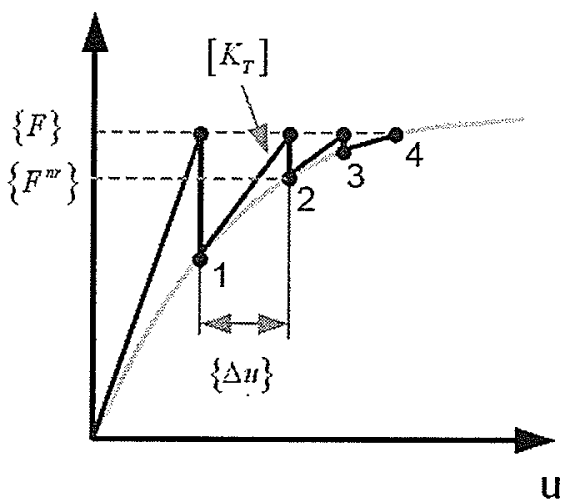

Fig. 3.18 Newton-Raphson iteration-up to equilibrium (ANSYS, 2004)

The ANSYS- FEA solves the equation:

$\left[K_{T}\right]\{\Delta u\}=\{F\}-\left\{F^{n r}\right\}$

where: 
$\left[K_{T}\right]=$ tangent stiffness matrix,

$\{\Delta u\}=$ displacement increment

$\{F\}=$ external load vector

$\left\{F^{n r}\right\}=$ internal force vector

Iteration will continue until $\{F\}-\left\{F^{n r}\right\}$, the difference between external and internal loads, is within the prescribed tolerance. ANSYS, by default uses, force/moment and displacement/rotation convergence criteria for determining equilibrium convergence. A default tolerance of $0.5 \%$ for force/moment residuals and $5 \%$ for displacement/rotation increments is used. Experience suggests that these tolerances are adequate for most problems. Force based convergence provides an absolute measure of convergence, as it is a measure of equilibrium between the internal and external forces. Displacement based checking should only be used as a supplement to force based convergence.

\subsubsection{Static FEA of $45 \mathrm{~m}$ (147 ft) FRP Guyed Tower}

To assess the behaviour of the tower segment selected for testing, a FE model of the $45 \mathrm{~m}$ (147 ft) guyed tower was developed. This tower consisted of

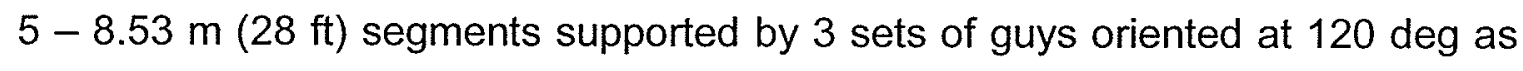
shown in Fig. 3.1. The Continuous FEM Model was used, in which tower sections, as well as tower segments, were assumed to be fully connected with no splices between them. The tower was supported by means of a pinned connection at the base providing full moment release. The wind loading acting on 
the tower was computed according to the Canadian Standard CSA-S37-01 and the loadings are given in Table 3.2. The ANSYS 8.1 Finite Element Program was used to model the full tower. Orthotropic material properties and BEAM4 elements similar to those used in modelling the tower segments were used to model the full scale tower. Link10 elements were introduced to model the guy cables. The guy cable properties were the same as these used for modelling the tower segment in Section 3.3. The cables were modeled without a prestress (initial strain INSTR $=0$ ). To account for the non-linear behaviour, large static displacements were permitted which, automatically, accounted for large deflections in the results. Automatic time stepping was triggered to allow the program to choose the most appropriate sizes to define the load steps. Initially, the structure was loaded with $1 / 10$ of the total load while for the remaining sub steps the load was determined on the basis of the material response to the previous load increment. The maximum number of sub steps was limited to 1000 , causing the program to terminate if the solution did not converge after 1000 loading steps. The weight of the tower and guys were accounted for in the program by including the densities of the materials and activating gravity acting in the vertical direction. Wind loadings were not applied to guy cables because the element they were modelled with does not allow for any surface loads. The perpendicular wind loading pattern shown in Fig. 3.19, (wind acting along $z$ axis) was considered to be the most critical for lateral deflections. The wind loading acting on the tower for deflection analysis was taken without any load safety 
factors. The side wind loading case shown in Fig. 3.19 was critical for tower twisting

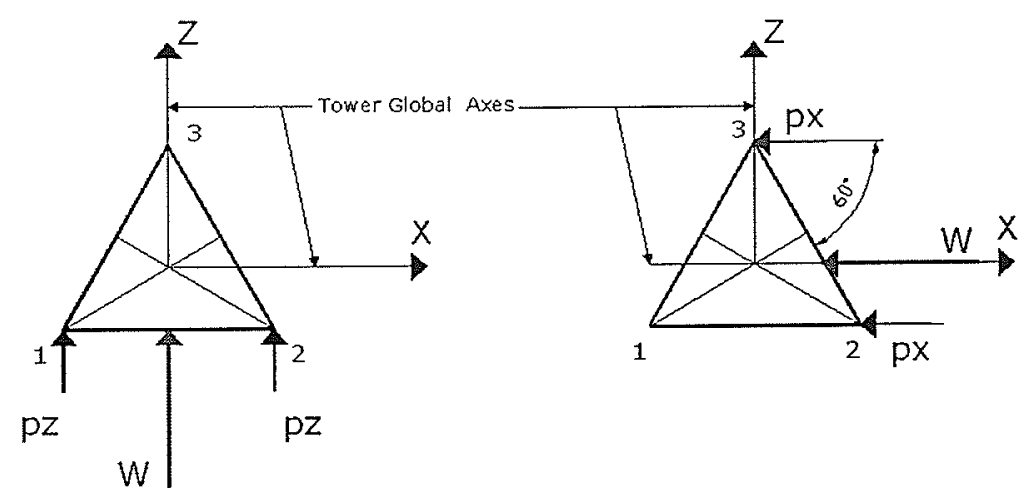
(a) Load Case-1
Perpendicular wind
(b) Load Case-2
Side wind

Fig. 3.19 Tower loadings patterns

Based on the FEM results for wind load Case-1, the maximum deflection at the top of the tower, with no initial prestress in cables, was $259.79 \mathrm{~mm}$ (10.238 in), as shown in Fig. 3.20. The maximum deflection at the elevation of first cables

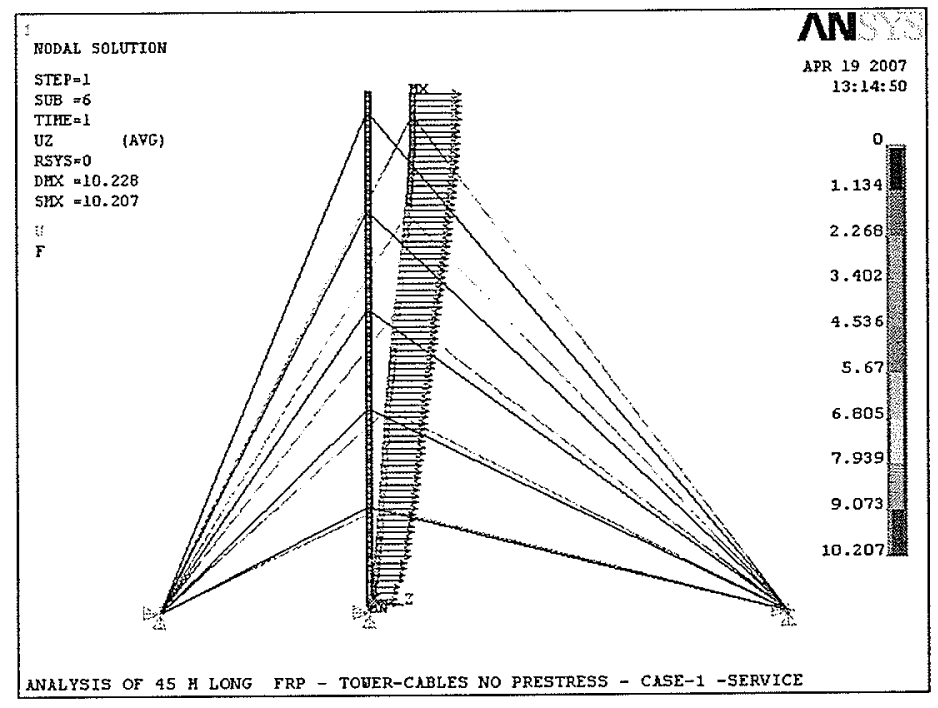

Fig. 3.20 Deflections (in inches) of $45 \mathrm{~m}$ (147 ft) tower for wind load CASE-1 
was $69.19 \mathrm{~mm}$ (2.724 in), as shown in Fig. 3.21.

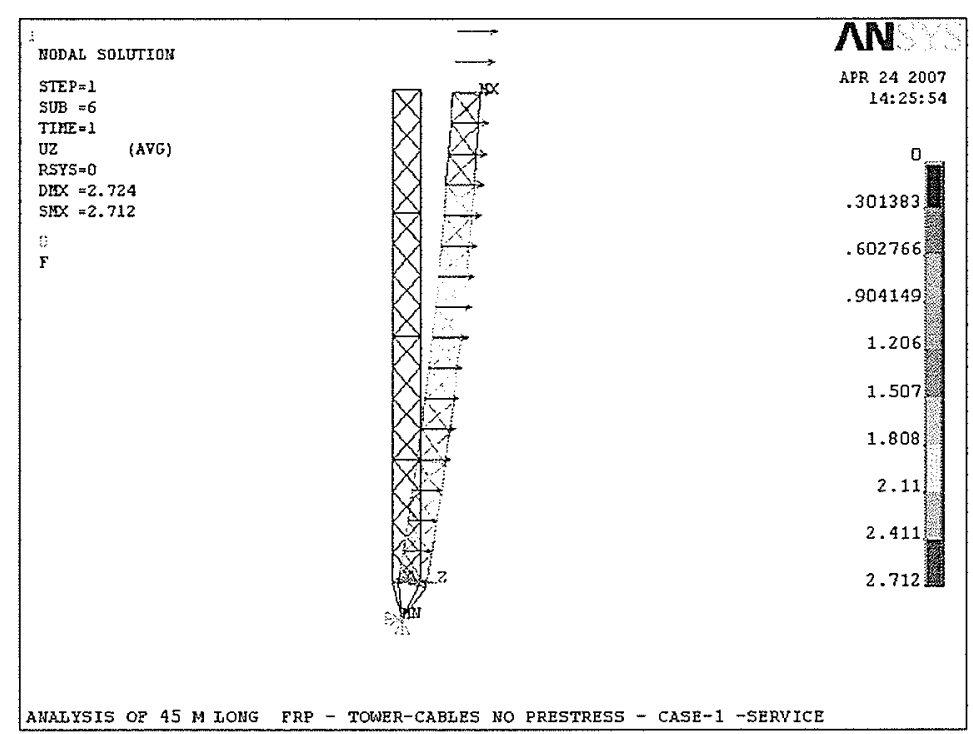

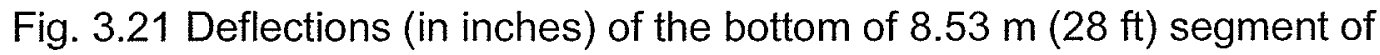
the $45 \mathrm{~m}(147 \mathrm{ft})$ tower for wind load CASE-1

A typical input file for the full scale model is included in Appendix - A.

\subsubsection{Deflection Comparison between Finite Element Analysis of Tower Segment and Full Scale Tower}

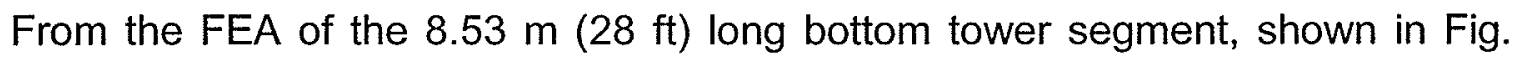
3.14 , the maximum deflection at the guy level was $30.22 \mathrm{~mm}(1.19 \mathrm{in})$. From the analysis of the full scale model, shown in Fig. 3.21, the maximum deflection at the top of the same segment was found to be $69.19 \mathrm{~mm}$ (2.724 in).

The difference of $38.96 \mathrm{~mm}$ (1.534 in) is attributed to the additional loading exerted on the section immediately above the segment being investigated and 
the restraints provided by the continuous chord members which were not accounted for in the FEA of the bottom segment.

In order to account for this additional loading and the constraints acting above the $8.53 \mathrm{~m}(28 \mathrm{ft})$ tower segment an additional load was included at the top of the segment. From the analysis of the wind loading profile between $8.53 \mathrm{~m}(28 \mathrm{ft})$ and $17.07 \mathrm{~m}(56 \mathrm{ft}$ ) in elevation, this additional load was calculated to be 1564.35 $\mathrm{N}(351.68 \mathrm{lbs})$. Repeating the analysis of the $8.53 \mathrm{~m}(28 \mathrm{ft})$ tower segment with an additional load applied at the end equal to $1564.35 \mathrm{~N}$ (351.68 lbs) the maximum end deflection was found to be $61.06 \mathrm{~mm}$ (2.404 in), as shown in Fig. 3.22. This is $8.13 \mathrm{~mm}(0.32 \mathrm{in})$ less than the deflection of the $45 \mathrm{~m}(147 \mathrm{ft})$ tower at the same elevation. The difference is attributed to the stiffness of the continuous tower shaft loaded with the rest of the wind profile and supported by the remaining four levels of guy cables, shown in Fig. 3.23.The difference of 8.13 $\mathrm{mm}(0.32 \mathrm{in})$ which correspond to $L / 1050$ (where $L$ is the length of the segment) was considered to be sufficient for assuming that FEA model of tower segment and full scale tower model describe the tower displacement correctly. The purpose of above comparative analysis was to calibrate the deflection of the 8.53 $m(28 \mathrm{ft})$ tower segment with the deflections of the same segment in $45 \mathrm{~m}(147 \mathrm{ft})$ tower under the same loading conditions, by adjusting guy cable stiffnesses.

By performing the above comparative analysis between the tower segment and the full scale tower it was shown that the FEA model of the full scale tower described tower displacements with good accuracy, and therefore, was suitable 
for use in further analysis of the composite tower under service and factored wind and ice loadings.

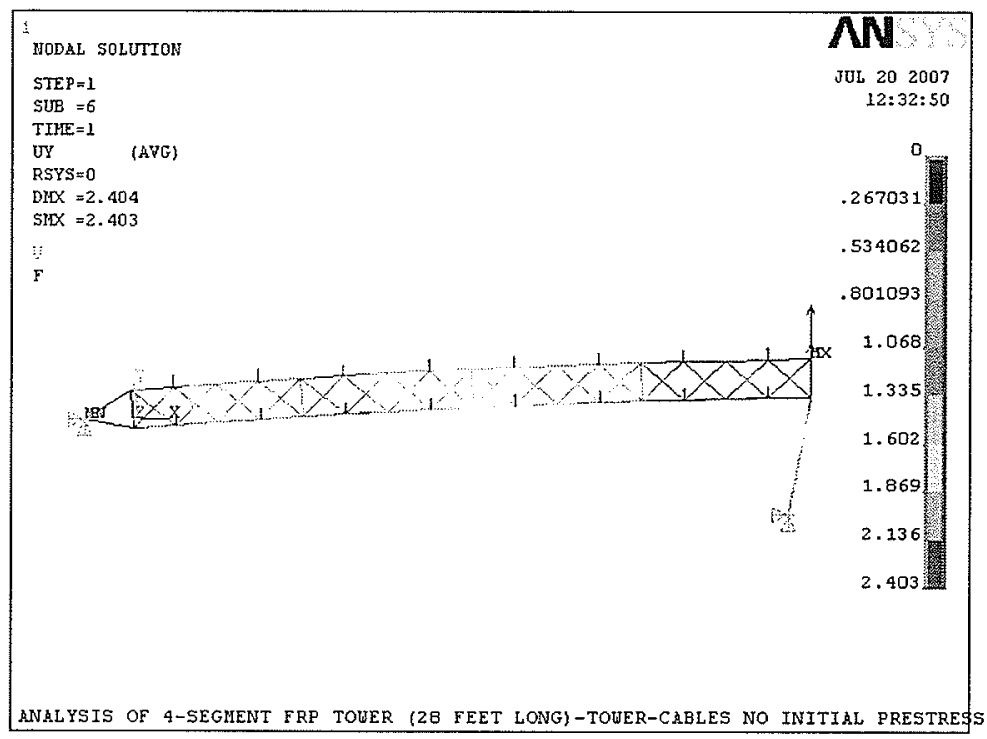

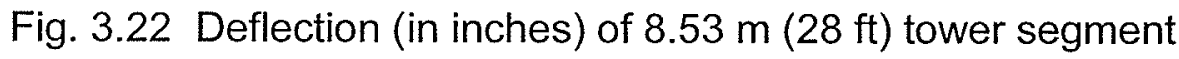
under wind load CASE-1 and a concentrated load

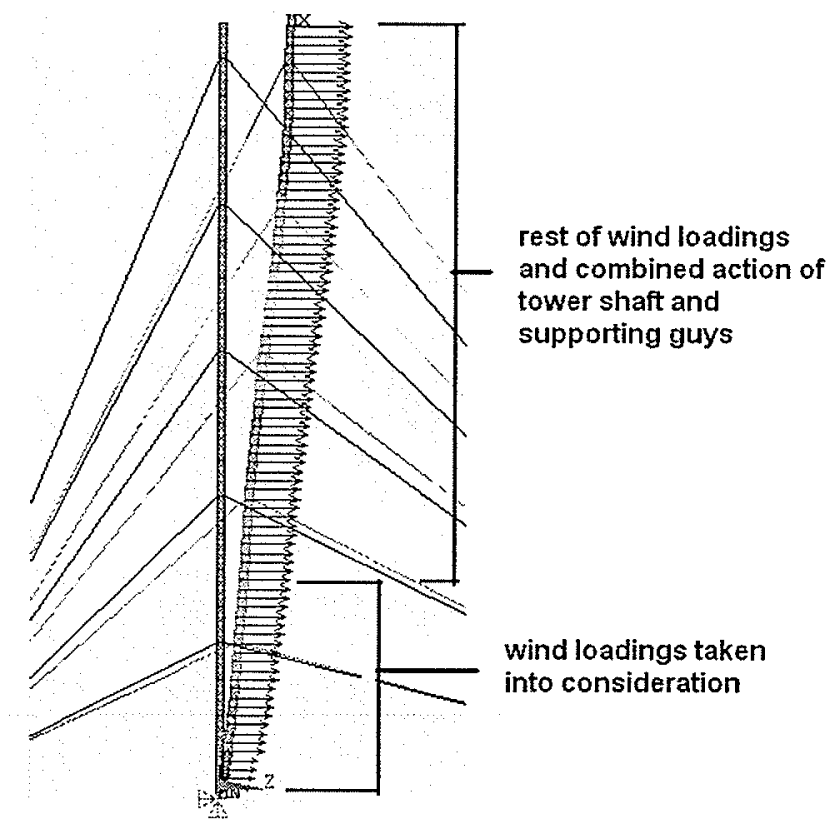

Fig. 3.23 Wind loadings under consideration 


\subsubsection{Final Static FEM Analysis of the $45 \mathrm{~m}$ (147 ft) FRP Tower}

Before attempting a final structural analysis of the full scale tower the following steps were undertaken:

- Geometry definition

- Antenna selection

- Load cases preparation

- ANSYS Analysis

- Review of results

- Conclusions

These have been described in earlier sections of this Thesis. Information about the tower geometry and material properties are included in Sections 3.1 to 3.3. Antennae loadings, as well as load cases preparation, are described in Section 3.5 .

Three subsequent analyses were examined for each load case using ANSYS. These were:

- Deflection analysis under service loads

- Force analysis under factored loads

- Stress analysis under factored loads

The three cases examined are discussed in detail below. 


\subsection{Deflection Analysis}

A review of the deflection values obtained from the FEA for Load Case- 1 shown in Fig. 3.19, under service loadings was carried out. The guy cables were assumed to be not prestressed and a maximum tip deflection was found to be $259.79 \mathrm{~mm}$ (10.228 in) as shown in Fig. 3.24. Then, the same case was analysed with guy cables prestressed equally with a force of $S=1779.28 \mathrm{~N}(400 \mathrm{lbs}$ ) equivalent to $10 \%$ of the breaking strength of cables. This force is equivalent to an initial strain in the cables equal to $\varepsilon_{\text {initial }}=0.00048397$. According to the FEA, the tip deflection of the tower was equal to $\mathrm{DMX}=177.19 \mathrm{~mm}$ (6.976 in), as shown in Fig. 3.25.

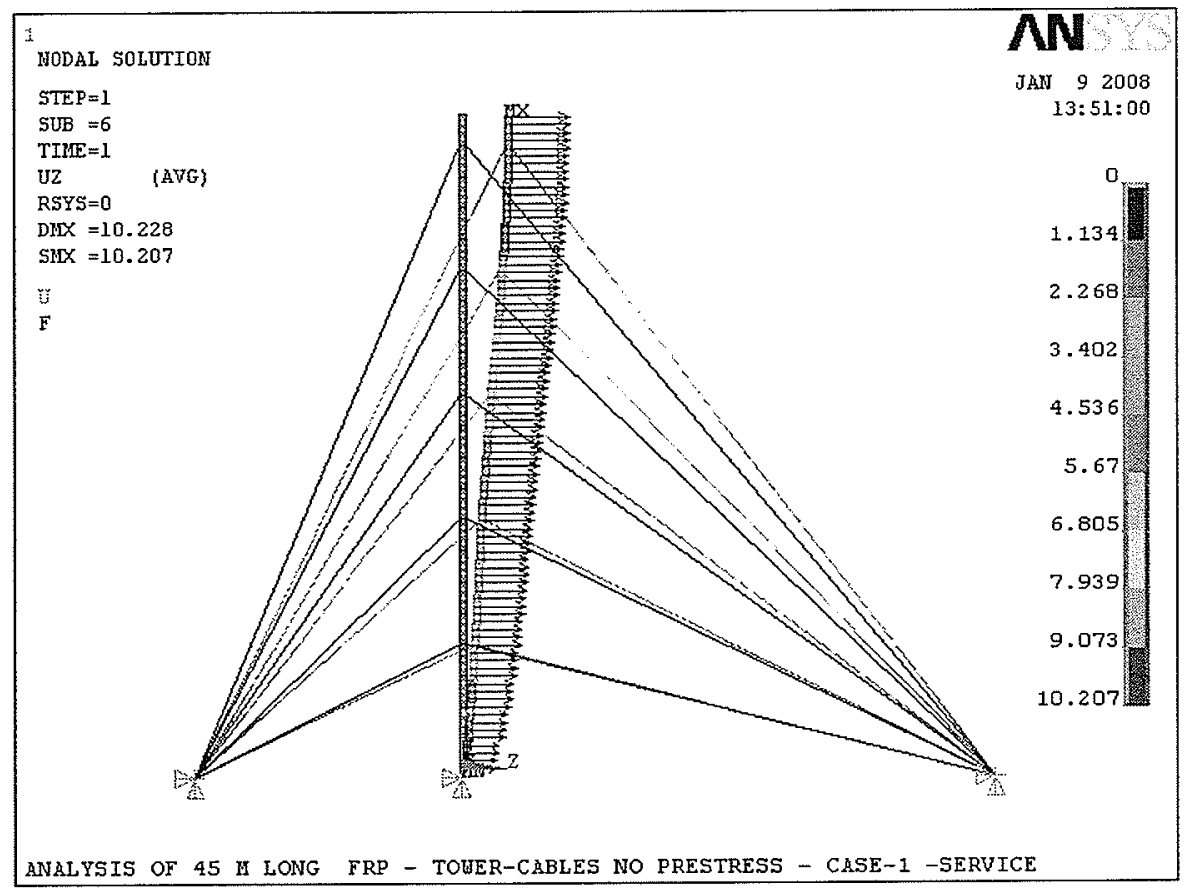

Fig. 3.24 Load Case-1: Deflection with no prestress in cables (units are in inches) 


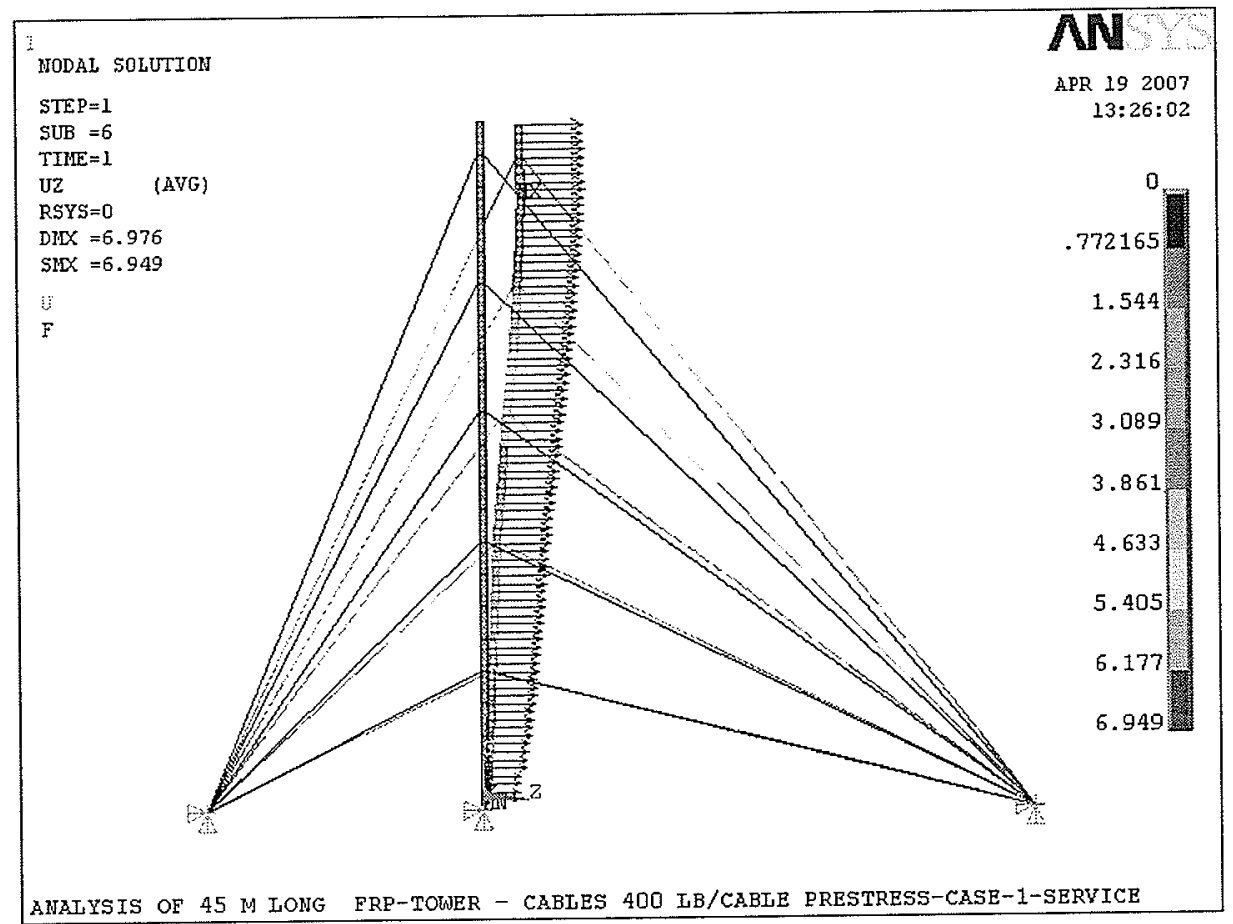

Fig. 3.25 Load Case-1: Deflection with a prestress $=1779.28 \mathrm{~N}(400 \mathrm{lb})$ in cables (units are in inches)

Comparing the deflections in Load Case-1 with a prestress in the cables and without prestress, as depicted on Fig. 3.26 , a conclusion can be drawn that by introducing an equal prestress in all cables, the tip deflection of the tower without antenna can be reduced from $206.88 \mathrm{~mm}$ to $177.19 \mathrm{~mm}$, a decrease of $14.4 \%$. 


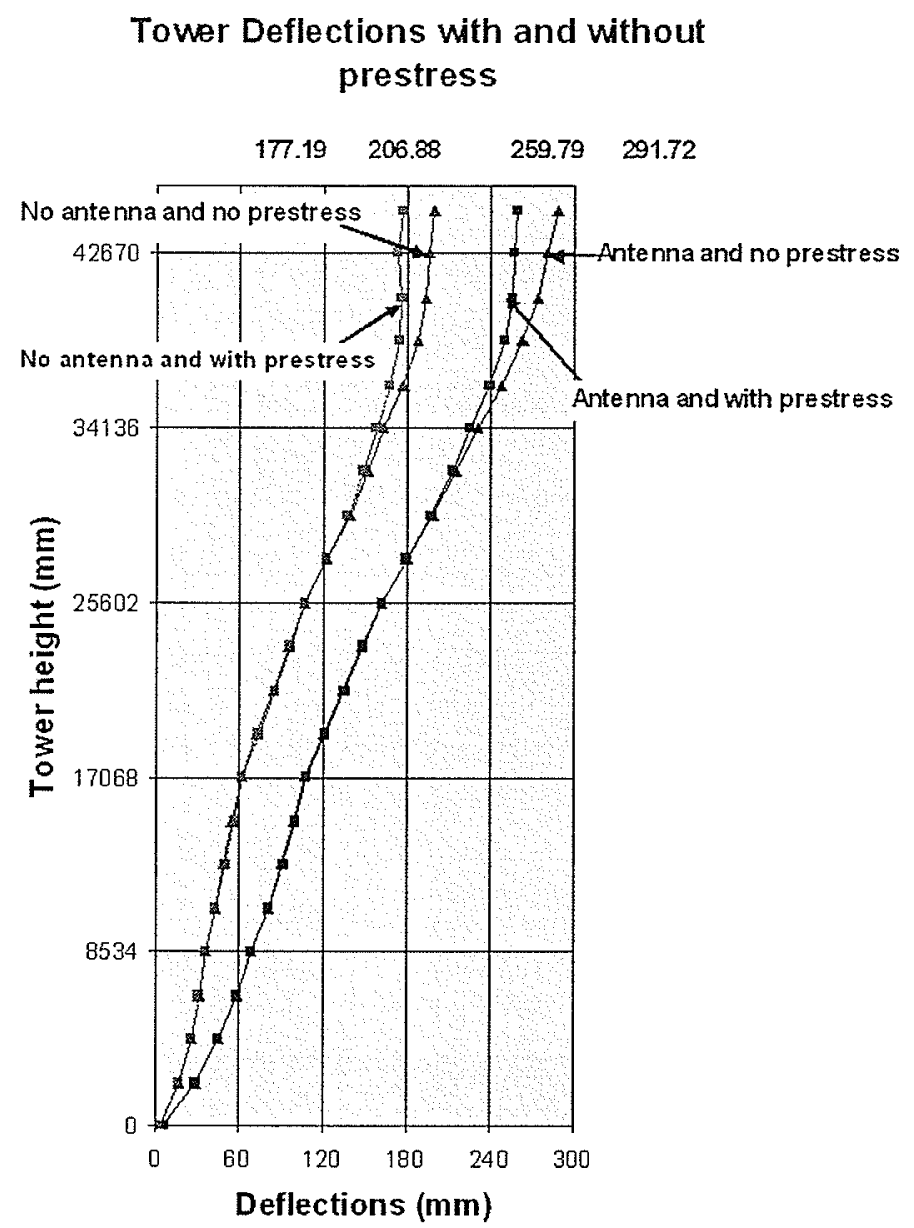

Fig. 3.26 Load Case-1: Tower deflections with and without cable prestress

By prestressing the tower cables, the overall lateral deflections of the tower can be kept in check in order to meet strict directional criterion for telecommunication antennae. This is however limited to a maximum prestress in the cables equal to $10 \%$ of cable breaking strength as specified by both Canadian and American codes of practices. In the two previous cases, the towers were analyzed assuming no antennae were attached to the tower. By introducing a typical 610 $\mathrm{mm}(2 \mathrm{ft})$ outside diameter Standard Industry Antenna with radome, as shown in Fig. 3.9, to the middle of the top segment, the deflection pattern changes as shown in Fig. 3.27, for the case of non prestressed cables, and in Fig. 3.28 for 
the case when a $1779.28 \mathrm{~N}(400 \mathrm{lb})$ prestressing force was applied to the cables. By introducing one antenna to the top of the tower with no cable prestress the tip deflection increases from $206.88 \mathrm{~mm}$ (8.14 in) to $291.72 \mathrm{~mm}$ (11.48 in) representing an increase of $84.84 \mathrm{~mm}(3.34 \mathrm{in})$ or $41 \%$ over the tower without antenna. The prestress reduces the deflection of the tower with antenna from $291.72 \mathrm{~mm}(11.48 \mathrm{in})$ to $259.79 \mathrm{~mm}$ (10.23 in) representing a decrease of $31.93 \mathrm{~mm}$ (1.26 in) or $11 \%$, as shown in Fig. 3.26.

Antennae, therefore, make a significant contribution to overall lateral deflections of towers due to larger area of the wind resistance.

Fig. 3.29 shows rotation values of the windward chords of the tower for Load Case-2, under wind only and under wind plus ice. The cables in this case were assumed to be prestressed and loads were unfactored. It can be seen that under wind loading only, the rotation was higher at the bottom while for wind plus ice the rotation was higher on the top. Smaller rotation on the middle of the tower compared to the bottom and top of the tower are due to extra restrains from guy cables.

In order to control tower rotation at the location of the microwave antennae star mounts are introduced (Khala, 1993), as shown in Fig. 3.30. By adding star mounts extra rotational constraints are being provided to the tower chords. These have the ability to minimize angular rotations of towers and therefore keep antennae in alignment and within a prescribed limit. 


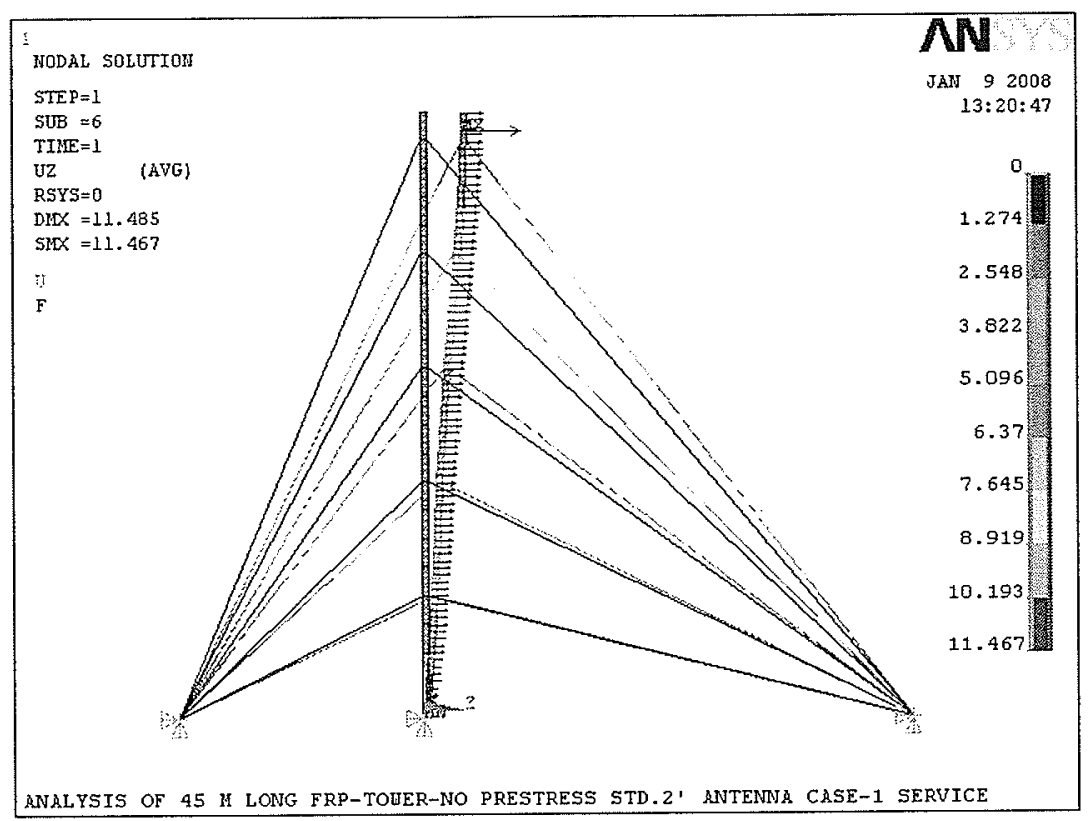

Fig. 3.27 Load Case-1: Deflection of the tower with no prestress in cables and antenna mounted at the top (units are in inches)

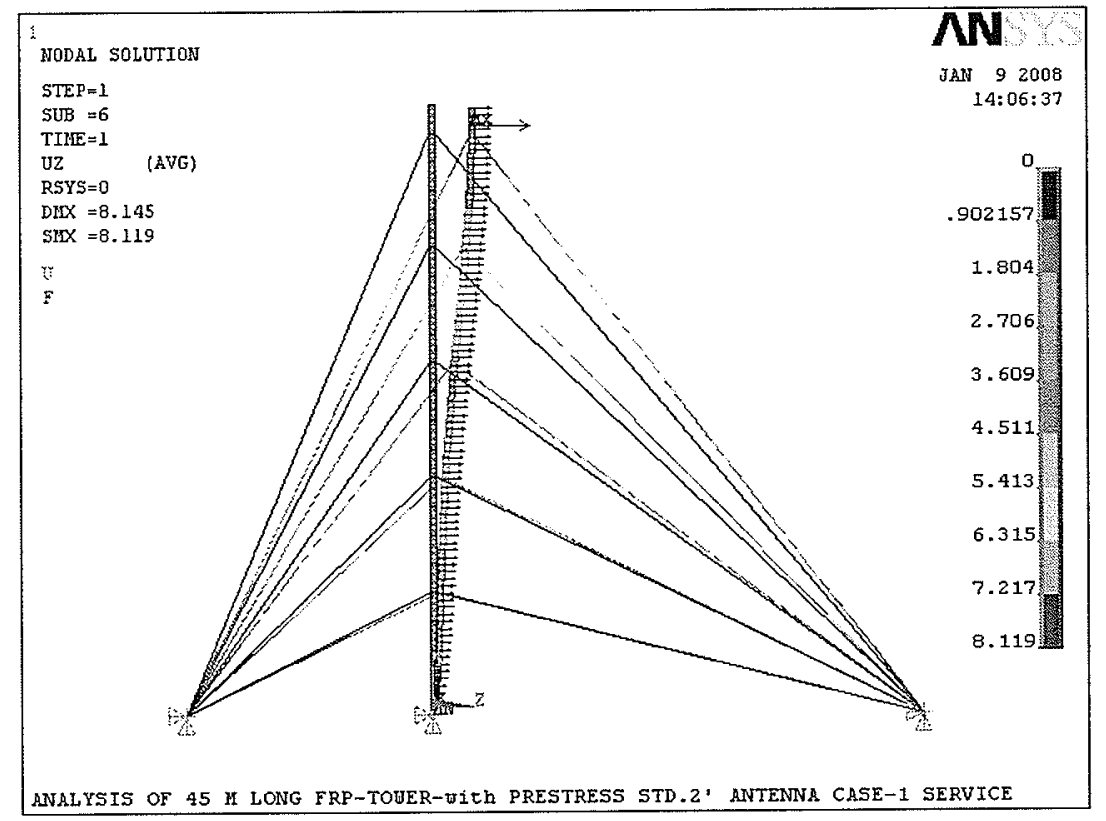

Fig. 3.28 Load Case-1: Deflection at prestress $=1779.28 \mathrm{~N}(400 \mathrm{lb})$ in cables and antenna mounted at the top (units are in inches) 


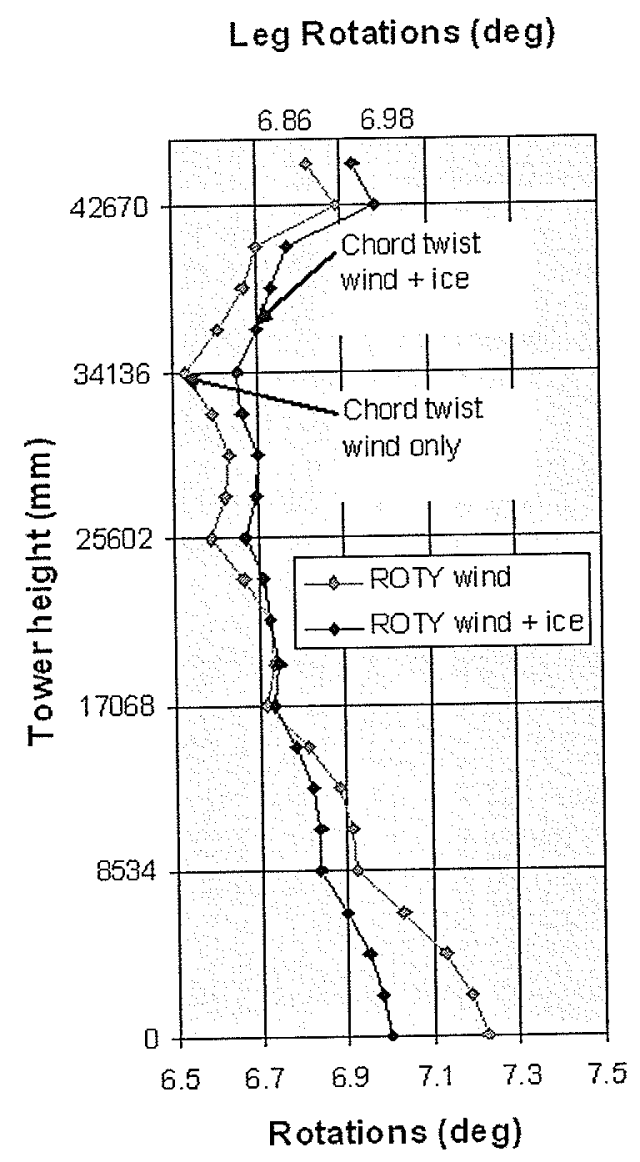

Fig. 3.29 Case-2: Chord rotation (deg)

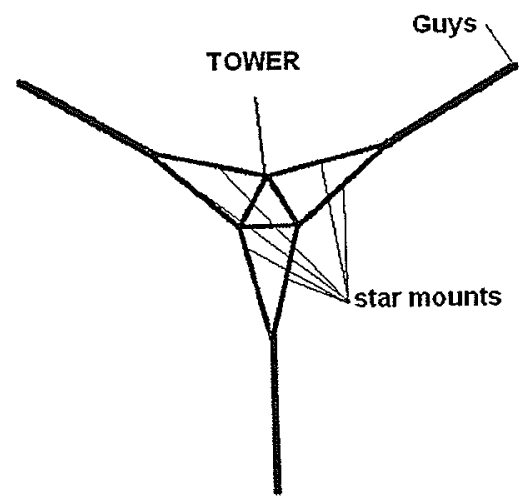

Fig. 3.30 Star mounts for triangular tower 


\subsection{Force Analysis}

Following the deflection analysis, a force analysis under factored loads was undertaken to determine the maximum forces in the tower chords, tower cables and also the maximum forces in the bracing members. The tower was analyzed with a $1779.29 \mathrm{~N}(400 \mathrm{lb})$ prestress in the cables $(10 \%$ of cable breaking strength) and an antenna mounted at the top.

Altogether, the following four loading cases were considered:

a) Factored wind, applied perpendicular to side, as in Case-1 (Fig. 3.19)

b) Factored wind plus ice, applied perpendicular to side, as in Case-1 (Fig. 3.19)

c) Factored wind, applied parallel to the side, as in Case-2 (Fig. 3.19)

d) Factored wind plus ice, applied parallel to the side, as in Case-2 (Fig. 3.19)

Factored wind and factored wind plus ice loads for Case- 1 and Case-2 were used to distinguish between different loads factor for those two cases.

The maximum chord forces due to factored wind load applied perpendicular to the side (Case-1) with and without ice are shown in Fig. 3.31. As indicated, the maximum chord force occurs at the bottom of the tower and is equal to $-18.43 \mathrm{kN}(-4143.2 \mathrm{lb})$ for factored wind only and $-34.73 \mathrm{kN}(-7808.7 \mathrm{lb})$ for factored wind plus ice. 


\section{LEG (CHORD) FORCES MFRXI (KN)}

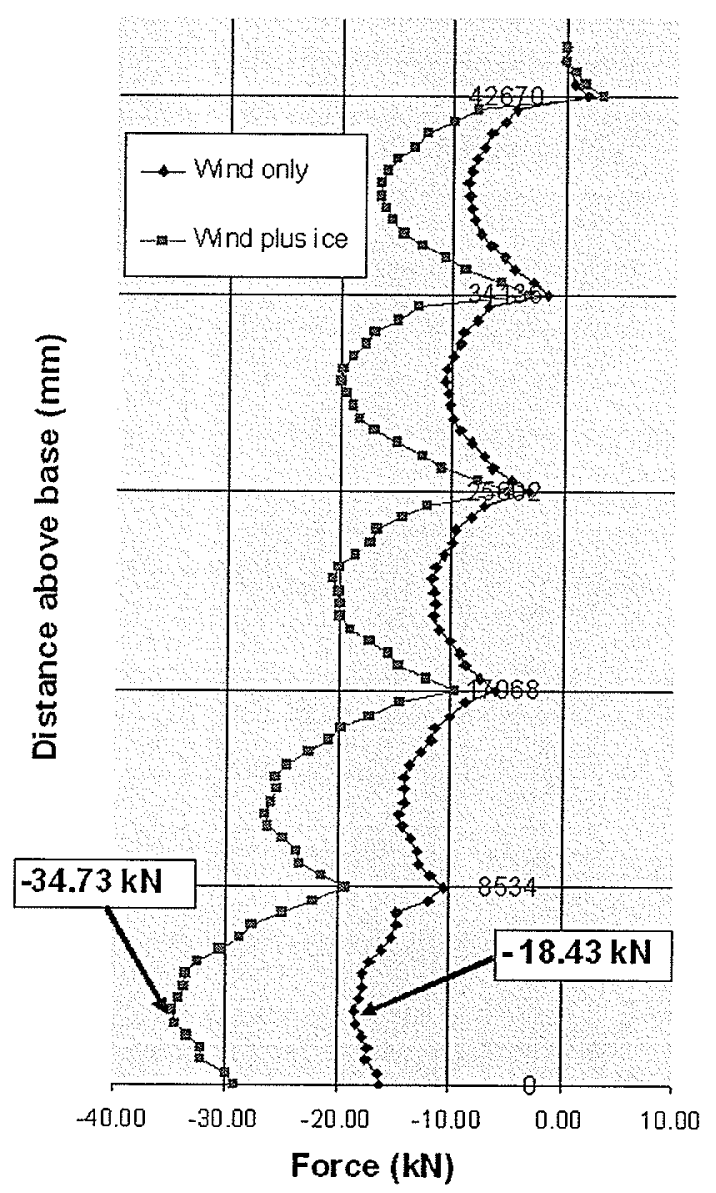

Fig. 3.31 Maximum chord forces* for load Case-1

${ }^{*}$ Refers to chords 1 and 2 in Fig. 3.19

The maximum chord forces due to factored wind load and also due to factored wind plus ice applied at an angle to the tower are shown in Fig. 3.32. The maximum chord forces are $-17.61 \mathrm{kN}(-3958.1 \mathrm{lb})$ and $-33.01 \mathrm{kN}(-7420.2 \mathrm{lb})$, respectively. These occur near the mid height of the tower. From a review of the results in Figs. 3.31 and 3.32 it can be concluded that the wind loads perpendicular to the side, Case- 1 , of magnitude of $-34.73 \mathrm{kN}(-7808.7 \mathrm{lb})$ are critical for tower design. 


\section{LEG (CHORD) FORCES MFRXI (KN)}

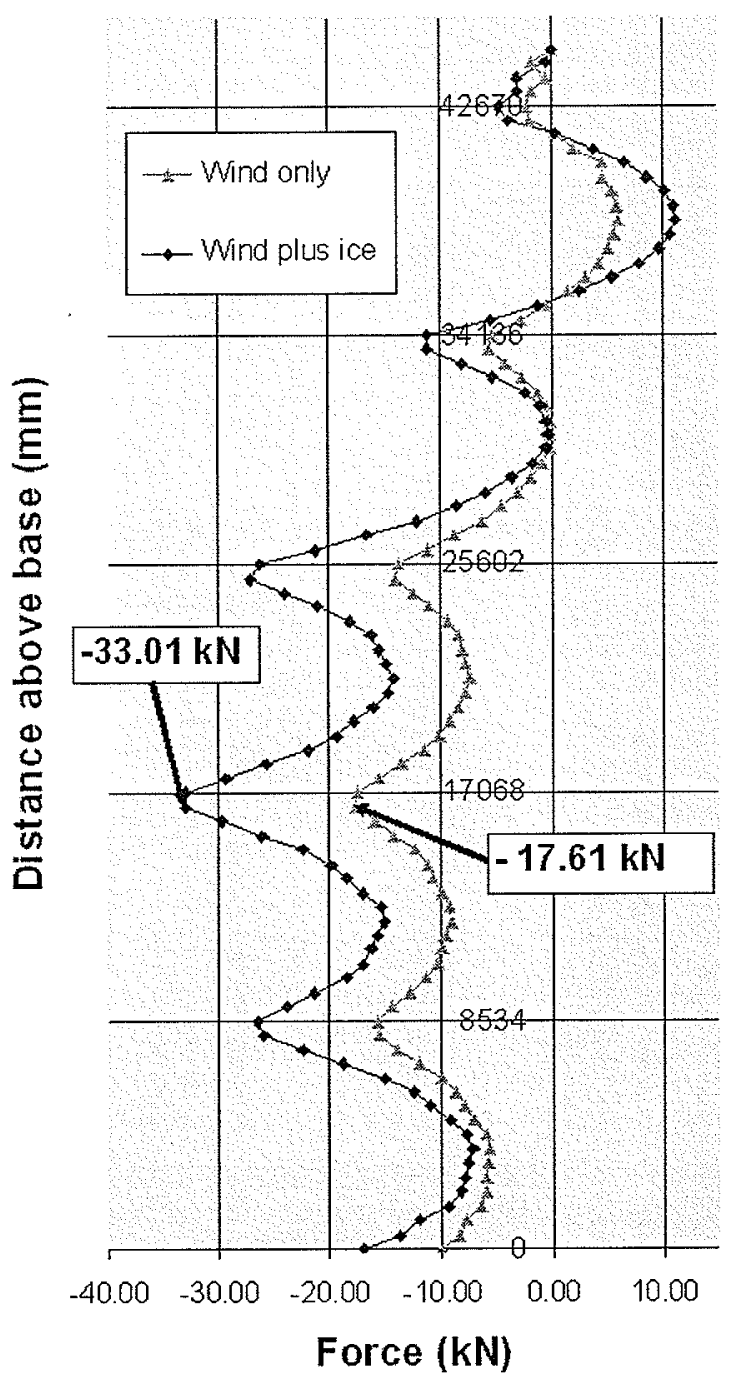

Fig. 3.32 Maximum chord forces ${ }^{*}$ for Case-2

* Refers to chord 3 in Fig. 3.19

The maximum factored guy forces for both cases are summarized in Table 3.5.

The maximum guy force is acting at an elevation of $34.14 \mathrm{~m} \mathrm{(112} \mathrm{ft)} \mathrm{and} \mathrm{is} \mathrm{equal}$ to $17.37 \mathrm{kN}$ (3906.6 lb) which is just below the maximum cable strength of 17.75 kN (3990 lb). 
Table 3.5 Maximum factored guy forces

\begin{tabular}{|l|c|c|c|c|}
\hline \multicolumn{5}{|c|}{$\begin{array}{c}\text { Factored Guy Forces kN (lb) } \\
\text { (Cables prestress 400 lbs) }\end{array}$} \\
\hline \multirow{2}{*}{ Elevation } & \multicolumn{2}{|c|}{ Case-1 } & \multicolumn{2}{c|}{ Case-2 } \\
& \multicolumn{2}{|c|}{ Perpendicular wind } & Side wind \\
\cline { 2 - 5 } & wind & wind +ice & wind & wind +ice \\
\hline $8.53 \mathrm{~m}(28 \mathrm{ft})$ & $4.97(1116.4)$ & $9.41(2115.9)$ & $5.81(1305.3)$ & $10.92(2454.3)$ \\
\hline $17.07 \mathrm{~m}(56 \mathrm{ft})$ & $5.97(1342.1)$ & $11.23(2523.9)$ & $6.90(1552.3)$ & $12.96(2913.3)$ \\
\hline $25.60 \mathrm{~m}(84 \mathrm{ft})$ & $7.20(1619.2)$ & $13.56(3048.3)$ & $8.36(1880.0)$ & $15.74(3538.6)$ \\
\hline $34.14 \mathrm{~m}(112 \mathrm{ft})$ & $8.09(1820.6)$ & $15.13(3401.9)$ & $9.18(2063.8)$ & $17.37(3906.6)$ \\
\hline $42.67 \mathrm{~m}(140 \mathrm{ft})$ & $7.64(1716.6)$ & $13.67(3074.0)$ & $7.95(1788.0)$ & $14.85(3338.1)$ \\
& & & & \\
\hline
\end{tabular}

\subsection{Stress Analysis}

A stress analysis has the predominant importance in the overall tower performance analysis. The axial or the centroidal stress according to ANSYS is determined as follows:

$\sigma_{i}^{d i r}=\frac{F_{x, j}}{A}$

where: 


$$
\begin{gathered}
\sigma_{i}^{d i r}=\text { centroidal stress (output as SDIR in FEA) and } \\
F_{x, j}=\text { axial force (output as FX or MFRX in the FEA) }
\end{gathered}
$$

The bending stresses of a beam element, in the $x$-direction, at end i shown in

Fig. 3.33 are:

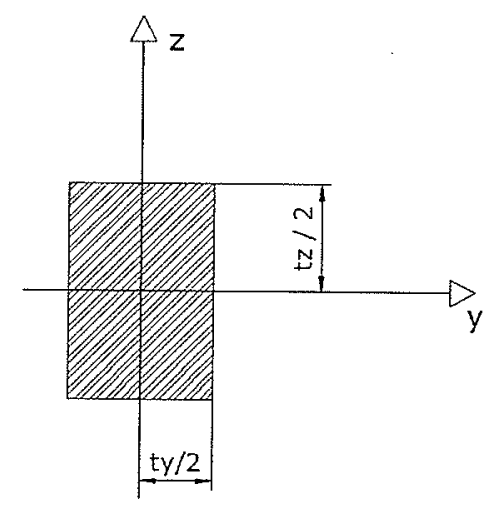

Fig. 3.33 Bending stresses of beam element

$$
\begin{gathered}
\sigma_{z, i}^{b n d}=\frac{M_{y, i} \times t_{z}}{2 \times I_{y}} \\
\sigma_{y, i}^{b n d}=\frac{M_{z, i} \times t_{y}}{2 \times I_{z}}
\end{gathered}
$$

where:

$\sigma_{z, i}^{b n d}=$ stress in the element due to bending about the $y$-axis (output as SBZ in the FEA).

$\sigma_{y, i}^{b n d}=$ stress of the element due to bending about the $z$-axis (output as SBY in the FEA). 
$M_{y, i}, M_{z, i}=$ bending moments about the element $\mathrm{y}$ and $\mathrm{z}$ axes, respectively at end $\mathrm{i}$.

$t_{z}, t_{y}=$ thickness of beam element in $\mathrm{z}$ and $\mathrm{y}$ directions, respectively.

The maximum and minimum stresses are calculated with the help of the following formulae:

$$
\begin{aligned}
& \sigma_{i}^{\max }=\sigma_{i}^{d i r}+\left|\sigma_{z, i}^{b n d}\right|+\left|\sigma_{y, i}^{b n d}\right|, \text { or } \quad S M A X I=S D I R+|\mathrm{SBZ}|+|\mathrm{SBY}| \\
& \sigma_{i}^{\min }=\sigma_{i}^{\text {dir }}-\left|\sigma_{z, i}^{b n d}\right|-\left|\sigma_{y, i}^{b n d}\right|, \text { or } \quad S M I N I=S D I R-|\mathrm{SBZ}|-|\mathrm{SBY}|
\end{aligned}
$$

The maximum stresses occur at the corners of the rectangular cross sections of the tower members where compression stresses due to axial load and bending are additive. To be able to extract these stresses from the FEA output files, NonSummable Miscellaneous Items (NMISC) variables with appropriate sequence numbers were inserted to create ETABLES. The ANSYS program determines stresses at nodes $\mathrm{I}$ and $\mathrm{J}$ at the beginning and end of the beam element, respectively. NMISC 1 and NMISC 2 are associated with the maximum and minimum bending stresses at node I, while NMISC 3 and NMISC 4 are describing the maximum and minimum bending stresses at node $\mathrm{J}$, as shown in Fig. 3.34. Maximum stresses SMAXI and SMINJ for the chords are illustrated in Fig. 3.35. The stresses for the two cases shown in Fig. 3.36 were calculated for the factored wind plus ice loads and with the antenna mounted and the cables prestressed. The ice loading was applied to tower only. The maximum and minimum stresses for the windward chords members under load Case-1 are 
shown in Fig. 3.37. It was found that the maximum factored chord stress occurred at the bottom sections of the tower and is equal to $-58.65 \mathrm{MPa}(-8505.8$ psi), as shown in Fig. 3.37.

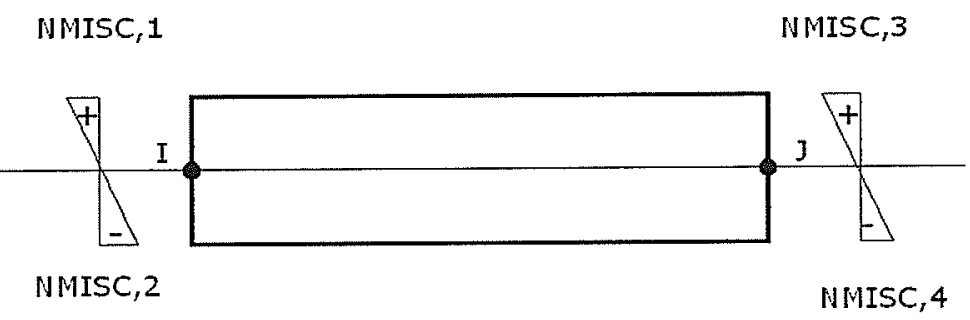

Fig. 3.34 Max bending stresses SMAXI and SMINJ for beam element
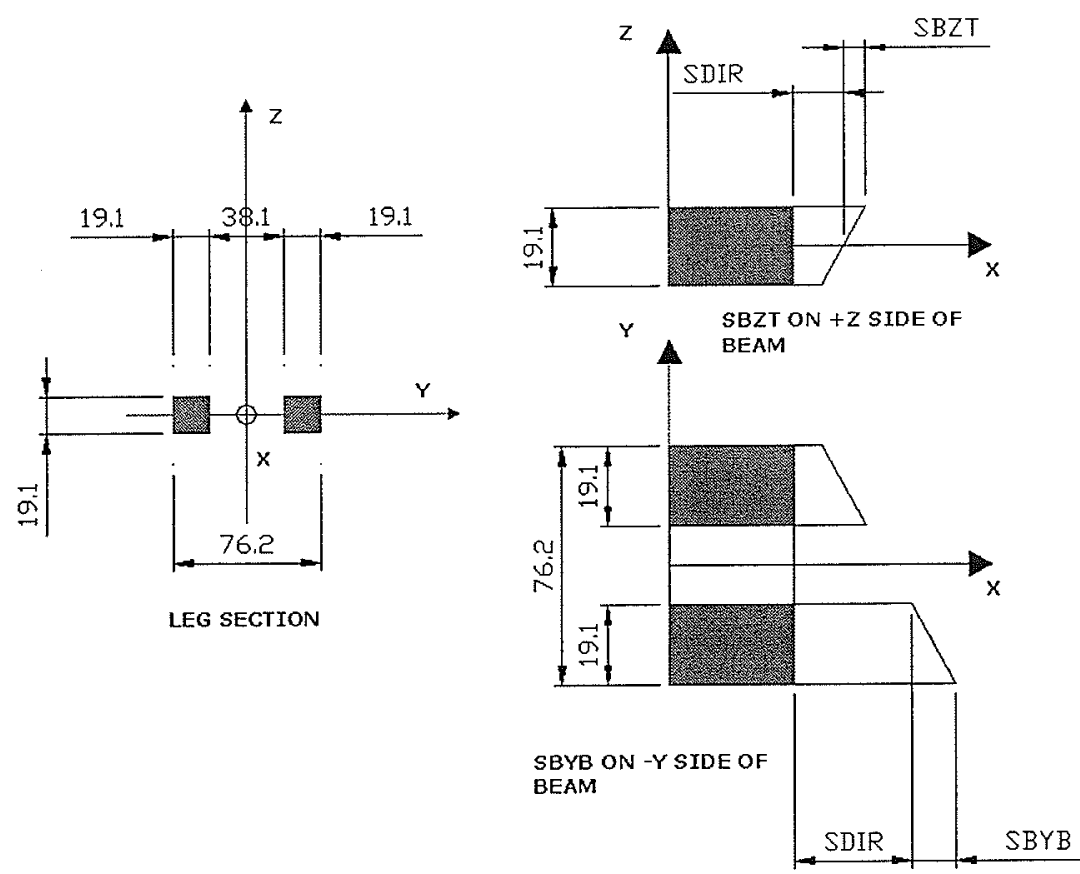

Fig. 3.35 Maximum stresses SMAXI and SMINJ for chord members In local coordinate system (units are in $\mathrm{mm}$ ) 


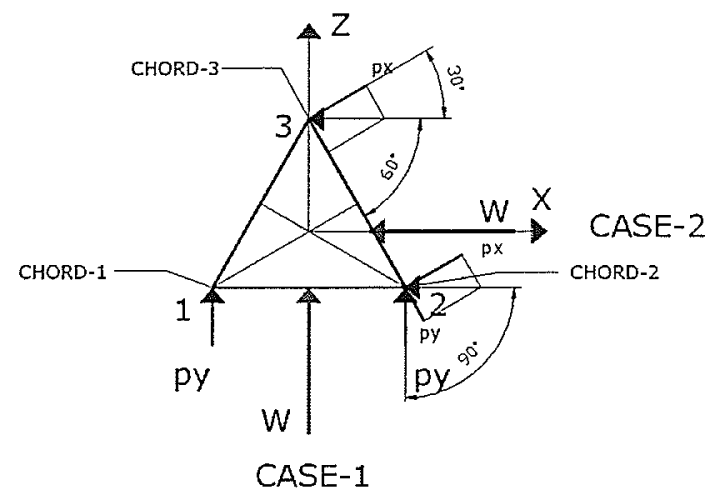

Fig. 3.36 Tower chords annotation for Load Case-1 and Case-2

SMAX I,J-SMIN I,J

Max and Min Combined Stress (MPa)

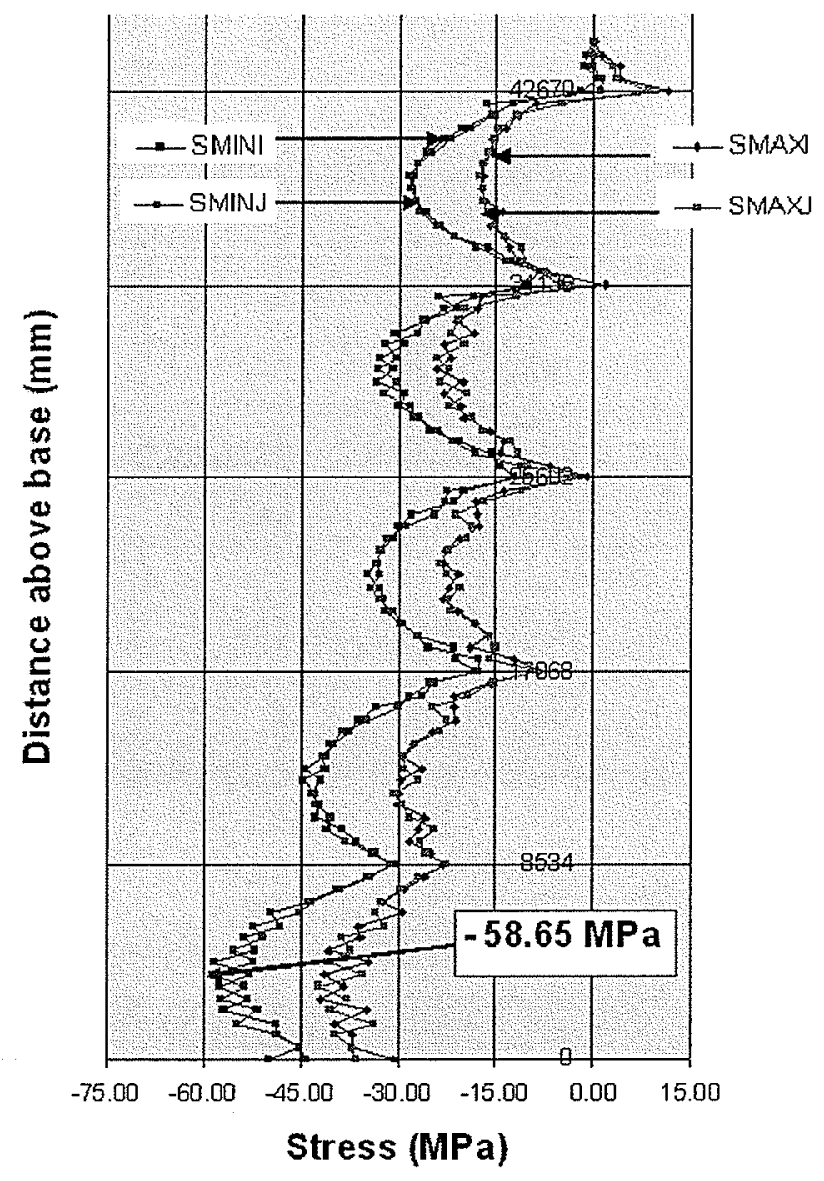

Fig. 3.37 Combined stresses ${ }^{*}$ SMAXI and SMINJ for load Case-1

${ }^{*}$ Refers to chords 1 and 2 in Fig. 3.36 
According to the results from Load Case- 1 it was established that the extreme stresses occurred not in the windward chords 1 and 2, but in chord 3 as shown in Figs. 3.37 and 3.38. According to Fig. 3.38, the maximum combined stresses in chord 3 was $-68.22 \mathrm{MPa}$ (-9894.6 psi). This stress is the highest of both Load Cases 1 and 2 and it will govern the design of tower.

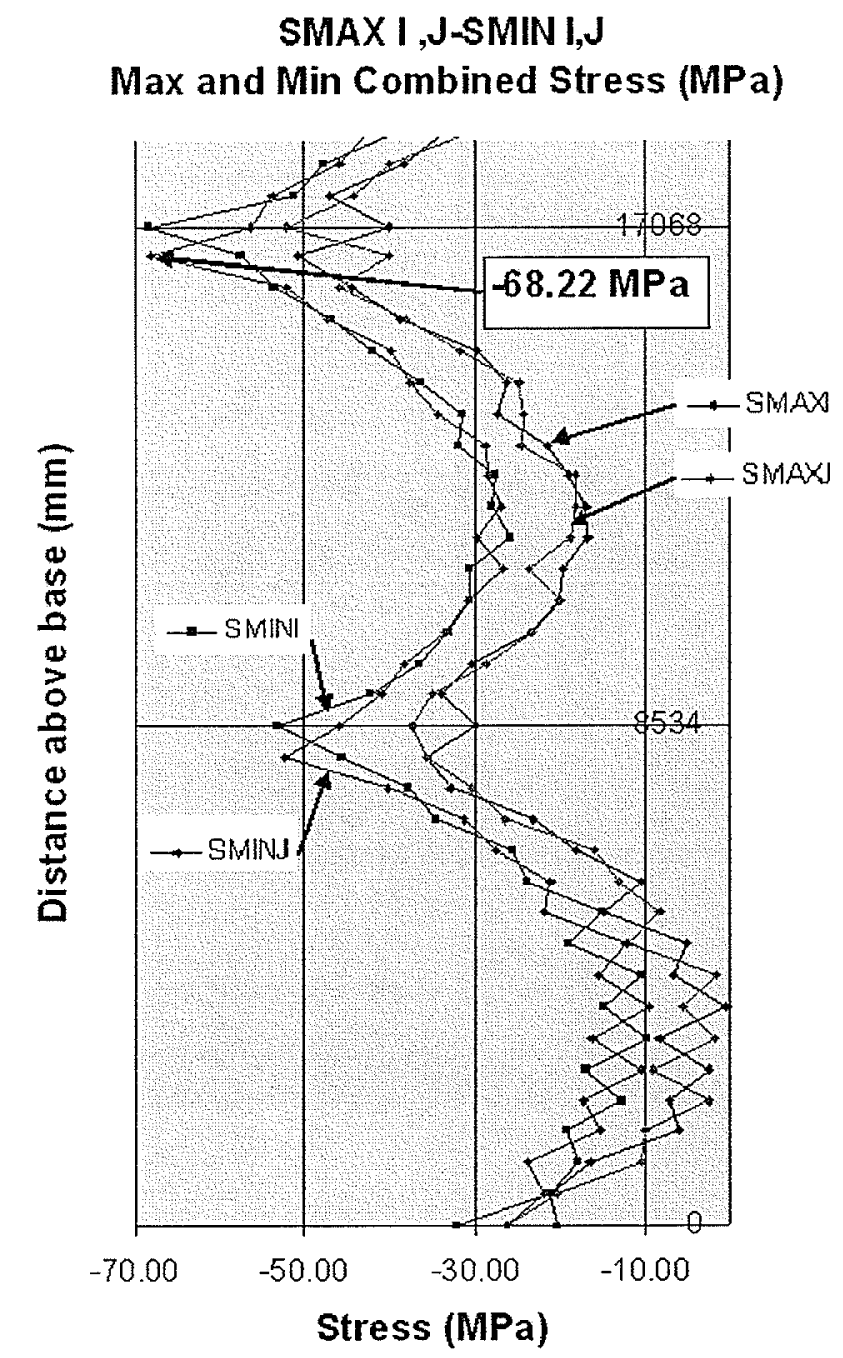

Fig. 3.38 Combined stresses* SMAXI and SMINJ for load Case-1

* Refers to chord 3 in Fig. 3.36 
The maximum combined stress for chord 1, load Case-2, depicted in Fig. 3.39, was $-61.42 \mathrm{MPa}(-8908.9 \mathrm{psi})$ and is not governing the design of tower.

SMAX I ,J-SMIN I,J

Max and Min Combined Stress (MPa)

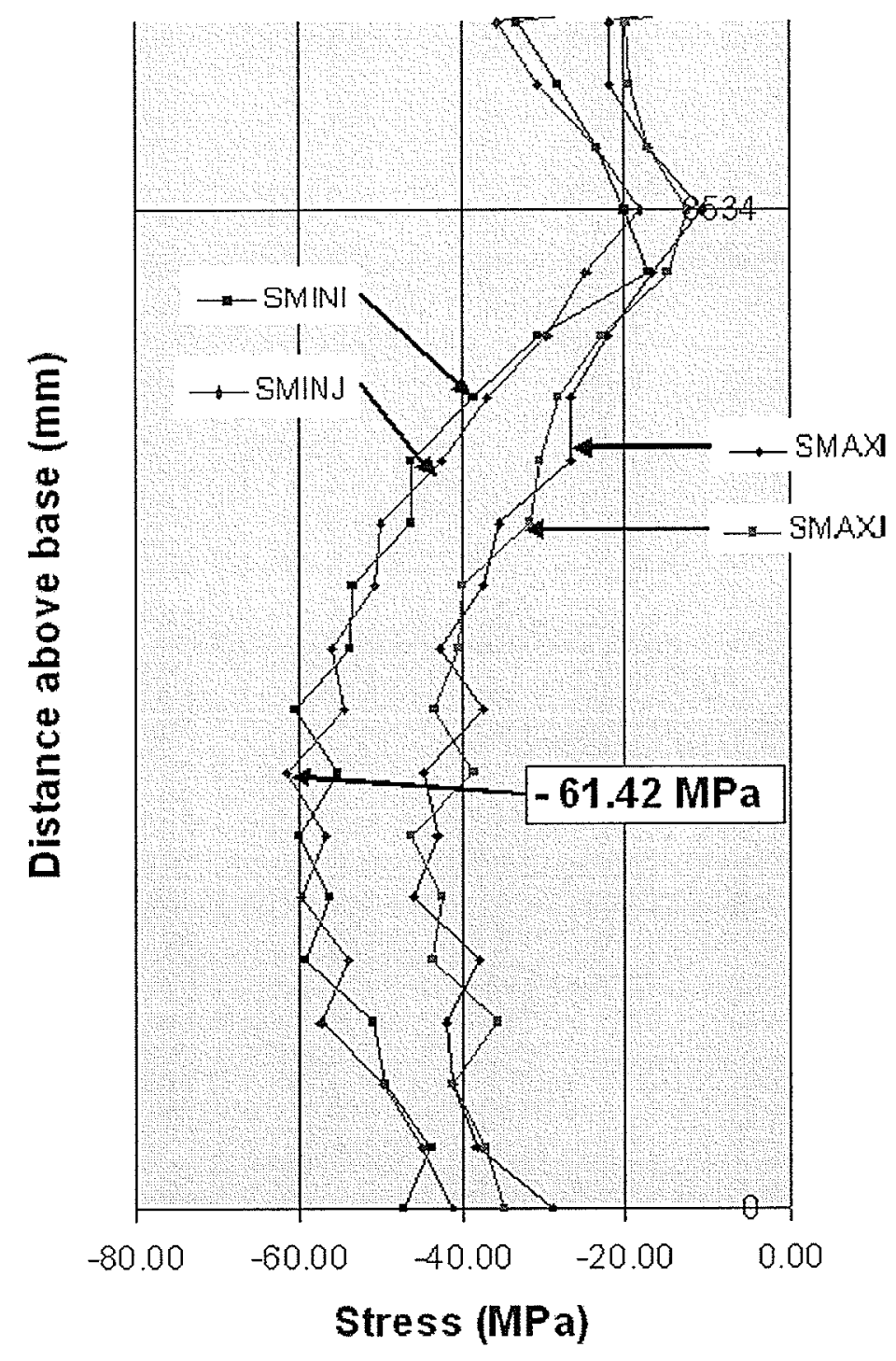

Fig. 3.39 Combined stresses* SMAXI and SMINJ for load CASE-2

* Refers to chord 1 in Fig. 3.36 
The material properties used in this analysis were taken from tests conducted by Burachynsky (2006) and Ungkurapinan (2005). These are included in Table 3.6. The test coupons were fabricated using Type 30, 1100 Tex Roving E-Glass supplied by FAROEX Ltd., Gimli, Manitoba, Canada, and modified polyester resin system formulated by Faroex with low viscosity between 200$300 \mathrm{cps}$ (centipoise) plus hardener in the ratio of mixing $(5: 1)$. The fibre volume fraction was determined to be between $36.8 \%$, using burn out test.

Table 3.6 Strength values from unidirectional test coupons (Burachynsky (2006) and Ungkurapinan (2005)

\begin{tabular}{|c|c|c|}
\hline \multirow{2}{*}{ Strength } & \multicolumn{2}{|c|}{ Values MPa (ksi) } \\
\cline { 2 - 3 } & Burachynsky (2006) & Ungurapinan (2005) \\
\hline $\begin{array}{c}\text { Axial or Longitudinal Strength in tension } \\
\left(F_{1}^{\text {tu }}\right)\end{array}$ & $610.2(88.5)$ & $597.15(86.61)$ \\
\hline $\begin{array}{c}\text { Transverse Strength in tension } \\
\left(F_{2}^{\text {tu }}\right)\end{array}$ & $12.29(1.783)$ & $18.06(2.62)$ \\
\hline $\begin{array}{c}\text { Axial or Longitudinal strength in } \\
\text { compression } \\
\left(F_{1}^{c u}\right)\end{array}$ & $342.67(49.7)$ & $361.56(52.44)$ \\
\hline $\begin{array}{c}\text { Transverse Strength in compression } \\
\left(F_{2}^{c l}\right)\end{array}$ & $69.64(10.1)$ & $69.98(10.15)$ \\
\hline $\begin{array}{c}\text { Shear strength } \\
\left(F^{s u}\right)\end{array}$ & $37.26(5.404)$ & $47.02(6.82)$ \\
\hline
\end{tabular}

In conclusion, the maximum values of combined stresses for Case-1 are well below the strength values shown in Table 3.6, both for tension and compression in the chords. A more detailed analysis with reference to failure theories is given in Section 6.3. 
In order to evaluate the contribution of direct axial stresses and bending stresses to combined stresses, two separate diagrams were created. The direct axial stress acting along the tower chord members has been plotted in Fig. 3.40. The maximum value of stress occurs, as expected, at the bottom of the tower and is equal to $-47.86 \mathrm{MPa}(-6941 \mathrm{psi})$. This direct stress represents $80 \%$ of combined stress.

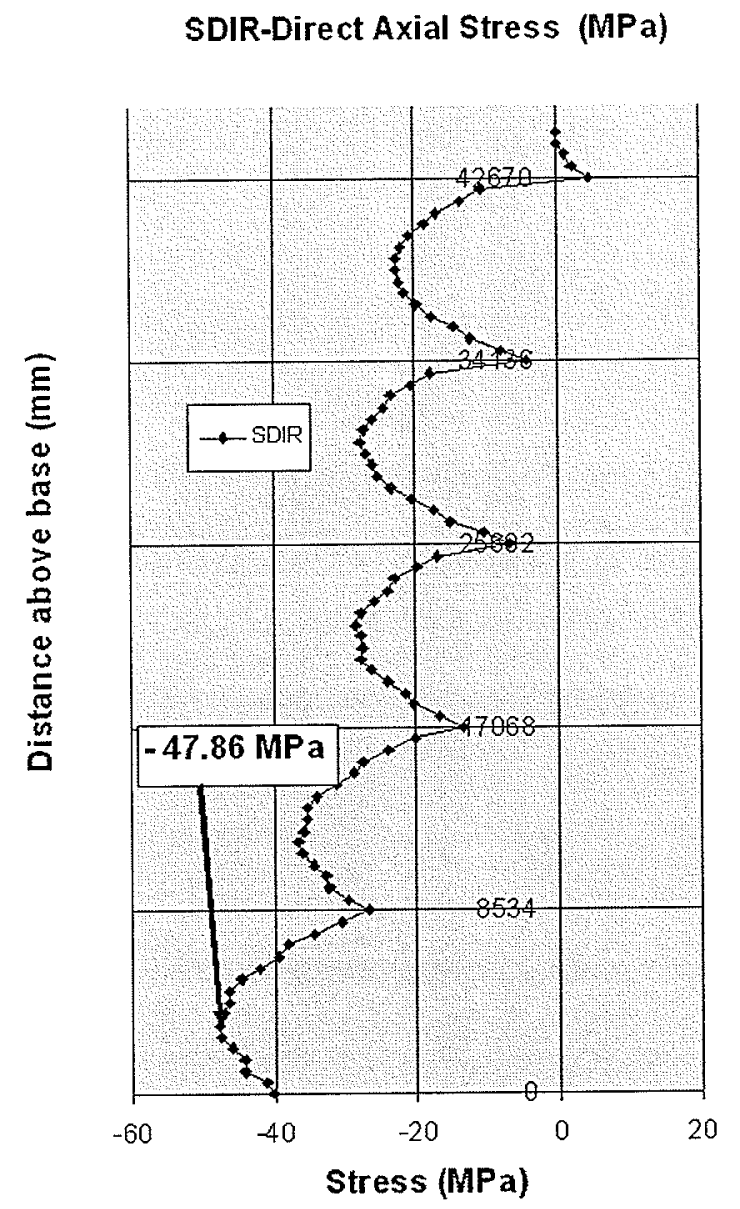

Fig. 3.40 Direct axial stress for load Case-1

${ }^{*}$ Refers to chord 1 and 2 in Fig. 3.36

The bending stress along the chord members, shown in Fig. 3.41, was created by subtracting from the values of maximum combined stresses (SMAXI and 
SMAXJ) values of direct axial stress (SDIR). As indicated in Fig. 3.41 for Case-1, the maximum bending stress was $11.71 \mathrm{MPa}$ (1698.3 psi) and occurred at the bottom section of the tower. This stress represents $20 \%$ of combined stress.

COMBINED BENDING STRESSES ALONG TOWER CHORDS $1 \& 2$ (MPa)

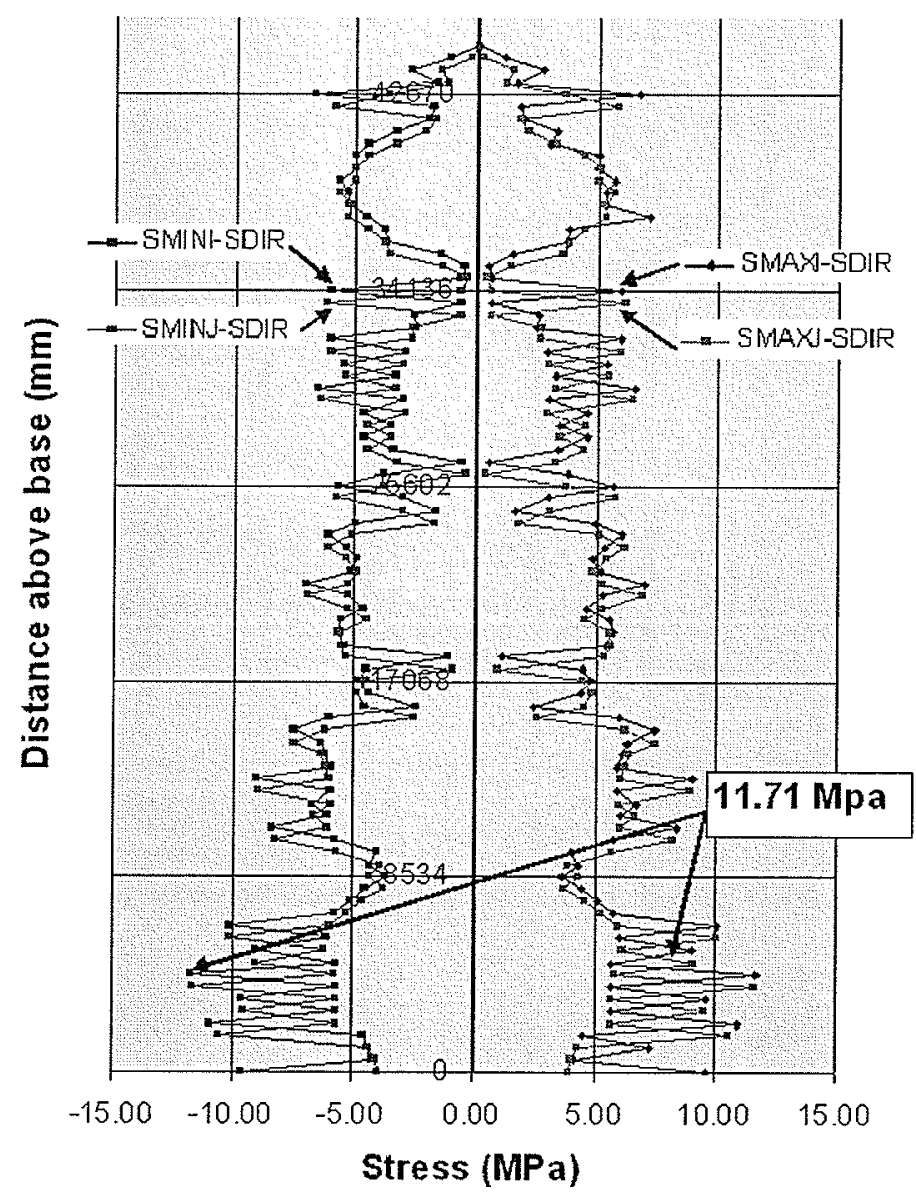

Fig. 3.41 Bending stress for load Case-1

* Refers to chord 1 and 2 in Fig. 3.36

The split of combined stresses into axial and bending stresses was done to show the significance of axial stress in guyed tower design, especially when ice load is considered. 
The maximum axial stress (SDIR) in the cross bracing members was recorded at the windward side of the bottom section of the tower. The magnitude of maximum bracing stress recorded was $3.68 \mathrm{MPa}(534.26 \mathrm{psi})$, a value that was deemed to be not critical to tower performance. Forces in the horizontal braces at the guy locations are transferred to the tower by steel brackets similar to those shown in Fig. 3.42, and therefore, are not considered critical for tower design.

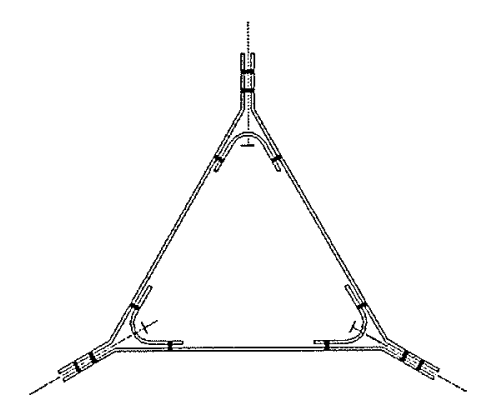

Fig. 3.42 Steel brace for guyed cables connection

\subsubsection{Preliminary Conclusions from the FEA of $45 \mathrm{~m}(147 \mathrm{ft})$ Tower}

From the FEA of a $45 \mathrm{~m}(147 \mathrm{ft})$ tower with an antenna mounted on top and subjected to two loading cases the following conclusions were drawn:

- Deflections of an $8.53 \mathrm{~m}(28 \mathrm{ft})$ tower segment chosen for testing compare well with deflections of the bottom $8.53 \mathrm{~m}(28 \mathrm{ft})$ of a $45 \mathrm{~m}$ (147 ft tower), provided the appropriate tension is applied to guy cables of the tower segment. Thus, test results from an $8.53 \mathrm{~m}(28 \mathrm{ft})$ segment can be used to verify the FEA model developed for the full scale tower. 
- The axial stresses in the chord members are far more significant than the bending stresses. The maximum ratio of axial to bending stress is $4.1: 1$ (47.86 MPa to 11.71MPa).

- For Load Case -1 (factored wind loading only), the maximum stresses in chords members are well under the maximum longitudinal strength of the composite material in tension and compression.

- For Case -1 (factored wind loading only), the maximum stress in the bracing members is well under the maximum strength of the composite material in tension and compression.

- By introducing an equal prestress of $1.78 \mathrm{kN}(400 \mathrm{lb})$ to all cables, the tower tip deflection without antenna is reduced by $14.4 \%$ and by $11 \%$ for the tower with antenna.

- The maximum factored guy force with $10 \%$ guy prestress equivalent to $1.78 \mathrm{kN}(400 \mathrm{lb})$ is equal to $17.37 \mathrm{kN}$ (3.9 kips), as shown in Table 3.5, which is just under the breaking strength of $17.78 \mathrm{kN}$ (3.99 kips) of the guy cables.

\subsubsection{Development of the Sleeve Model}

The comparative analysis described in the previous section, between a full scale tower model and a tower segment was carried out using the continuous model in which no discontinuity between tower sections was assumed. In reality however, tower sections are connected by sleeve brackets, as described in more detail in 
Chapter 6 . Such discrete joints tend to reduce the overall stiffness of the tower and affect its overall deflections. To account for the reduced stiffness, a new FEM sleeve model was developed. All assumptions outlined in Section 3.6 for the continuous model are still valid for the sleeve model except for the introduction of sleeve bracket connectors between segment sections which were modelled in ANSYS by beam elements. As a first step, a comparative analysis was carried out between the two models, one assuming the tower is continuous and the other assuming sleeve brackets are used to connect the segments. The sleeve bracket properties were represented by beam element real constants R8. The ANSYS parametric language variable constant called "gap" represented by letter "s" was used to model the spacing between the segments. By adjusting spacing between tower segments and changing geometry of sleeve connectors the required stiffness of sleeve brackets was obtained. A comparison between the results from the continuous and sleeve models was done using the basic wind profile acting on the bottom segment of the full scale tower. The connectors in the sleeve model, shown in Fig. 3.43, were represented as beam elements with an area, $A=1411.28 \mathrm{~mm}^{2} \quad\left(2.1875 \mathrm{in}^{2}\right)$, a moment of inertia $I_{z z}=4.7 \times 10^{5} \mathrm{~mm}^{4}$ $\left(1.13 \mathrm{in}^{4}\right)$ and a moment of inertia $I_{y y}=3.74 \times 10^{5} \mathrm{~mm}^{4} \quad\left(0.9001 \mathrm{in}^{4}\right)$. The corresponding thicknesses were $t_{k z}=44.45 \mathrm{~mm}(1.75 \mathrm{in})$ and $t_{k y}=73.03 \mathrm{~mm}$ $(2.875 \mathrm{in})$

A $12.7 \mathrm{~mm}(0.5 \mathrm{in})$ fibreglass flat sheet made by Bedford Reinforced Plastics Inc. was used in the experimental program. The recommended orthotropic mechanical properties of the pultruded plates (Bedford Manual, 2007) are 
as follows: $E_{x}=E_{y}=E_{z}=4.826 \mathrm{GPa}\left(0.7 \times 10^{6} \mathrm{psi}\right), G_{x y}=G_{y z}=G_{x z}=3.1 \mathrm{GPa}$ $\left(0.45 \times 10^{6} \mathrm{psi}\right), \quad v_{X Y}=v_{Y Z}=v_{X Z}=0.35$ and $\rho=0.00188 \mathrm{~g} / \mathrm{mm}^{3}\left(0.068 \mathrm{lb} / \mathrm{in}^{3}\right)$.

The tower sections were assumed to be in contact with each other and the tower was assumed to be supported by guy cables having a spring constant equal to $k=A E / L=97.82 \mathrm{kN} / \mathrm{m}(558.67 \mathrm{lbs} / \mathrm{in})$.

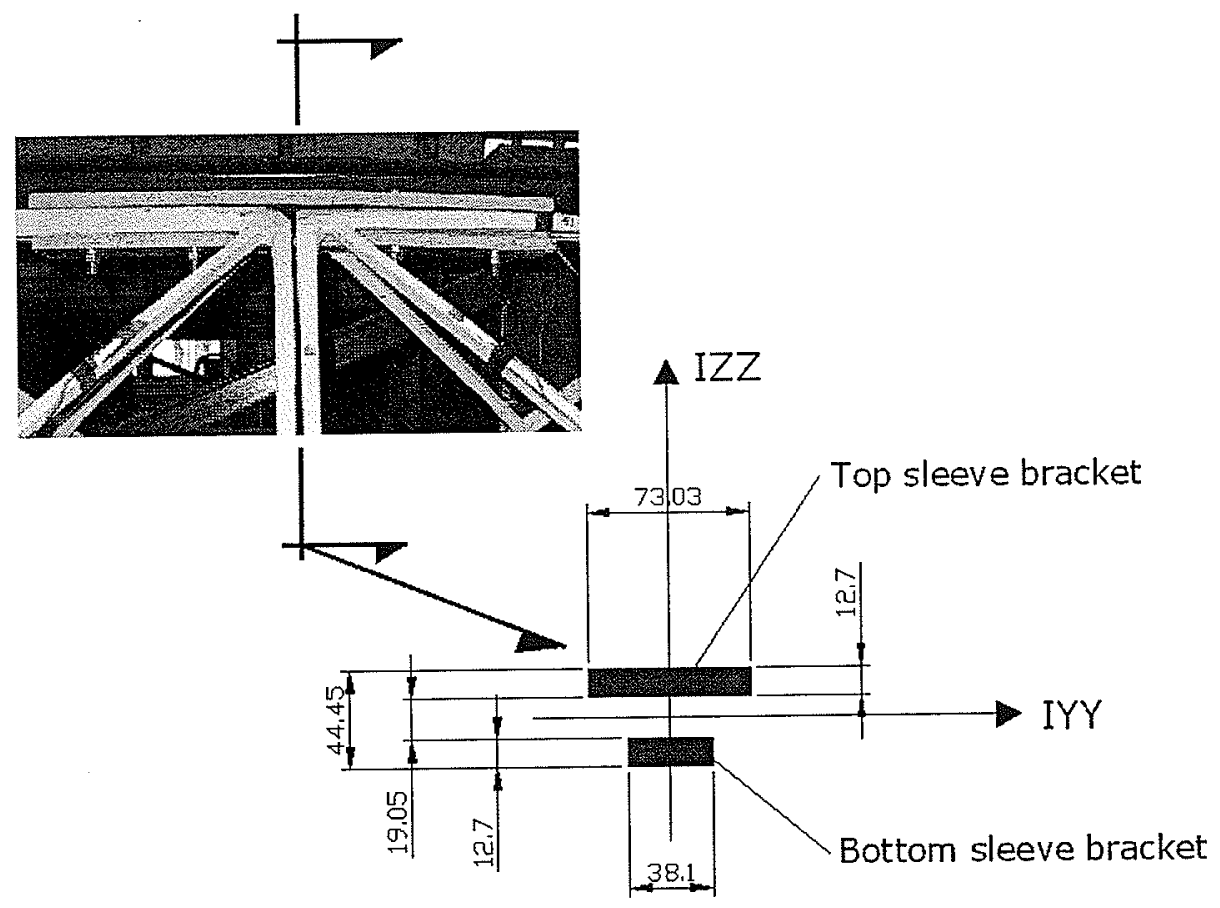

Fig. 3.43 Sectional properties of sleeves at segments splices (units are in $\mathrm{mm}$ )

The tower segment sleeve model shown in Fig. 3.44 was loaded with 8 equal forces $P=328 \mathrm{~N}(73.74 \mathrm{lb})$. The stiffness of individual sleeve bracket was calculated based on FEM findings as $\mathrm{k}=83.38 \mathrm{kN} / \mathrm{m}(476.19 \mathrm{lb} / \mathrm{in})$.

The FEM results for the two models are shown in Fig. 3.45. As the results point out, there is a close match in deflections along the $8.53 \mathrm{~m}(28 \mathrm{ft})$ tower segment between the two models. 


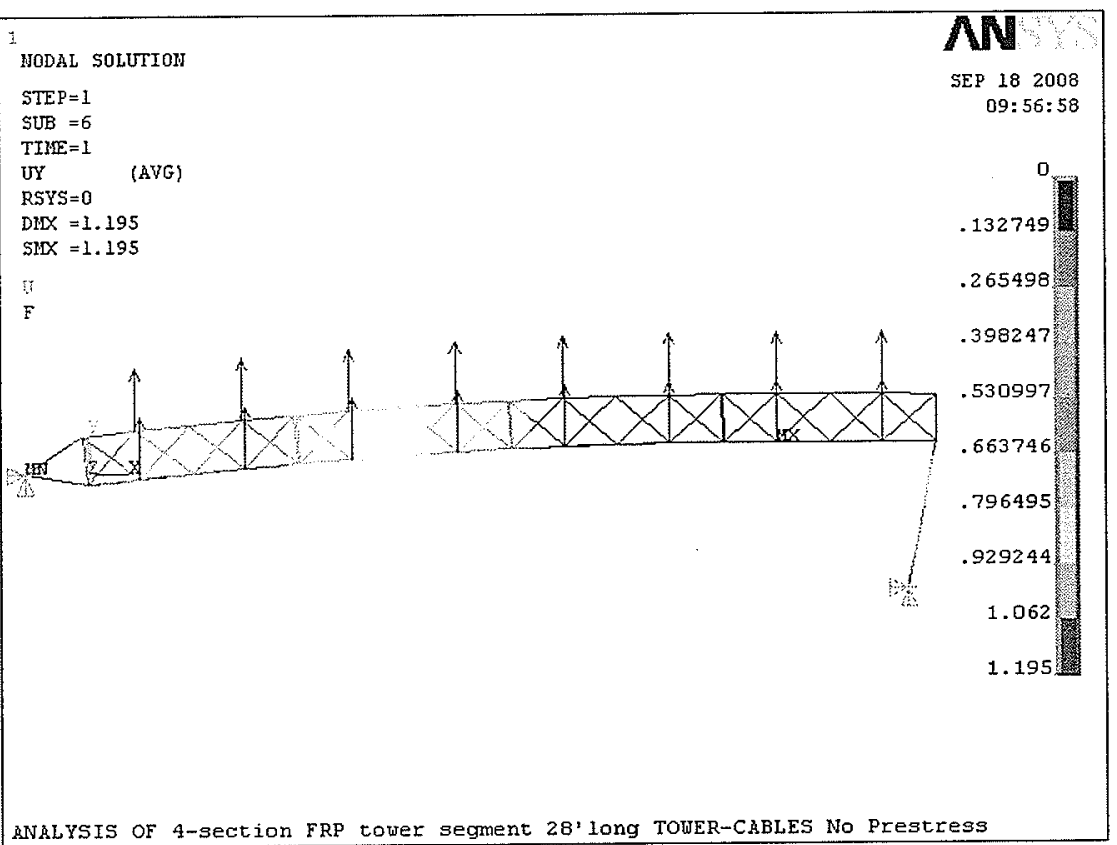

Fig. 3.44 FEM sleeve model loading condition

Deflection vs. distance at $2.62 \mathrm{kN}(589.92 \mathrm{lbs})$

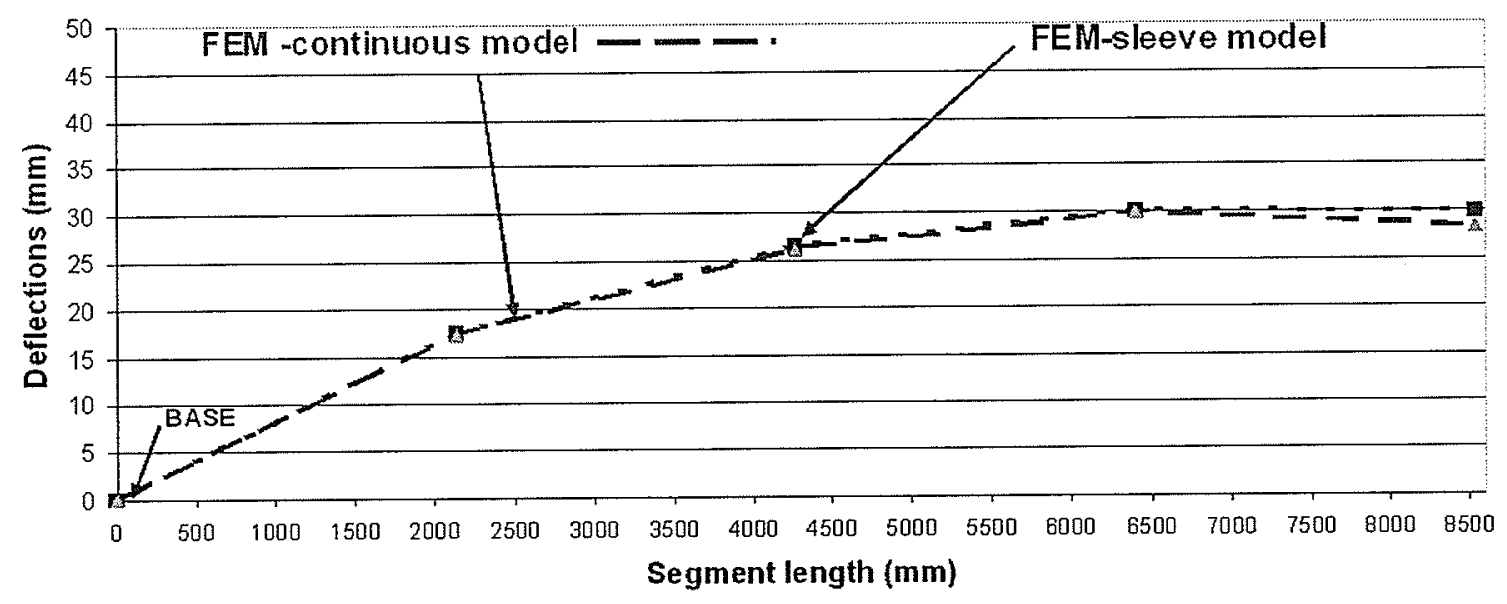

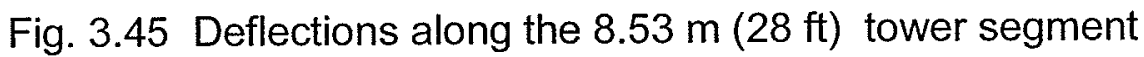

Therefore, introducing appropriate sleeve connectors between tower sections makes the sleeve model equivalent to the continuous model. The sleeve model procedure and the comparison to continuous model provides a method for obtaining required sleeve dimensions. 
The continuous model is evaluated through comparison with experimental results in Chapter 5.

\subsubsection{Dynamic FEA of $8.53 \mathrm{~m}(28 \mathrm{ft})$ FRP Tower Segment}

An $8.53 \mathrm{~m}$ (28 ft) tower segment was also tested under dynamic loading. In order to verify the experimental data from this dynamic testing a vibration analysis was carried out using the FEM program ANSYS 8.1. Two analysis techniques, the modal and the harmonic, were used to obtain natural frequencies and associated mode shapes. These techniques are discussed below.

\subsubsection{Modal Analysis}

Every structural system has, theoretically, infinite number of natural frequencies. There is a unique pattern of displacements associated with each natural frequency in which the structure will vibrate, called mode shape. Modal analysis, in general, is used to determine natural frequencies and mode shapes of continuous structures. It is the most fundamental analysis before any other type of dynamic analysis can be done. The general equation of motion for a vibrating structure (ANSYS, 2004) can be expressed by the following equation:

$$
[M]\{\ddot{u}\}+[C]\{\dot{u}\}+[K]\{u\}=\{F(t)\}
$$

where: 
$[M]=$ structure mass matrix

$[C]=$ structure viscous damping matrix

$[K]=$ structure stiffness matrix

$\{F(t)\}=$ structure external load vector matrix

$\{\ddot{u}\},\{\dot{u}\},\{u\}=$ structure acceleration, velocity and displacement vectors, respectively.

Assuming that there is no damping and ignoring any nonlinearities and any force acting on the structure, the general equation for modal analysis becomes:

$[M]\{\ddot{i}\}+[K]\{u\}=\{0\}$

Assuming the harmonic motion takes the form:

$u=U \cos (\omega t)$

where:

$u=$ displacement vector; and

$U=$ amplitude,

the solution to equation (3.38) takes the form:

$\left([K]-\omega^{2}[M]\right)\{u\}=\{0\}$

The roots of Eq. 3.40 are $\omega_{i}{ }^{2}$, the eigenvalues ( the natural frequencies of the system). The index $i$ ranges from 1 to $n$, where $n$ is equal to the number of 
degrees of freedom. Corresponding vectors $\{u\}_{i}$ are the eigenvectors which represent mode shapes when the structure vibrates at frequency $f_{i}$. The square roots of the eigenvalues are $\omega_{i}$, the structure's natural circular frequencies given in (radians/sec). They are converted to natural frequencies in $\mathrm{Hz}$ (cycles/sec) using a formula $f_{i}=\omega_{i} /(2 \times \pi)$ and are given as an output by the ANSYS program. The eigenvectors $\{u\}_{i}$ represent the mode shapes, the shape assumed by the structure when vibrating at frequency $f_{i}$.

\subsubsection{Modal Analysis of Tower Segment by ANSYS}

The development of a model for modal analysis, up to the solution stage, is similar to that used for the static analysis. In the solution stage, the only constraint imposed on the tower segment was that zero displacements were applied at the base of the tower as well as at the location of the three cable anchors. A modal analysis was selected with a subspace mode extraction method consisting of 25 modes. A solution with mode shapes 1 and 2, shown in Fig. 3.46 and an associated damped natural frequency of $f_{d}=4.292 \mathrm{~Hz}$, was closely related to the experimental results presented in Chapter- 5 . 


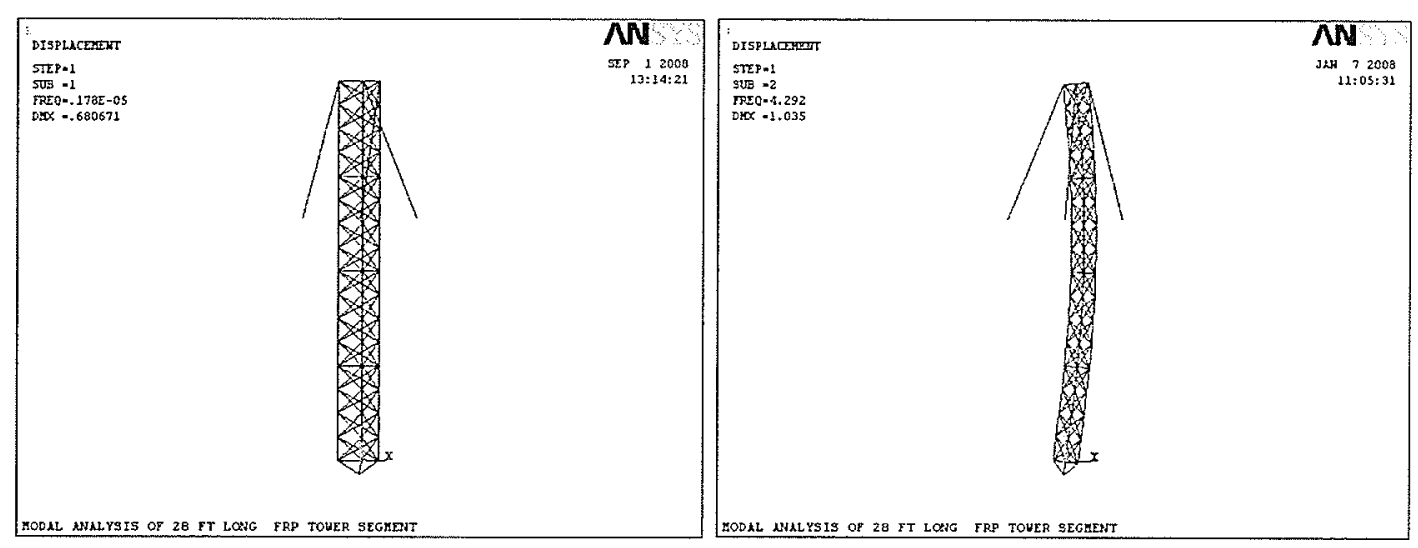

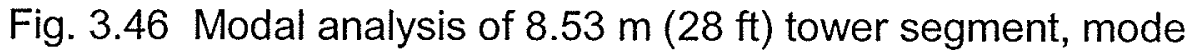
shape -1 and 2 at $0.17 \mathrm{~Hz}$ and $4.292 \mathrm{~Hz}$

The other mode shapes and associated natural frequencies are shown in Figs. 3.47 to 3.49. Fig. 3.46, mode shape-1 and Fig 3.47 mode shape-4 show the first and second rotational vibration mode in the $z$ direction. In Fig. 3.49 mode shape7 shows the first double concave bending mode shape at an associated frequency of $23.446 \mathrm{~Hz}$.

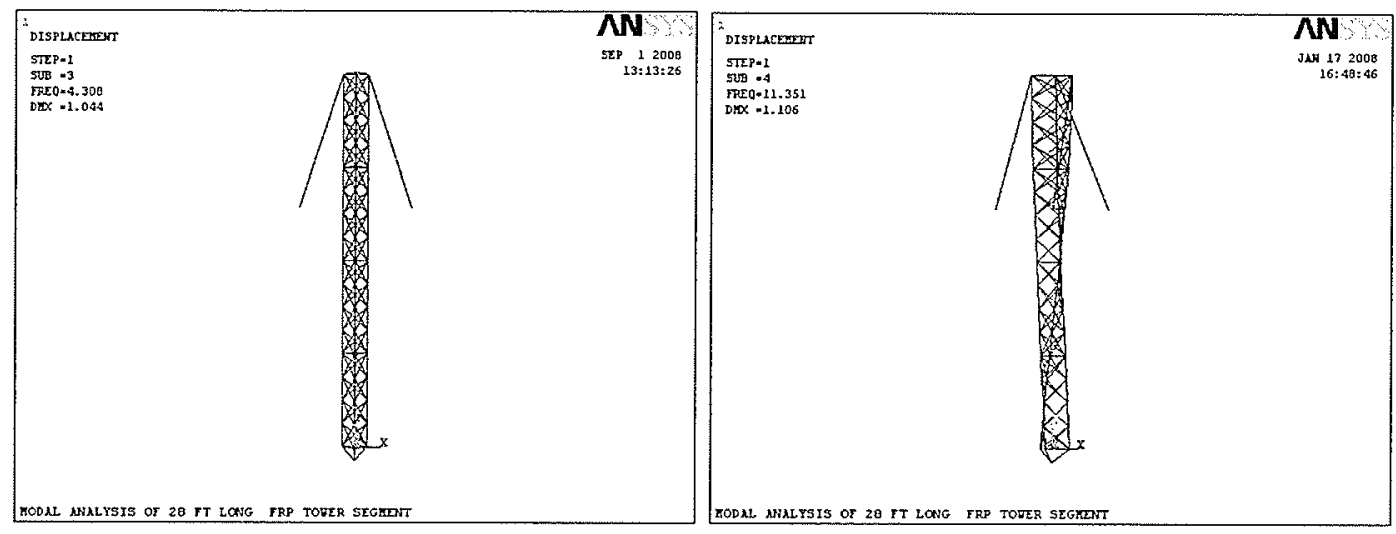

Fig. 3.47 Modal analysis of $8.53 \mathrm{~m}(28 \mathrm{ft})$ tower segment, mode shape -3 and 4 at $4.308 \mathrm{~Hz}$ and $11.351 \mathrm{~Hz}$ 


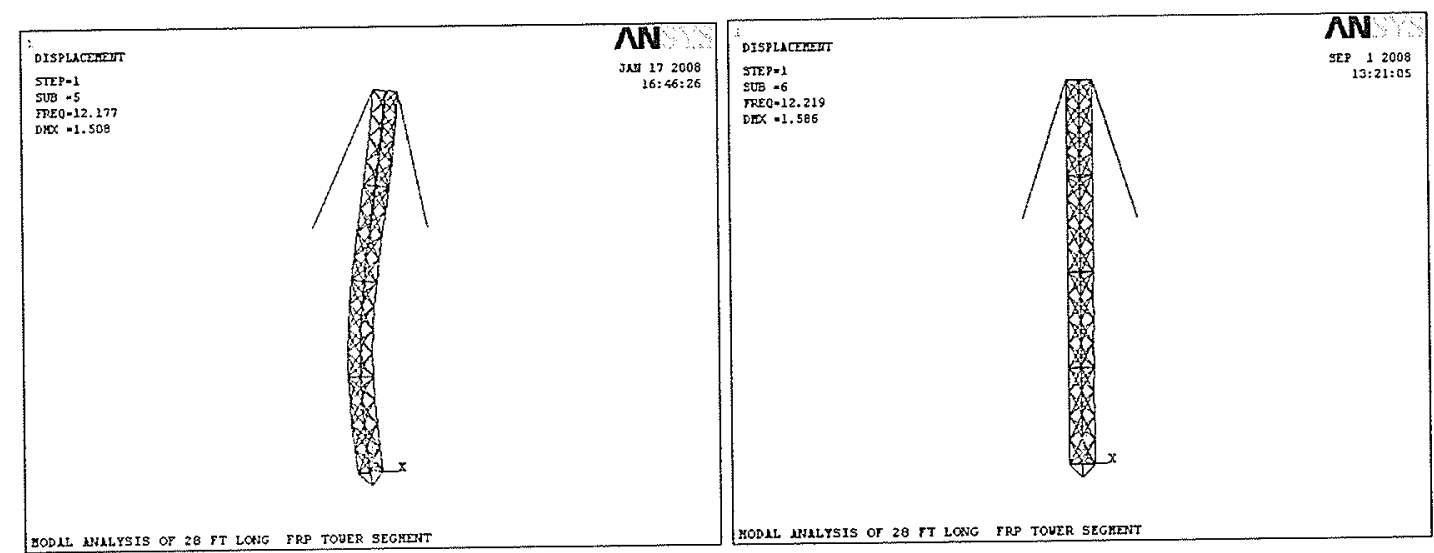

Fig. 3.48 Modal analysis of $8.53 \mathrm{~m}(28 \mathrm{ft})$ tower segment, mode shape -5 and 6 at $12.177 \mathrm{~Hz}$ and $12.219 \mathrm{~Hz}$

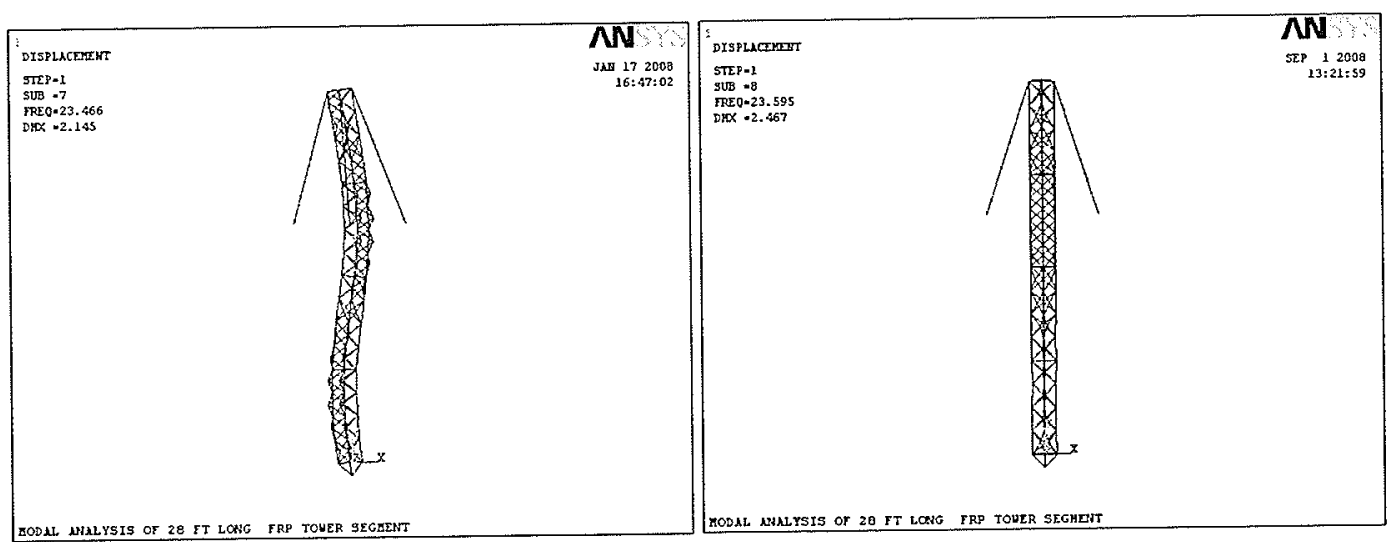

Fig. 3.49 Modal analysis of $8.53 \mathrm{~m}(28 \mathrm{ft})$ tower segment, mode shape -7 and 8 at $23.446 \mathrm{~Hz}$ and $23.595 \mathrm{~Hz}$

\subsubsection{Harmonic Analysis}

A harmonic analysis is a technique used to determine the response of the structure under a steady-state sinusoidal (harmonic) loading at a given frequency. The entire structure is assumed to have constant stiffness, damping, and mass properties. The equation of motion (ANSYS, 2004) in this case is as follows:

$[M]\{\ddot{u}\}+[C]\{\dot{u}\}+[K]\{u\}=\left\{F_{A}\right\}$ 
Where $[M],[C]$, and $[K]$ were defined earlier and $F_{A}$ is an applied force vector. In a harmonic analysis, the loading and response of the structure are assumed to be harmonic (cyclic) and can be expressed in terms of complex numbers as:

$$
\begin{aligned}
& \{F\}=\left\{F_{0} e^{j \psi}\right\} e^{j \Omega t} \\
& \{u\}=\left\{u_{0} e^{j \phi}\right\} e^{j \Omega t}
\end{aligned}
$$

where:

$\Omega=$ the excitation frequency of loading

$\psi=$ force phase shift

$\phi=$ displacement phase shift

$j=$ square root of -1

$u_{0}=$ maximum displacement

$F_{0}=$ maximum force

Equation 3.43 can be expressed as

$\{u\}=\left\{u_{0}(\cos \phi+j \sin \phi\} e^{j \Omega t}\right.$

or, simply as

$\{u\}=\left\{\left\{u_{1}\right\}+j\left\{u_{2}\right\}\right\} e^{j \Omega t}$

where:

$\left\{u_{1}\right\},\left\{u_{2}\right\}=$ real and imaginary displacements vectors, respectively

Similarly, the force can be expressed as:

$$
\{F\}=\left\{\left\{F_{1}\right\}+j\left\{F_{2}\right\}\right\} e^{j \Omega t}
$$


where:

$\left\{F_{1}\right\},\left\{F_{2}\right\}=$ real and imaginary force vectors, respectively

Substituting Eq. 3.45 and 3.46 into Eq. 3.41 yields the following characteristic equation:

$$
\left([K]-\Omega^{2}[M]+j \Omega[C]\right)\left(\left\{u_{1}\right\}+j\left\{u_{2}\right\}\right)=\left\{F_{1}\right\}+j\left\{F_{1}\right\}
$$

Equation 3.47 (ANSYS, 2004) can be solved using the Full Solution Method in which the matrix equation is solved directly in nodal coordinates, analogous to a linear static analysis except that complex numbers are used. Thus, using

$$
\begin{aligned}
& {\left[K_{C}\right]=\left(-\Omega^{2}[M]+j \Omega[C]+[K]\right)} \\
& \left\{u_{C}\right\}=\left\{u_{1}+j u_{2}\right\} \\
& \left\{F_{C}\right\}=\left\{F_{1}+j F_{2}\right\}
\end{aligned}
$$

Eq. 3.48 is simplified to the following form:

$$
\left[K_{C}\right]\left\{x_{C}\right\}=\left\{F_{C}\right\}
$$

where, index $C$ denotes complex matrix or vector.

\subsubsection{Harmonic Analysis of Tower Segment by ANSYS}

The model for the harmonic analysis is similar to those used for static and modal analysis. In the solution phase, boundary conditions had to be imposed along with an assumed force equal to $4.45 \mathrm{kN}(1000 \mathrm{lbs})$, applied at mid height of the tower segment. Full harmonic analysis was used with stepped loading up to 100 
load intervals. The frequency range was set from 0 to $100 \mathrm{~Hz}$. In time history, post processing monitoring of the displacements was set in the $z$ direction. The final result of the harmonic analysis, showing the amplitude in logarithmic scale versus the frequency domain, is given in Fig. 3.50.

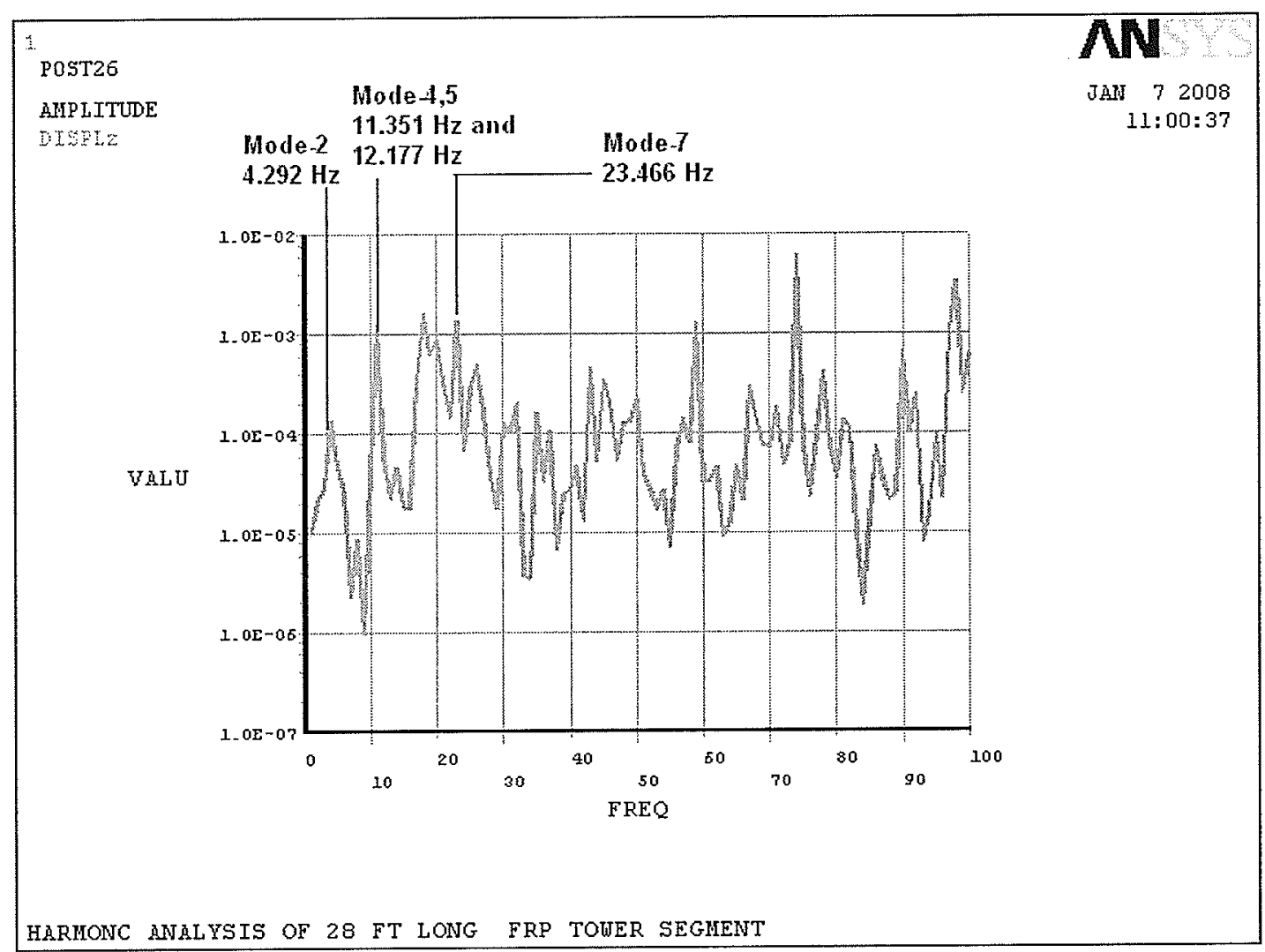

Fig. 3.50 Harmonic analysis of tower segment

By analysing the results shown in Fig. 3.50, a conclusion can be drawn that the amplitude peak at frequency of $4 \mathrm{~Hz}$ corresponds well to the first natural frequency calculated from the empirical formula based on test data discussed in Chapter-5. It also matches well with the second mode of shape and natural frequency predicted by the modal analysis. The other peaks in amplitudes, at 11 
$\mathrm{Hz}, 12 \mathrm{~Hz}$ and $23 \mathrm{~Hz}$, point out the tower segment resonances at those frequencies. These frequencies, therefore, should be avoided or passed quickly to avoid resonance.

\subsubsection{Dynamic FEA of $45 \mathrm{~m}$ (147 ft) FRP Tower}

In order to gain insight into vibration characteristic of the full $45 \mathrm{~m}$ (147 ft) FRP tower, a modal analysis was undertaken. As an input for modal analysis the FE model of the full scale tower with zero displacements imposed on keypoints, representing tower boundary conditions, was implemented. As analysis option "Subspace method" with 25 modes extraction was selected.

\subsubsection{Modal FEA of $45 \mathrm{~m}(147 \mathrm{ft})$ FRP Tower}

Modal analysis using ANSYS was conducted to account for mode shapes and associated frequencies of the full scale tower. The only constraints imposed on the tower were zero displacements on boundary conditions. Also, the dynamic properties of the cables were excluded since they were being treated as straight lines with axial stiffness and density only. Because the mode shapes were closely spaced, only the characteristic orthogonal shape modes were considered. The results from this analysis are shown in Fig. 3.51 to Fig. 3.59 and include tower vibrations according to a particular mode shape at a specific to this mode natural frequency. 
The results show that the natural frequency of the full scale tower is lower than the natural frequency of the short tower segment. This can be attributed to increased self weight of the tower and the increased weight of guy cables in the full scale tower.

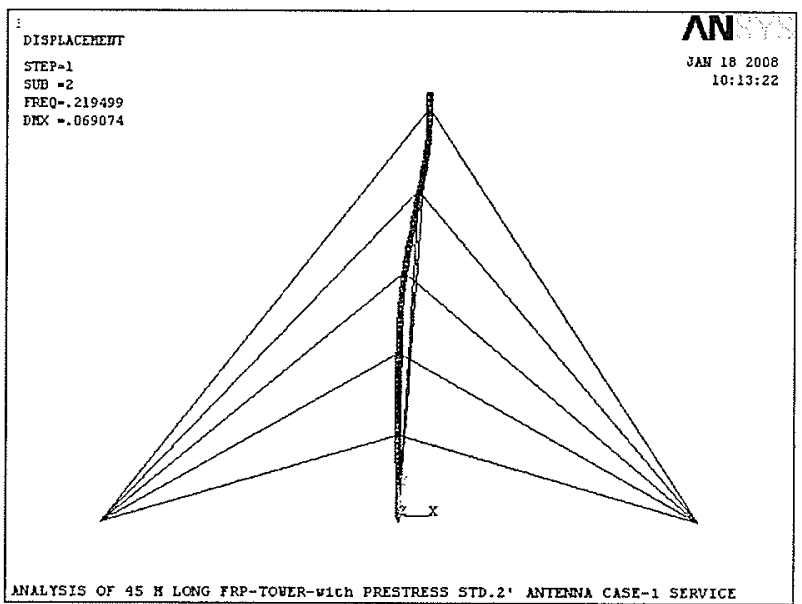

Fig. 3.51 Mode shape -2 at $0.219 \mathrm{~Hz}$

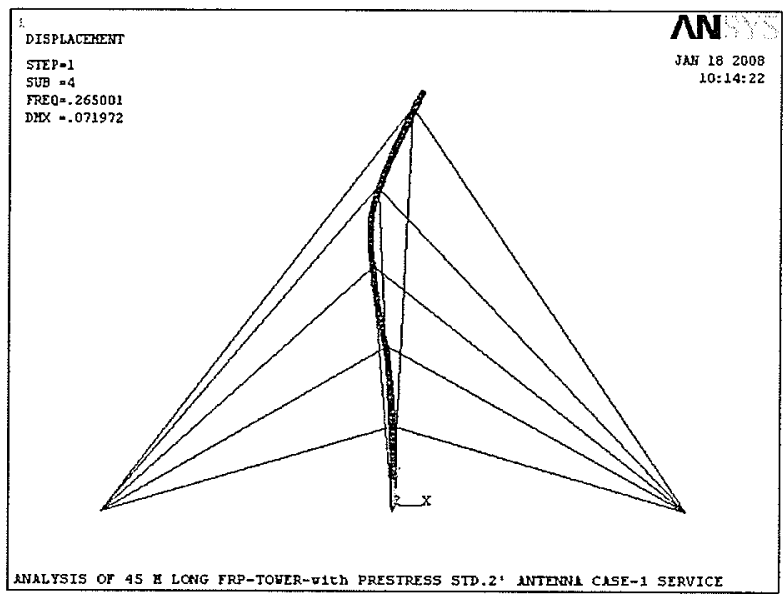

Fig. 3.52 Mode shape -4 at $0.265 \mathrm{~Hz}$ 


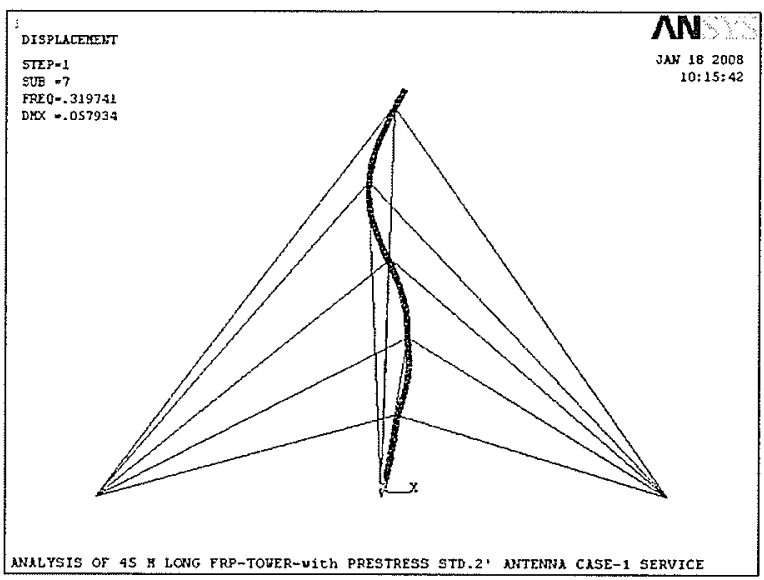

Fig. 3.53 Mode shape -7 at $0.319 \mathrm{~Hz}$

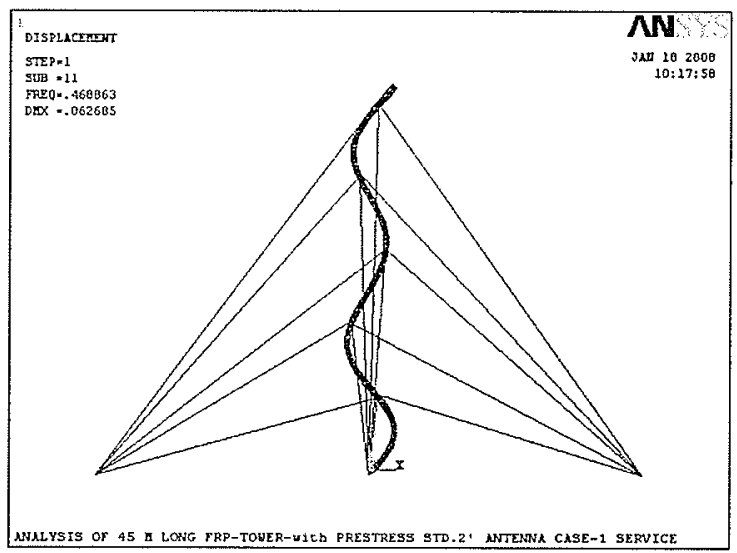

Fig. 3.54 Mode shape -11 at $0.468 \mathrm{~Hz}$

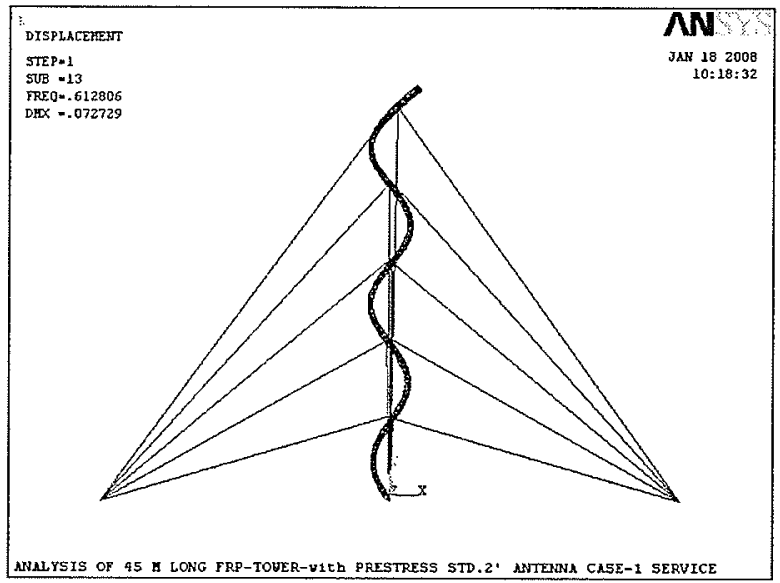

Fig. 3.55 Mode shape -13 at $0.6128 \mathrm{~Hz}$ 


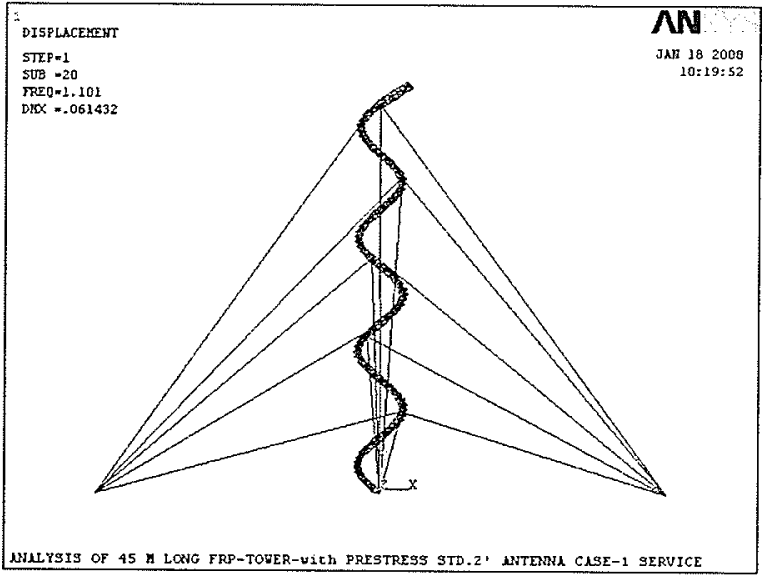

Fig. 3.56 Mode shape -20 at $1.101 \mathrm{~Hz}$

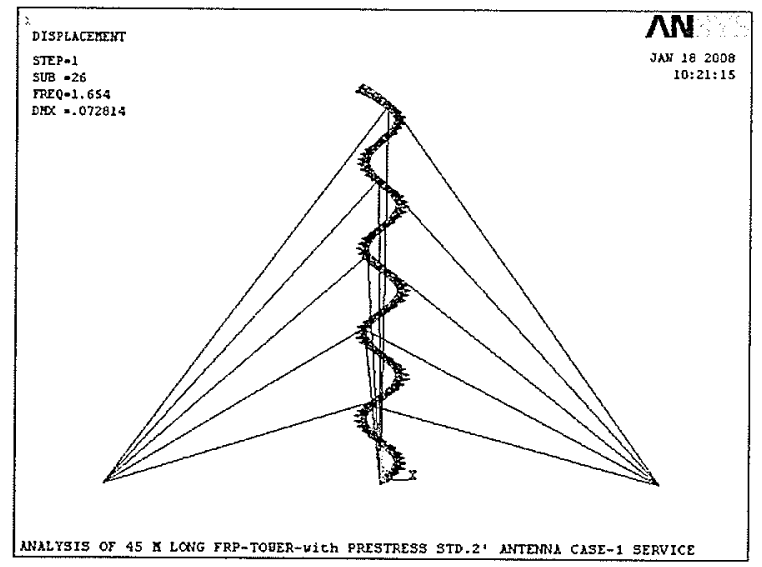

Fig. 3.57 Mode shape -26 at $1.654 \mathrm{~Hz}$

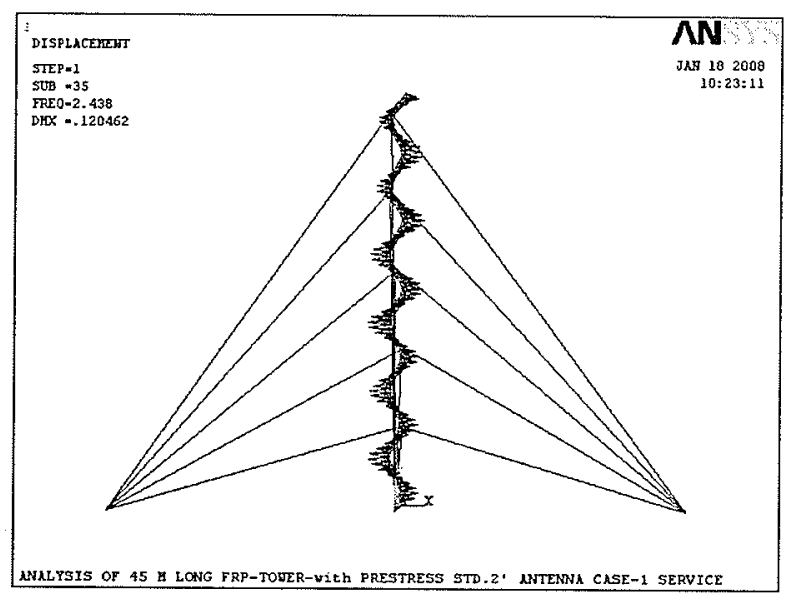

Fig. 3.58 Mode shape -35 at $2.438 \mathrm{~Hz}$ 


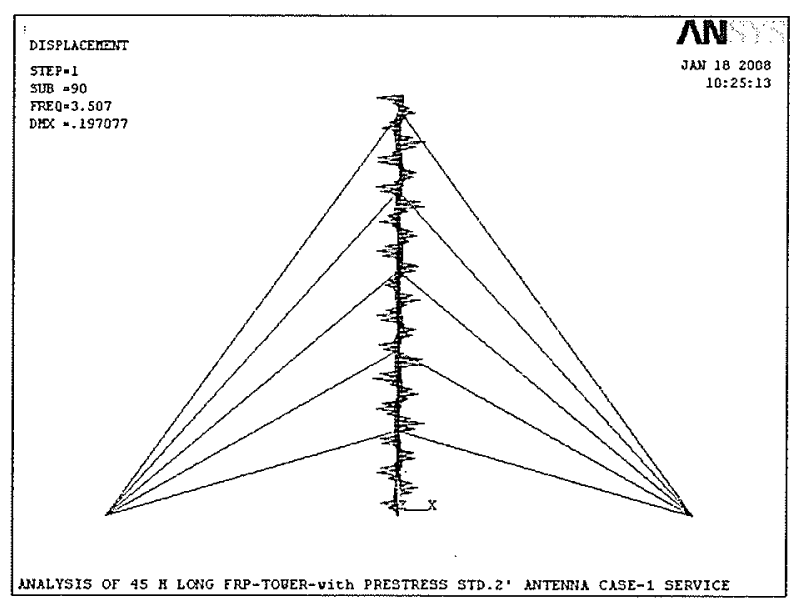

Fig. 3.59 Mode shape -90 at $3.507 \mathrm{~Hz}$

\subsubsection{Numerical Model for Dynamic Analysis of $8.53 \mathrm{~m} \mathrm{(28 \textrm {ft } )}$ FRP Tower Segment.}

Due to the fact that ANSYS 8.1 does not have the capability to perform full dynamic analysis of a tower under fluctuating wind loadings, the dynamic response of the $8.53 \mathrm{~m}$ (28 ft) FRP tower segment was investigated using a pseudo-dynamic analytical model, as described in CSA S37-01 Standard. The so called "Gust factor method" is based on the assumption that the tower vibrates linearly about its static equilibrium position under the design wind pressure $\mathrm{P}$ derived from Clause 4.8.1 of the CSA S37-01 Standard with a uniform gust factor $C_{g}=2.0$ along the tower height. This modified static wind pressure is intended to produce the same peak response as that caused by a turbulent and fluctuating wind pressure. The deflections under the service wind loading equivalent to a single force $\mathrm{P}=2.62 \mathrm{kN}(589.92 \mathrm{lbs})$ applied at mid height of the tower segment 
are shown in Fig. 3.60. Since this force includes the gust factor $C_{g}=2.0$, the dynamic effect due to fluctuating wind was taken into account. Therefore, it can be assumed that the deflected shape of the tower segment represents the equivalent peak response to dynamic effects.

Davenport and Sparling (1992) proposed a simplified dynamic analysis, called "Patch Load Method", which takes into account the dynamic response characteristics of guyed towers together with special correlation of wind gust in turbulent wind along the tower height.

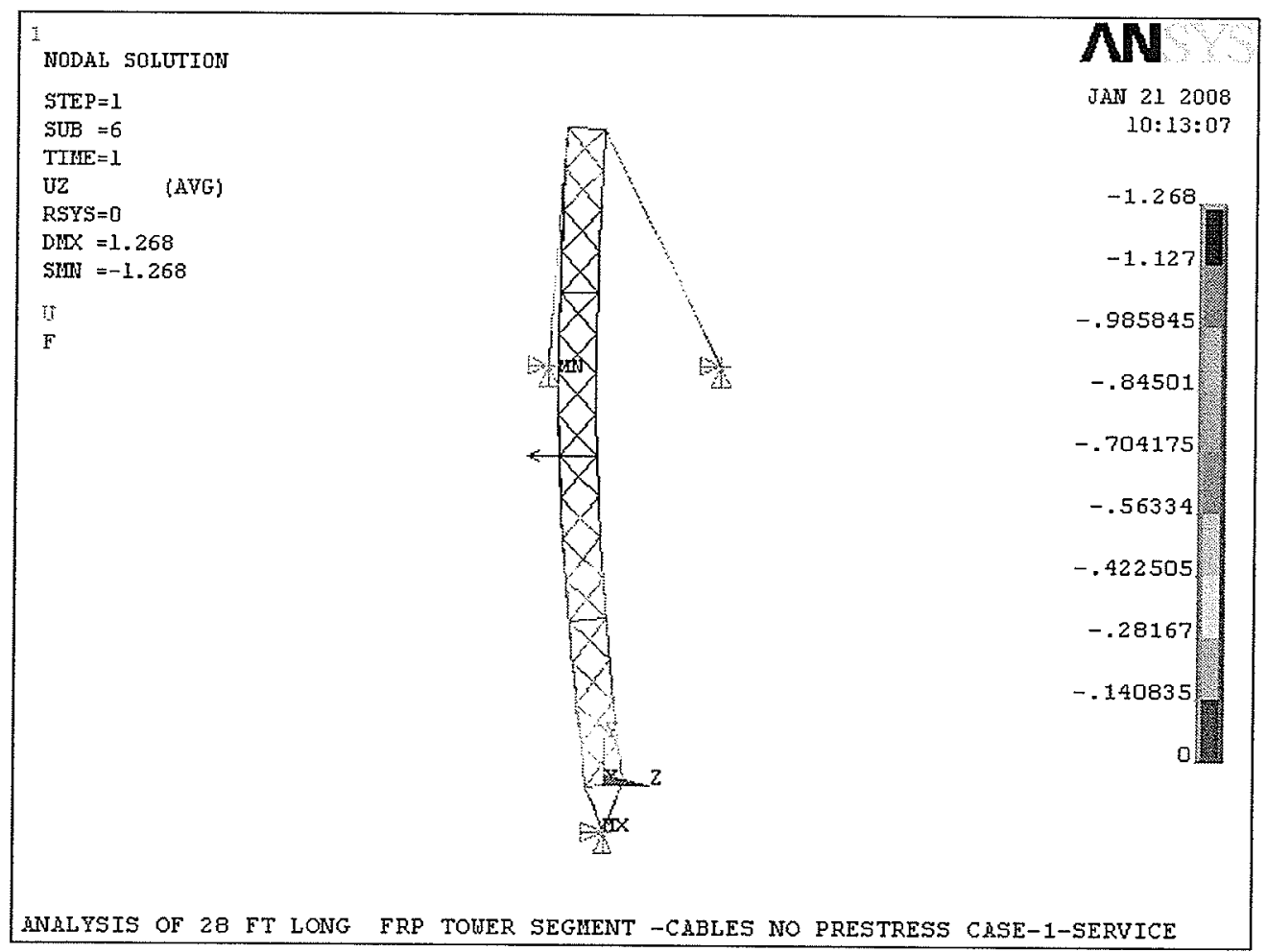

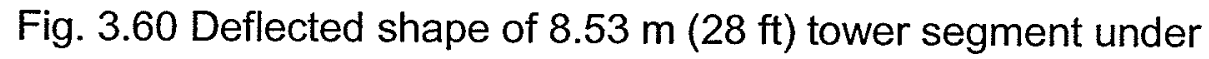
service loading (units are in inches)

This method involves the use of a series of static load patterns to model the effect of turbulent winds. Because the only loads being involved are static, the 
"Patch Load Method" can be programmed using conventional ANSYS 8.1 software. The Patch Load Method, outlined in the CSA-37-01 Standard was used, and described, in Section 3.6.8 to analyse the full scale $45 \mathrm{~m}(147 \mathrm{ft})$ FRP tower.

\subsubsection{Dynamic Analysis of $45 \mathrm{~m}$ (147 ft) FRP tower according to CSA-37-01 Standard}

In Section 3.6.7.2 the dynamic response of the tower segment was investigated using the gust factor method. This method used in the current Canadian Standard CSA-S37-01 relies purely on the static analysis of the tower incorporating the dynamic response to the wind through a uniform gust effect factor $C_{g}=2.0$ which is uniformly applied to the design wind pressure $\mathrm{P}$ to produce the same peak response as would be caused by dynamic loads from wind turbulence. A most accurate dynamic analysis would be to solve equations of motions in the form of $m \ddot{u}+c \dot{u}+k u=p(t)$. More refined methods however, are available to account for the dynamic response of guyed towers to wind turbulence. One such approach, called "analysis of dynamic response components", consists of performing a full dynamic analysis which takes into account the tower response to the dynamic wind characteristics and includes the effects of inertia forces coming from the Newton's second law (Sparling and Davenport, 1998). According to the analysis of dynamic response components, three major response components: mean, background and resonant, are evaluated. The mean response component is evaluated by applying mean wind 
loads on the guyed tower and performing non-linear static analysis. Mean bending moment components acting along the tower are than plotted. Background response component represents the quasi-static response of the tower to slowly varying, partially correlated wind loads, and is based on linear, static stiffness properties of the tower taken at mean equilibrium position. Background response components are calculated from root mean square values (rms) of fluctuating wind load and after that static nonlinear analyses are performed and the results of background bending moments are plotted. Finally, the most difficult resonant response components are calculated by using the full modal analysis. Between 15 to 30 tower vibration modes have to be accounted for and the root mean square resonant response for each mode is calculated separately and combined together to get the total root mean square response.

From this analysis the resonant bending moment components can be obtained.

Finally, the total dynamic response of the tower is determined as the algebraic sum of all response components. The dynamic analysis of the components is extremely time consuming, and, even with the latest high speed desktop computers it can take several hours to complete. Therefore, significant amount of research has been conducted to develop simplified methods of analysis which can produce similar results as a full dynamic analysis. The Patch Load method developed by Sparling (1995), as an extension of the work done by Gerstoft and Dovenport (1986), has been widely adopted by Eurocode 3, the UK Standard BS81000-4, as well as the Canadian CSA-S37-01 (CSA ,2001) Standard. The procedure is based on a series of static load patterns simulating the turbulent 
winds acting along the guyed tower. The analysis is performed in two distinctive steps. In first step, the major response component $\bar{r}$ is calculated by applying mean wind loads on the guyed tower and running the non-liner FEA analysis.

The second step involves calculating the peak fluctuating response $\tilde{r}_{P L}$ using the patch load method. This method involves a series of static analyses of the tower under the static load pattern prescribed in clause $\mathrm{H} 3$.1.2.1-Appendix $\mathrm{H}$ of the CSA-S37-01 Standard.

The design peak response $\hat{r}$ at any location along the tower can be expressed, using detailed scaling, as:

$\hat{r}=\bar{r} \pm \tilde{r}_{P L} \times \lambda_{B} \times \lambda_{R} \times \lambda_{T L} \times g$

where,

$\bar{r}=\quad$ mean response component calculated according to the CSA-S37-01 Standard;

$\tilde{r}_{P L}=\quad$ resultant patch load response calculated according to CSA-S37-

01 Standard;

$\lambda_{B}, \lambda_{R}, \lambda_{T L}=$ scaling factors for background, resonant and turbulent length, respectively described in the CSA-S37-01 Standard;

$g=\quad$ a peak factor taken as 4.0.

The design response can be, conservatively, determined using simple scaling as follows: 
For the main tower below the top guys:

$\hat{r}=\bar{r} \pm 3.8 \times \tilde{r} P L$

For the cantilever above the top guys:

$\hat{r}=\bar{r} \pm 5.5 \times \tilde{r}_{P L}$

The results of the dynamic analysis using the Patch Load Method are in the format of peak response envelopes of the mast deflections, internal forces and stresses which are used to design particular tower components. The application of this method is demonstrated in the following section.

\subsubsection{Analysis of Dynamic Response of $45 \mathrm{~m}$ (147 ft) FRP Tower Using the Patch Load Method}

As described earlier, the Patch Load Method of analysis is conducted in two distinctive steps. First, the static tower response to mean wind loading is determined. Second, the static tower response to several patch load cases is examined. The mean wind load can be calculated in accordance with Clause 4.8 of CSA-S37-01, where the design wind pressure $P$ is replaced by the mean wind pressure $\bar{P}=q \times C_{e}$, where $q$ is the reference wind velocity pressure. For Winnipeg, Manitoba $q=0.45 \mathrm{kPa}(0.06526 \mathrm{psi})$ and $C_{e}$ is the height factor, as defined in Eq.3.27.

Therefore, the wind load $\mathrm{W}$ is determined as, 


$$
\bar{W}=\bar{P} \times\left(C_{d f} \times A_{f}\right)
$$

where,

$C_{d f}=$ drag factor for flat members, as defined by Eq. 3.28 ; and,

$A_{f}=$ a face area of flat members, as defined in Section 3.5.

The typical mean wind loading per node under the mean wind is shown in Table 3.7. The typical tower response to mean wind loading was obtained through the non- linear static FEA. The minimum combined stresses due to wind on the windward side chords are shown in Fig. 3.61. These were selected as the most critical stresses for evaluating the tower's performance. 
Table 3.7 Typical mean wind loading per node

\begin{tabular}{|c|c|c|}
\hline $\begin{array}{l}\text { Distance above the } \\
\text { ground }(\mathrm{mm}))\end{array}$ & $\begin{array}{l}\text { P per } \\
\text { panel } \\
(\mathrm{N})\end{array}$ & $\begin{array}{l}P \text { per } \\
\text { node } \\
(\mathrm{N})\end{array}$ \\
\hline $42672-44806$ & 511.68 & 63.97 \\
\hline $40538-42672$ & 506.74 & 63.34 \\
\hline $38405-40538$ & 501.54 & 62.68 \\
\hline $36271-38405$ & 496.15 & 62.01 \\
\hline $34138-36271$ & 490.51 & 61.30 \\
\hline $32004-34138$ & 484.59 & 60.58 \\
\hline $29870-32004$ & 478.41 & 59.78 \\
\hline $27737-29870$ & 471.82 & 58.98 \\
\hline $25603-27737$ & 464.88 & 58.09 \\
\hline $23470-25603$ & 457.50 & 57.20 \\
\hline $21336-23470$ & 449.63 & 56.18 \\
\hline $19202-21336$ & 441.13 & 55.16 \\
\hline $17069-19202$ & 431.92 & 54.00 \\
\hline $14935-17069$ & 421.87 & 52.76 \\
\hline $12802-14935$ & 410.75 & 51.33 \\
\hline $10668-12802$ & 398.29 & 49.78 \\
\hline $8534-10668$ & 384.02 & 48.00 \\
\hline $6401-8534$ & 367.25 & 45.91 \\
\hline $4267-6401$ & 346.74 & 43.33 \\
\hline $2134-4267$ & 319.74 & 39.95 \\
\hline $0-2134$ & 278.33 & 34.79 \\
\hline
\end{tabular}




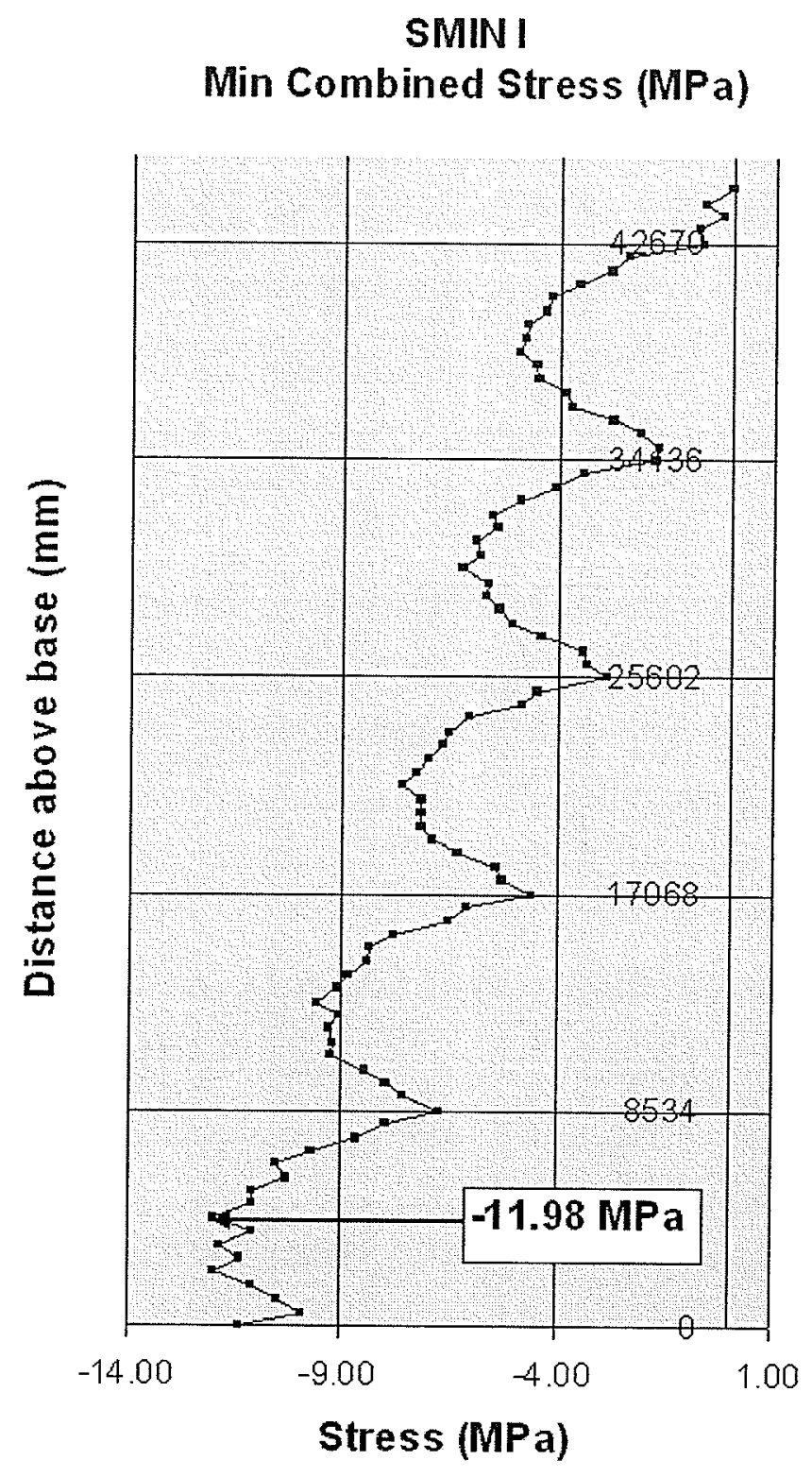

Fig. 3.61 SMIN I, Combined windward chord stress under men wind (MPa)

The next step in the Patch Load Analysis Method is outlined in Clause H3.1.2.1 of the CSA-S37-01 Standard. Required patch wind loading cases are assembled and applied to the tower as shown in Fig. 3.62. Load Cases 1 to 6 correspond to patch wind loading applied between supported lengths of tower, while Cases 7 to 
12 correspond to patch wind loading applied between the middle spans of the supported lengths.

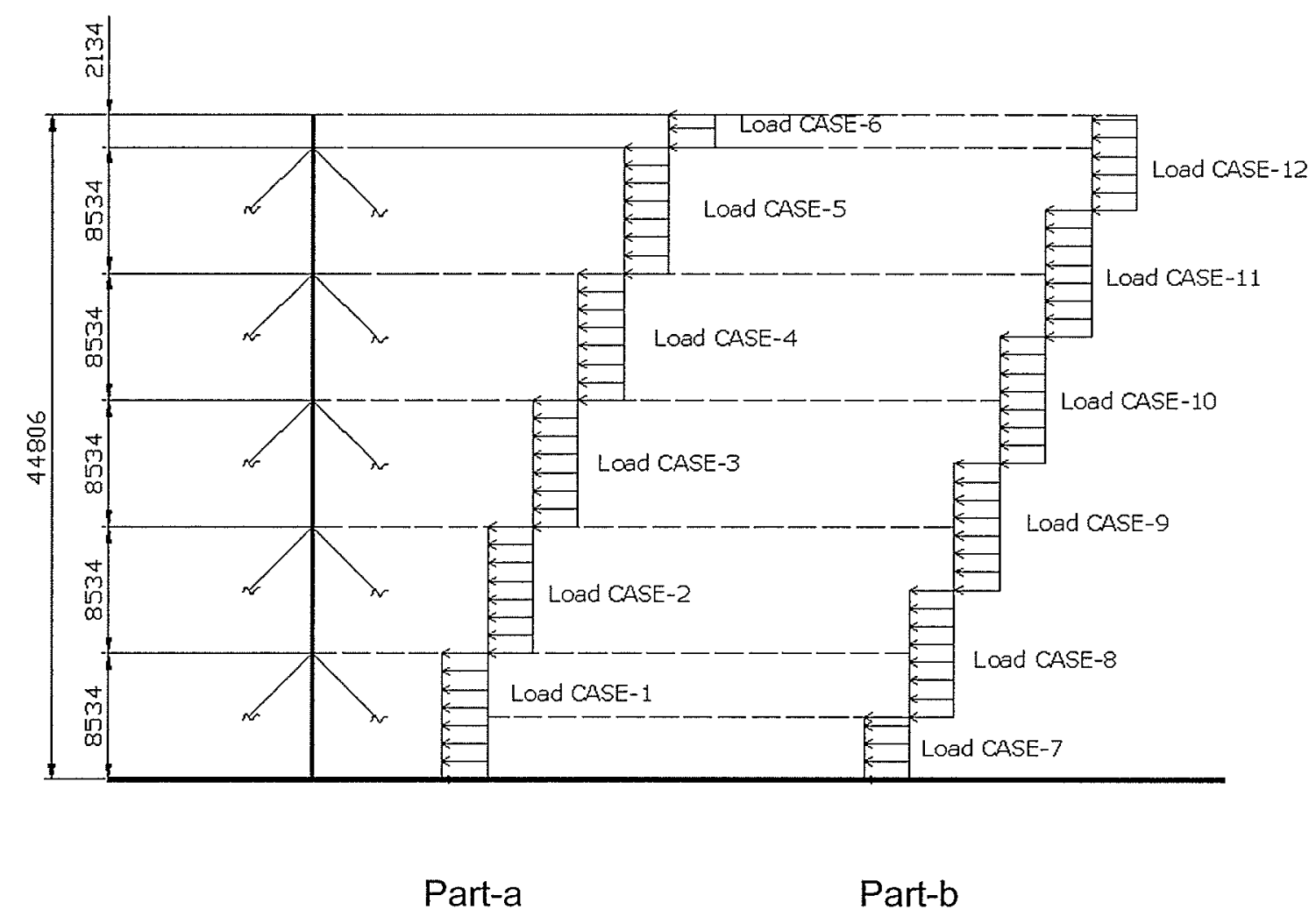

Fig. 3.62 Required patch wind loading cases

The patch load wind pressure, $P_{P L}$, can be computed from the Clause H3.1.2.2 of the CSA S37-01 Standard from the following equation:

$P_{P L}=2 \times q \times i \times \sqrt{C_{e}}$

where,

$q=$ the reference wind velocity pressure. For Winnipeg $q=0.45 \mathrm{kPa}$

$i=$ intensity of turbulence (varies between $0.18-0.27$ )

$C_{e}=$ height factor as provided by Clause 4.5 of the CSA-S37-01 Standard and 
calculated at midheight of the load patch in question.

Ther patch loads were calculated for the tower and are included in Tables 3.8 and 3.9.

Table 3.8 Patch Wind Load Cases Part- a

\begin{tabular}{|c|c|c|c|c|c|c|}
\hline \multicolumn{7}{|c|}{ Patch Wind Loads } \\
\hline \multirow[b]{2}{*}{$\begin{array}{l}\text { Patch } \\
\text { Load } \\
\text { Case }^{*}\end{array}$} & \multicolumn{2}{|c|}{$\begin{array}{c}\text { Distance above the } \\
\text { base }(\mathrm{mm})\end{array}$} & \multirow{2}{*}{$\begin{array}{l}\text { Mid-height of } \\
\text { patch load } \\
\text { Elevation } \\
(\mathrm{mm})\end{array}$} & \multirow{2}{*}{ 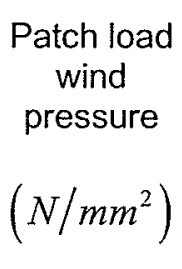 } & \multirow{2}{*}{$\begin{array}{l}\text { Load } \\
\text { per panel } \\
(\mathrm{N})\end{array}$} & \multirow{2}{*}{$\begin{array}{l}\text { Load } \\
\text { per node } \\
(\mathrm{N})\end{array}$} \\
\hline & $\begin{array}{c}\text { Bottom } \\
\text { end } \\
(\mathrm{mm})\end{array}$ & $\begin{array}{c}\text { Top } \\
\text { end } \\
(\mathrm{mm})\end{array}$ & & & & \\
\hline Case-1 & 0 & 8534 & 4267 & 223.16 & 751.65 & 23.49 \\
\hline Case-2 & 8534 & 17068 & 12802 & 249.08 & 838.93 & 26.22 \\
\hline Case-3 & 17068 & 25602 & 21336 & 262.13 & 882.90 & 27.59 \\
\hline Case-4 & 25602 & 34136 & 29870 & 271.10 & 913.12 & 28.53 \\
\hline Case-5 & 34136 & 42672 & 38404 & 278.00 & 936.35 & 29.26 \\
\hline Case-6 & 42672 & 44806 & 43738 & 281.64 & 237.15 & 29.64 \\
\hline
\end{tabular}

${ }^{*}$ Refer to Fig. 3.62 
Using the patch wind loads listed in Tables 3.8 and 3.9 twelve independent static non-linear analyses were carried out to determine the maximum absolute values of the combined windward chord stresses under the patch loading. Values of minimum stress is considered to be SMIN I, the most critical for tower design. These values, along with appropriate patch loads are shown in Figs. 3.63 to 3.75 .

Table 3.9 Patch Wind Load Cases Part-b

\begin{tabular}{|c|c|c|c|c|c|c|}
\hline \multicolumn{7}{|c|}{ Patch Wind Loads } \\
\hline \multirow[b]{2}{*}{$\begin{array}{l}\text { Patch } \\
\text { Load } \\
\text { Case }^{*}\end{array}$} & \multicolumn{2}{|c|}{$\begin{array}{c}\text { Distance above the } \\
\text { base }(\mathrm{mm})\end{array}$} & \multirow{2}{*}{$\begin{array}{l}\text { Mid-height of } \\
\text { patch load } \\
\text { Elevation } \\
(\mathrm{mm})\end{array}$} & \multirow{2}{*}{ 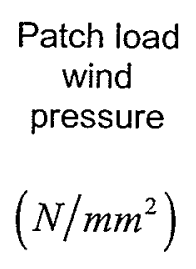 } & \multirow{2}{*}{$\begin{array}{l}\text { Load } \\
\text { per panel } \\
(\mathrm{N})\end{array}$} & \multirow{2}{*}{$\begin{array}{c}\text { Load } \\
\text { per node } \\
(\mathrm{N})\end{array}$} \\
\hline & $\begin{array}{l}\text { Bottom } \\
\text { end } \\
(\mathrm{mm})\end{array}$ & $\begin{array}{l}\text { Top } \\
\text { end } \\
(\mathrm{mm})\end{array}$ & & & & \\
\hline Case-7 & 0 & 4267 & 2134 & 208.22 & 349.15 & 21.82 \\
\hline Case-8 & 4267 & 12802 & 8534 & 239.18 & 805.60 & 25.17 \\
\hline Case-9 & 12802 & 21336 & 17069 & 256.35 & 863.42 & 26.98 \\
\hline Case-10 & 21336 & 29870 & 25603 & 266.95 & 899.15 & 28.10 \\
\hline Case-11 & 29870 & 38405 & 34138 & 274.74 & 925.39 & 28.92 \\
\hline Case-12 & 38405 & 44806 & 41605 & 280.23 & 709.62 & 22.18 \\
\hline
\end{tabular}

${ }^{*}$ Refer to Fig. 3.62 
From each of the twelve patch load cases, values of combined windward chord stress SMINI (MPa) were extracted and plotted for comparison purposes in Figs.

3.76 and 3.77. The resultant patch load response $\tilde{r}_{P L}$ was than calculated using a square-root-sum-of-squares (SRSS) method from the following equation:

$$
\tilde{r} P L=\sqrt{\sum_{i=1}^{n} \tilde{r}^{2} P L_{i}}
$$

where:

$\tilde{r}_{P L_{i}}=$ value of the response in question for the $\mathrm{i}$-th patch load case, and, $\mathrm{n}=$ total number of patch load cases.

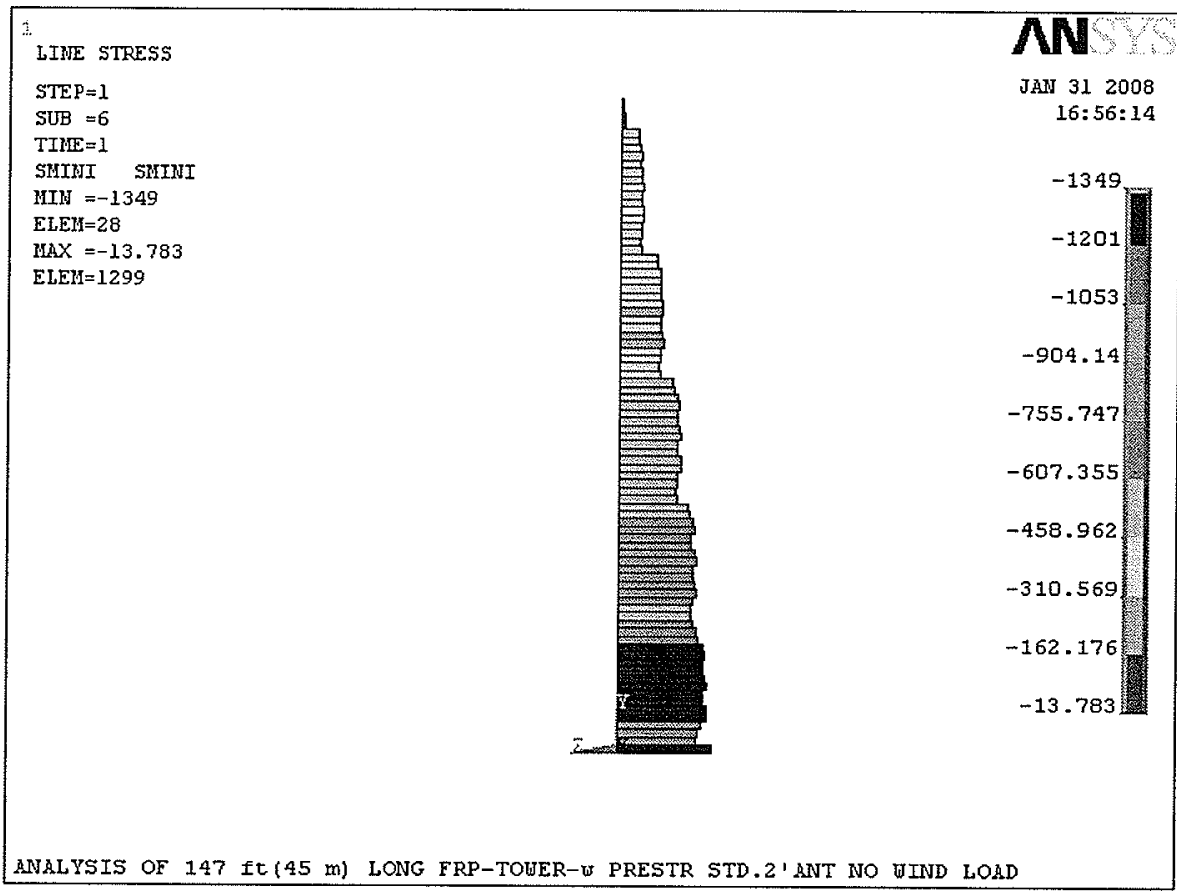

Fig. 3.63 SMIN I, Combined windward chord stress no wind loading (units are psi) 


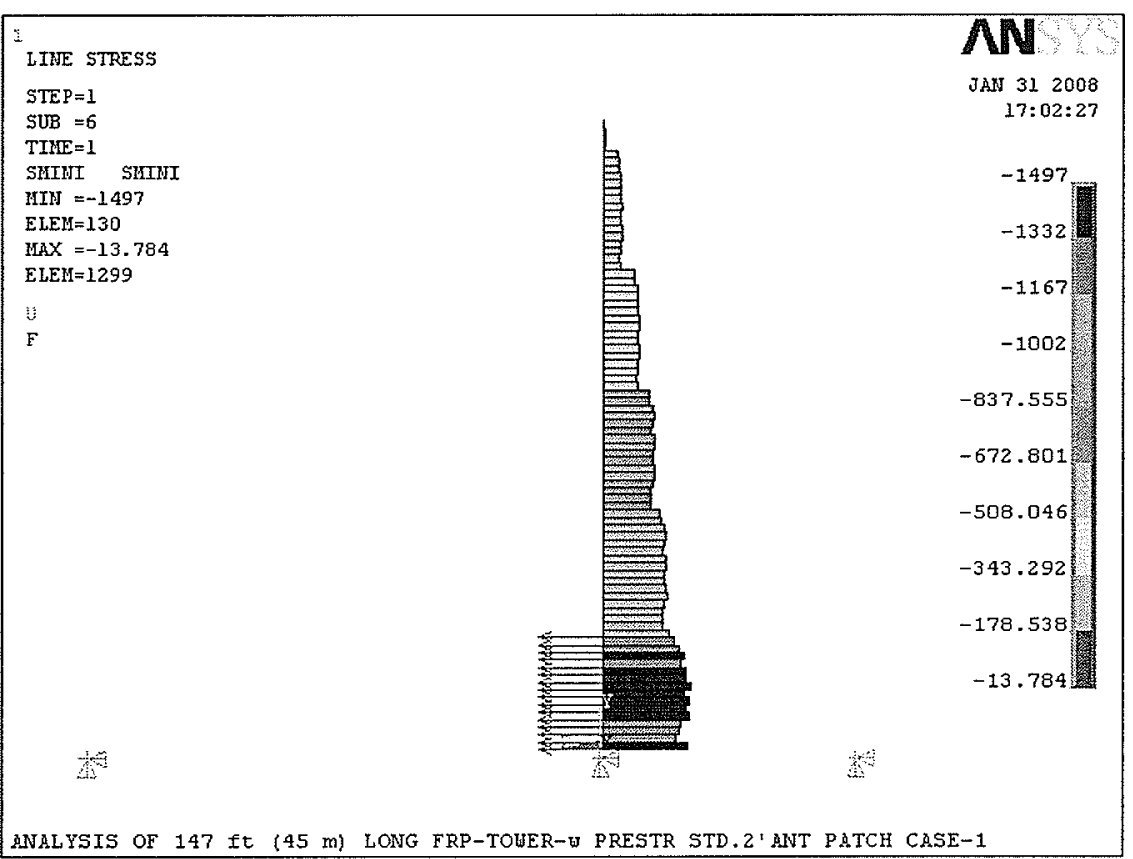

Fig. 3.64 SMIN I, Combined windward chord stress Patch Load Case-1 (units are in psi)

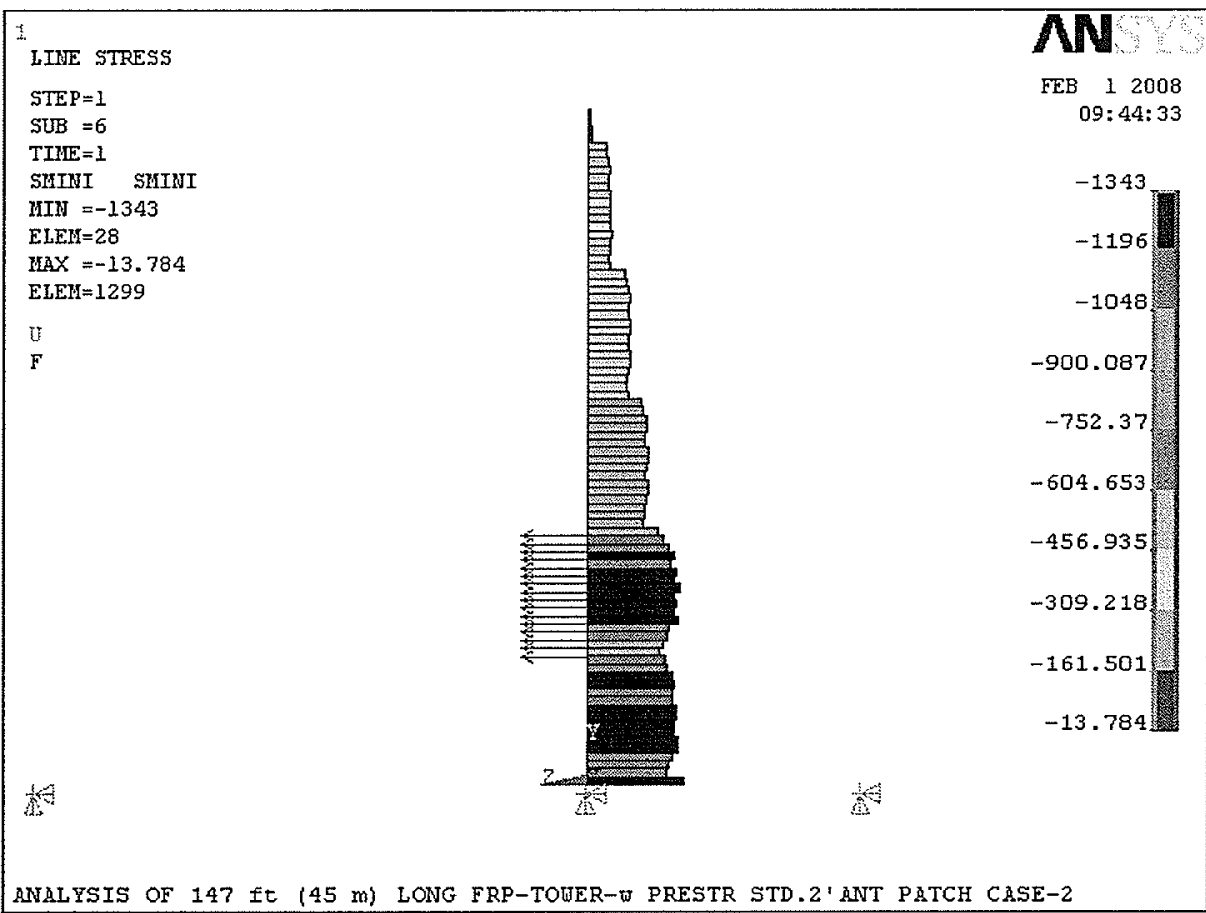

Fig. 3.65 SMIN I, Combined windward chord stress Patch Load Case-2 (units are in psi) 


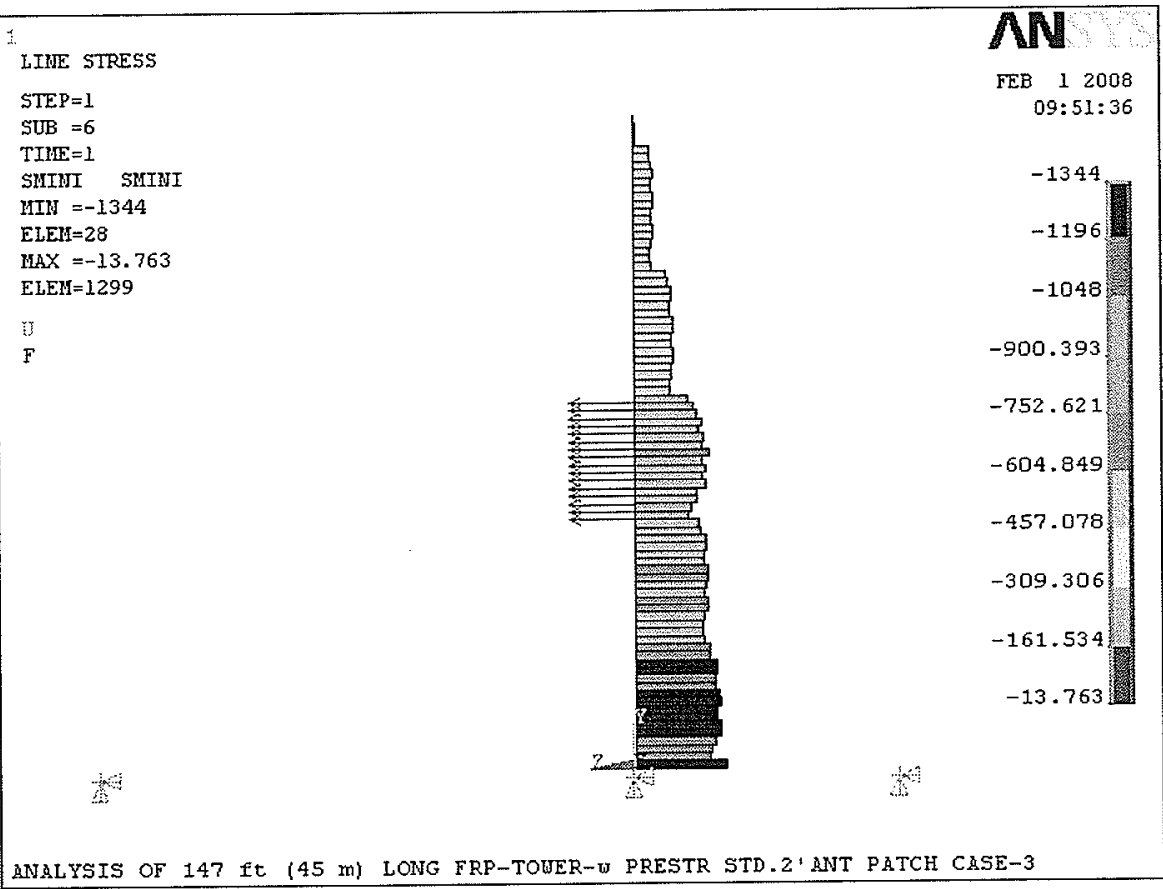

Fig. 3.66 SMIN I, Combined windward chord stress Patch Load CASE-3 (units are in psi)

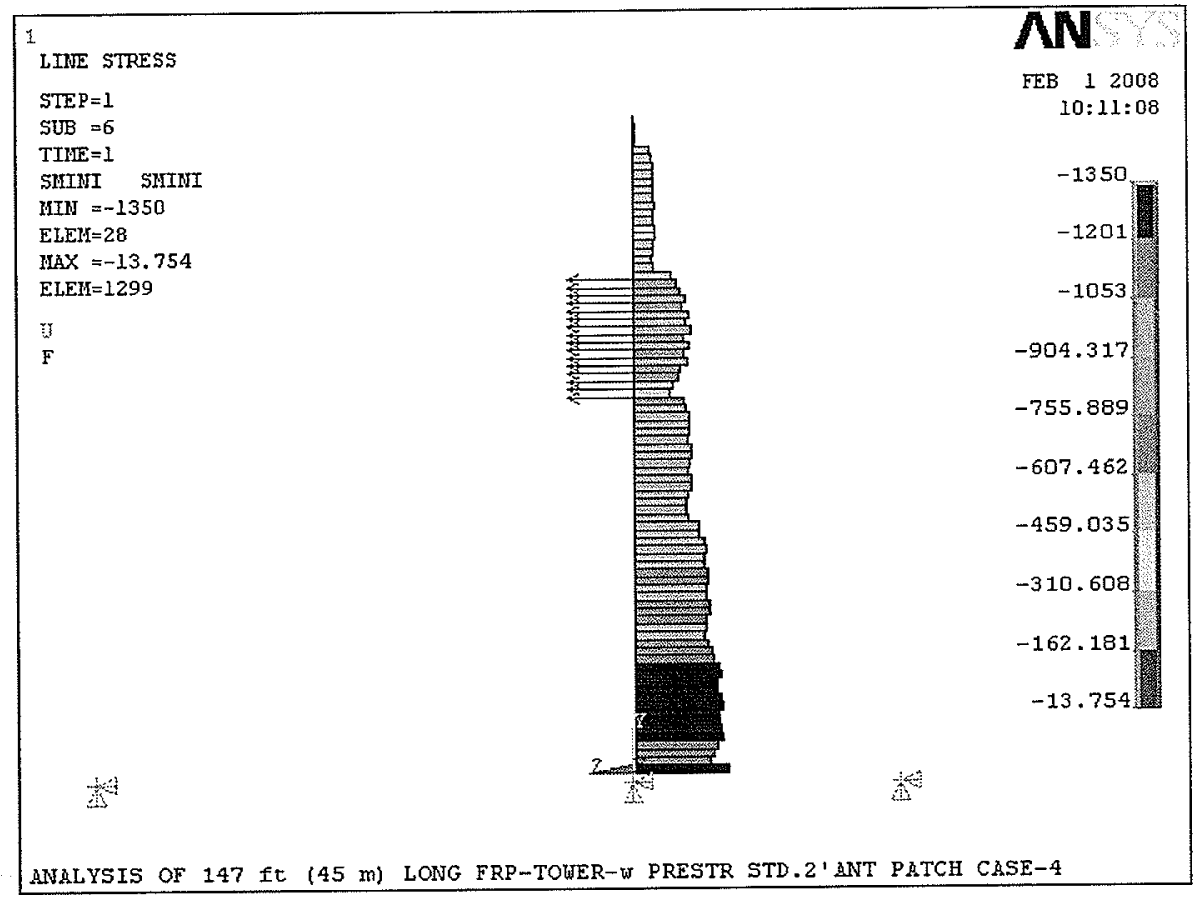

Fig. 3.67 SMIN I, Combined windward chord stress Patch Load Case 4 (units are in psi) 


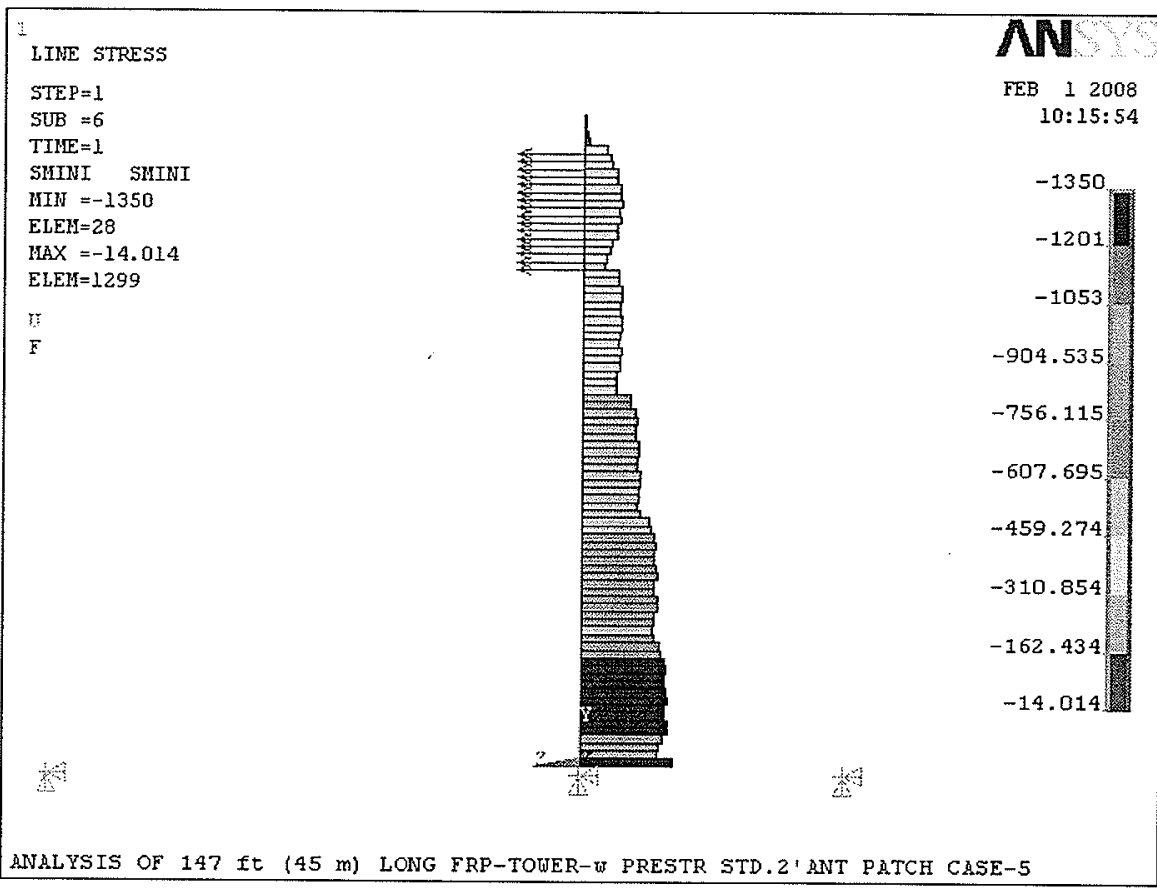

Fig. 3.68 SMIN I, Combined windward chord stress Patch Load Case-5 (units are in psi)

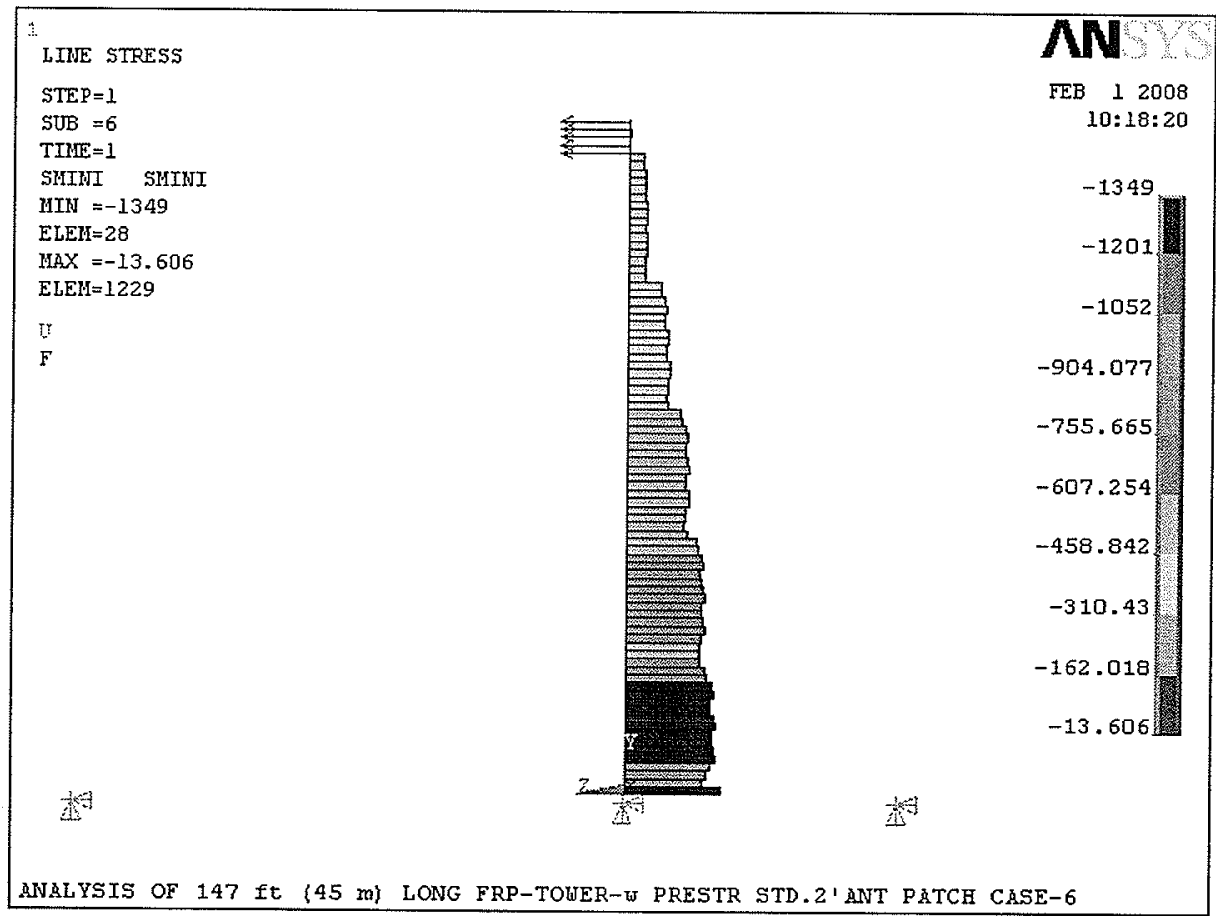

Fig. 3.69 SMIN I, Combined windward chord stress Patch Load Case-6 (units are in psi) 


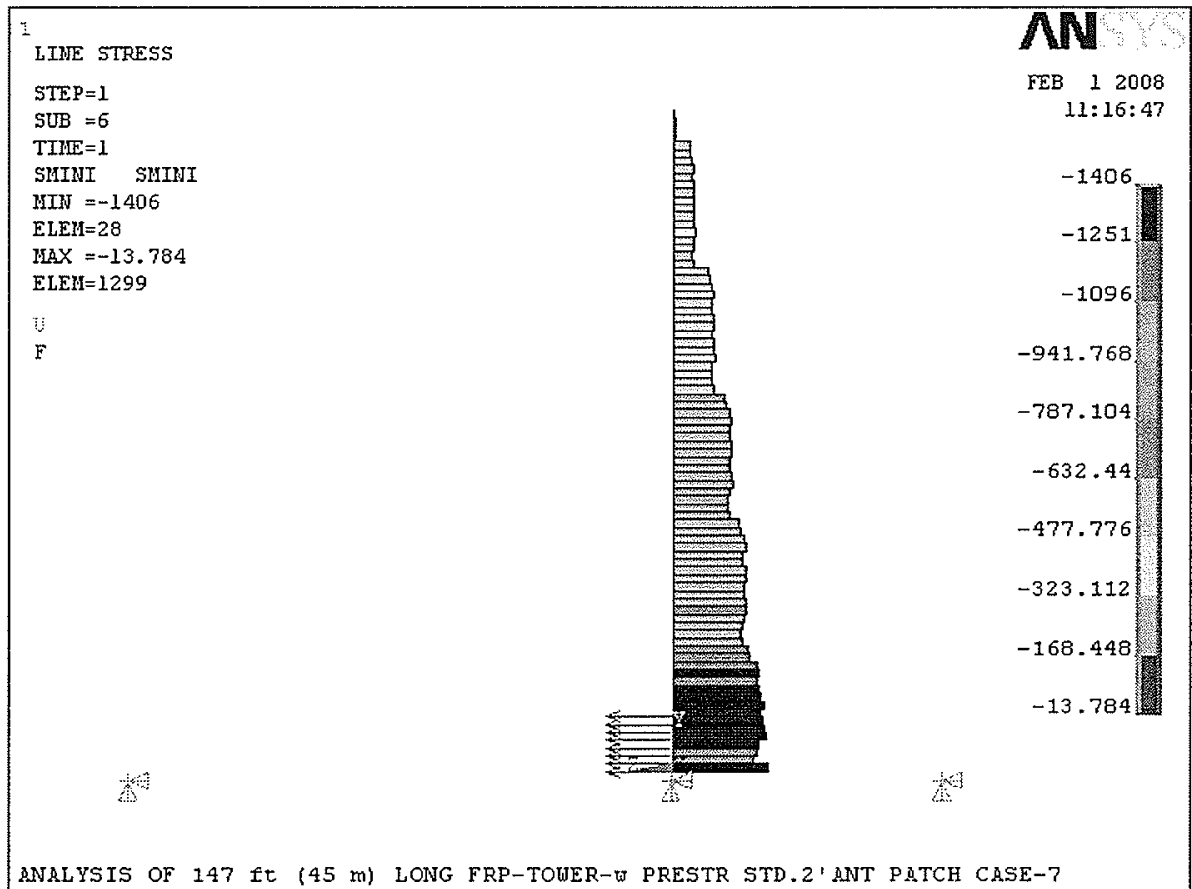

Fig. 3.70 SMIN I, Combined windward chord stress Patch Load Case-7 (units are in psi)

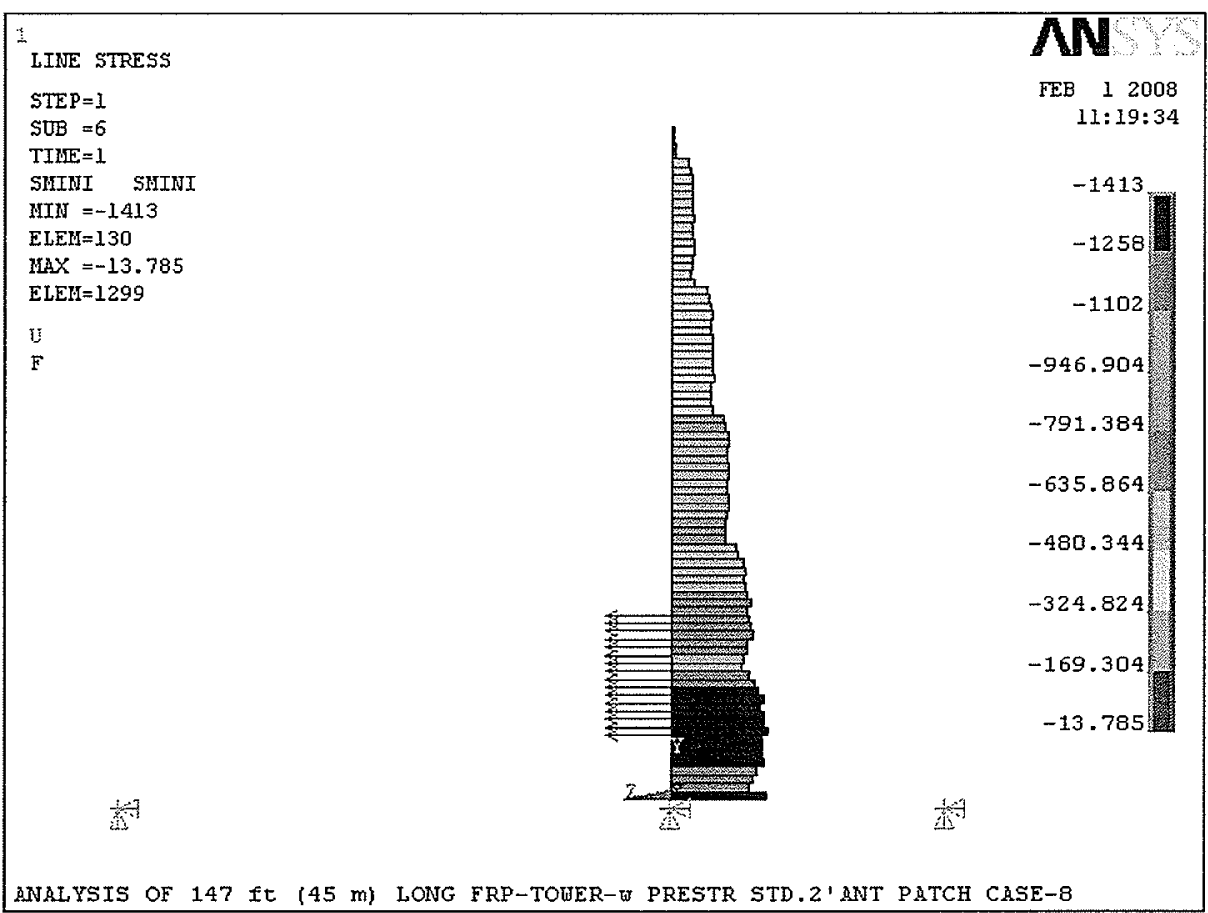

Fig. 3.71 SMIN I, Combined windward chord stress Patch Load Case-8 (units are in psi) 


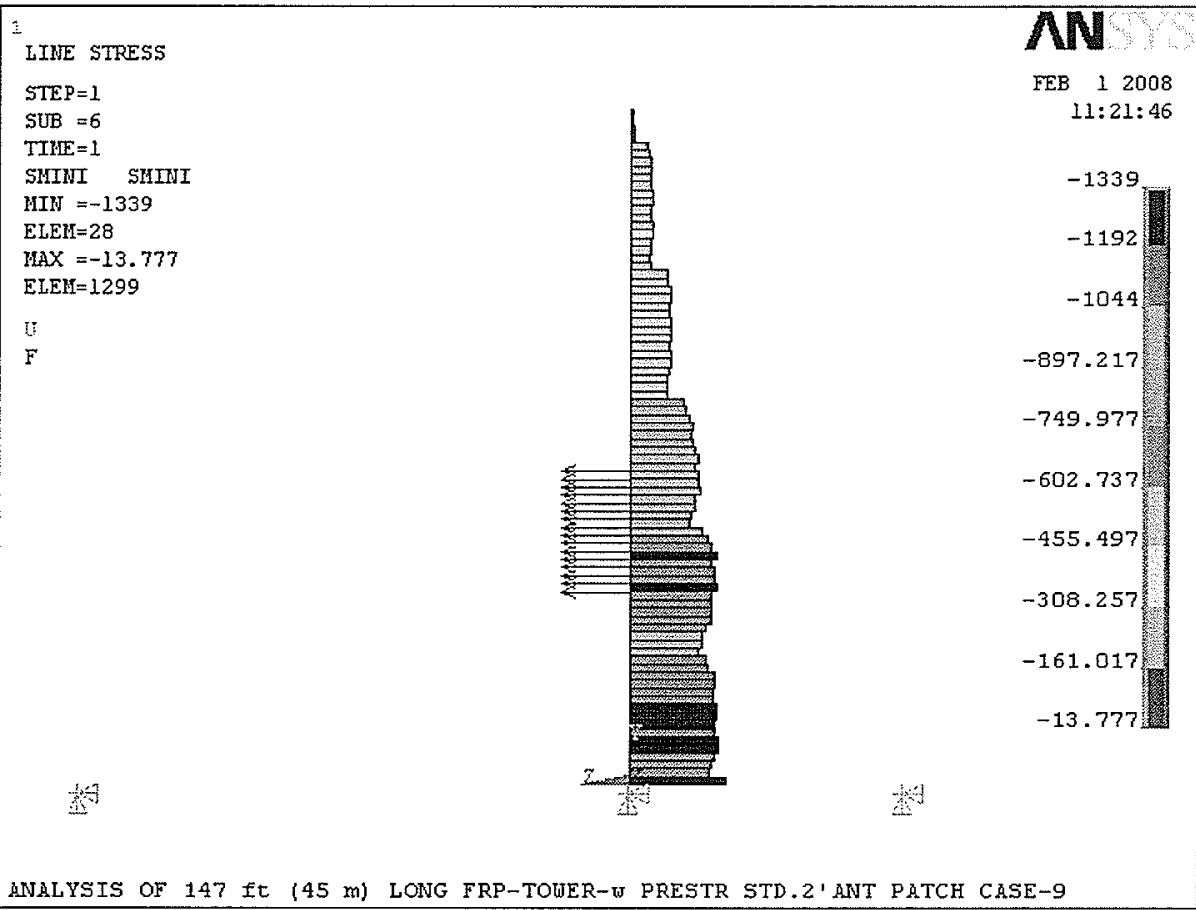

Fig. 3.72 SMIN I, Combined windward chord stress Patch Load Case-9 (units are in psi)

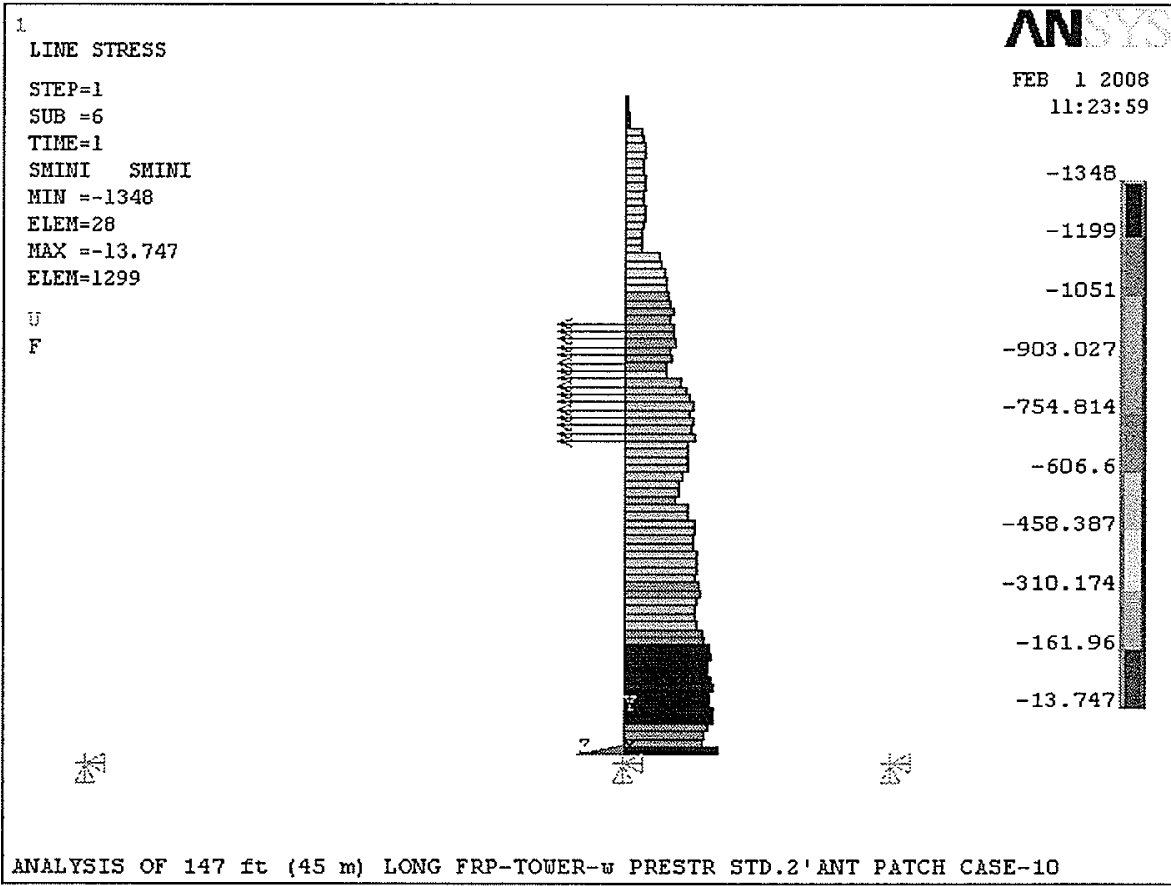

Fig. 3.73 SMIN I, Combined windward chord stress Patch Load Case -10 (units are in psi) 


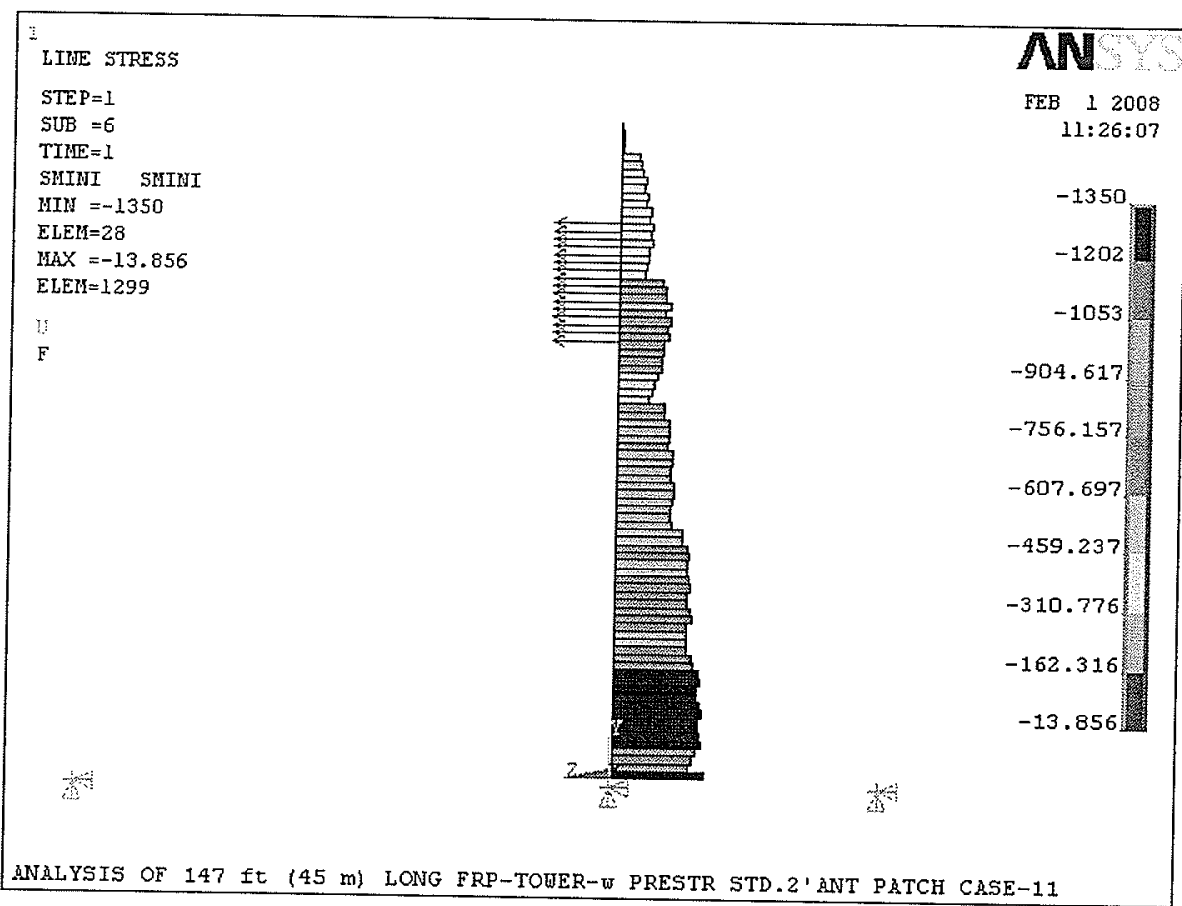

Fig. 3.74 SMIN I, Combined windward chord stress Patch Load Case-11 (units are in psi)

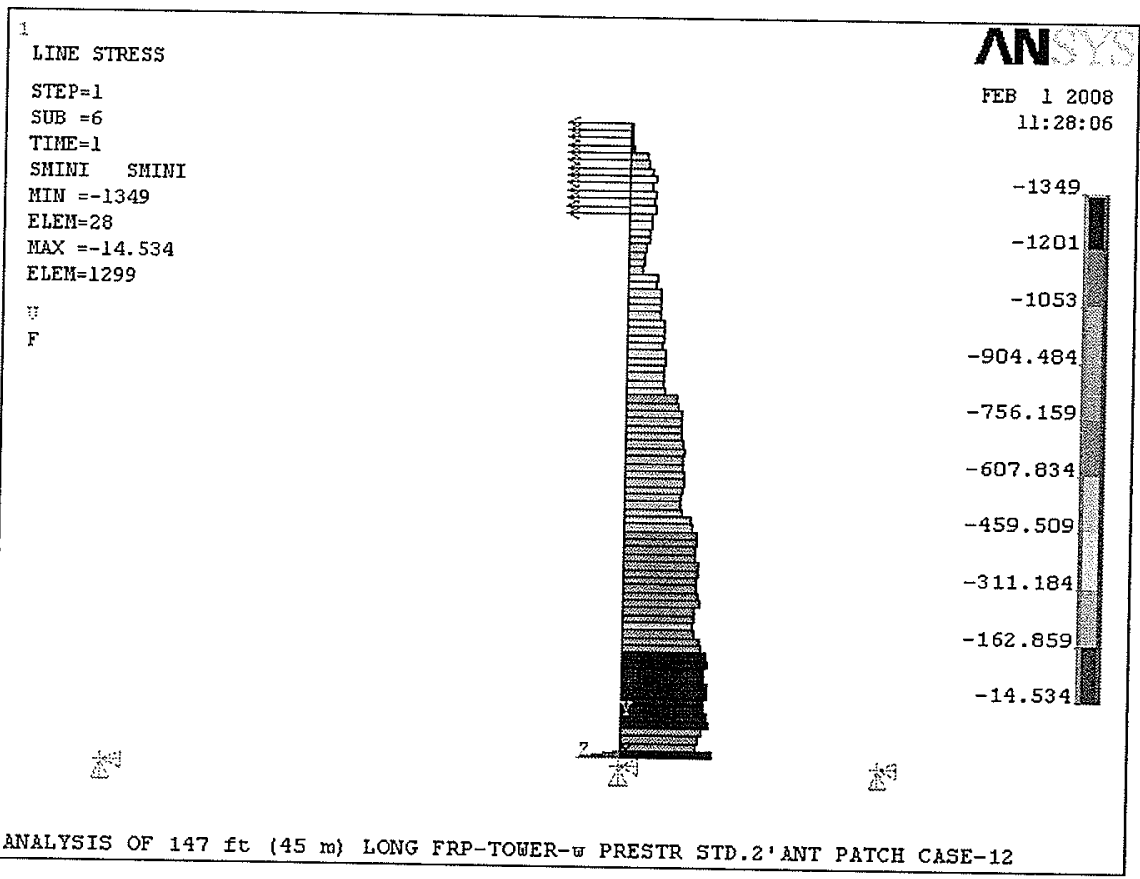

Fig. 3.75 SMIN I, Combined windward chord stress Patch Load Case-12 (units are in psi) 
Patch Load Case-1,2,3,4,5,6

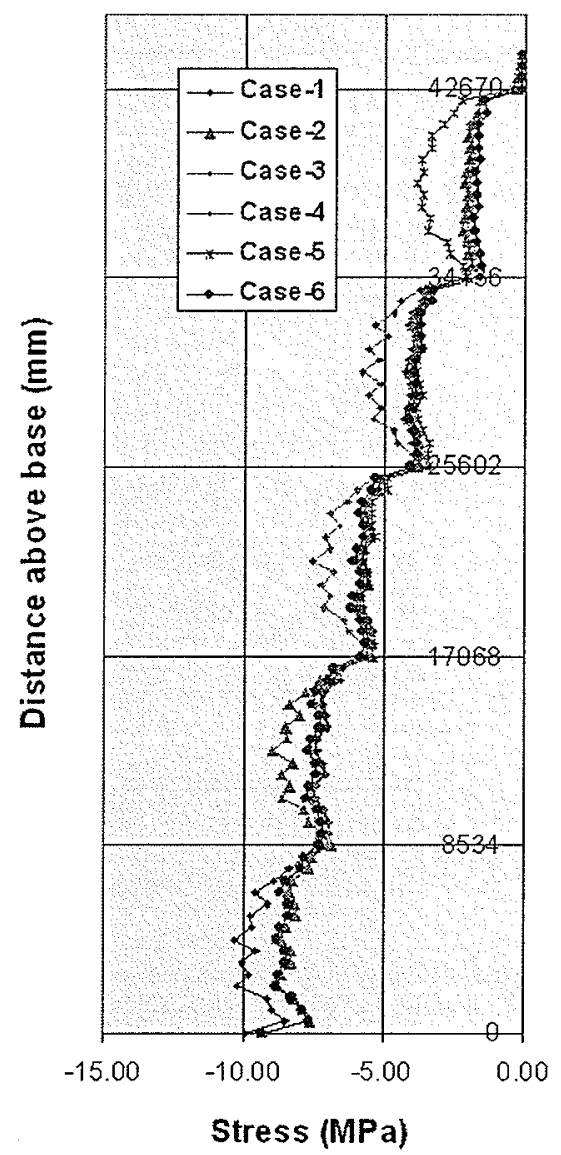

Fig. 3.76 SMINI, for Patch Load Case1-6
Patch Load Case-7,8,9,10,11,12

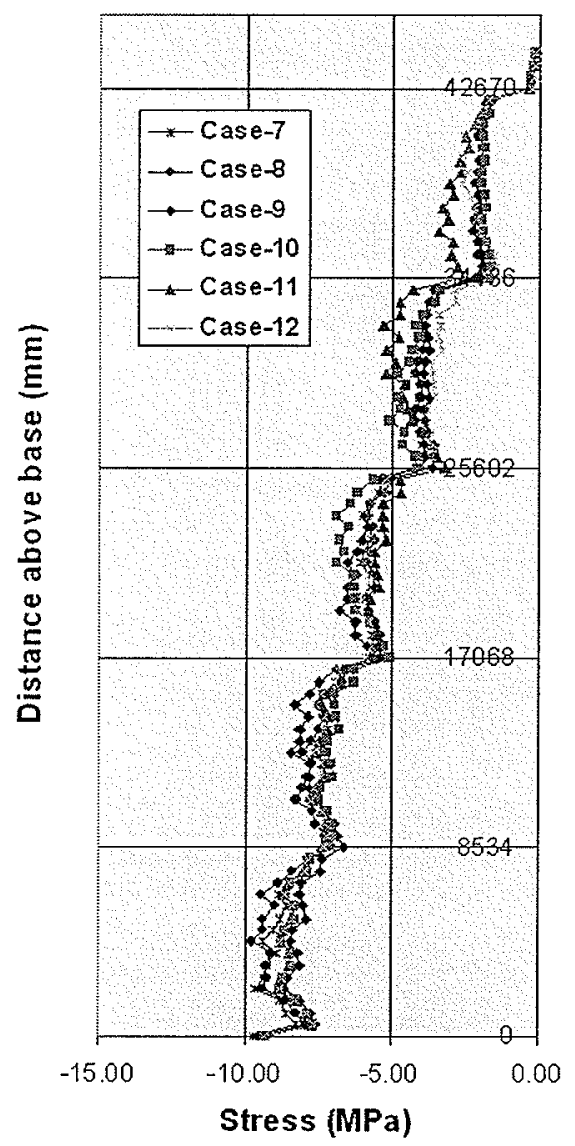

Fig. 3.77 SMINI, for Patch Load Case 7-12

The resultant patch load response from all loading cases is shown in Figs. 3.78.

Using the conservative formula for simple scaling outlined in Clause H3.1 of CSA-S37-01 Standard, the dynamic response at any location along the tower was calculated according to formula given by Eq. 3.53 and is shown in Fig. 3.79. By analysing the peak response to simple scaling it can be seen that the maximum stresses (SMINI) occur at the bottom of the tower and are equal to: $-130.89 \mathrm{MPa}(-18984 \mathrm{psi})$ and 106.94 $\mathrm{MPa}(15509 \mathrm{psi})$, as shown in Fig. 3.79. 
Resultant patch load response (MPa)

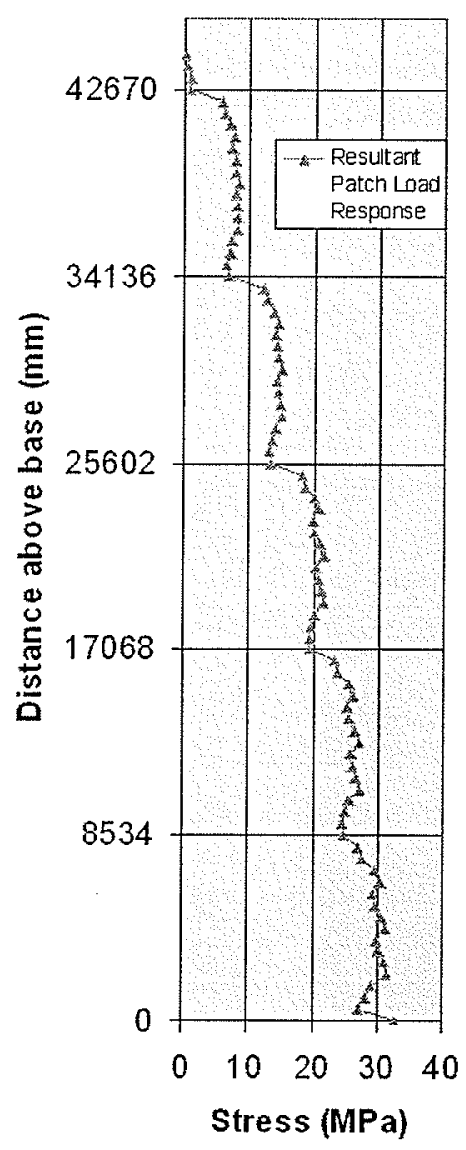

Fig. 3.78 Resultant patch load response

\section{Peak Response Simple Scaling}

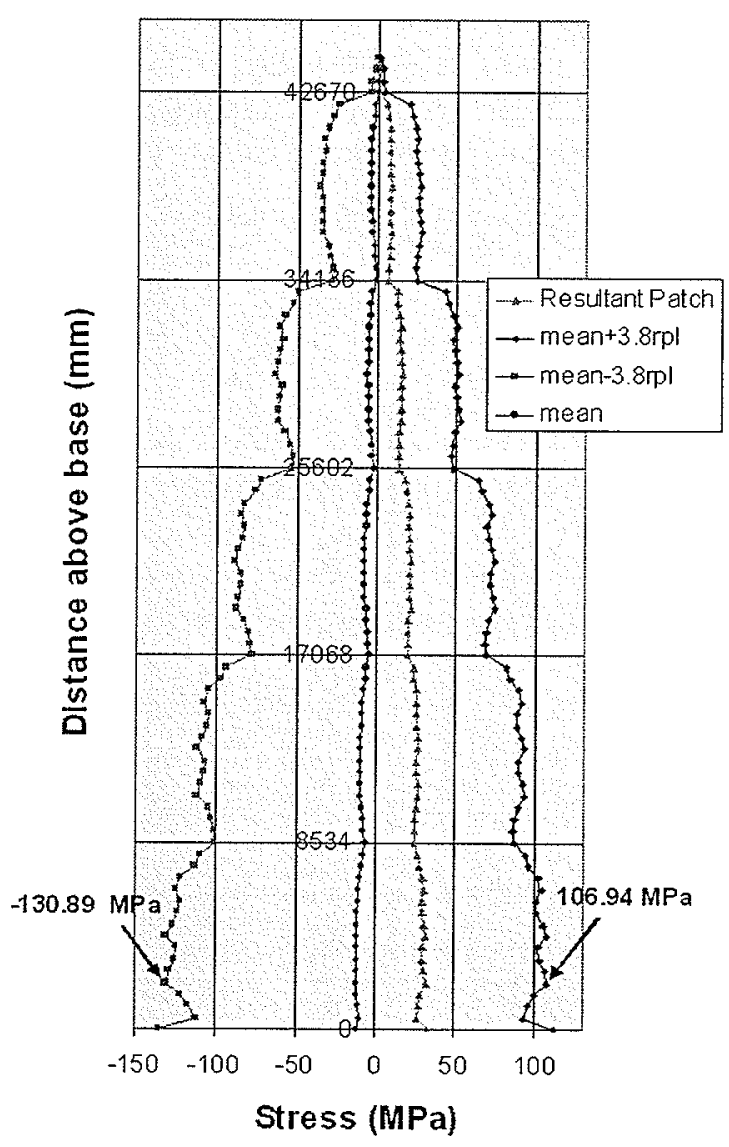

Fig. 3.79 Peak response simple scaling

These results indicate a significant increase in the magnitude of stress as compared to the maximum stresses obtained from static analysis. The peak response analysis, using the simple scaling, results in a conservative estimation of the desired response. Therefore, a more detailed approach prescribed by Clause H3.1 of the CSA-S37-01 Standard, must be undertaken. Using a background scaling factor $\lambda_{B}=0.7$; a resonant magnification factor $\lambda_{R}=0.99$; a 
turbulent length scale factor $\lambda_{T L}=0.77$; and, a peak factor $g_{p}=4.00$, the design response of the mast can be evaluated as follows:

$$
\hat{r}_{P L}=\bar{r} \pm \tilde{r} P L \times \lambda_{B} \times \lambda_{R} \times \lambda_{T L} \times g_{p}=\bar{r} \pm \tilde{r} P L \times 2.13
$$

Results based on detailed scaling are plotted along with the results from simple scaling in Fig. 3.80. The values of peak response for detailed scaling are in the range of $-78.63 \mathrm{MPa}(-11404 \mathrm{psi})$ and $54.68 \mathrm{MPa}(7930 \mathrm{psi})$ which are closer to the values of $-70.82 \mathrm{MPa}(-10272 \mathrm{psi})$ and $75.82 \mathrm{MPa}(10998 \mathrm{psi})$ obtained from static analysis.

On the basis of the results from the dynamic analysis, the tower must be designed for a maximum combined compressive stress equal to $-78.63 \mathrm{MPa}$ $(-11404$ psi). This value will be compared in Chapter 6 with a compressive buckling strength of the tower bottom chords. 


\section{Peak Response SMINI (MPa)}

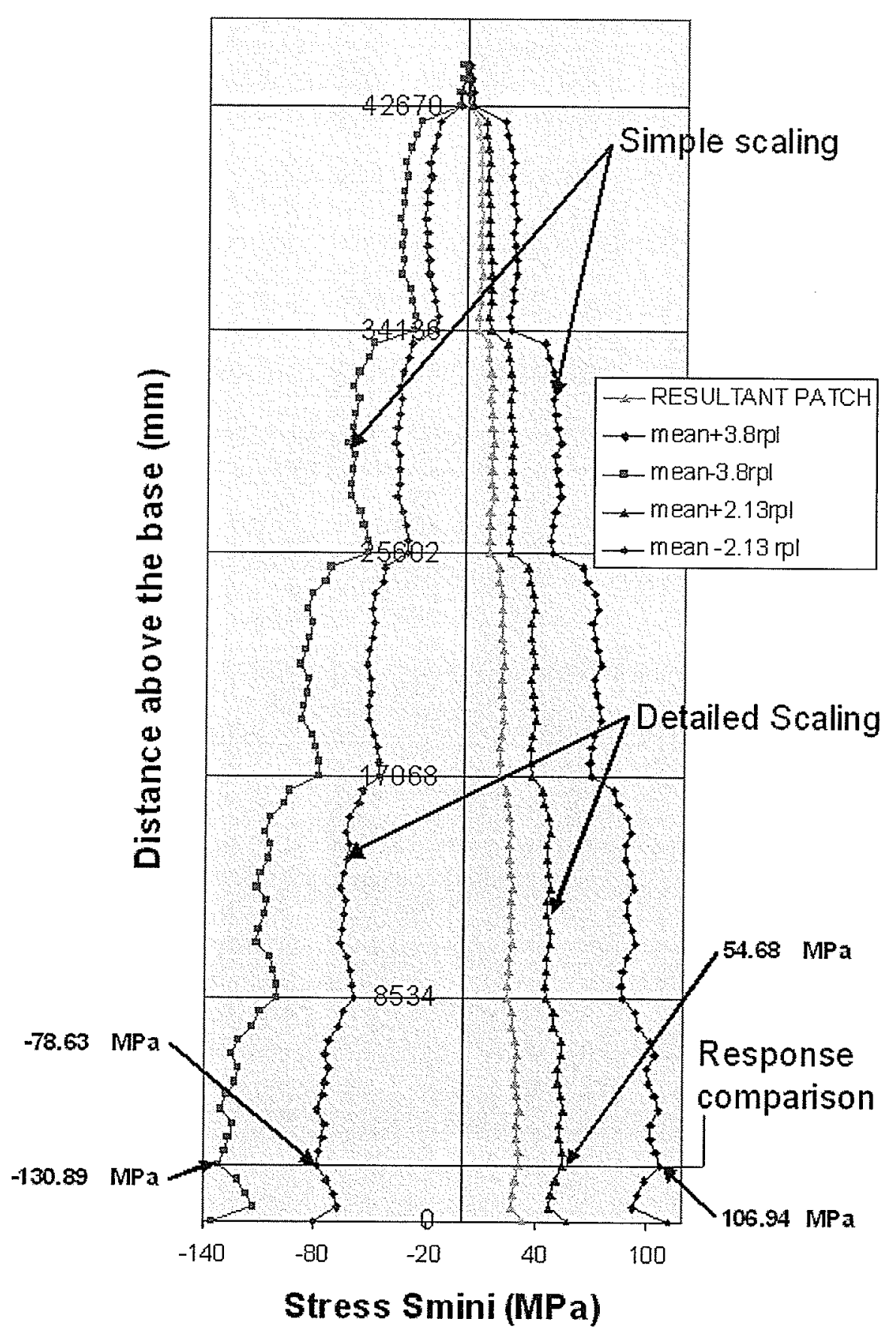

Fig. 3.80 Peak response simple and detailed scaling 


\section{CHAPTER 4}

\section{EXPERIMENTAL PROGRAM}




\subsection{Introduction}

The purpose of the experimental program was to validate the finite element model developed in the research program. The tower segment chosen for testing

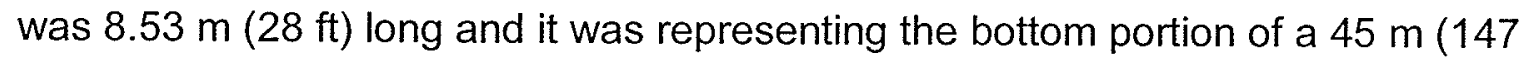
ft) tower. This segment consisted of four equal parts interconnected with sleeve brackets. The experimental program consisted of both static and dynamic testing of the tower segment under service and factored wind loadings

\subsubsection{Composite Latticed Truss Development}

The idea of a filament wound composite latticed towers was introduced by Dr. Dimos Polyzois ${ }^{3}$, as a consequence of his studies in filament wound poles and filament wound wind turbine towers. The major benefit of this new technology would be significant reduction of the structure's weight and low maintenance costs due to their excellent resistance to corrosion. To make it possible, the filament winding of lattice towers required the manufacturing of a special collapsible mandrel. Such a mandrel was designed and manufactured by Cormorant Advanced Composites of Winnipeg ${ }^{4}$. Mandrel folding sides ensured that the latticed tower wound on the outer surface of the mandrel could be easily removed after curing. The mandrel cross sectional dimensions were dictated by size of the tower parts, the mandrel weight, as well as the overall cost of mandrel

\footnotetext{
${ }^{3}$ Professor, Faculty of Engineering University of Manitoba

${ }^{4}$ Patent is pending through Cormorant Advanced Composites
} 
manufacturing. The mandrel had to be light enough to enable manual, multiple tread continuous winding.

\subsubsection{Initial Selection of Cross Section}

Initially, a significant amount of time was spent to establish the desired tower section dimensions. The final arrangement of chord and bracing diagonals, was selected for ease of production and to provide the bending and torsional stiffness required. One of the leading factors in selecting these properties was the mandrel cost which dictated the maximum dimensions of the specimen. Also, ease of winding and de-moulding, together with weight, were the crucial factors especially since all manufacturing was done manually.

The structural properties of the section, shown in Fig. 3.2, were established through the Finite Element Analysis. The completed tower section is shown in Fig. 4.1.

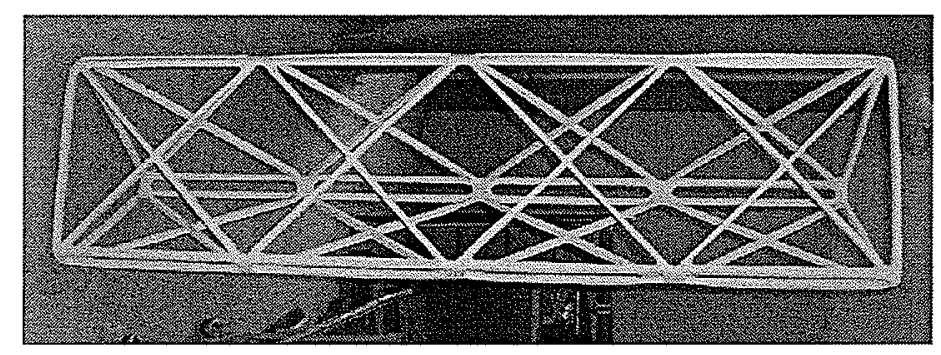

Fig. 4.1 Completed Tower Section

\subsection{Static Testing of FRP Tower Segment Test Set-Up}

The tower segment specimen consisted of four identical sections assembled horizontally, with the loading applied vertically (upwards) as shown in Fig. 4.2. 


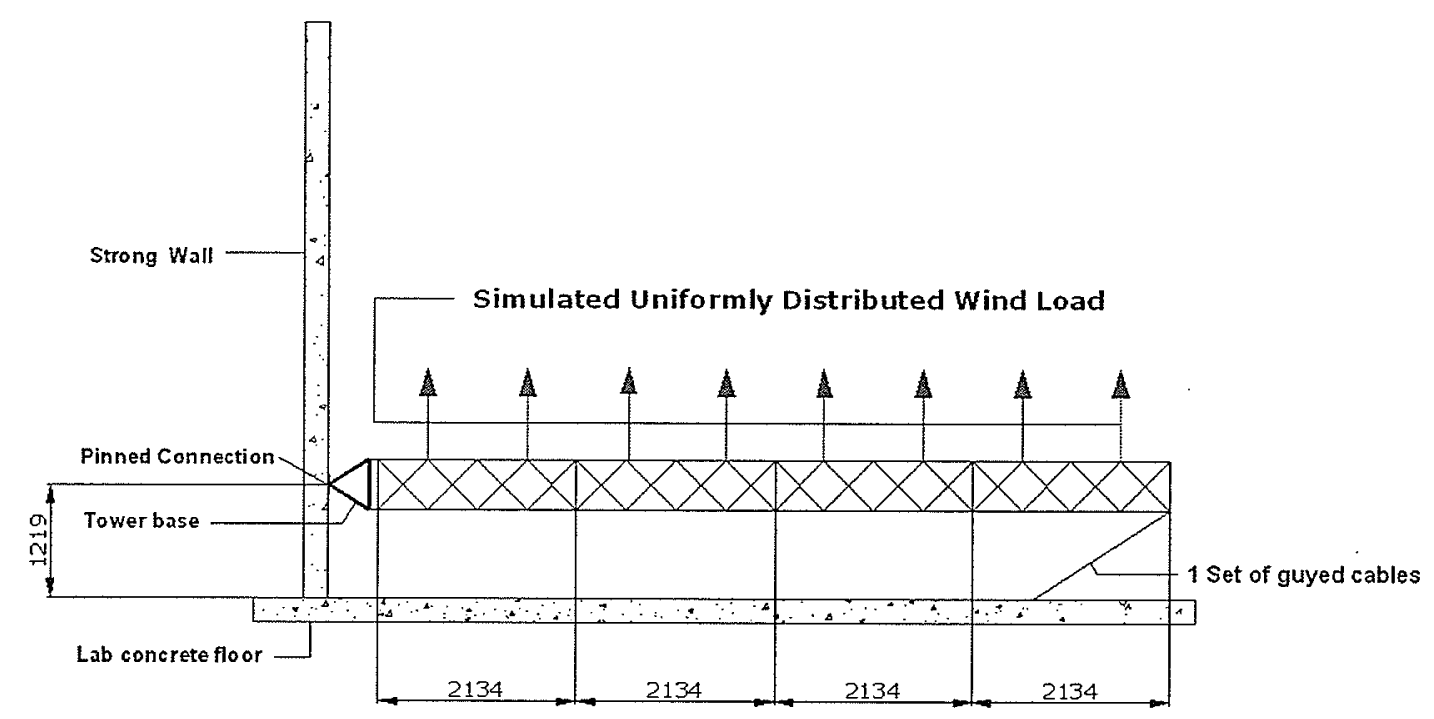

Fig. 4.2 Tower segment configuration for testing (units are in $\mathrm{mm}$ )

Four, $2.134 \mathrm{~m}(7 \mathrm{ft})$ sections were joined by specially designed FRP sleeve brackets. The right side of the specimen was supported by one set of cables and the left side was attached to a vertical concrete wall via steel base. A "whiffle tree" loading arrangement, shown in Figs. 4.3, 4.4, and 4.5, was designed to provide the uniformly distributed lateral load to the tower. The loading was applied by an overhead crane and was monitored by a calibrated load cell. The eight distributed forces applied to the tower specimen were measured using calibrated strain gauges, shown in Fig. 4.6. The deflection of the tower was monitored by three Linear Motion Transducers (LMT's) at spliced locations and one Linear Variable Displacement Transducer (LVDT) at the end as shown in Fig. 4.4. The tower segment was tested horizontally, attached to a concrete strong wall through a knife edge which allowed for free rotation of the tower in the plane of loading. The base plate holding the tower to concrete strong wall was 
secured by diwidag bars prestressed to $165 \mathrm{MPa}$ (24 kips) tensile force to avoid any lateral movements.

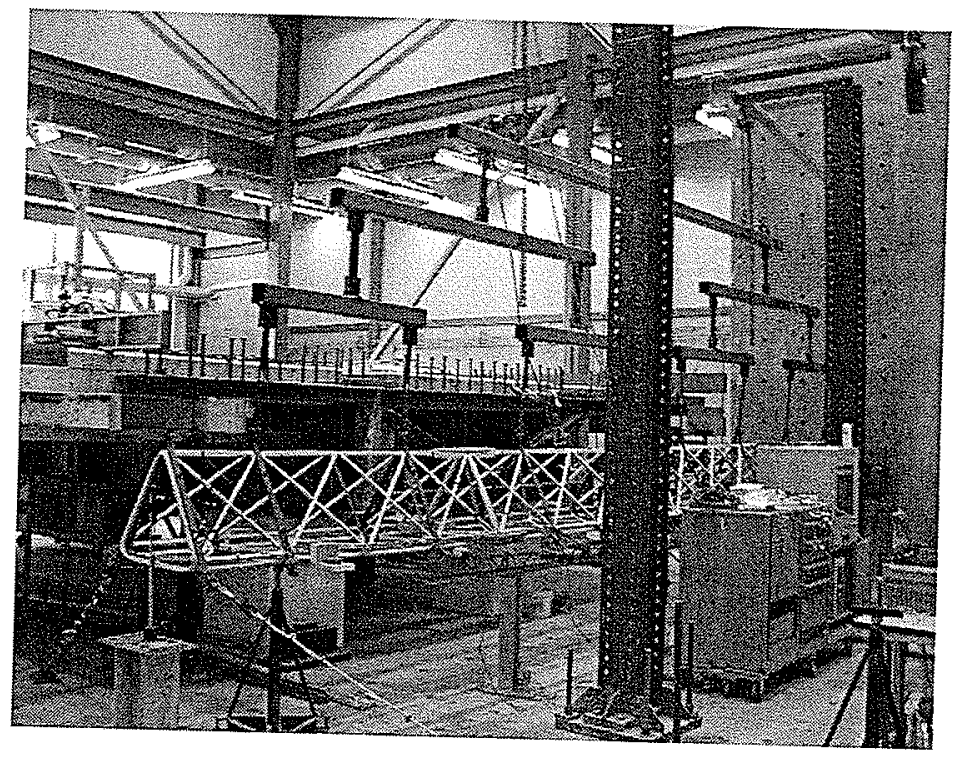

Fig. 4.3 Test set-up

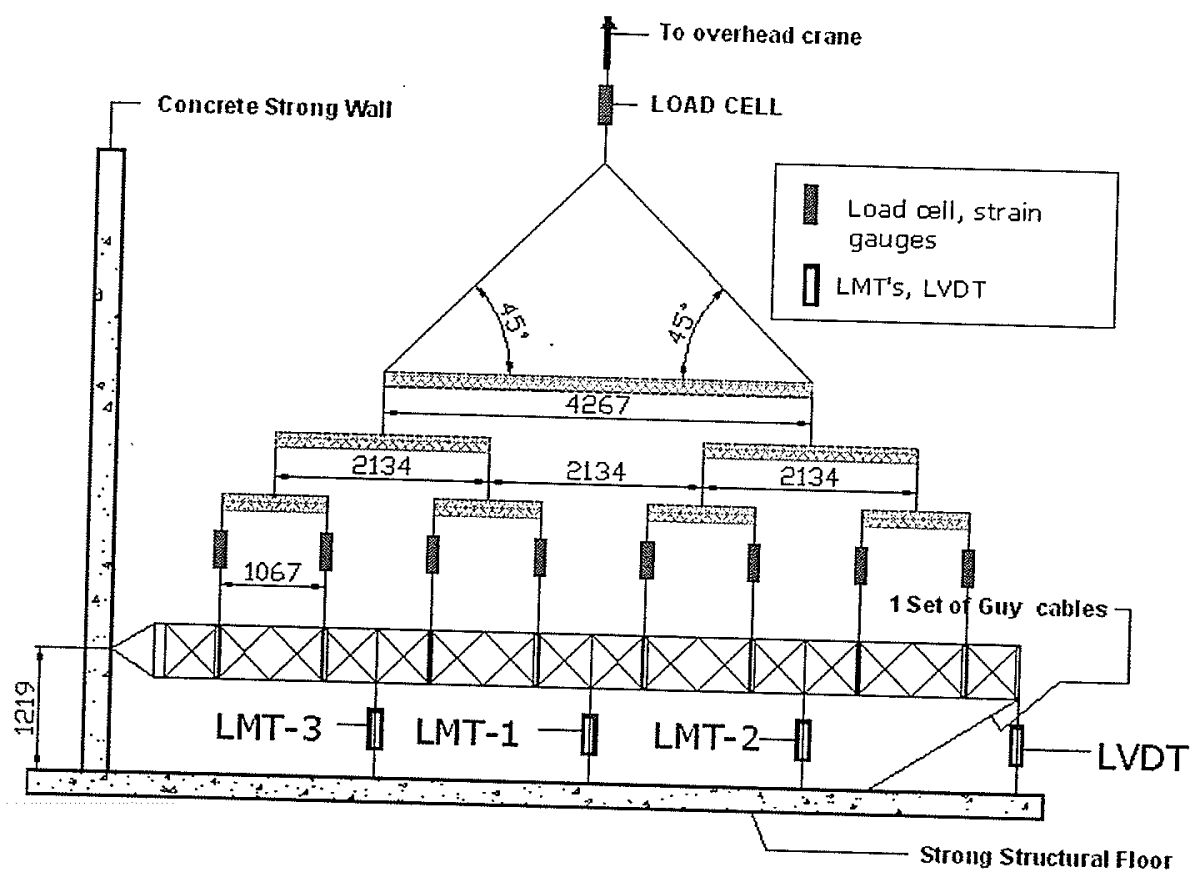

Fig. 4.4 Schematic drawing of scaled test set-up (units are in $\mathrm{mm}$ ) 


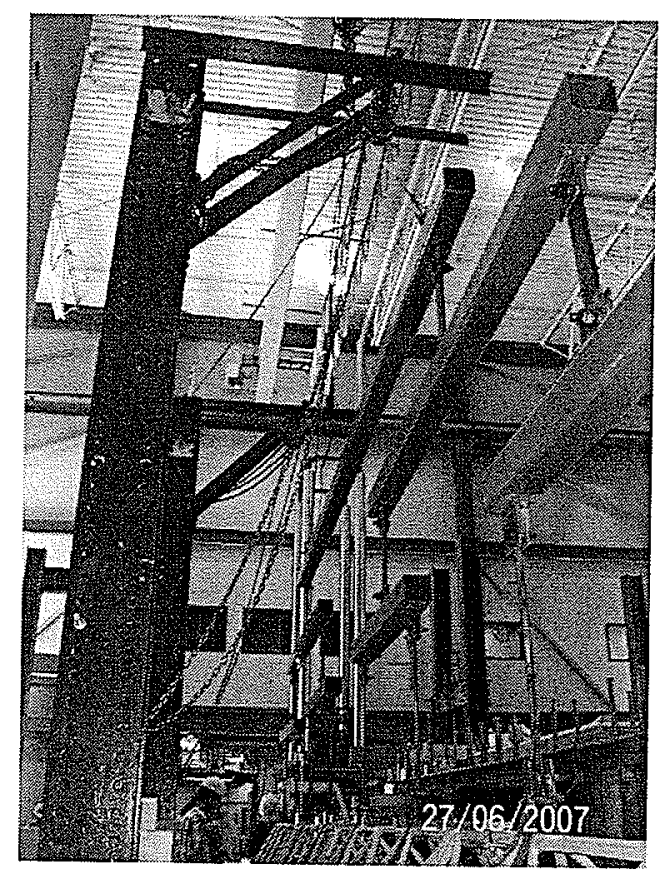

Fig. 4.5 Loading applied to "wiffle tree system"

To measure stress variation across the specimen a total of 32 strain gauges were attached to one side of the test segment plus two at the supporting guy cables, as shown in Fig. 4.6.

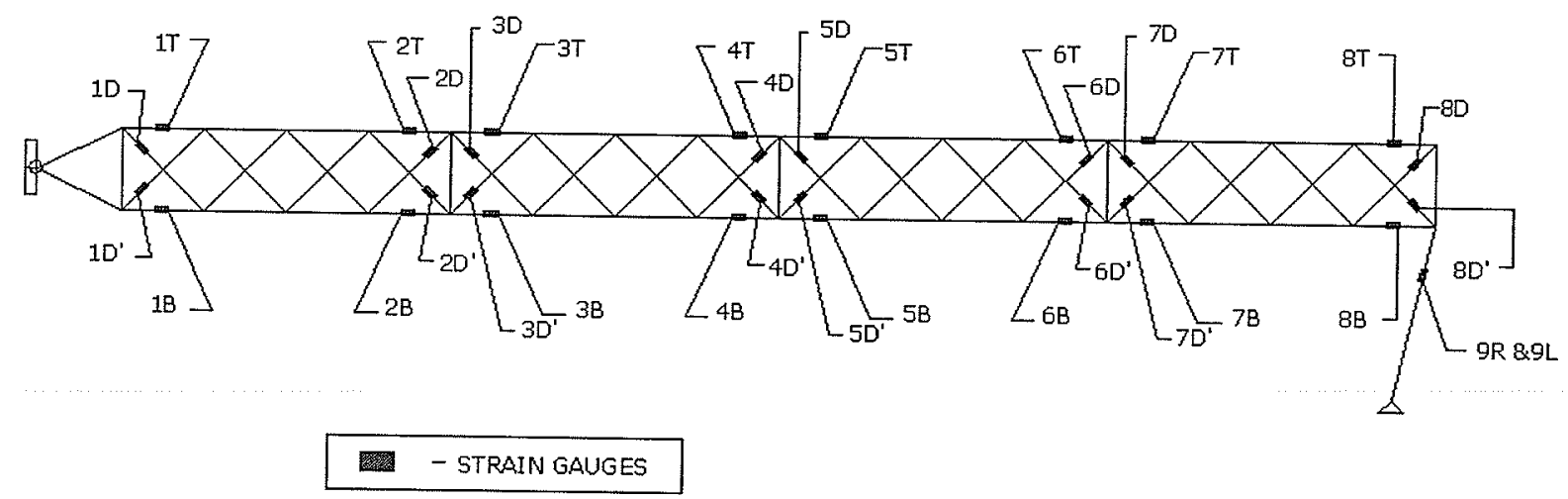

Fig. 4.6 Strain gauges attachments 


\subsubsection{Design and Manufacturing of Tower Base}

The tower specimen was designed to be simply supported with a pinned base at one end and cable supports at the other end. The steel tower base is shown in Figs. 4.7 and 4.8. The base was fabricated from $76.2 \mathrm{~mm}$ ( 3 in) O.D. standard steel pipes, structural steel angles, and a circular $12.7 \mathrm{~mm}(0.5 \mathrm{in})$ thick steel base plate (CSA-S-16.1-94, 1995). All parts were welded together. The base legs were attached to the FRP tower sections by $12.7 \mathrm{~mm}(0.5 \mathrm{in})$ dia. steel bolts connected with countersink nuts and washers to prevent slip under loading reversals. The end of the tower base was connected to a wall plate via a pin with full moment release. The bolts were tightened manually using a calibrated torque wrench.

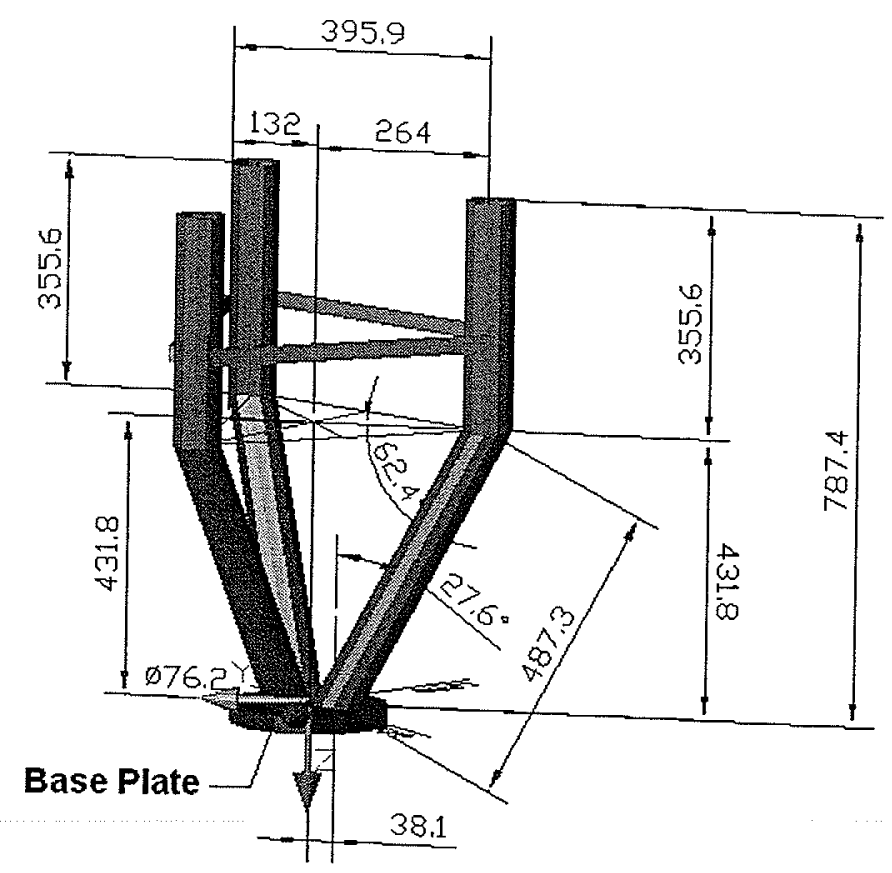

Fig. 4.7 Tower base detail 


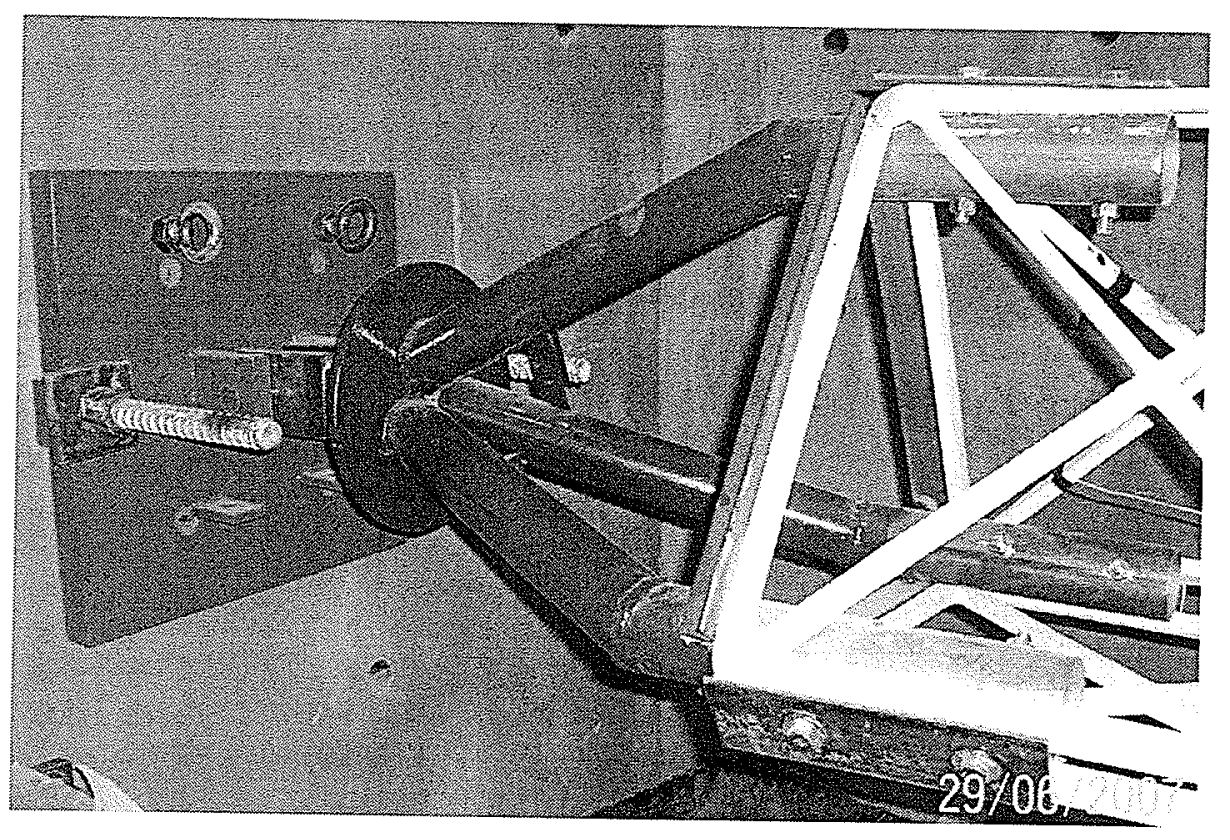

Fig. 4.8 Tower base attachment

\subsubsection{Design and Manufacturing of Tower Connections}

The tower specimen consisted of four identical sections as described earlier. Individual sections were interconnected by means of a sleeve bracket system consisting of two identical pieces, shown in Fig. 4.9, and joined together, as shown in Fig. 4.10.
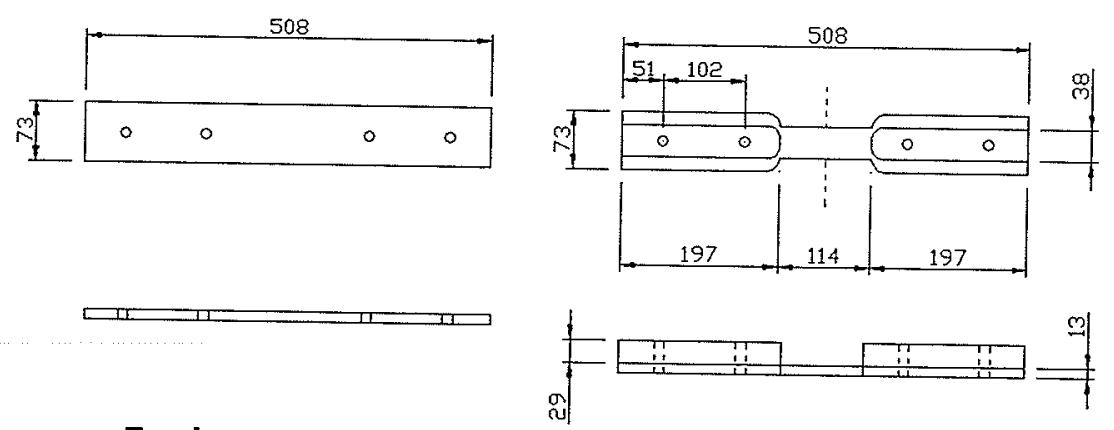

Top brace

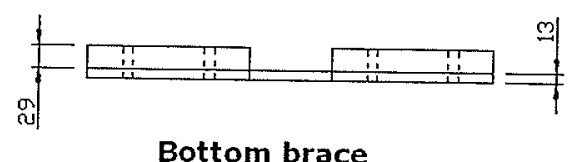

Fig. 4.9 Bracket for joining segments together (units are in $\mathrm{mm}$ ) 


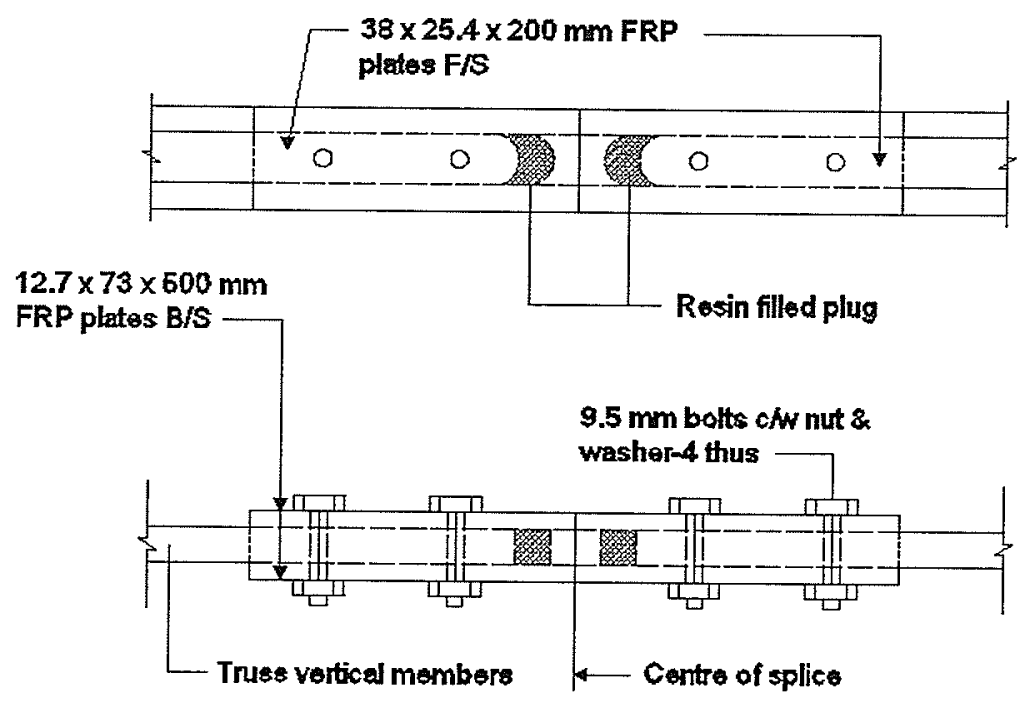

Fig. 4.10 Sleeve bracket connection (units are in $\mathrm{mm}$ )

The sleeve connection consisted of two pultruded FRP plates, glued together with resin. They were cut from a $12.7 \mathrm{~mm}$ ( $0.5 \mathrm{in})$ thick flat sheet fabricated by Bedford Reinforced Plastics Inc. (Bedford Reinforced Plastic Manual, 2007). This sheet was reported to have an ultimate tensile strength of $165 \mathrm{MPa}(24 \mathrm{ksi})$ in the fiber direction and $69 \mathrm{MPa}$ (10 ksi) perpendicular to the fibers, respectively. Their ultimate compressive strength was listed as $165 \mathrm{MPa}(24 \mathrm{ksi})$ in longitudinal direction and $121 \mathrm{MPa}(17.5 \mathrm{ksi})$ in the transverse direction, respectively. Outside brackets were connected by four $9.5 \mathrm{~mm}$ ( $3 / 8$ " dia.) bolts connected with countersink nuts and washers. The bolts were also tightened with a calibrated wrench. The sleeve bracket was inserted from the bottom of the chords and than resin filled plugs were applied, as shown in Fig. 4.10, to prevent any bracket movement in horizontal direction during testing. The trial sleeve connection is shown in Fig. 4.11. 


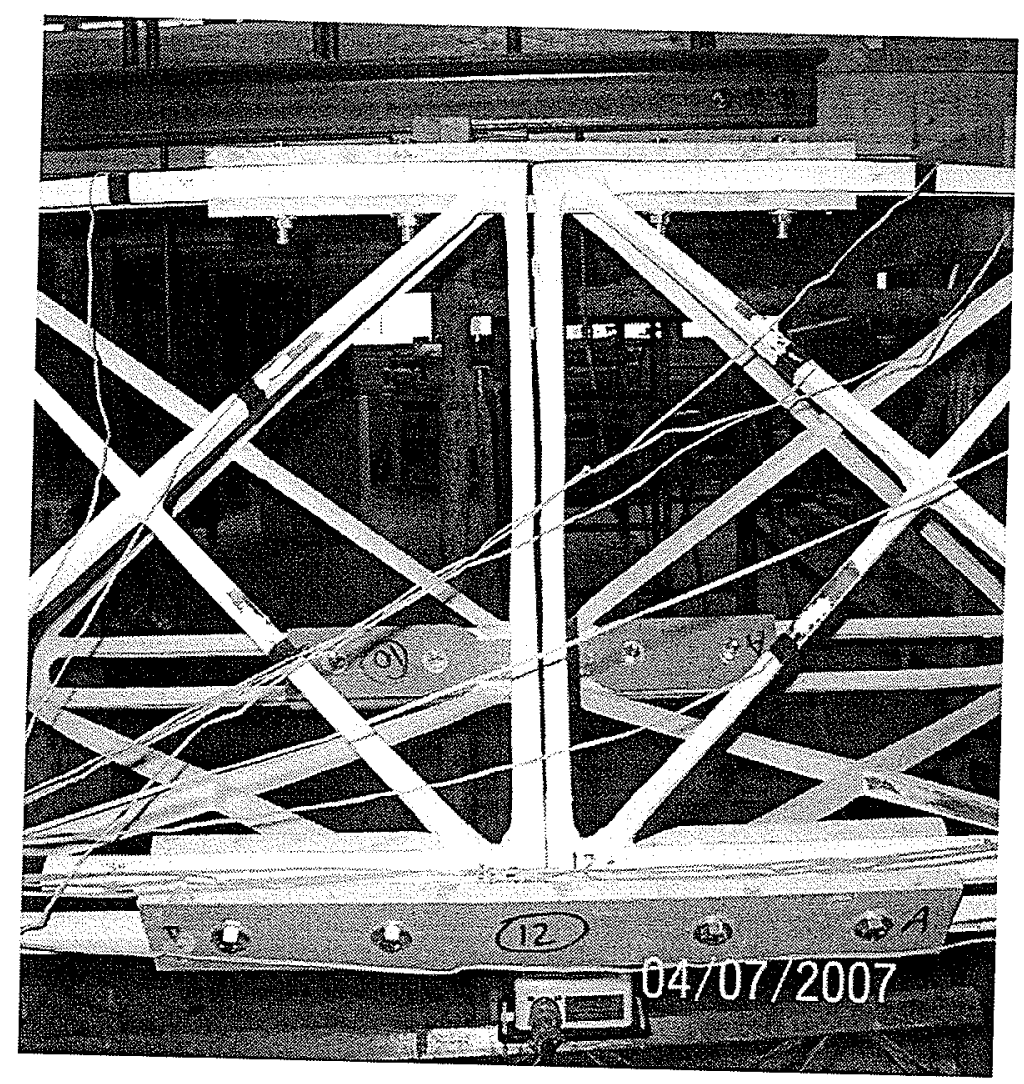

Fig. 4.11 Strain gauges attachments

\subsubsection{Test Procedure}

The test set-up for the tower specimen is shown in Fig. 4.3. The test started by setting the initial readings for all instruments on the data acquisition system equal to zero. By using the overhead crane, a vertical loading was applied to the top of the "wiffle tree" loading arrangement shown in Fig. 4.5. The loading was monitored by a load cell and eight strain gauges attached to load bars and two strain gauges attached to end brackets, shown in Fig. 4.12. To monitor strain, strain gauges were attached on both sides of the splice in the connected segments, as shown in Fig. 4.11. 


\section{Experimental Program}

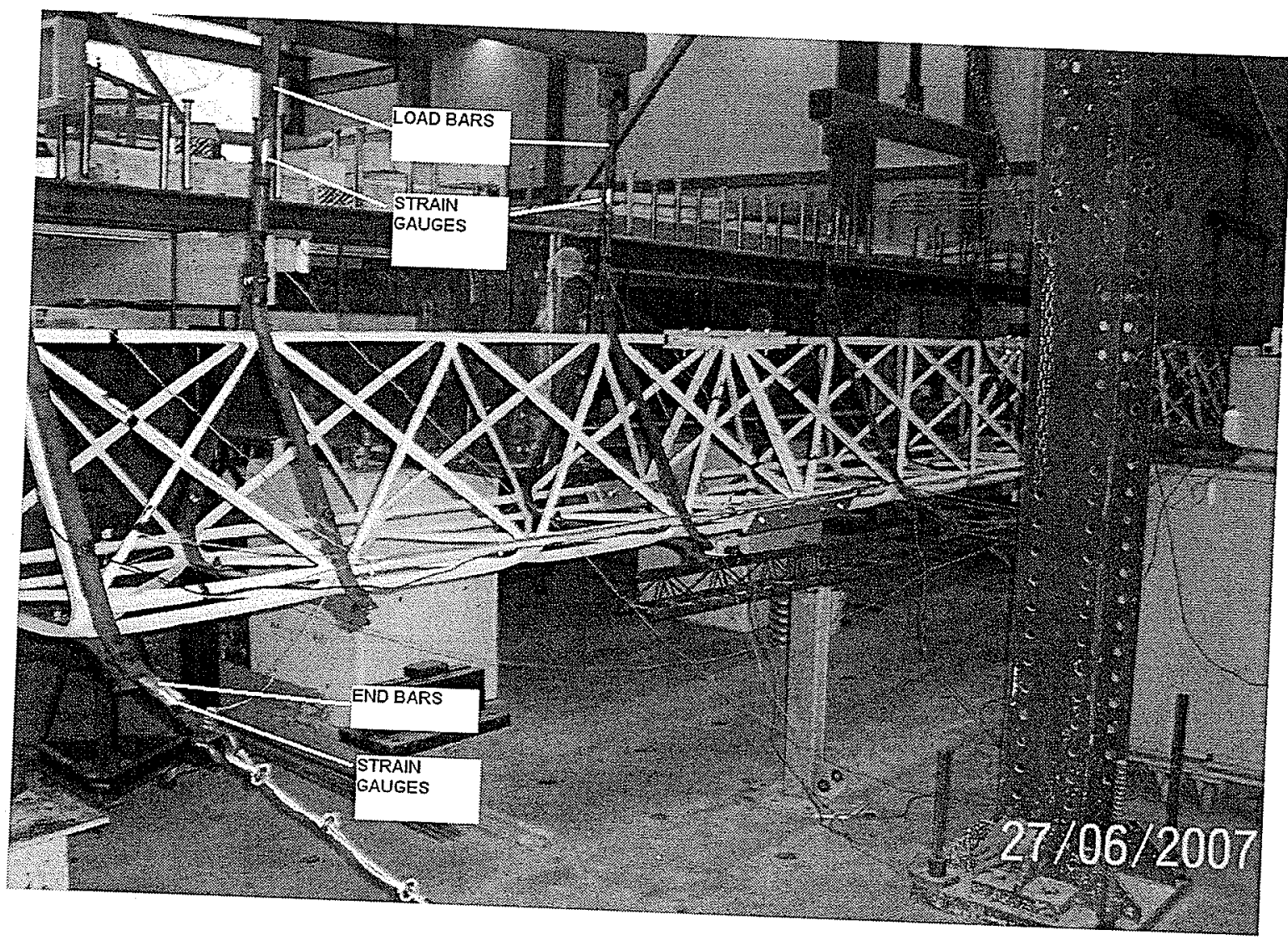

Fig. 4.12 Bars with strain gauges

The loading was applied slowly until the load cell readings recorded a force equal to $5.14 \mathrm{kN}(1155.47 \mathrm{lbs})$. This loading was equivalent to a uniformly distributed factored wind load acting on the bottom segment of the full scale tower. The eight equal loads applied to the tower specimen approximated this uniform wind profile well. Readings from three LMT's located at the joint sections and one LVDT at the end of segment, ten strain gauges attached to loading bars and 32 strain gauges attached to the one side of tower itself, were automatically recorded by the data acquisition system. Because of the significant amount of data being generated, the LabVIEW program was set to record 4 readings per second. All data were collected and stored on a personal computer for further analysis. 


\subsection{Dynamic Testing of FRP Tower Segment Test Set-Up}

Instead of testing the tower segment in the first mode of vibration which is torsional, as shown in Figure 3.46, we choose to perform dynamic test in the first flexural mode. This was due to the fact that the utility available was not suitable for set up in torsional mode. As the weight distribution play a dominant role for natural frequencies, the tower specimen was erected in the vertical position for dynamic testing, as shown in Fig. 4.13.

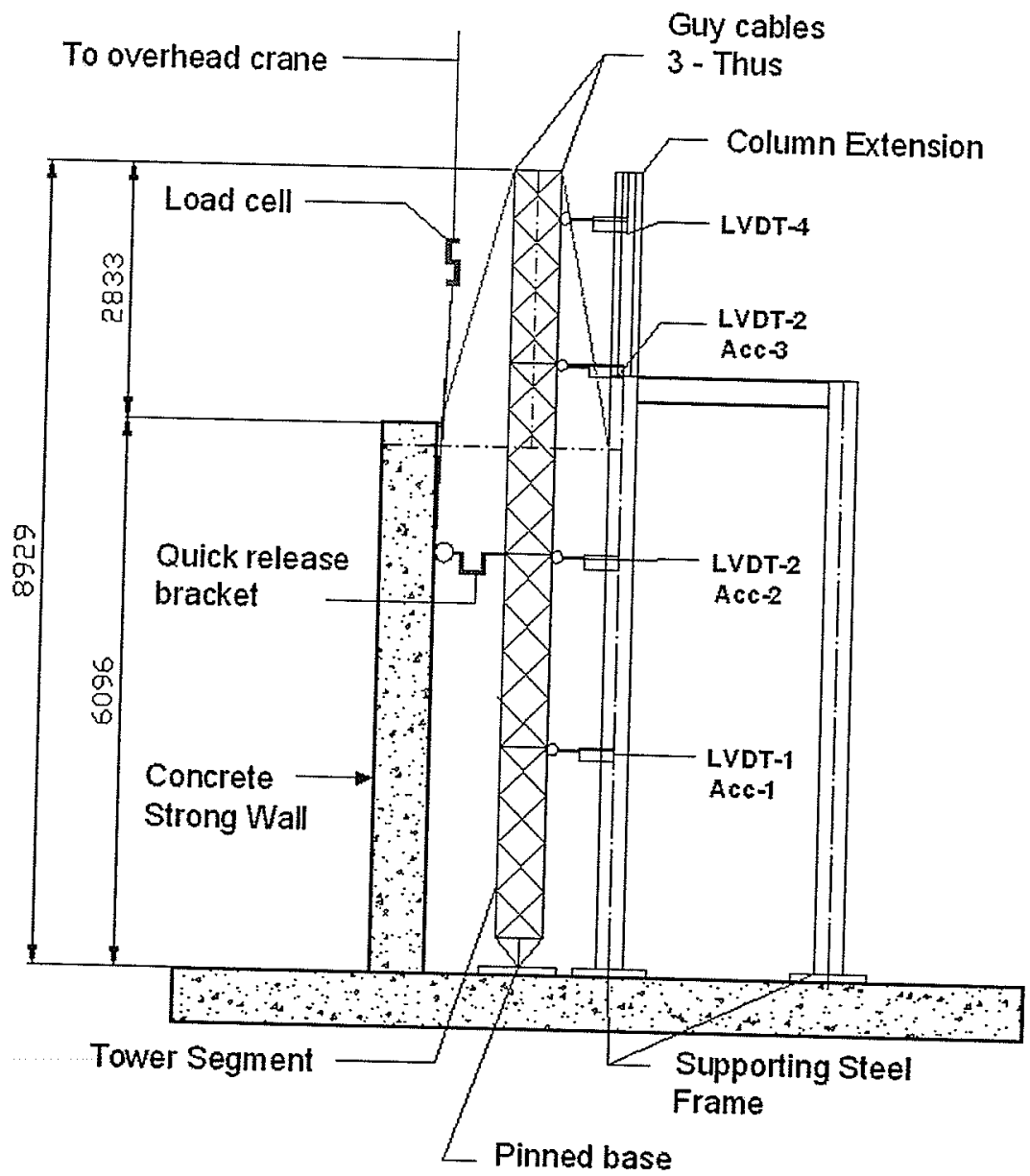

Fig. 4.13 Tower segment configuration for dynamic testing-elevation (units are in $\mathrm{mm}$ ) 
The tower specimen was connected at the bottom to a steel pinned base and was supported at the top by 3 guy cables oriented at $120 \mathrm{deg}$, as shown in Fig. 4.14.

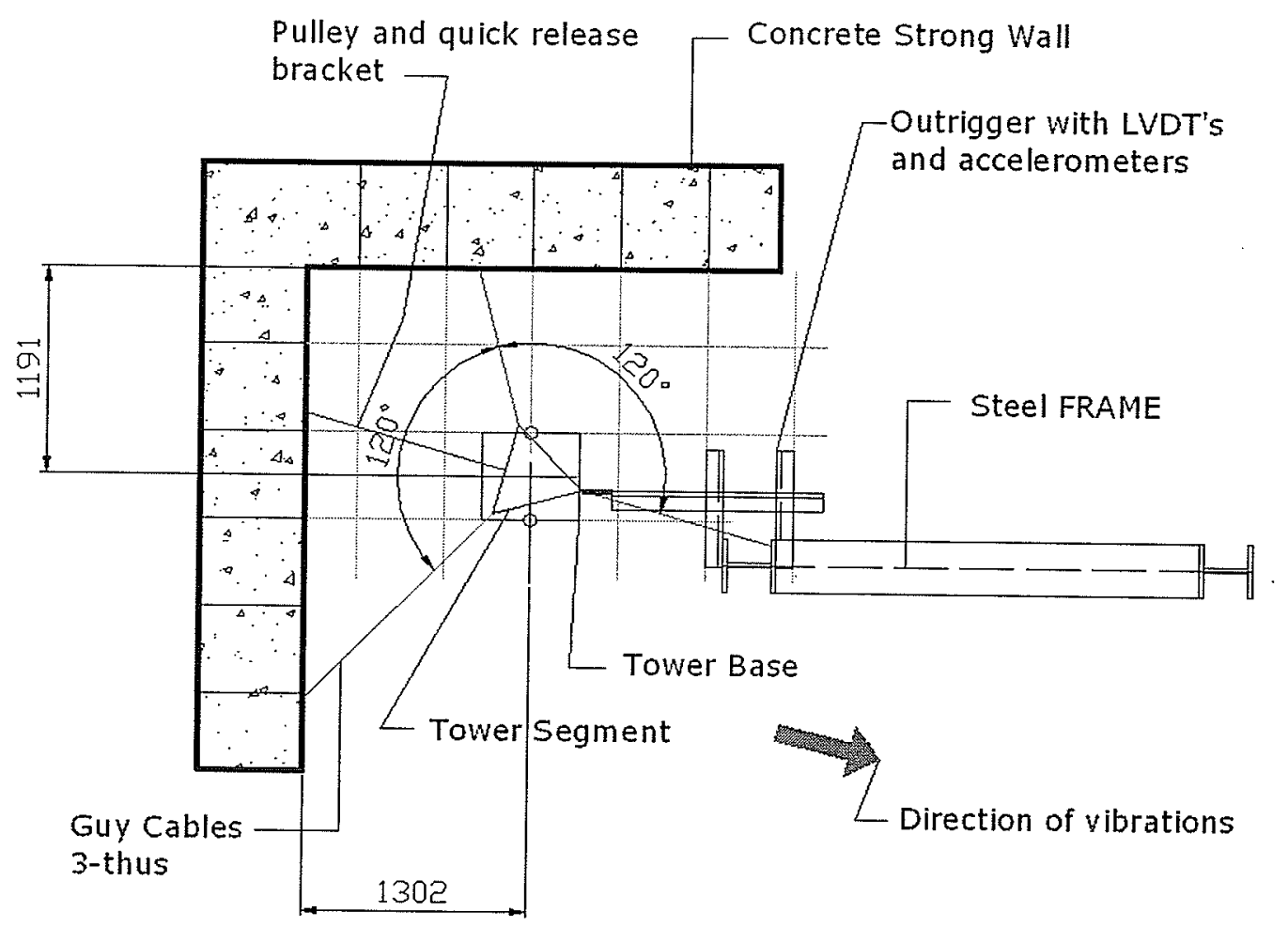

Fig. 4.14 Tower segment configuration for dynamic testing-plan (units are in $\mathrm{mm}$ )

The guy cables were hand pretensioned by three turnbuckle bolts and the whole tower was carefully aligned to a vertical position using a level. The tower specimen consisted of four, $2.134 \mathrm{~m}(7 \mathrm{ft})$ sections joined together by sleeve connections. This base was shorter than that used for static testing, but provided the same degree of freedom. The loading at the middle section of the tower was applied by the overhead crane through a pulley and the readings were recorded by a calibrated load cell, as shown in Fig. 4.15. All instrumentation was secured by heavy structural steel frame connected to concrete strong wall by extra steel 
bracket to eliminate frame movement in the perpendicular direction, as shown in Fig. 4.16.

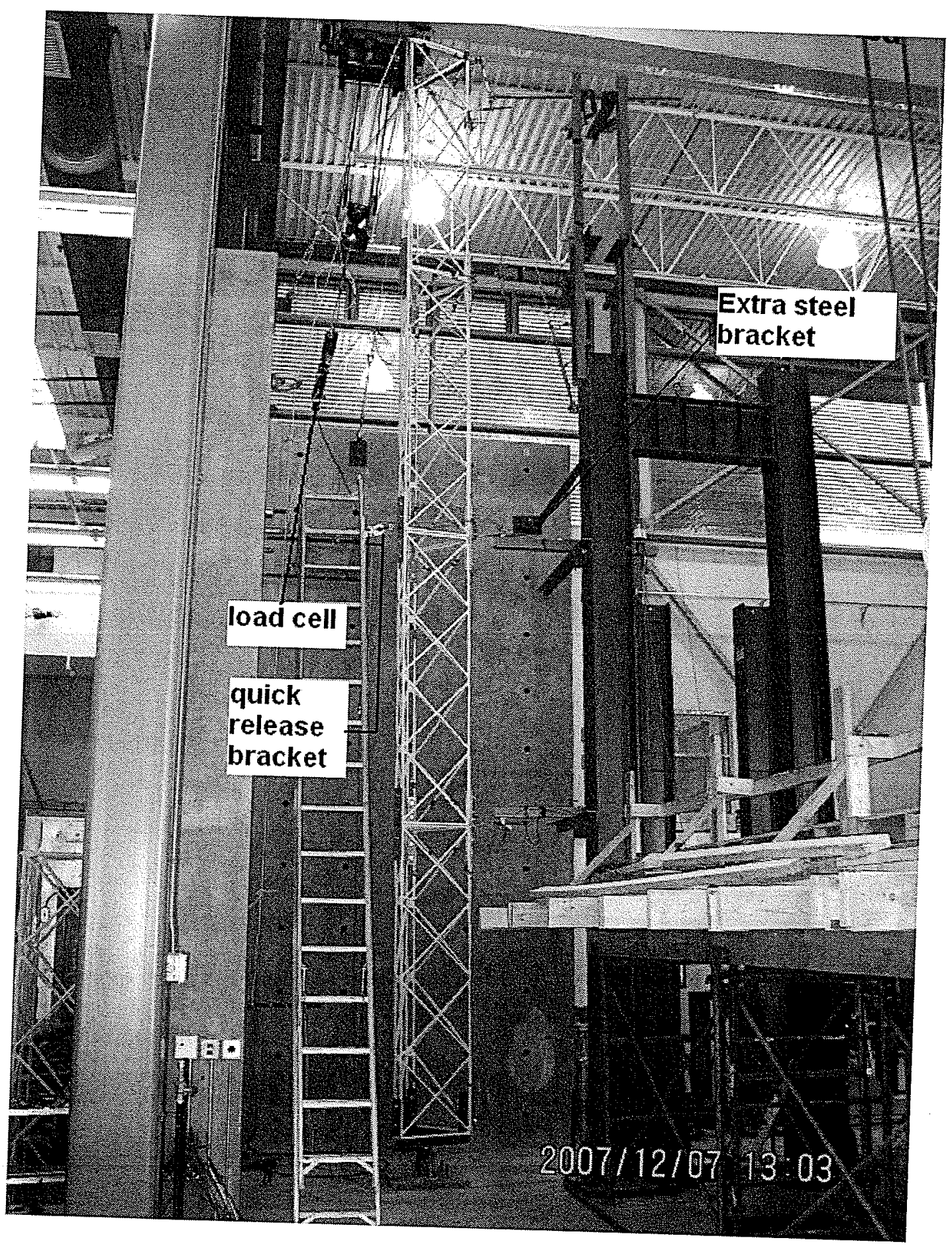

Fig. 4.15 Test set-up, north -south configuration 


\section{Experimental Program}

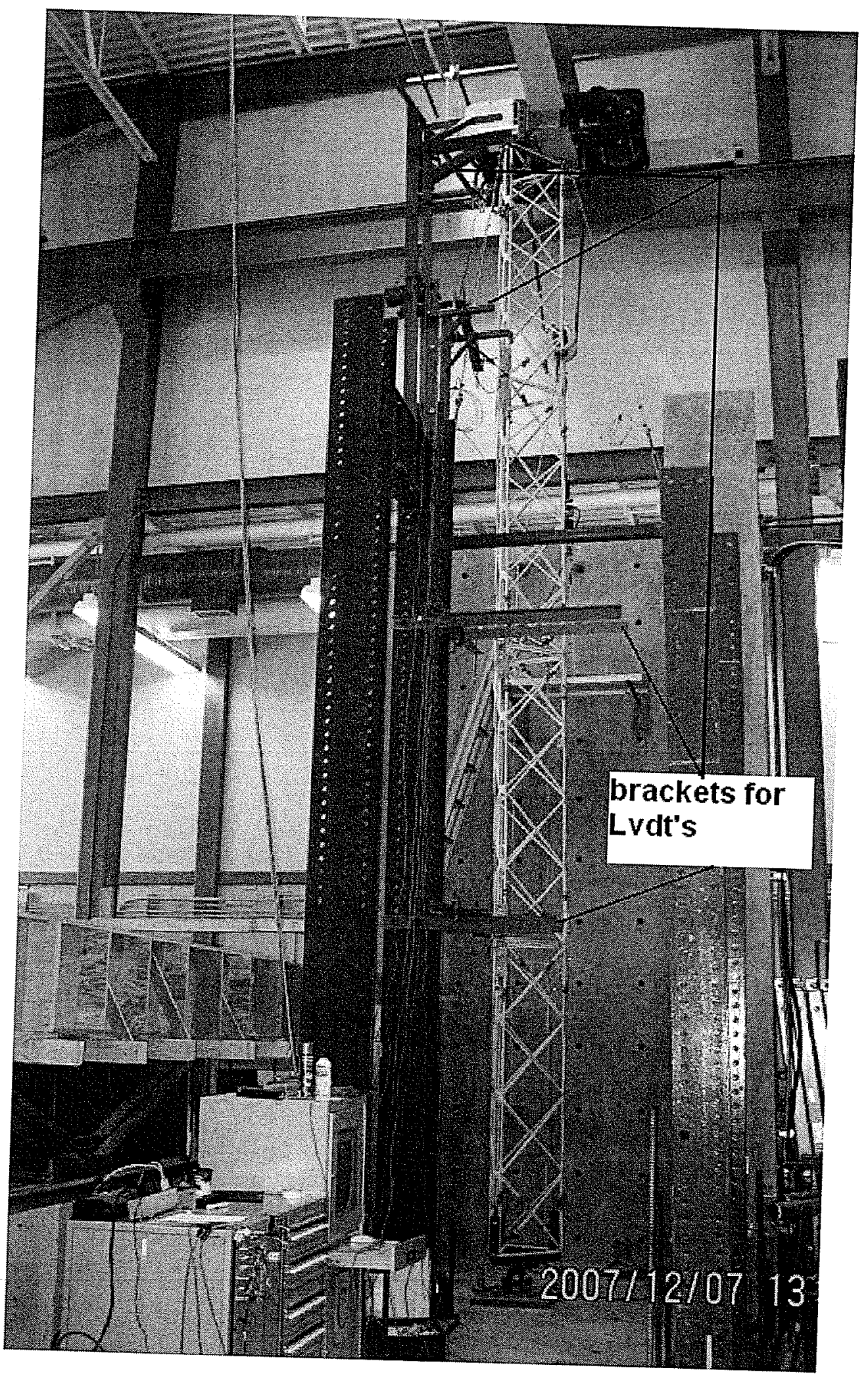

Fig. 4.16 Test set-up, west -east configuration 
The tower's initial deflection and vibrations were measured by Linear Motion Transducers (LMT's) attached at four locations: three at splice locations and one near the top as, shown in Figs. 4.13, 4.15 and 4.16. Additionally, three accelerometers were attached at segment splices to monitor the vibrations of the tower, as shown in Fig. 4.17.

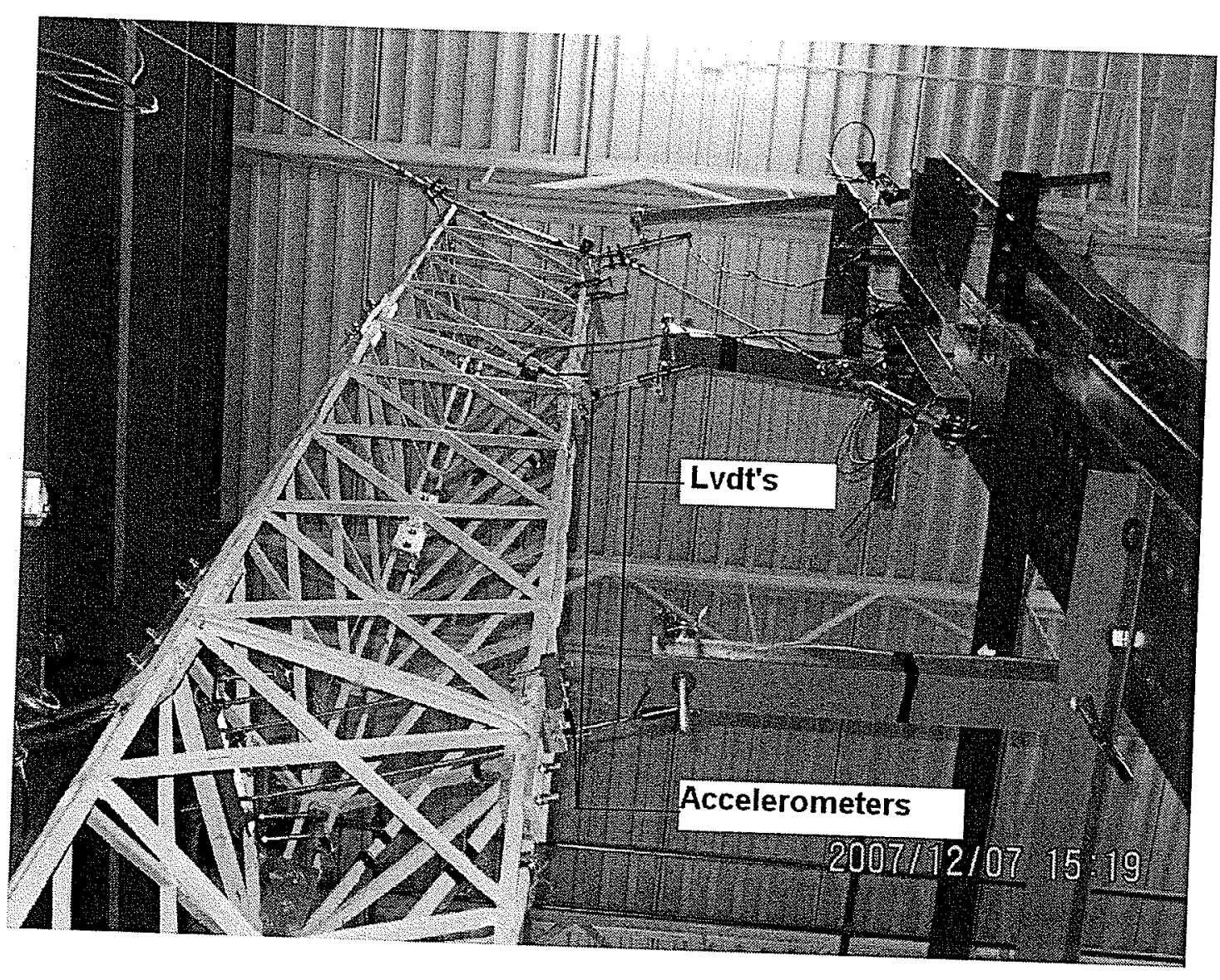

Fig. 4.17 Test set-up, instrumentation

The load was transmitted via a cable attached to a pulley and a quick release bracket as shown in Fig. 4.15. Due to clearance restrictions in the lab, the tower base was redesigned, as described in Section 4.3.2. 


\subsubsection{Improvements to Tower Sleeve Connections}

After static testing, the tower segment was disassembled and the FRP inserts were glued to the chord members by resin, as shown in Fig. 4.18. Also, new resin plugs were placed at the end of each insert. After that, the connection was

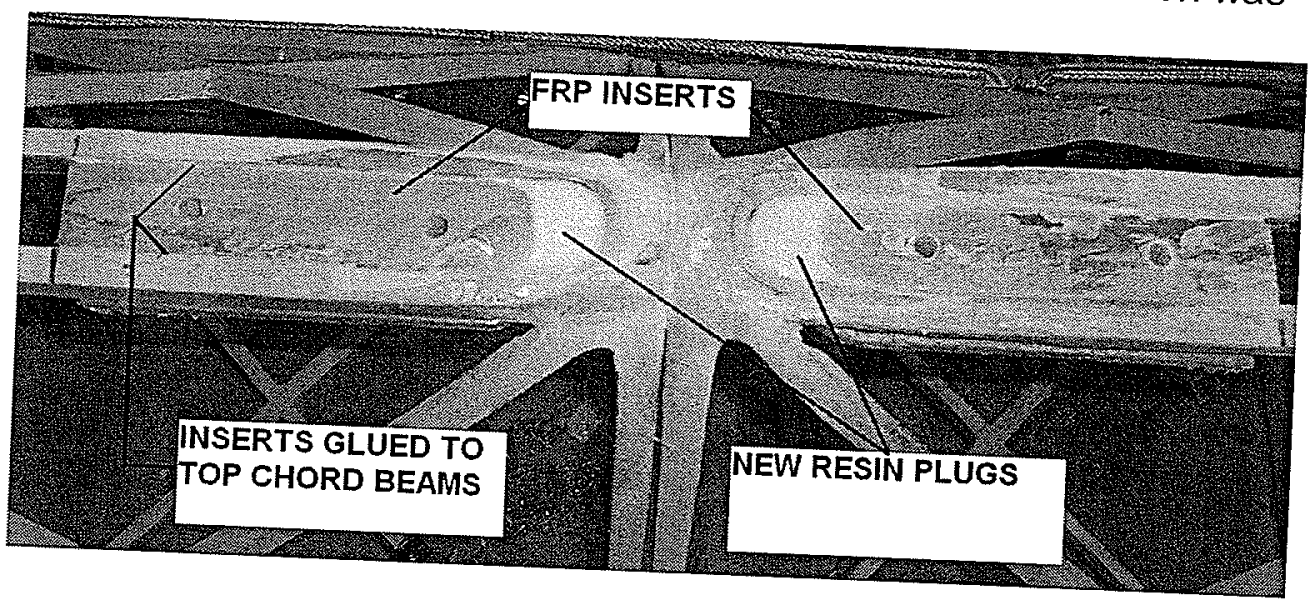

Fig. 4.18 Sleeve bracket connection for dynamic testing before attachment of plates

ground flatted and top and bottom plates were positioned and interconnected by four $9.53 \mathrm{~mm}$ ( $3 / 8 \mathrm{in})$ dia bolts with lock nuts and split washers as shown in Fig.

4.19. The bolts were tightened by a calibrated torque wrench.

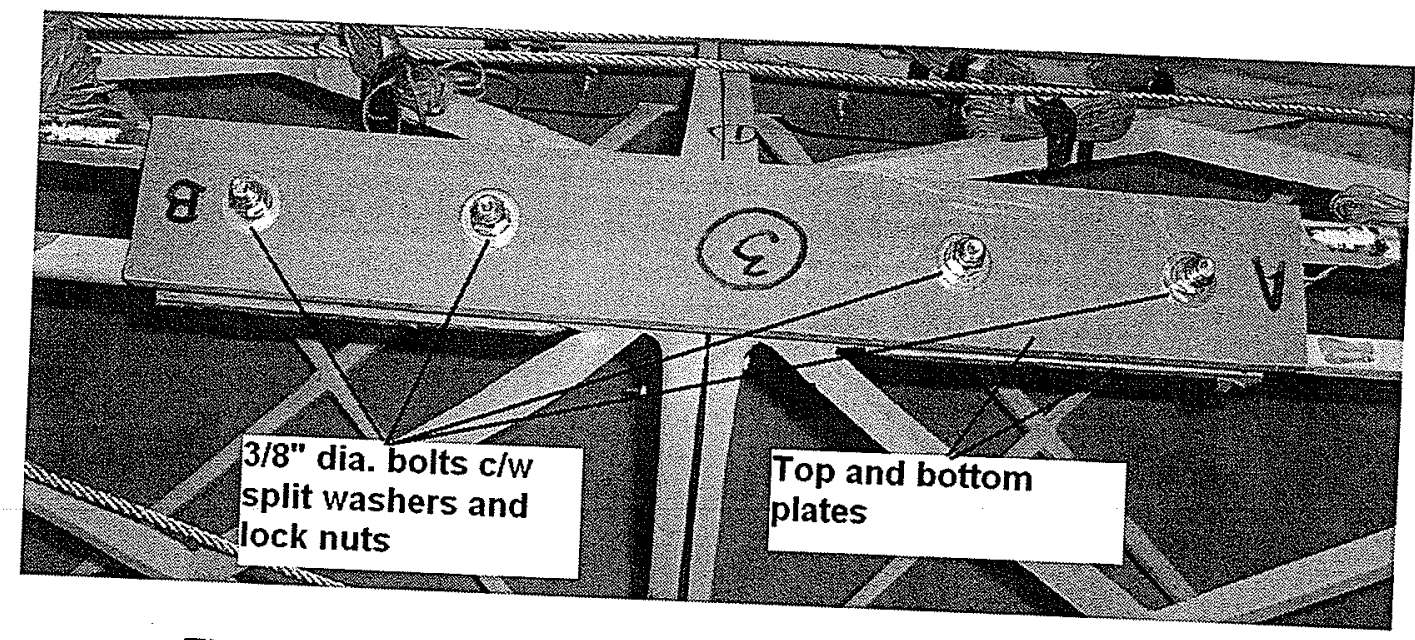

Fig. 4.19 Sleeve bracket connection for dynamic testing after attachment of plates 


\subsubsection{New Tower Base}

Due to a clearance restriction between the lab floor and the overhead crane girder, the tower could not be erected vertically with the same base used for static analysis. Therefore, a new, shorter base was fabricated to accommodate the height restrictions, as shown in Fig. 4.20.

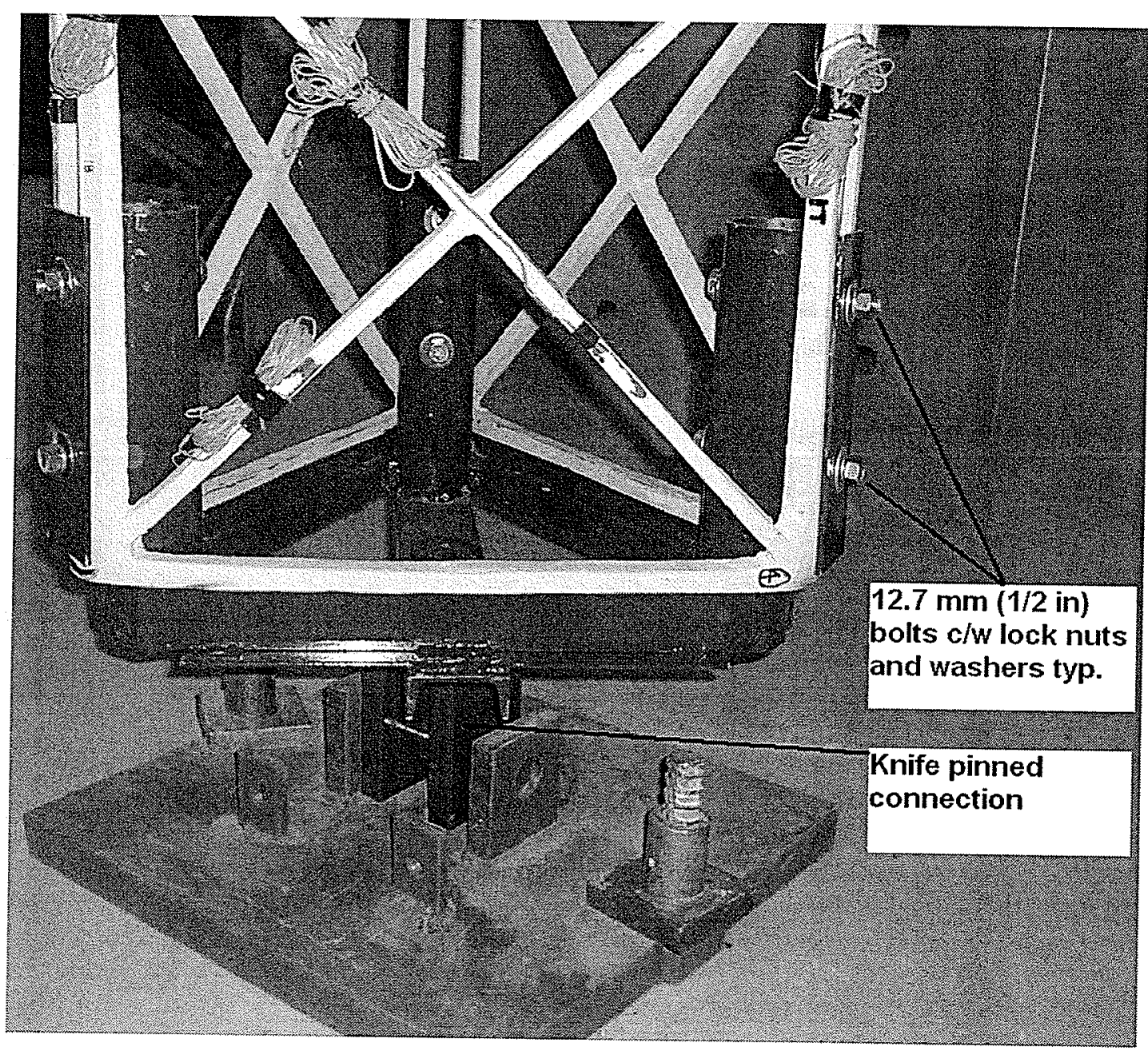

Fig. 4.20 Tower base for dynamic testing

The tower base plate was secured to the concrete floor by two prestressed diwidag rods (up to $275 \mathrm{MPa}$ (40 ksi) per rod) and connected with nuts and washers. 


\subsubsection{Vibration Test Procedure}

All instruments were calibrated prior to their attachment to the tower specimen. The LVDT's were calibrated using a micrometer. The following scale factors were used: LVDT1- scale factor $37.2949 \mathrm{~mm} / \mathrm{V}$; LVDT2- scale factor $36.8232 \mathrm{~mm} / \mathrm{V}$; LVDT3- scale factor $37.9237 \mathrm{~mm} / \mathrm{V}$; and, LVDT4- scale factor $37.1916 \mathrm{~mm} / \mathrm{N}$.

Three- high sensitivity 3 -axis, accelerometers, with a precision reading of $+/-2 \mathrm{~g}$ (series CXL02LF1Z-R-AL) were used. These did not require calibration, although small DC voltage was applied due the length of the extension wires. The load cell was calibrated using an MTS machine as shown in Fig. 4.21.

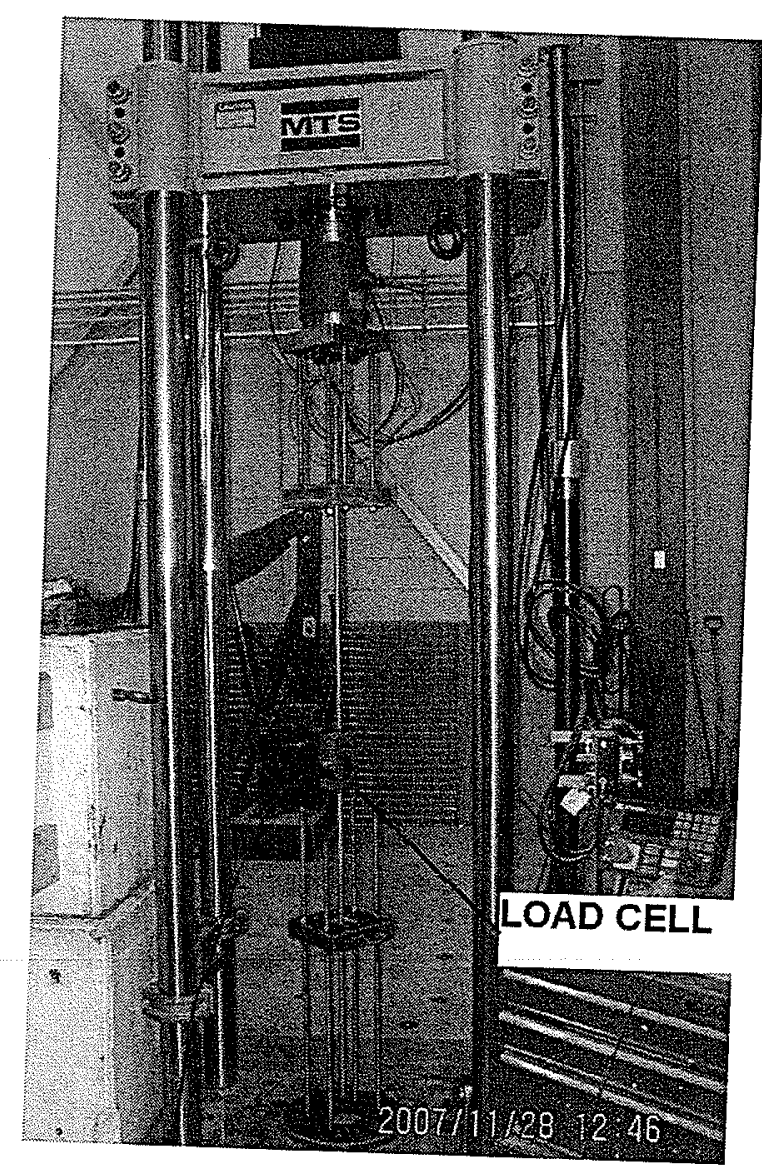

Fig. 4.21 Load cell calibration 
From calibration data, the scale factor for the load cell was found to be $4.47 \mathrm{kN} /$ $\mathrm{mV}$. After the instruments were attached to the data acquisition system, all initial readings were set to zero. Then, the overhead crane was connected through a cable to the load cell and the quick release bracket. The loading was applied in small increments. A calibrated load cell was used to monitor the applied load. Once a predetermined displacement of the tower was reached, the loading was suddenly released using the quick release bracket and the tower was allowed to vibrate freely until it came to a complete stop. The deflection limit was set to 55 $\mathrm{mm}(2.2 \mathrm{in})$ to match the maximum deflection recorded during static testing of the tower. The readings were collected on a desktop computer. Altogether, readings from three accelerometers, four LVDTs and one load cell were collected. The Lab VIEW program was set to record 128 readings per second in order to obtain smooth and accurate vibration curves. Altogether eight tests were conducted for the tower from which four were selected for further data analysis. The objective was to get the applied force at the predetermined level of $5.14 \mathrm{kN}$ or, at $55 \mathrm{~mm}$ lateral deflections, as used for static segment testing. The vibration test data from only four tests conducted (tests 16 to 19) met these criteria.

This was not an easy task since the load was applied manually by increment using an overhead crane and it sometimes was higher or smaller than required. After each test, the tower was carefully aligned to a vertical position using a level. The objective was to get the applied force at the predetermined level of $5.14 \mathrm{kN}$ or, at $55 \mathrm{~mm}$ lateral deflections, as used for static segment testing. The vibration test data from only four tests conducted met these criteria. 
CHAPTER 5

\section{DISCUSSION OF RESULTS}




\section{Discussions of results}

\subsection{GENERAL}

The experimental results from the $8.53 \mathrm{~m}(28 \mathrm{ft})$ tower segment are presented and discussed in this chapter in the form of load-deflection and deflection versus distance curves shown in Figs. 5.1, 5.2, 5.6 and 5.7. The test data are used to validate the two FEM models discussed in Chapter 5. One FEM model is used to analyse the full $45 \mathrm{~m}(147 \mathrm{ft})$ tower as well as the $8.53 \mathrm{~m}(28 \mathrm{ft})$ tower segment. Results from the Sleeve FEM model developed to account for sleeve connections between tower sections are also discussed. Since the data acquisition system used System International (SI) units, all loadings are shown in $\mathrm{kN}$, and all length units are given in $\mathrm{mm}$. Imperial units are provided in parenthesis.

\subsection{Analysis of Static Test Results}

The tower segment, shown in Fig. 4.3, was tested to a maximum load of $8 \mathrm{x}$ $0.644 \mathrm{kN}=5.14 \mathrm{kN}(1155 \mathrm{lbs})$. Since the objective of the testing was to gather data for the purpose of evaluating the FEM models, the tower was not tested to failure. The same tower segment was later retested to examine its behaviour under vibration. The load-deflection curves obtained from the LMT's and the LVDT are shown in Fig. 5.1. The largest deflections were registered by LMT1 at the midspan section of the segment. The results from the FEA along the span and at the maximum loading of $5.14 \mathrm{kN}$ (1155lbs) are shown in Fig. 5.2 along with the experimental results. As indicated in Fig. 5.2, there is a close correlation between the two FEM models discussed in Chapter 3. Both FEM models were developed with identical boundary condition; i.e. pinned base and the free end 


\section{Discussions of results}

supported by two guy cables with spring constants equal to the spring constant in the full scale model $(\mathrm{k}=97.82 \mathrm{kN} / \mathrm{m}$ (558.67lbs/in)). The maximum deflection at the midspan (LMT-1) was at $51.03 \mathrm{~mm}$ (2.01 in) as obtained from the sleeve model and

\section{Load-Deflection}

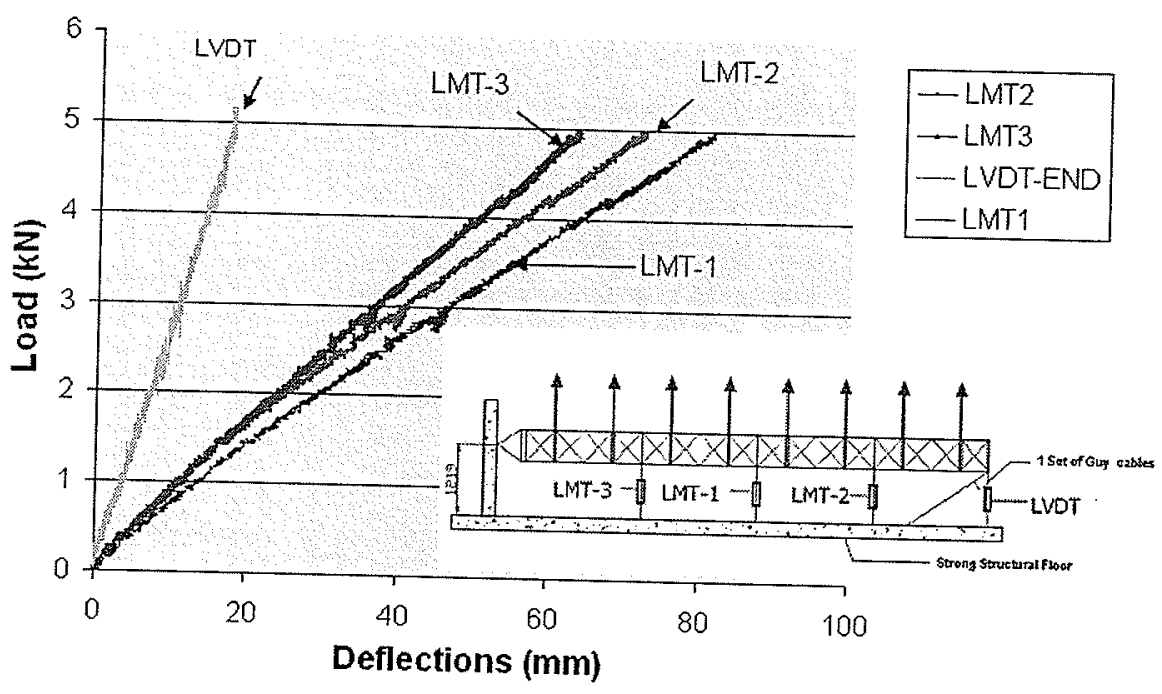

Fig. 5.1 Load-deflection

Deflections vs. distance at $5.14 \mathrm{kN}(1156 \mathrm{lbs})$

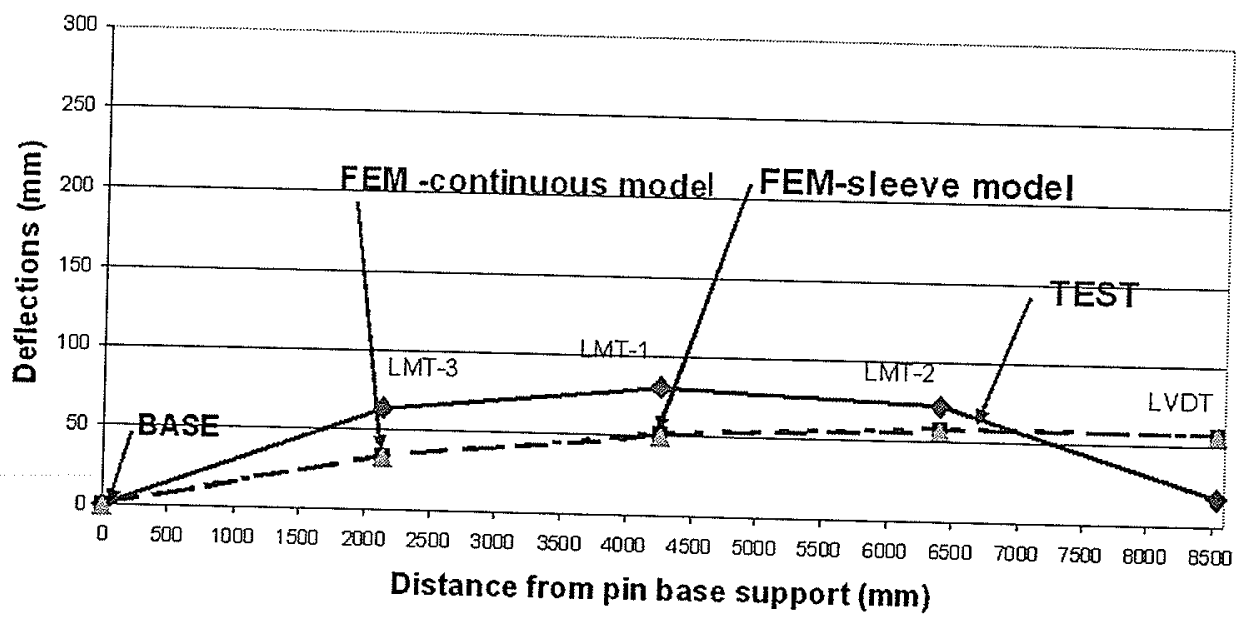

Fig. 5.2 Deflection along the tower segment at the maximum load of $5.14 \mathrm{kN}$ (1156 lbs) 


\section{Discussions of results}

$50.56 \mathrm{~mm}$ (1.99 in) as obtained from continuous model. The experimental result at the same location was $80.58 \mathrm{~mm}$ (3.17 in). The difference may be attributed to the flexibility of the cables supporting the tower segment and the slip of the sleeve brackets connecting the tower sections together. The slip which occurred at $1 / 4$ span, $1 / 2$ span and $3 / 4$ span from the support is evident in Figs. $5.3,5.4$ and 5.5

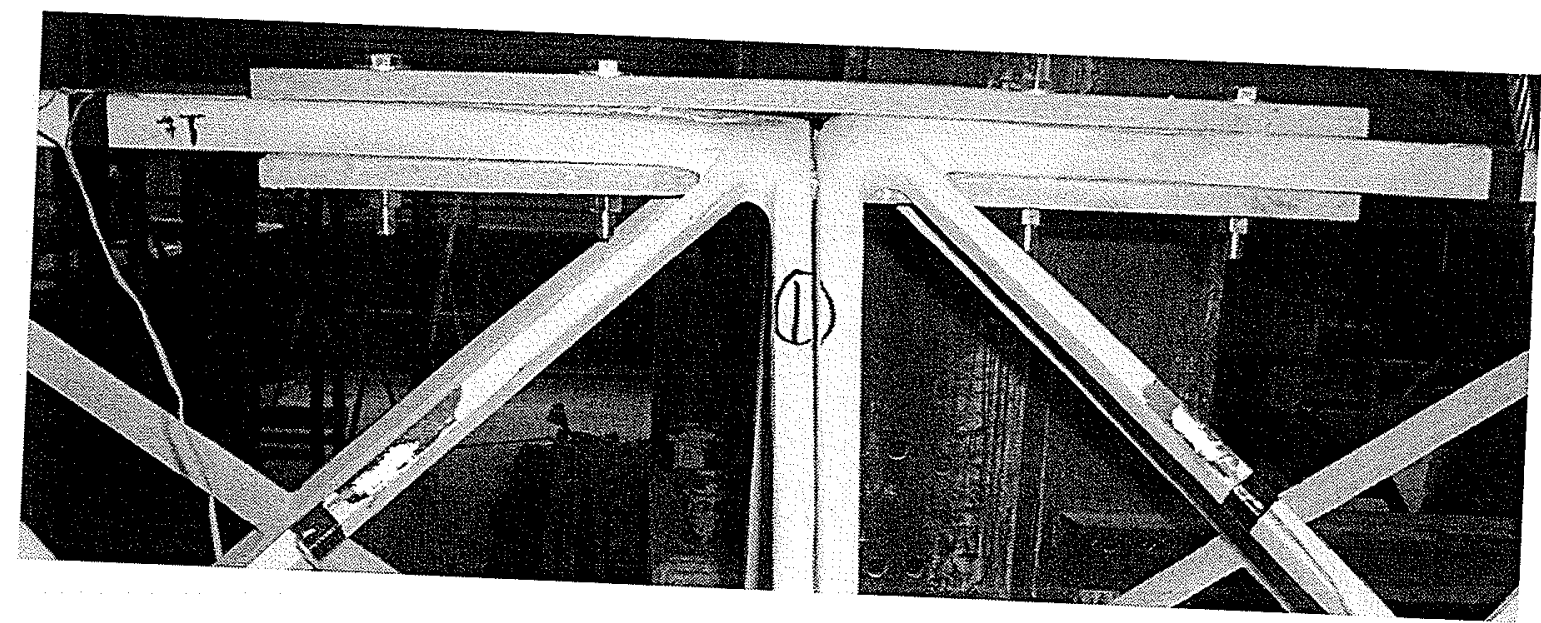

Fig. 5.3 Slip in top chord at $1 / 4$ span

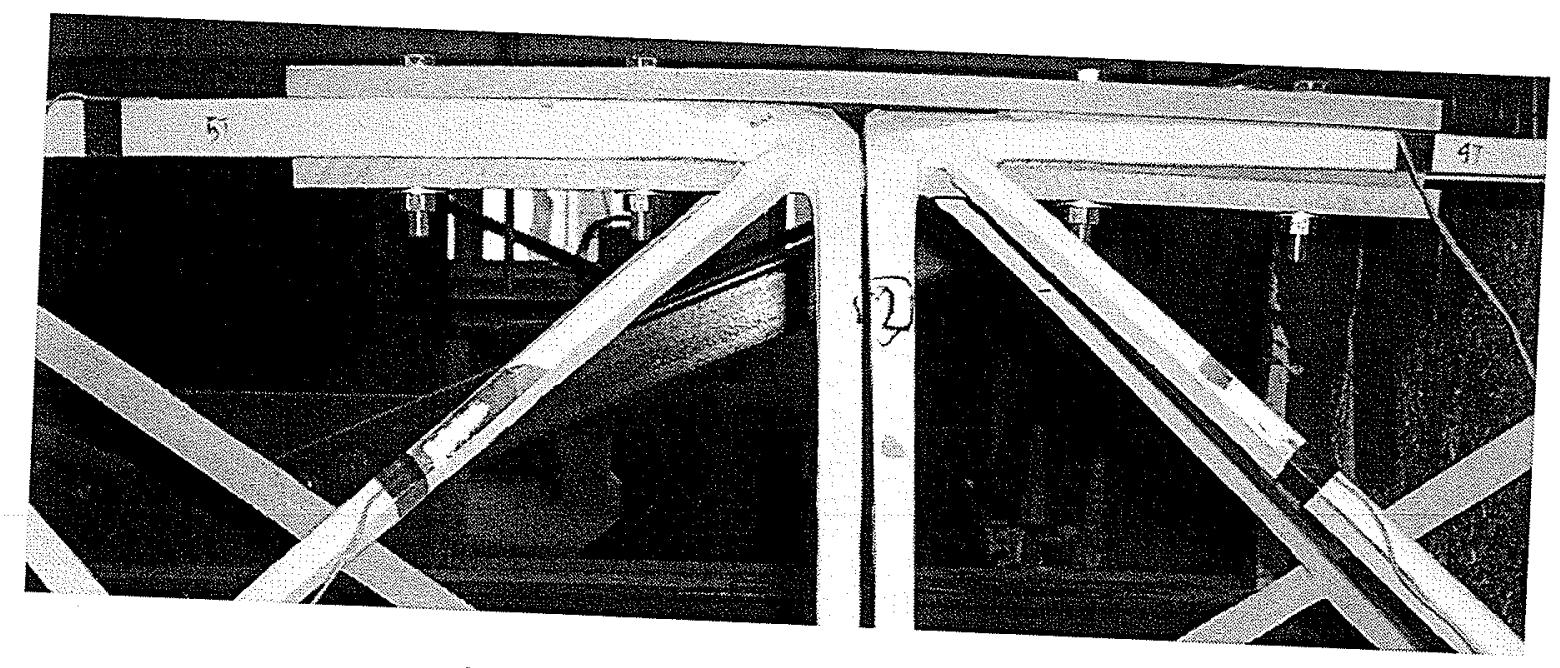

Fig. 5.4 Slip in top chord at $1 / 2$ span 


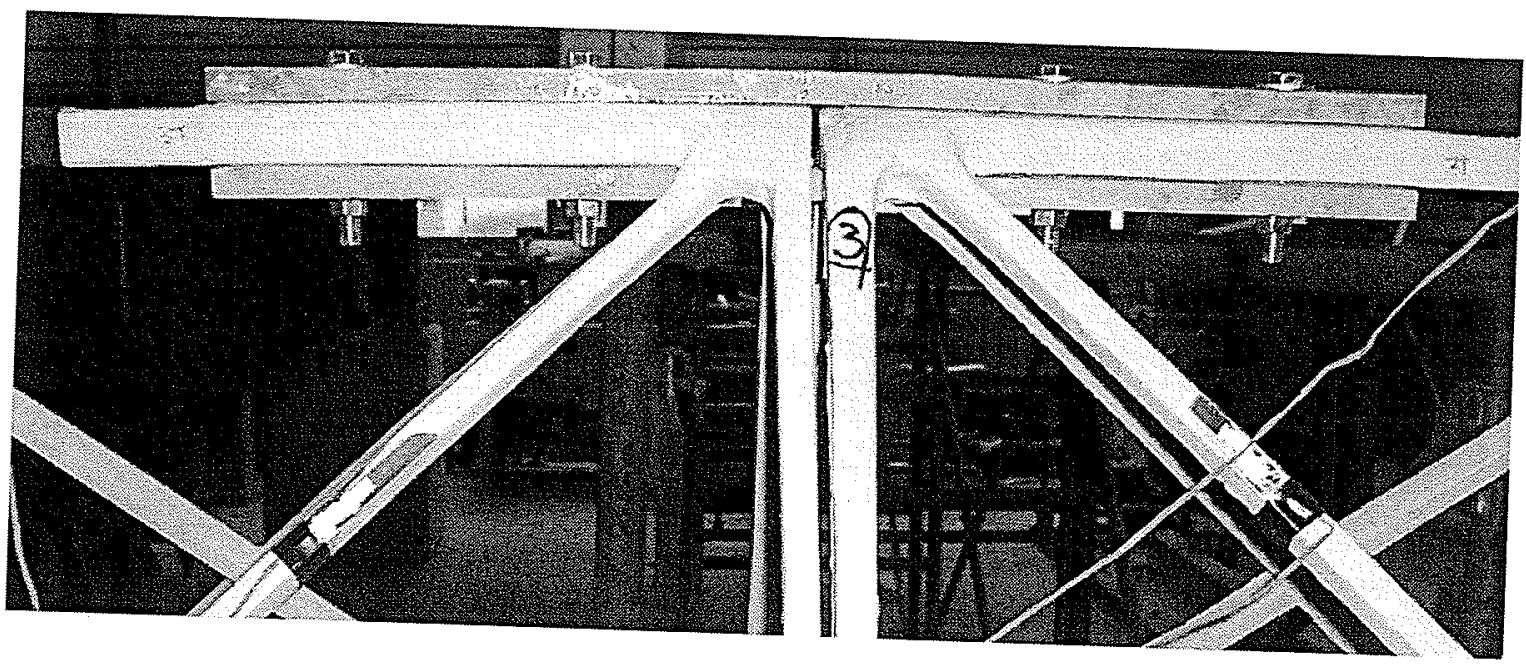

Fig. 5.5 Slip in top chord at $3 / 4$ span

Test data, FEM-sleeve model results and FEM-continuous model results using an applied loading equal to $2.62 \mathrm{KN}(589.92 \mathrm{lbs})$ are included in Fig. 5.6. The maximum deflection at midspan (LMT-1) during testing was $36.60 \mathrm{~mm}$ (1.44 in), while the sleeve F.E. model gave $26.45 \mathrm{~mm}(1.04 \mathrm{in})$ and the continuous F.E. model gave $26.21 \mathrm{~mm}$ (1.03 in). The experimental and predicted load-deflection curves at the midspan of the tested tower segment up to a maximum total load of $5.14 \mathrm{kN}$ (1155 lbs), are shown in Fig. 5.7.

Obviously, the results indicate that the test specimen exhibited much greater deflections than those predicted by the FEA. The difference in deflections between test and the FEM models, as shown in Figs. 5.2 and 5.6, at the end of the tower segment is attributed to the difference in the stiffness of the cables used for test and the stiffness of the cables used for FEM models. The stiffness in FEM models was adjusted to the stiffness in full scale tower, while the stiffness of cables used for testing was not adjusted in the same way. 
Deflections vs. distance at $2.62 \mathrm{kN}$ (589.92 lbs)

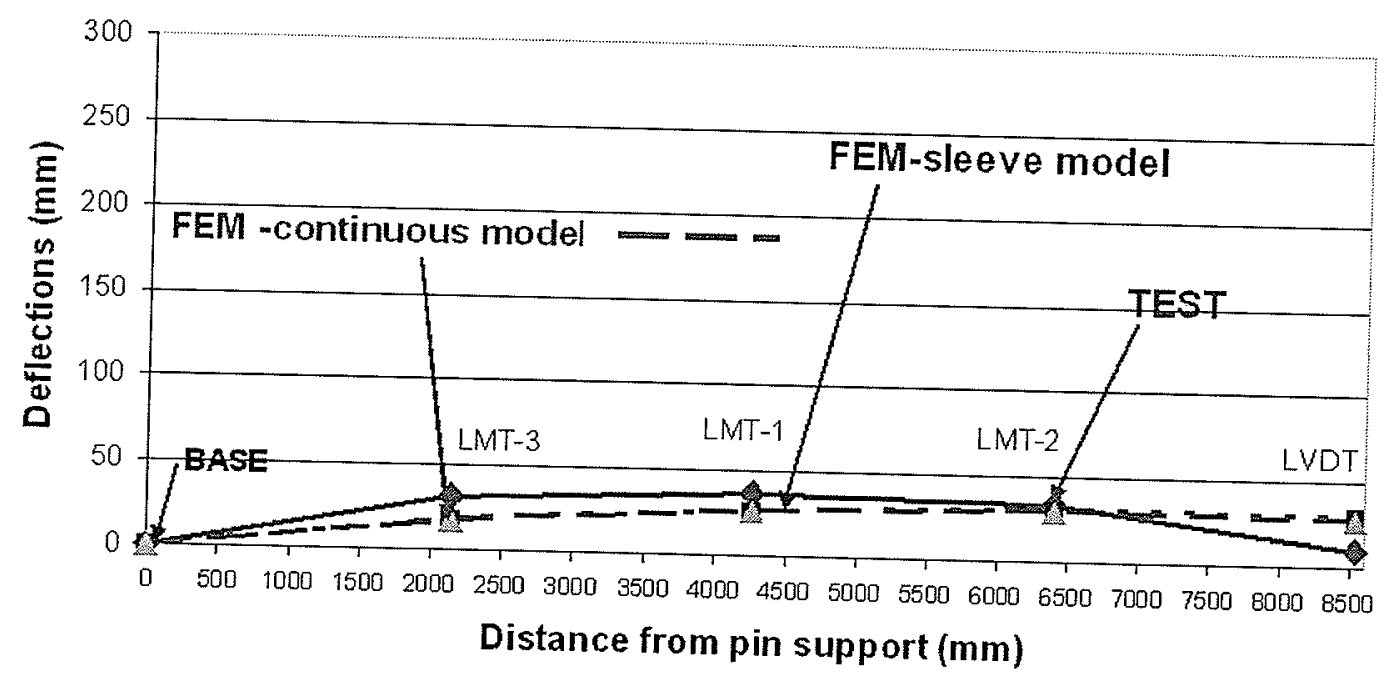

Fig. 5.6 Deflection along the $8.53 \mathrm{~m}(28 \mathrm{ft})$ tower segment

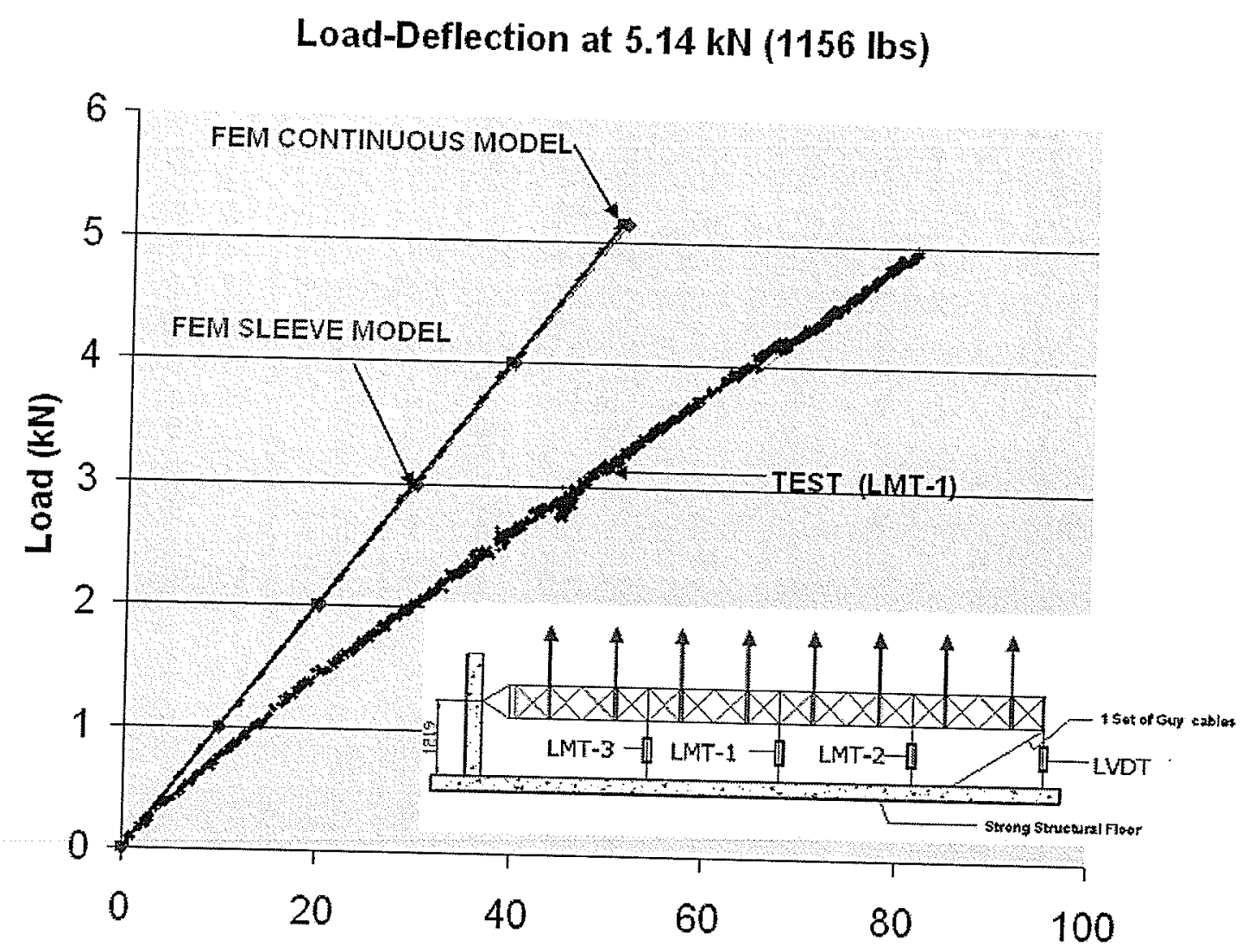

Fig. 5.7 Load deflection curves at the midspan 
The slip of the sleeve brackets which occurred in the static testing was caused by lack of bond between the inserts and chords as shown in Fig. 5.8.

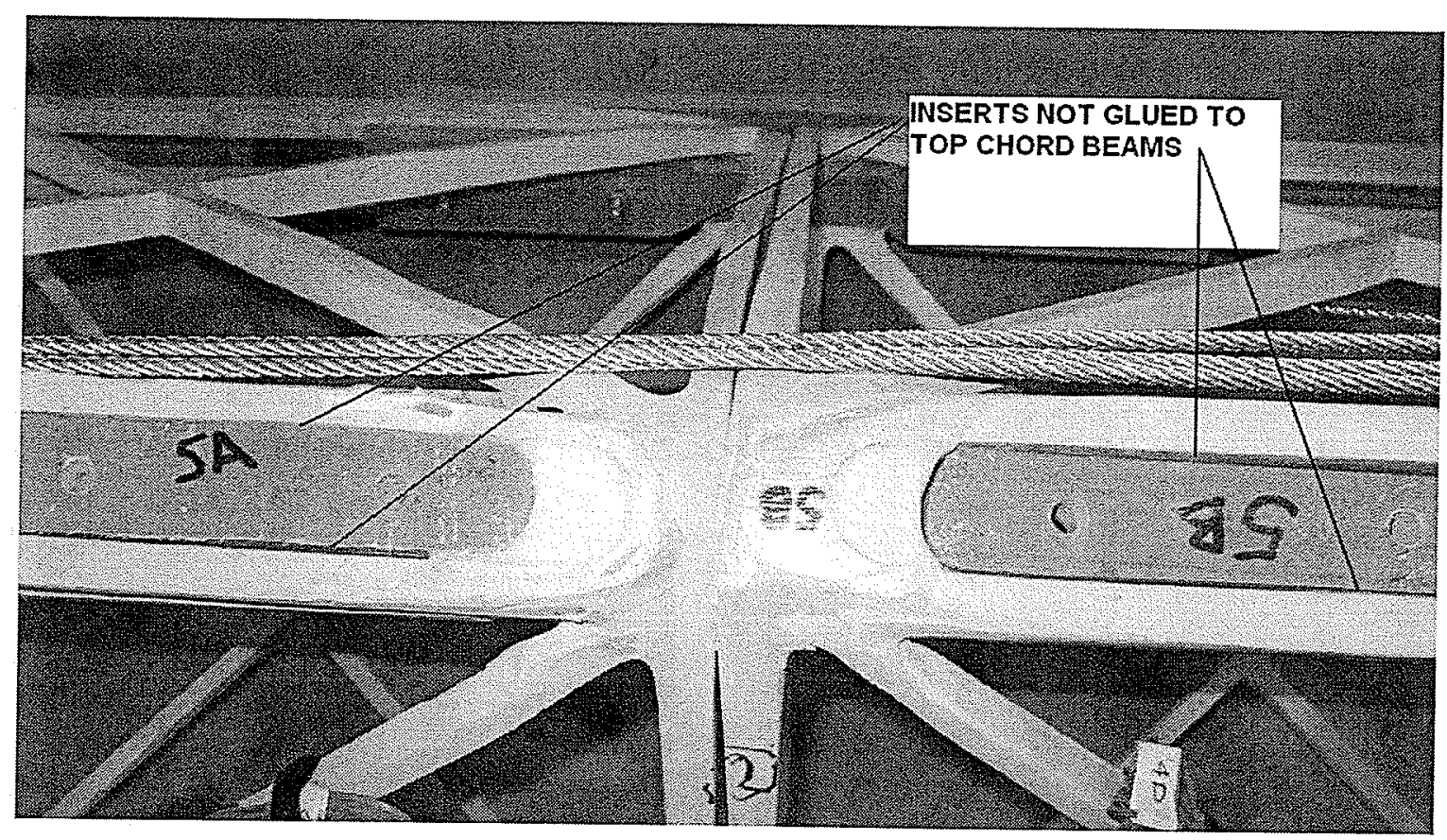

Fig. 5.8 Sleeve bracket connection for static testing

This problem was eliminated by improvements to tower sleeve connections described in Section 4.3.1.

\subsection{Strain Distribution Analysis}

Strains obtained from strain gauges located at various tower locations, shown in Fig. 5.9 were plotted to analyse the strain variation as a function of the applied loading. Strains curves were also verified by FEA of tower segment loaded with service loadings. As shown in Fig. 5.10 the tower acts as a beam with the top chord resisting tension and bottom chords resisting compression. 


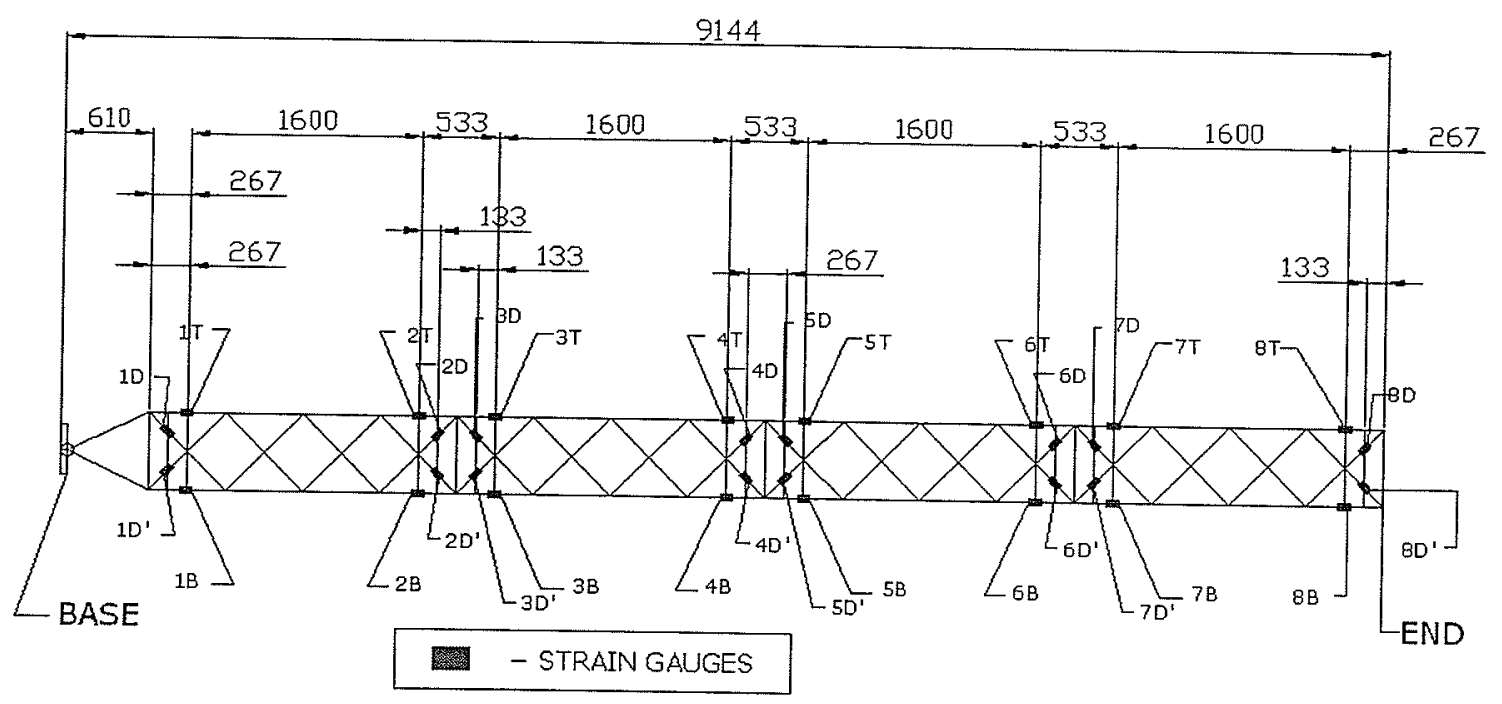

Fig. 5.9 Strain gauges location along one side of the tower segment (units are in $\mathrm{mm}$ )

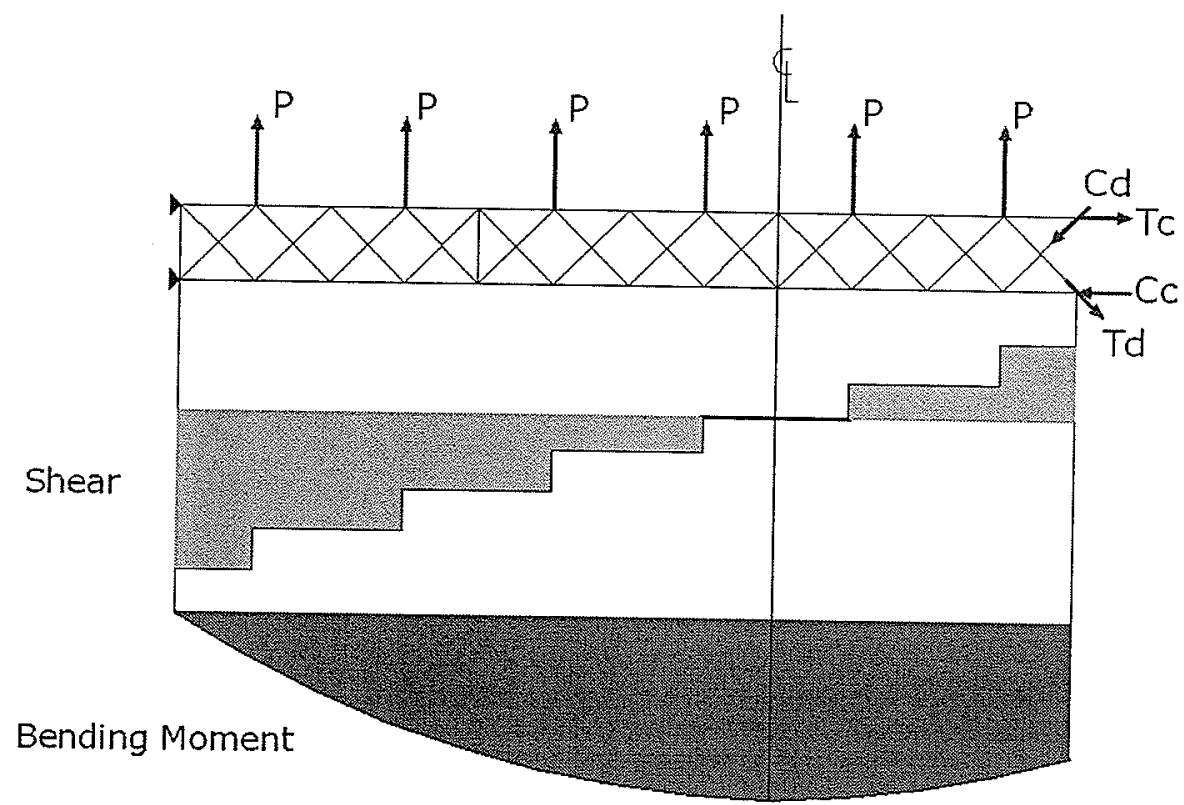

Fig. 5.10 Shear and bending moment diagrams for tower segment

The maximum magnitude of these forces is at the mid-span and diminishes towards the supports. The web of this beam, in this case, consists of diagonal members, resisting the shear. The maximum shear is in the diagonals closer to 
the supports and diminishes near the mid-span. This observation is evident in the strain values recorded along various points across the span of the tower. The results obtained through the FEA are shown in Fig. 5.11.

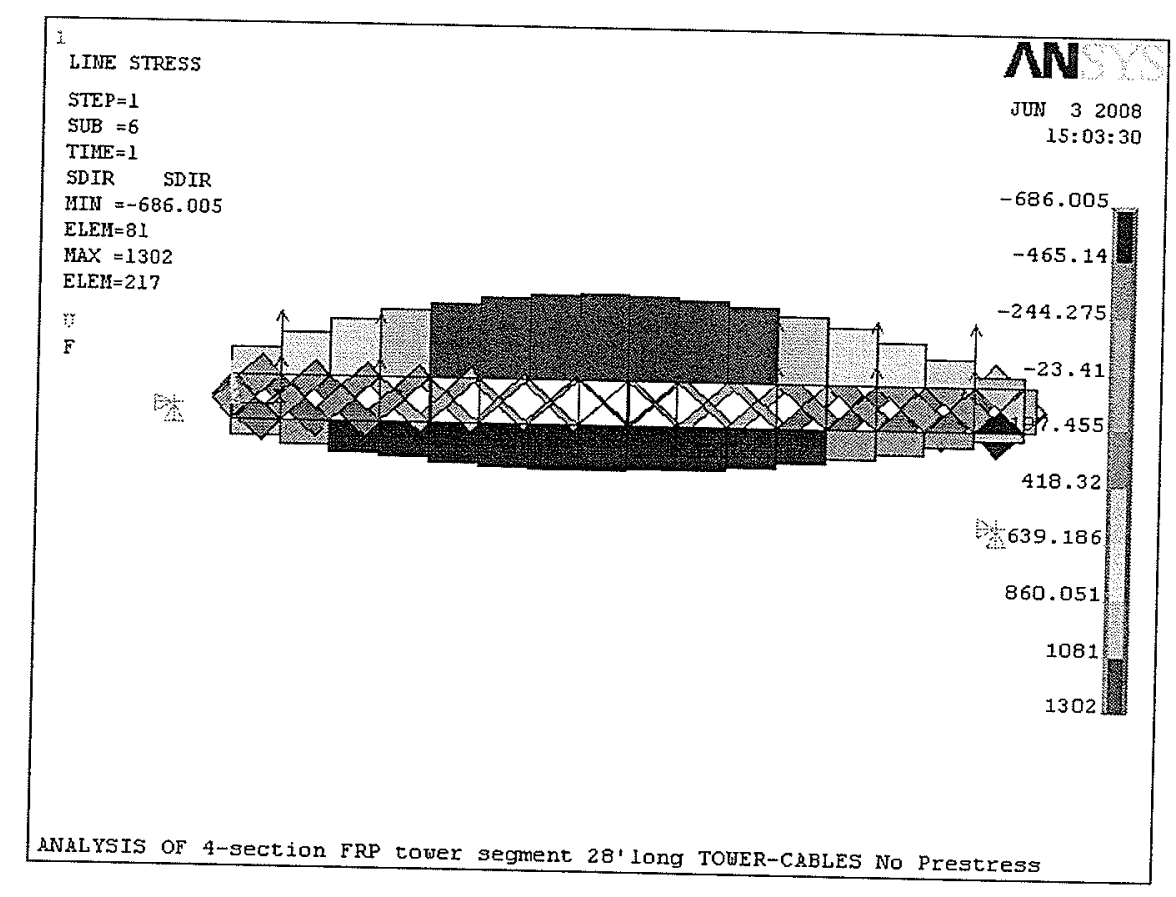

Fig. 5.11 SDIR, direct axial stress (psi) along the tower segment

The load strain curves, shown in Fig. 5.12, indicate that the top and bottom chords in the members located at the end of the specimen carried very small loading. This is to be expected since these chords are close to the simply supported ends provided by the guy cables. The maximum strain in diagonals at the same location was recorded in member 8D', as shown in Fig. 5.13. This is to be expected since this diagonal carries a substantial shear force, as shown in Fig. 5.10. Diagonal member $8 \mathrm{D}$ is a zero force member, as indicated in Fig. 5.13. 
Load-strain curve in chords at the end

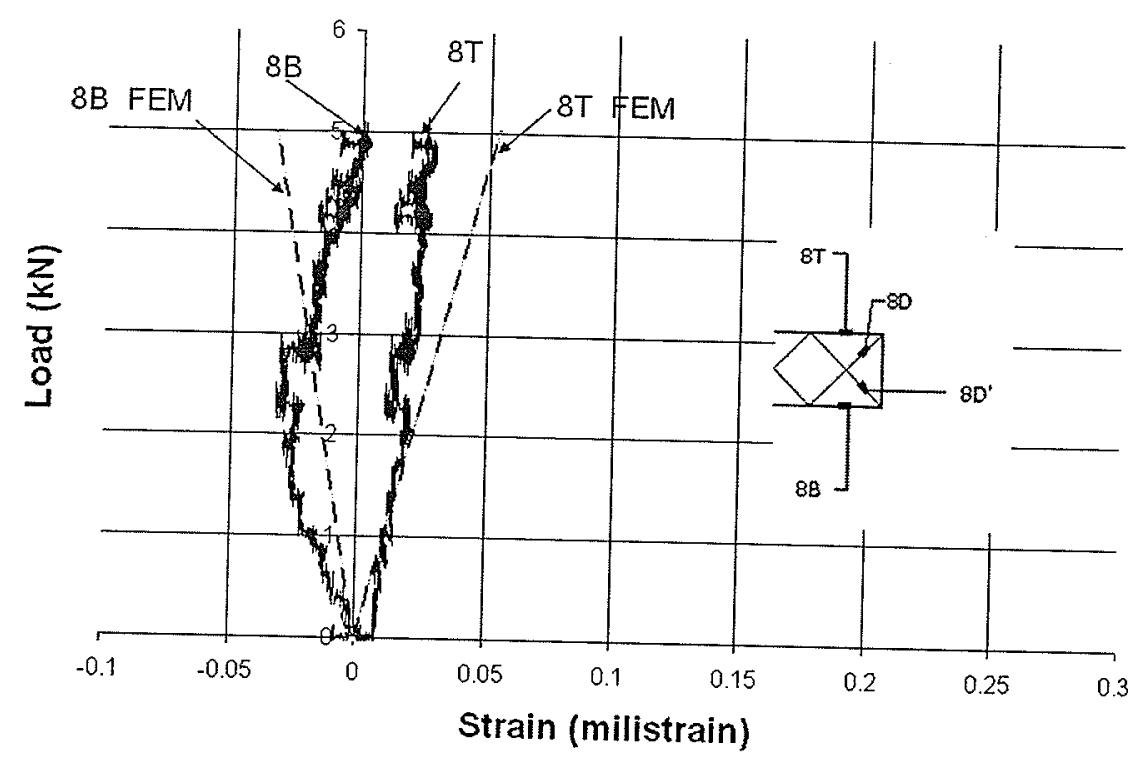

Fig. 5.12 Strains in chords at the end

Load-strain curve in diagonals at the end

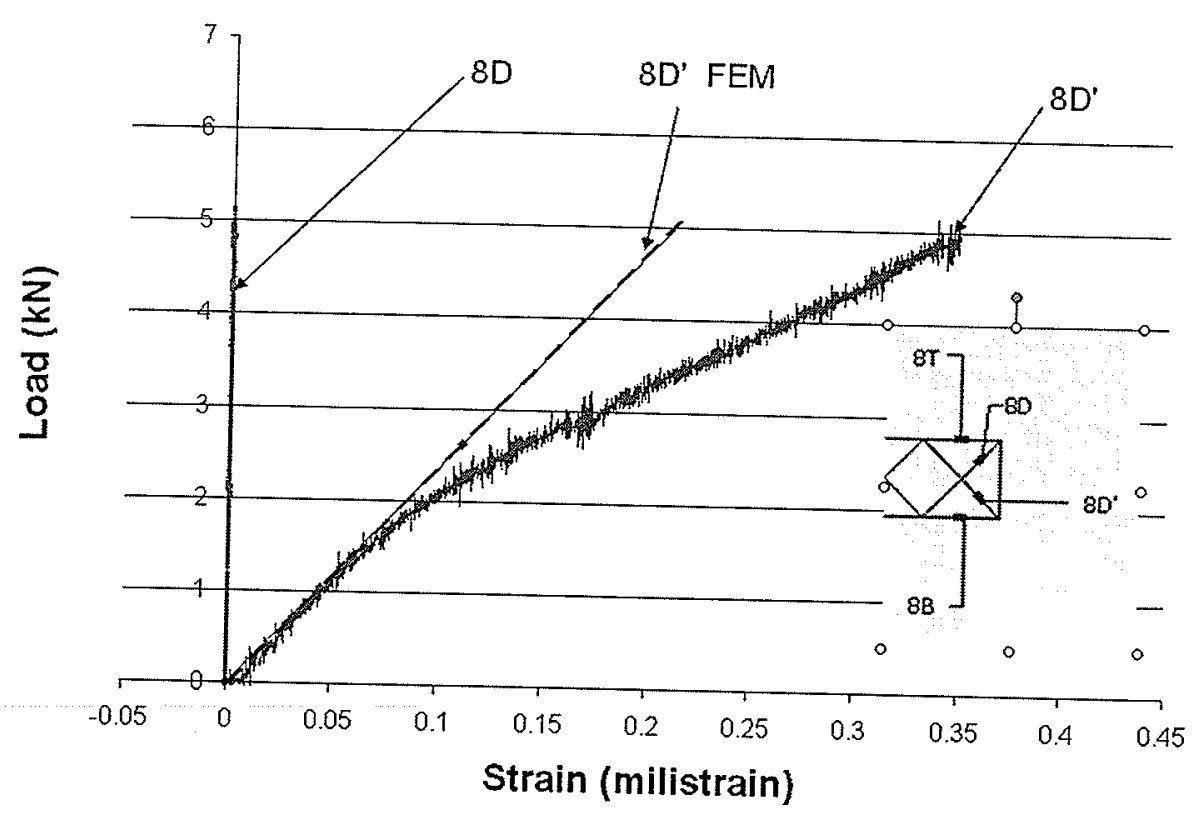

Fig. 5.13 Strains in diagonals at the end 


\section{Discussions of results}

The strains in the top and bottom chords at the $3 / 4$ - span from the tower base are shown in Fig. 5.14. The results indicate that the strains in the top chord, strain gauges $6 \mathrm{~T}$ and $7 \mathrm{~T}$, are considerably higher than the strains recorded by strain gauges $6 \mathrm{~B}$ and $7 \mathrm{~B}$ in the bottom chords. The strains in the top chord are almost double the strains recorded in the bottom chord. It should be pointed out, that there are two chords on the bottom (compression side) sharing the load, while there is only one chord in the top (tension side) of the latticed tower.

\section{Load-strain curve in chords at 3/4 span from base}

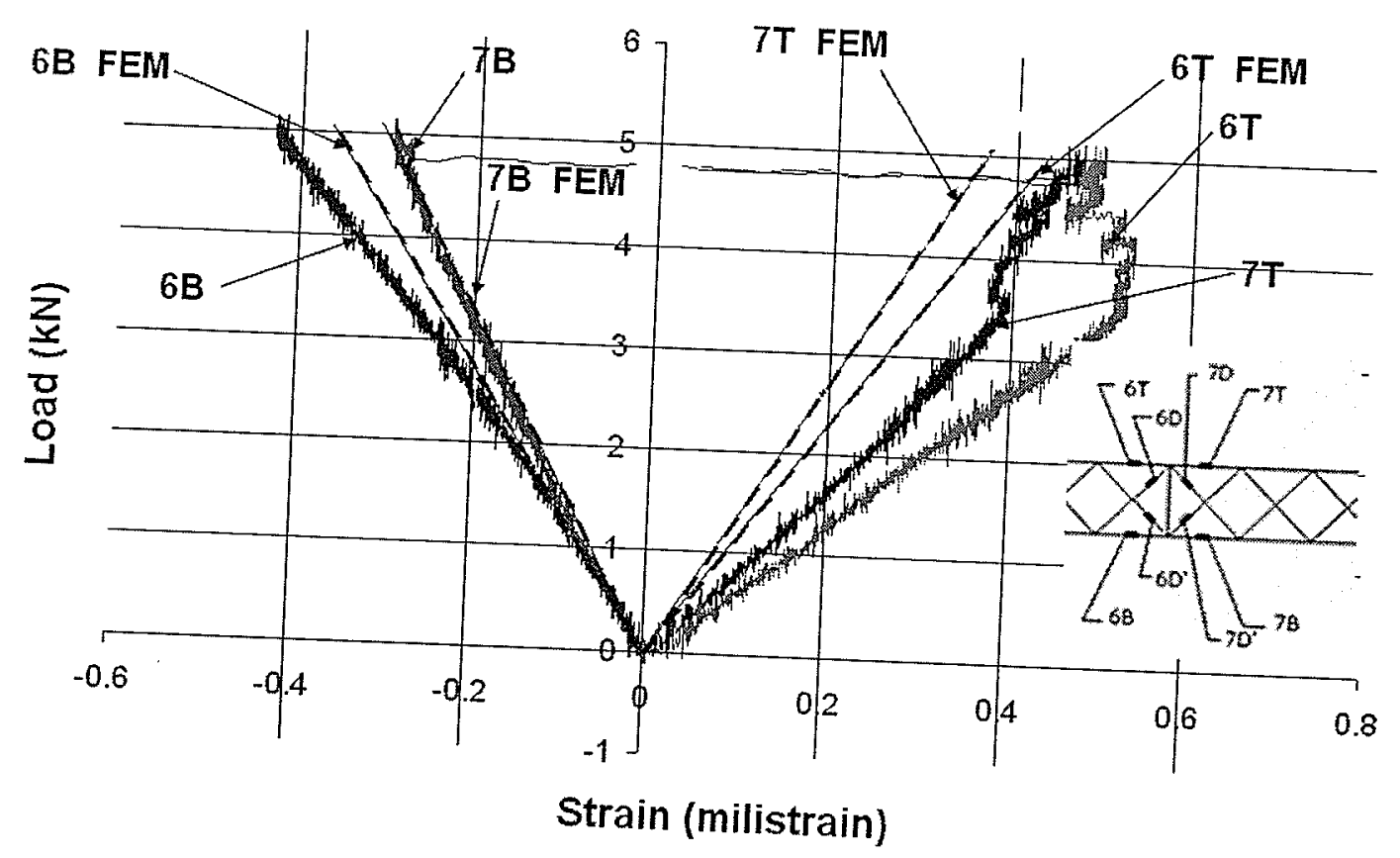

Fig. 5.14 Strains in chords at $3 / 4$ span

The strains recorded in the top chord (strain gauges $6 \mathrm{~T}$ and $7 \mathrm{~T}$ ) decrease above the applied loading of $3.5 \mathrm{kN}$, indicating that a sleeve connection relaxation 
occurred at that point. The strains in the diagonals at the $3 / 4$ - span, are shown in Fig. 5.15.

\section{Load-strain curve at $3 / 4$ span from base}

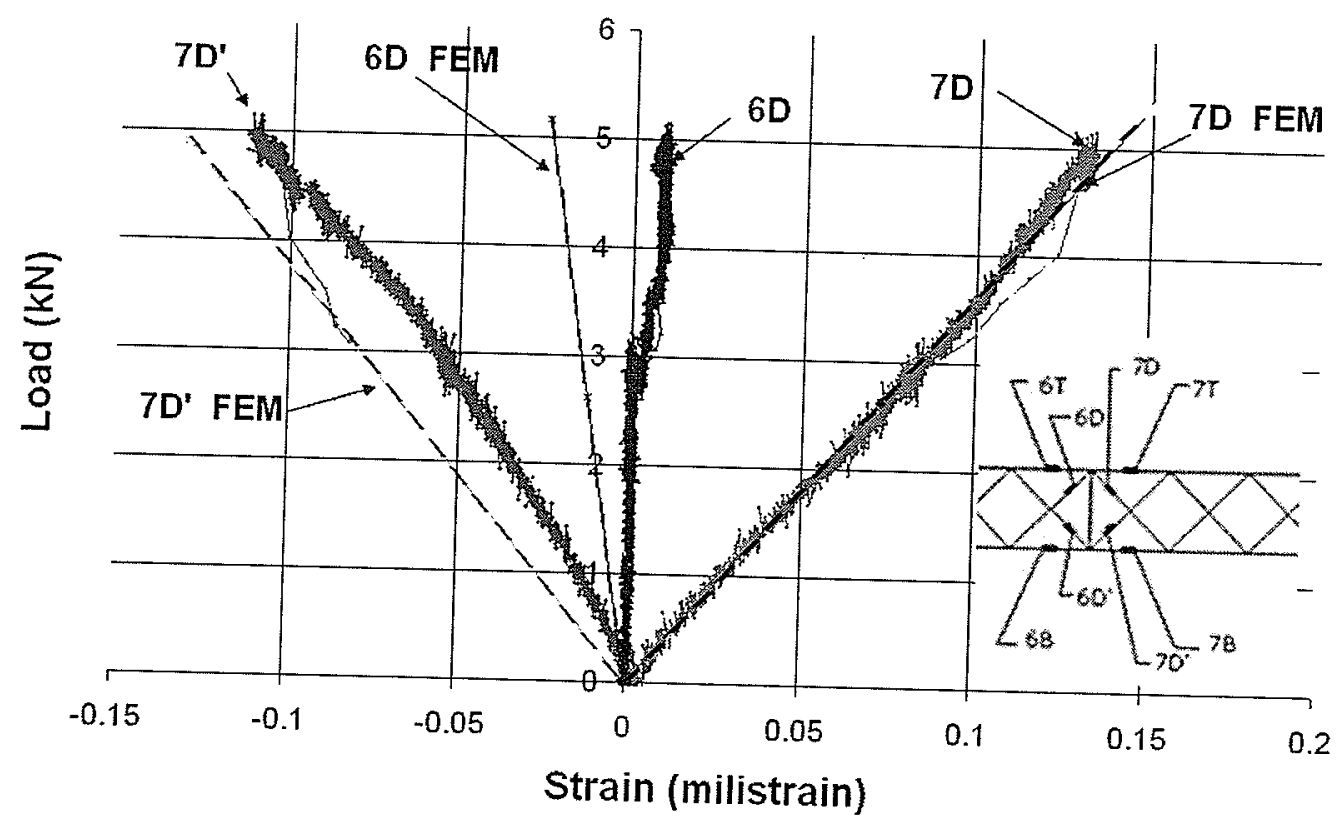

Fig. 5.15 Strains in diagonals at $3 / 4$ span

Strain in diagonal 6D' was not recorded due to malfunctioning of the strain gauge. The strains in diagonal $6 \mathrm{D}$ are significantly less than the strains in diagonals 7D and 7D', as expected.

The strains in the top and bottom chords at the mid-span are shown in Fig. 5.16. Strain gauges $5 \mathrm{~T}$ and $5 \mathrm{D}$ did not function properly and no data were recorded. As explained earlier, there are two chords along the bottom side (compression side) of the tower, while there is only a single chord along the top (tension side). As a result, the strains along the top are considerably higher than the strains along the bottom side, as shown in Fig. 5.16. In addition to the direct stresses, shown in 


\section{Discussions of results}

Fig. 5.11, there are bending stresses induced which vary along the span, as shown in Fig. 5.17 and Fig. 5.18.

Load-strain curve in chords at the midspan

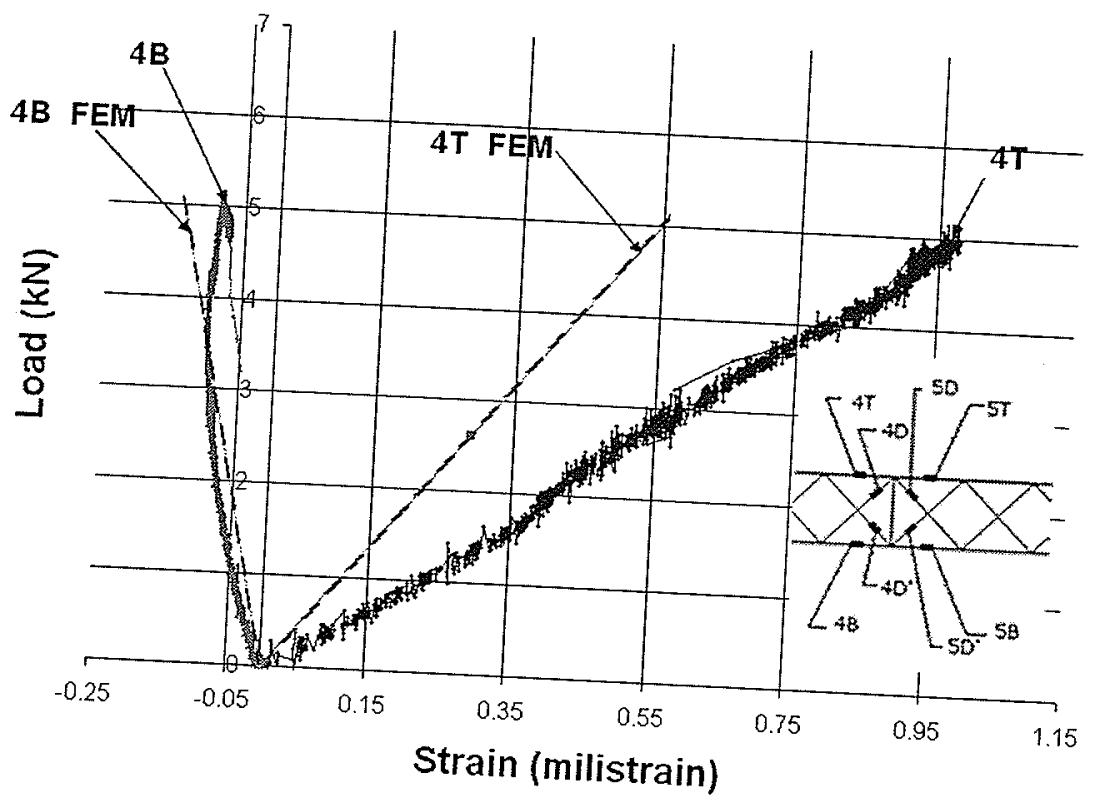

Fig. 5.16 Strains in chords at mid-span

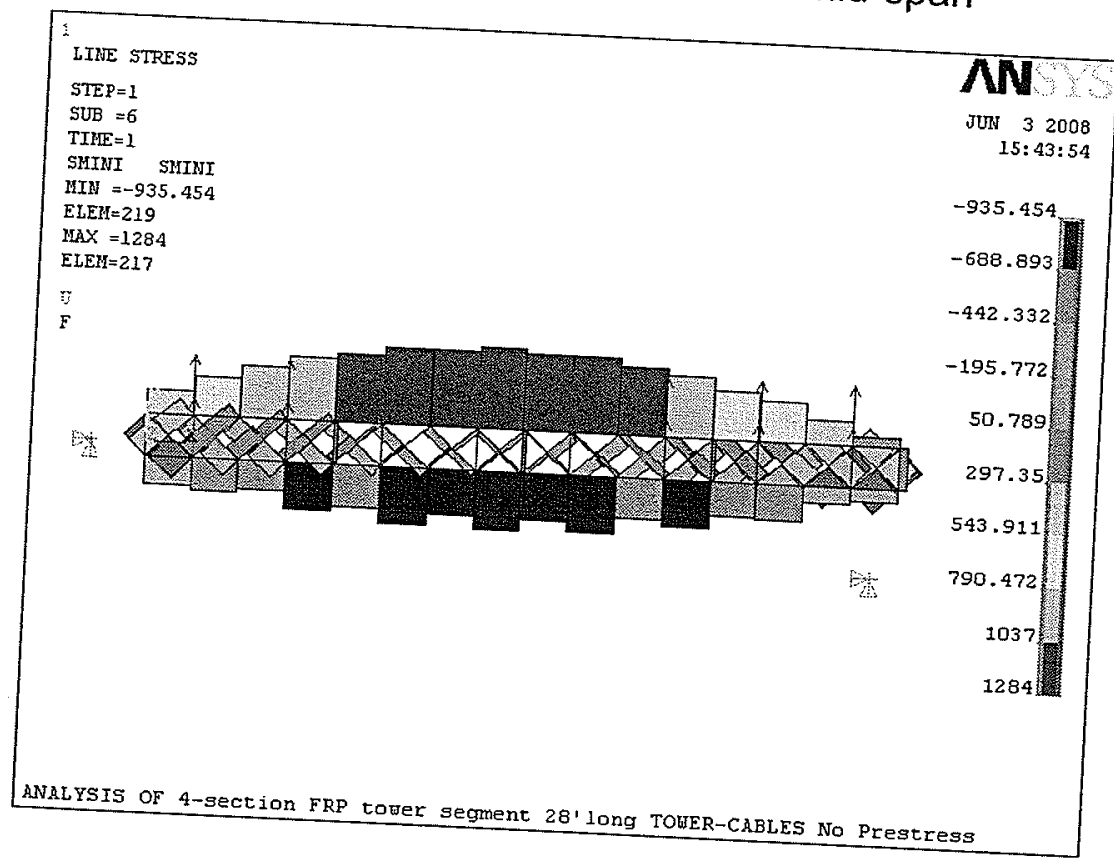

Fig. 5.17 SMINI minimum stress (psi) at joints i of the tower segment 


\section{Discussions of results}

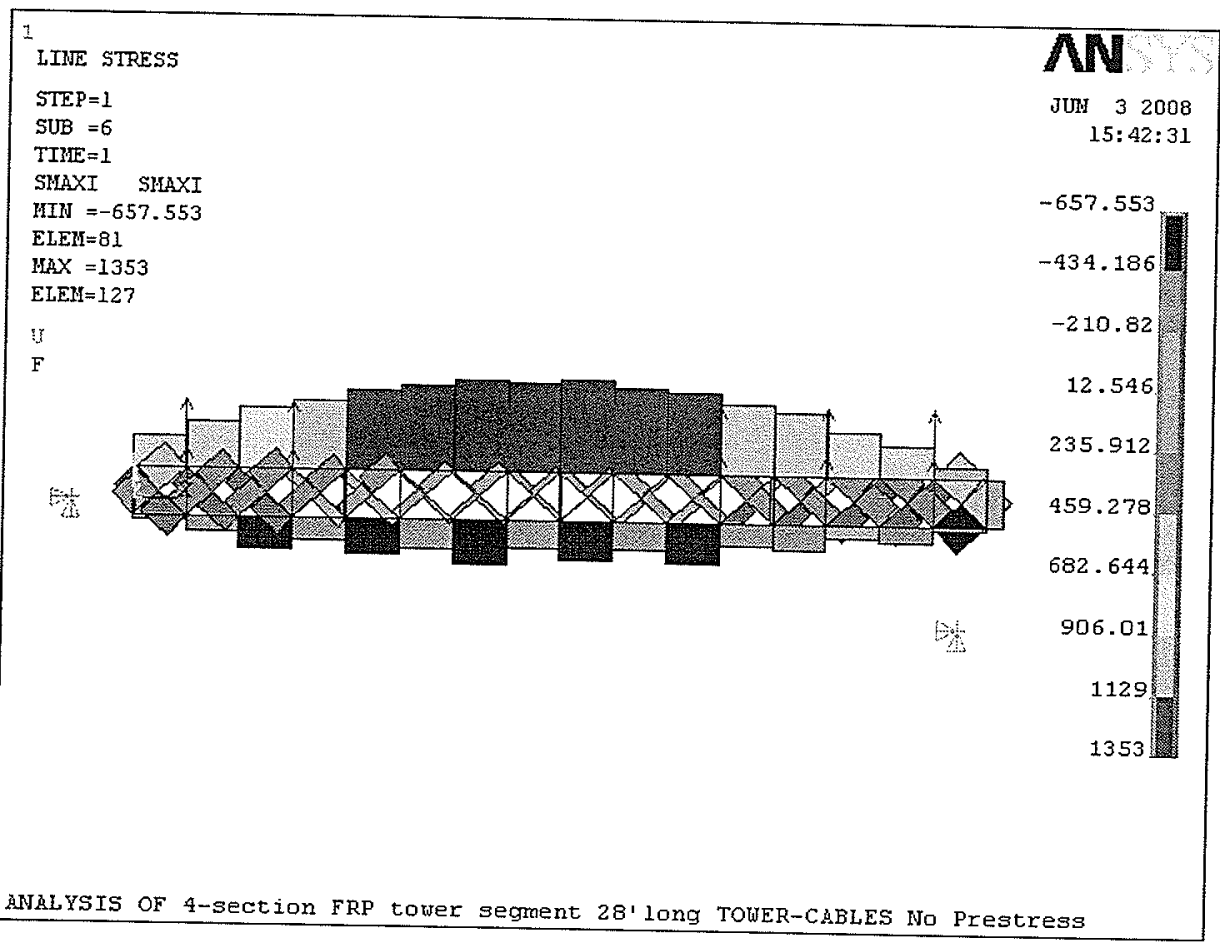

Fig. 5.18 SMAXI maximum stress (psi) at joints i of the tower segment

The maximum strain in the top chord, strain gauge $4 \mathrm{~T}$, corresponds to a tensile stress of 24.8 MPa (3.6 ksi). This is, however, not the maximum stress recorded along tower segment. The maximum stress was recorded at the base of the tower. The strains in the diagonals at mid-span are shown in Fig. 5.19. The strains in diagonals $4 D$ and $4 D^{\prime}$ are significantly higher than the strains in diagonals $5 \mathrm{D}$ and 5D', mostly due the increasing shear force towards the supports. The maximum strain was recorded by strain gauge 4D' which corresponds to a stress of $1.78 \mathrm{MPa}$ (253.8 psi). 
Load-strain curve in diagonals at the midspan

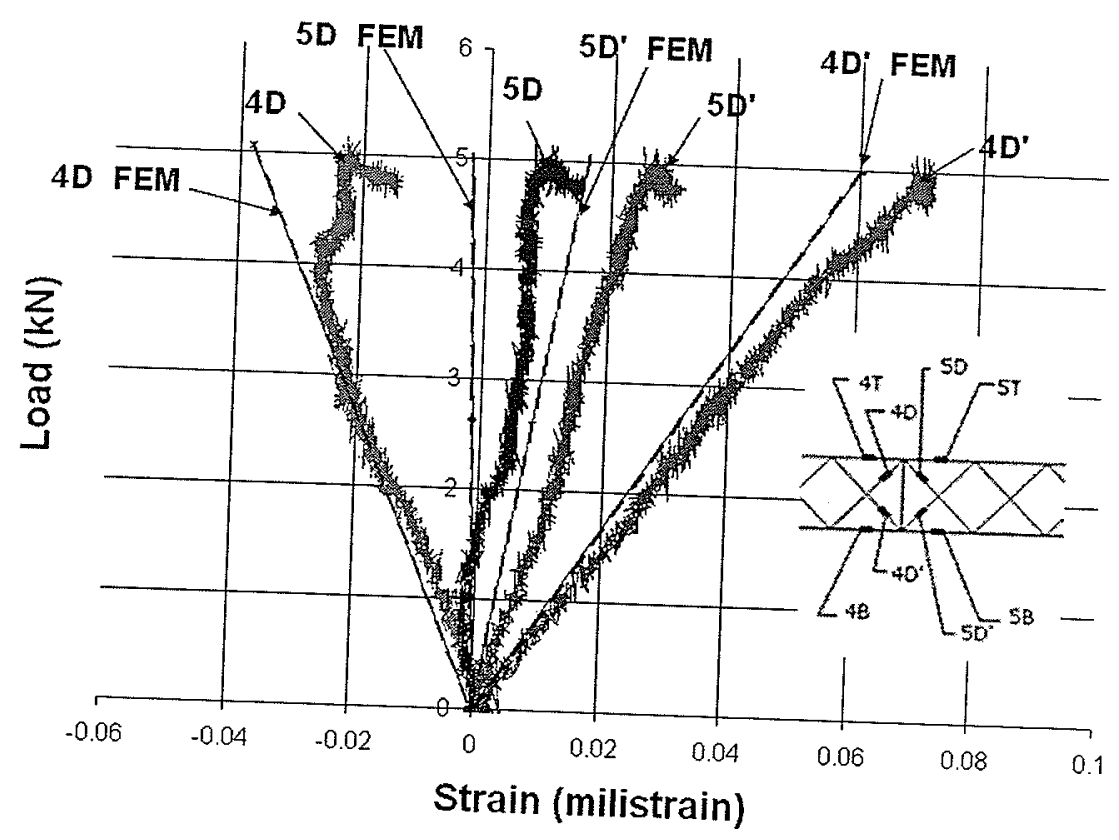

Fig. 5.19 Strains in diagonals at mid- span

The strains in the top and bottom chords at quarter span from the tower base are shown in Fig. 5.20. The strain recorded in location $2 \mathrm{~B}$ in the bottom chord shows a reversal in direction from compression to tension when the applied load reached $4 \mathrm{kN}$. While the direct stress in this member is compressive, as shown in Fig. 5.11, the bending stresses become increasingly tensile causing a reversal of stress at that point. Nevertheless the stress in this member remained small. The reversal of stress is attributed to the uneven contact area of the connected vertical braces. The stress in bottom chord $2 \mathrm{~B}$ is changing sign because the load bypass the bottom chord being transfer by a braces 2D' AND 3D'. The strains in the diagonals at the quarter span are shown in Fig. 5.21. The strains in diagonal follow the path of load transfer between diagonals and chords as verified by the FEA findings. 
Load-strain curve in chords at $1 / 4$ sapan from base

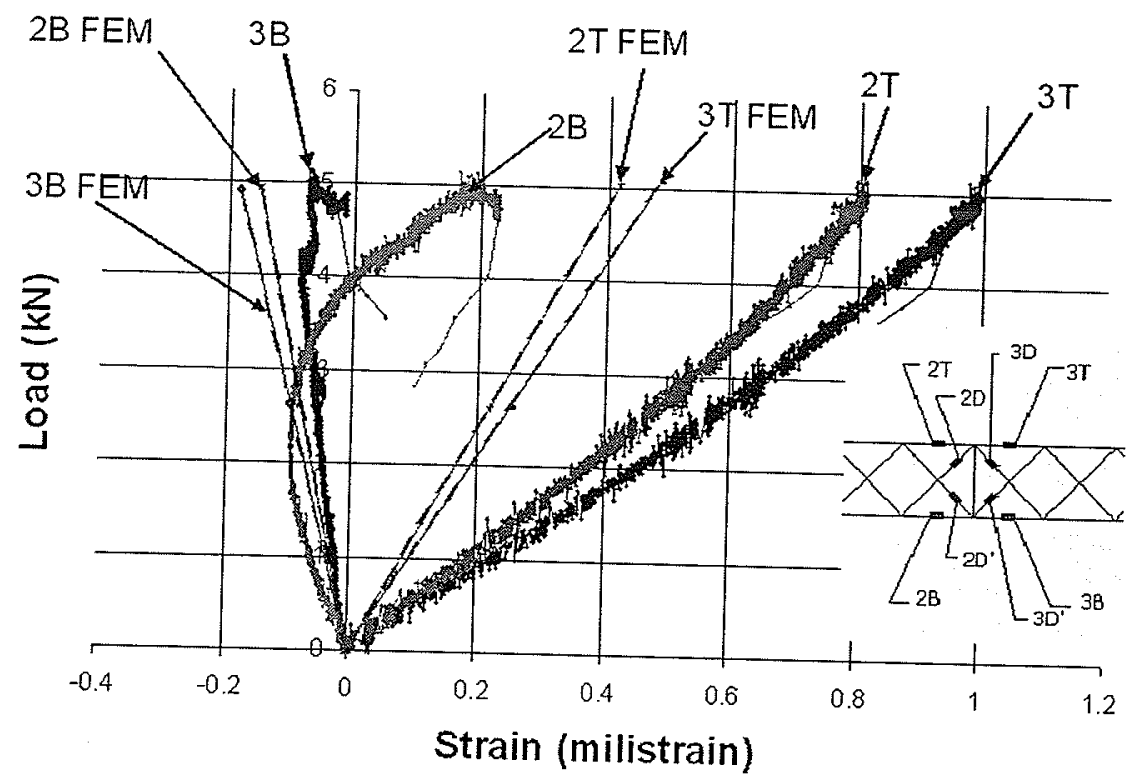

Fig. 5.20 Strains in chords at quarter span

Load-strain curve in diagonals at $1 / 4$ span from base

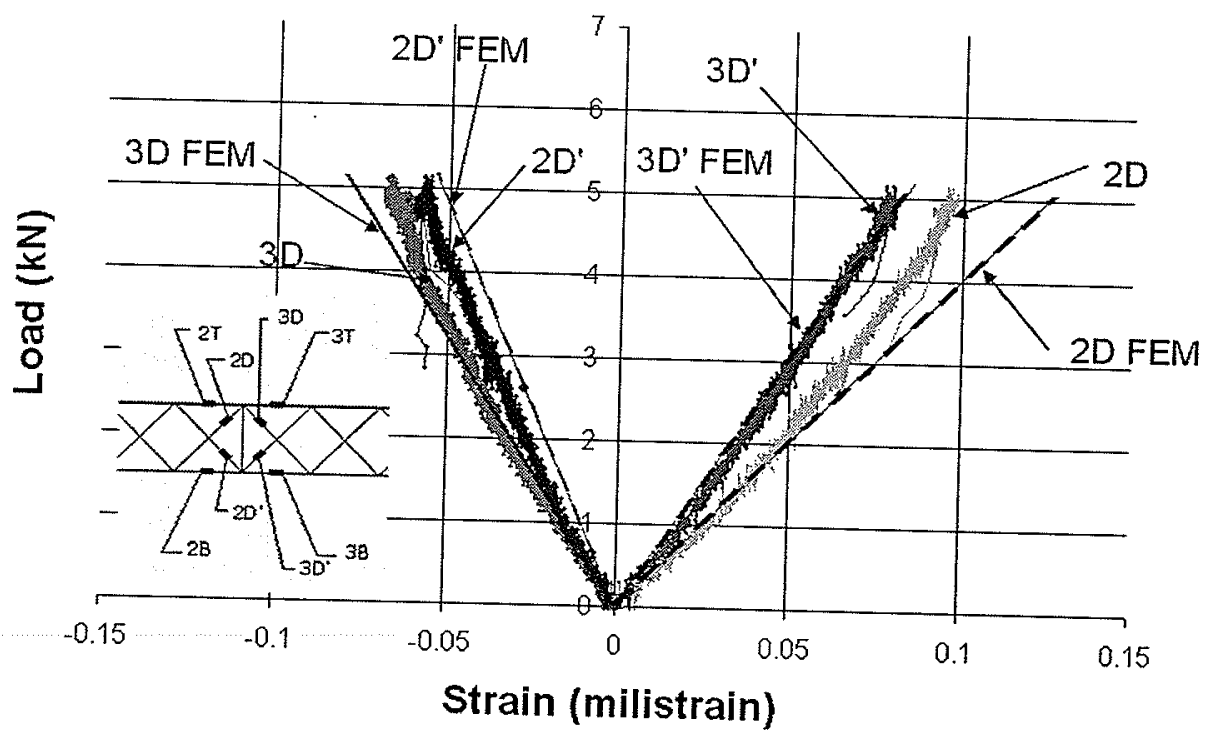

Fig. 5.21 Strains in diagonals at quarter span 
The strains in both the top and bottom chords at the tower base are shown in Fig. 5.22. They follow the load path at the end of the segment where presence of high bending stresses causes the strain in the bottom chord to reach a maximum for entire segment. While the FEA assumes a linear behaviour, the test results indicate that the member behaviour become non-linear after the load reached 1.5 $\mathrm{kN}$. The same observation can be made in the behaviour of the diagonal 1D', shown in Fig. 5.23. This behaviour may be attributed to the redistribution of forces from the bottom chords (1B) to the top chord (1T) and the diagonal (1D').

The maximum compressive strain recorded in the bottom chord $1 \mathrm{~B}$ was equal to $-2300 \mu \varepsilon(0.23 \%)$ as shown in Fig. 5.22. The maximum tensile strain registered in the top chord $1 \mathrm{~T}$ was equal to $1440 \mu \varepsilon(0.14 \%)$, as shown in Fig. 5.22 .

The strains in the bottom and top chords correspond to approximately $58.54 \mathrm{MPa}$ $(8.49 \mathrm{ksi})$ in compression and $36.61 \mathrm{MPa}(5.31 \mathrm{ksi})$ in tension using an average value for the modulus of elasticity in the longitudinal direction equal to $E_{1}=25.44 \mathrm{GPa}\left(3.69 \times 10^{3} \mathrm{ksi}\right)$. These stresses are $17 \%$ and $6 \%$ of the maximum compressive and tensile capacity of the material for longitudinal tensile and compressive strengths taken as $F_{1}^{t u}=610.2 \mathrm{MPa}(88.5 \mathrm{ksi})$ and $F_{1}^{c u}=342.7 \mathrm{MPa}(49.7 \mathrm{ksi})$ (Burachynsky,2006). 


\section{Load-strain curve in chords at the base}

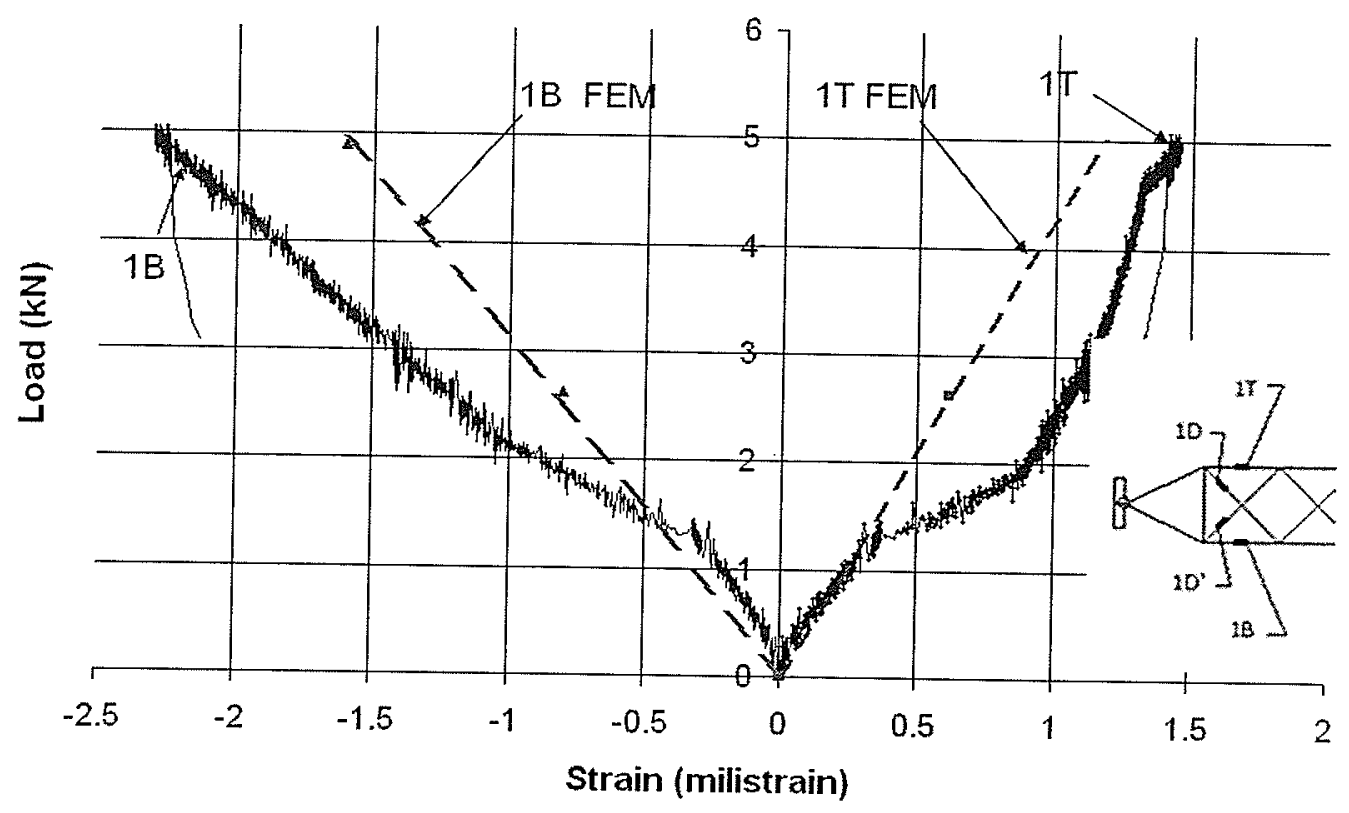

Fig. 5.22 Strains in chords at the base

Load-strain curve in diagonals at the base

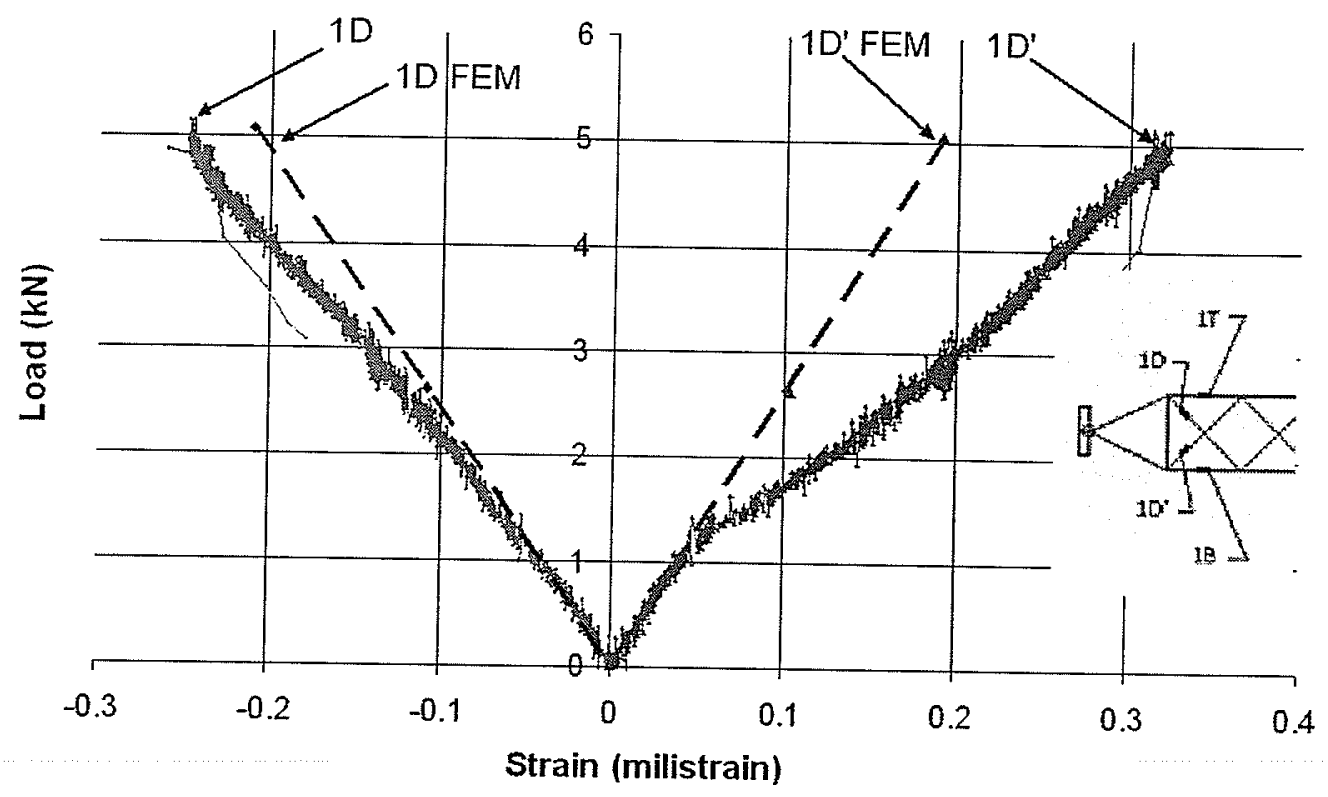

Fig. 5.23 Strains in diagonals at the base 


\section{Discussions of results}

The maximum compressive and tensile strains in the diagonals were also recorded at the base, as shown in Fig. 5.23 and were equal to $-250 \mu \varepsilon$ $(0.025 \%)$ for member $1 \mathrm{D}$ and $0.32 \mu \varepsilon(0.032 \%)$ for member 1D'. These strains correspond, approximately, to $6.34 \mathrm{MPa}(0.92 \mathrm{ksi})$ in compression and $8.13 \mathrm{MPa}$ $(1.18 \mathrm{ksi})$ in tension. It is evident that the values of maximum stresses at the support are well below the maximum strength limits.

\subsection{Analysis of Experimental Results from Dynamic Tests}

The tower segment, shown in Figs. 4.15 and 4.16, was loaded to a maximum load of $5.14 \mathrm{kN}(1155 \mathrm{lbs})$ applied at the mid height and the load was suddenly released. The diagram showing the initial deflections along the tower, prior to load release, is shown in Fig. 5.24. The test was repeated four times. The maximum initial deflections at the point of load application at mid height of the tower ranged from $55 \mathrm{~mm}(2.16 \mathrm{in})$ to $58 \mathrm{~mm}(2.28 \mathrm{in})$. For the purpose of validating a single degree of freedom model of the free vibrating tower segment, the data obtained from all LVDT's are included here. The vibration tests lasted about $60 \mathrm{sec}$. Typical time history diagrams for all LVDT's are shown in Fig. 5.25.

For the vibration analysis, $1 \mathrm{sec}$ interval of time was used, and typical displacements versus time curves for Tests 16 to 19 are presented on Figs. 5.26 to 5.29 , respectively. The test results show similar patterns of displacement for all LVDT readings. 


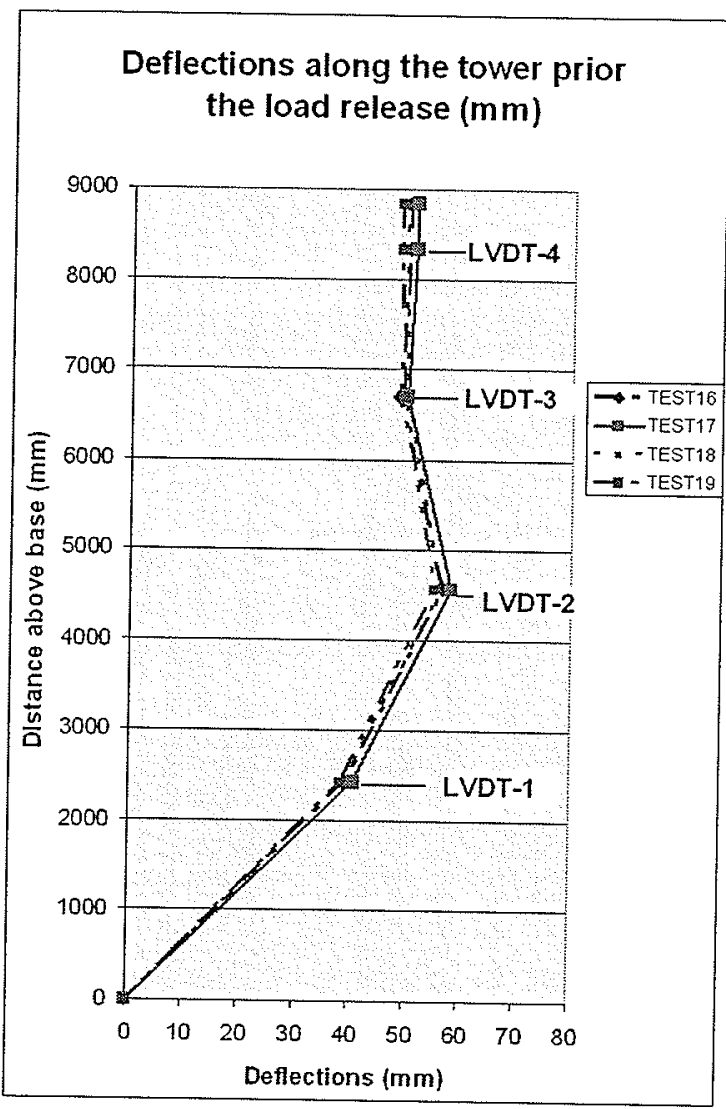

Fig. 5.24 Deflections along the tower prior the load release

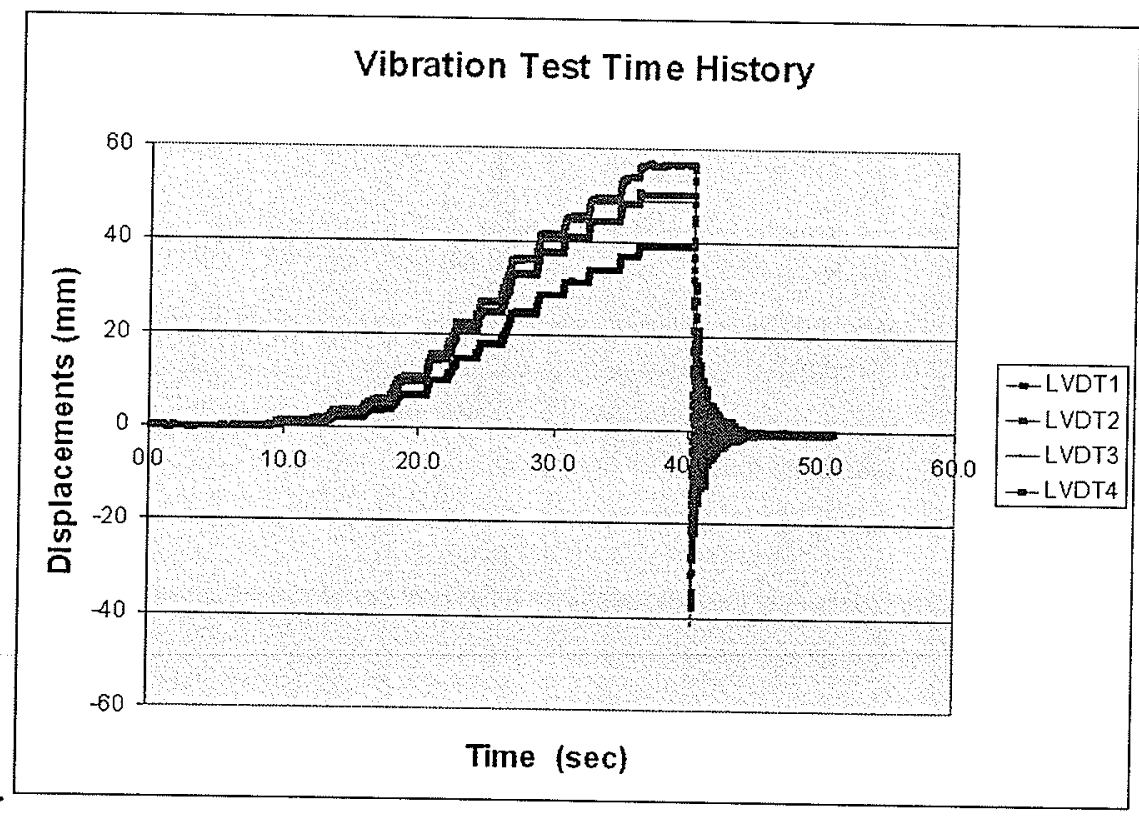

Fig. 5.25 Vibration Test Time History for Test-16 


\section{Discussions of results}

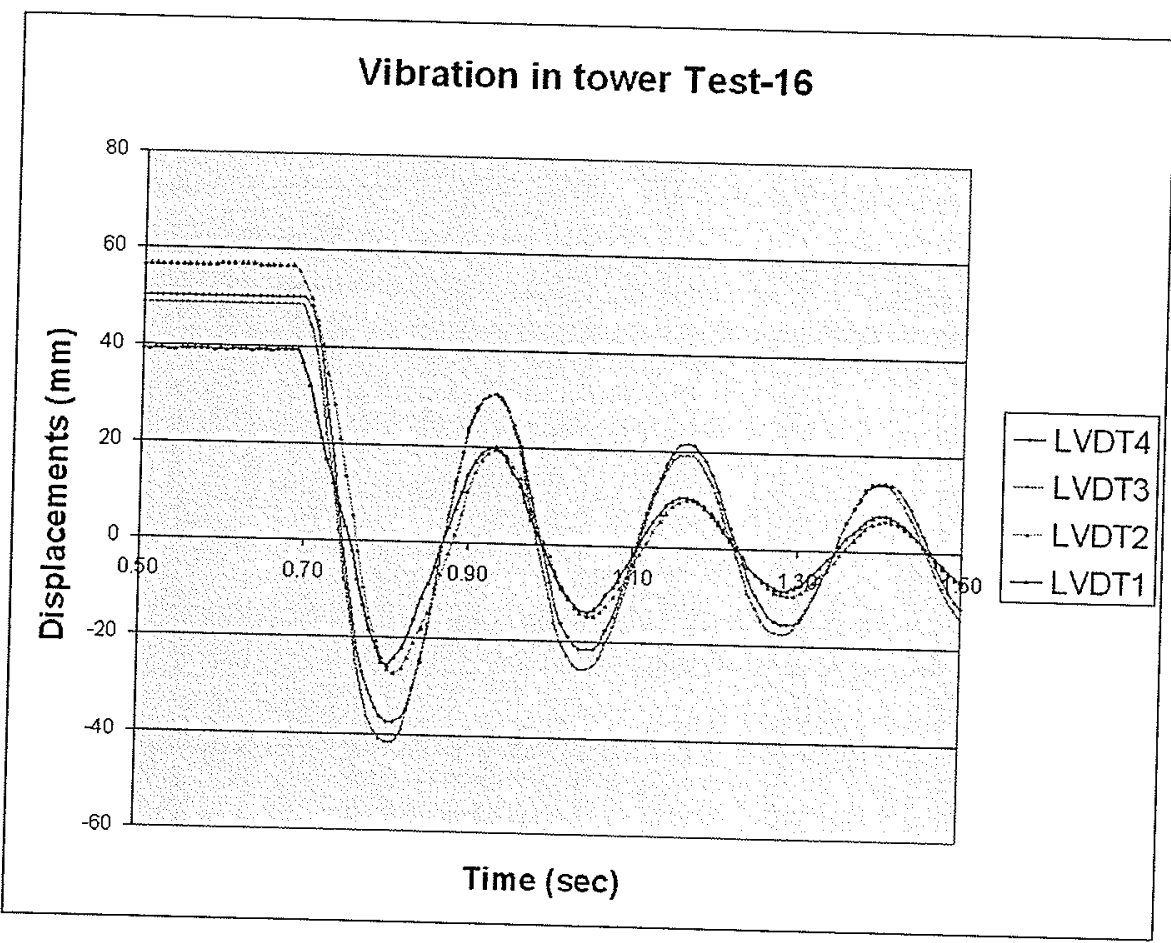

Fig. 5.26 Vibration in tower Test-16

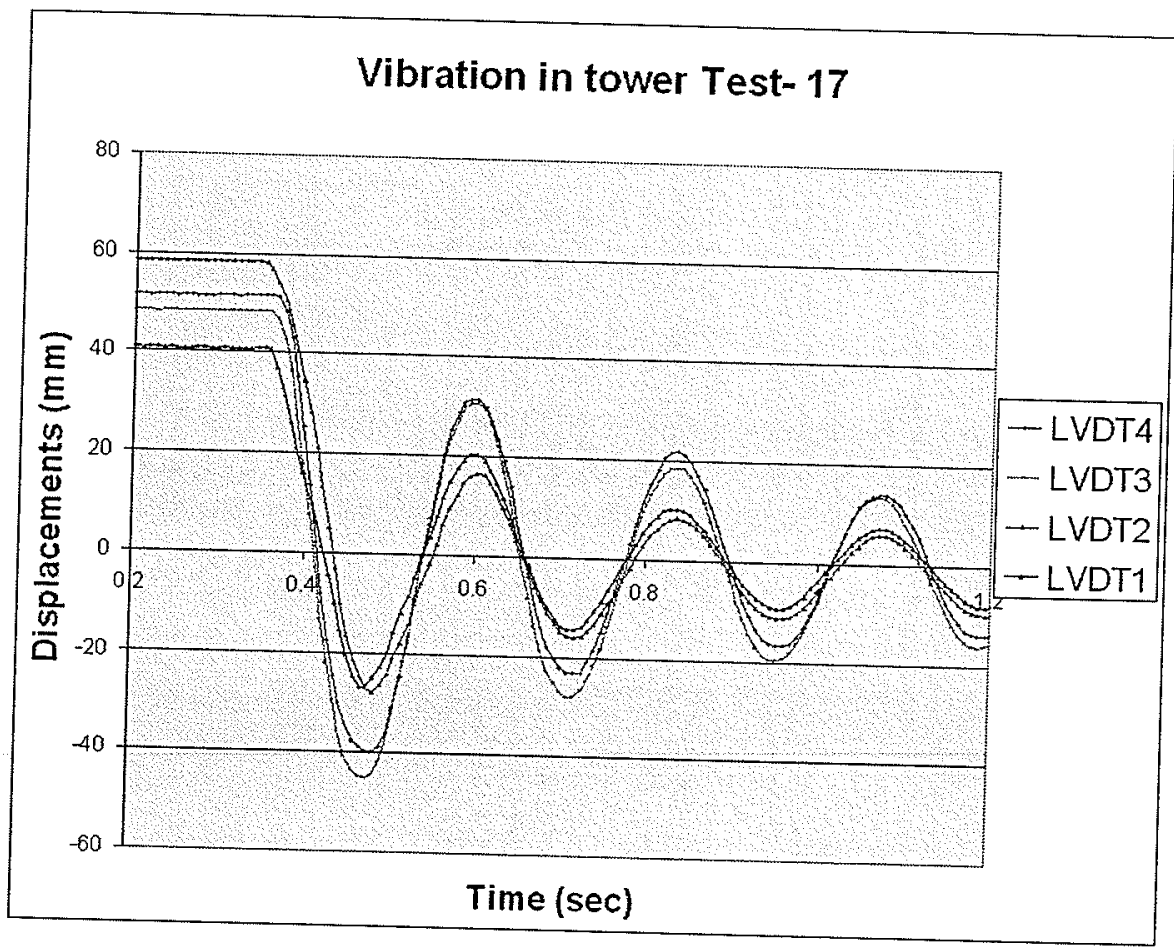

Fig. 5.27 Vibration in tower Test-17 


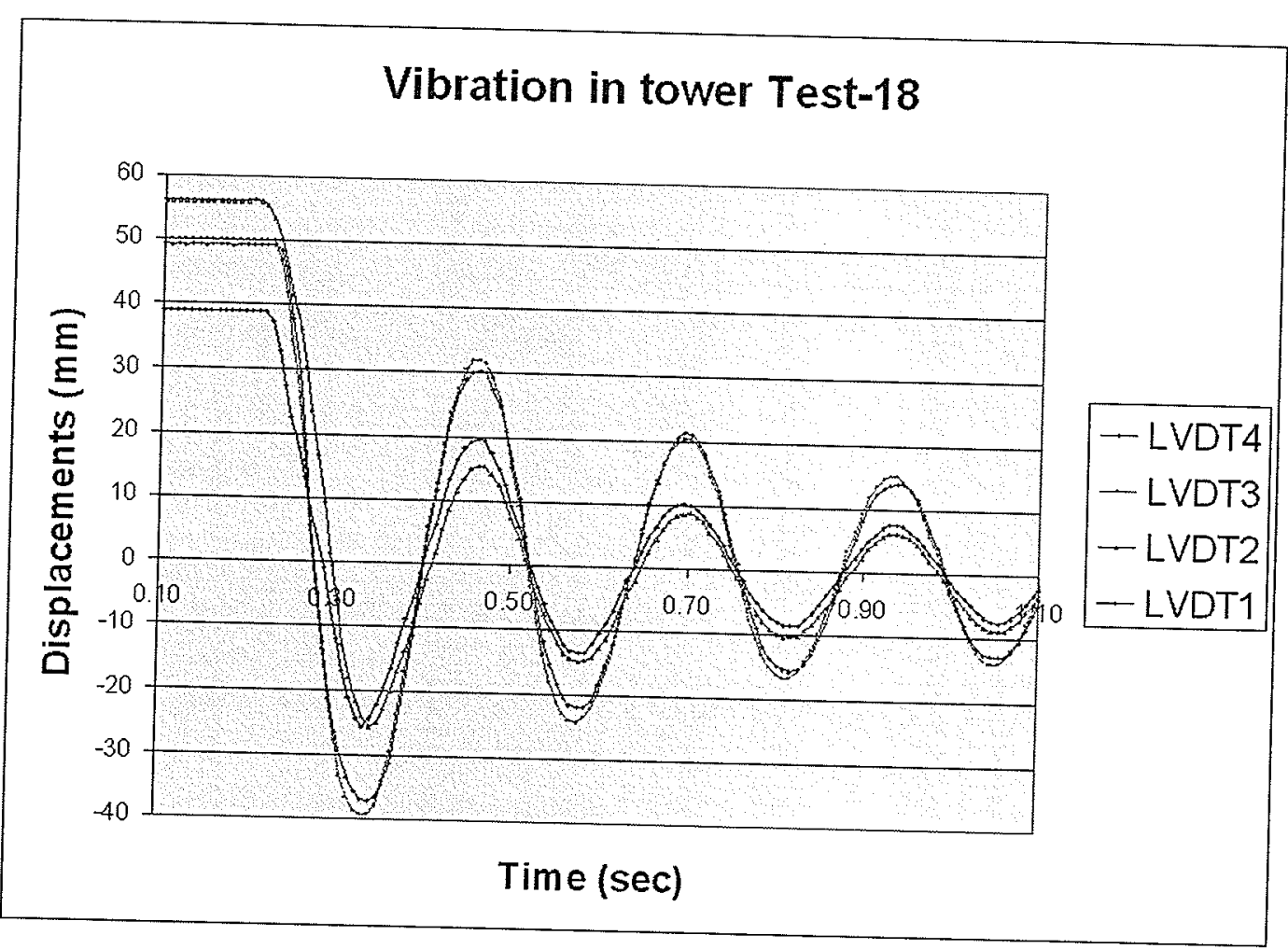

Fig. 5.28 Vibration in tower Test-18

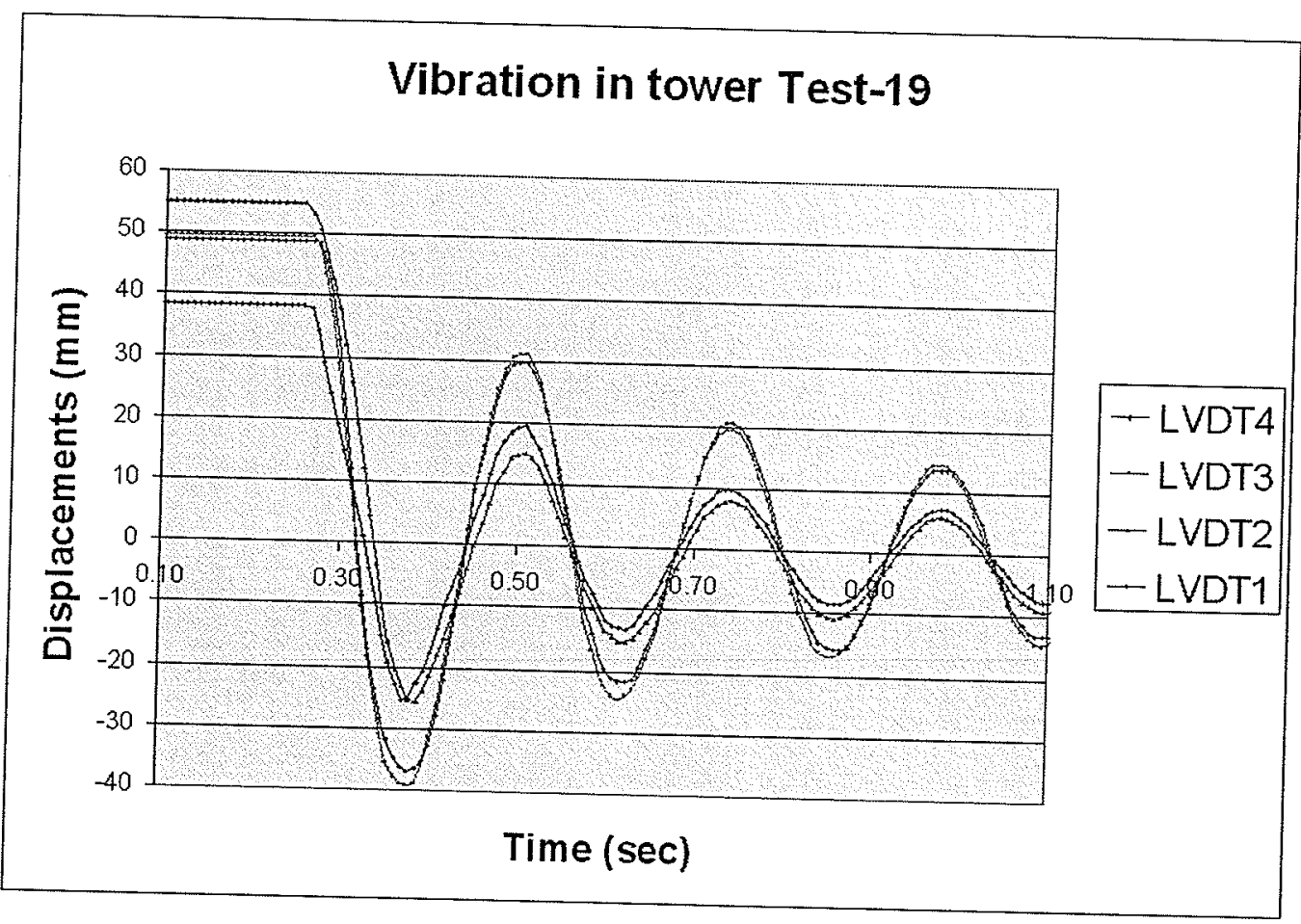

Fig. 5.29 Vibration in tower Test-19 
A schematic drawing showing the displacement versus time for all LVDT's along the tower height for Test-16 is presented in Fig. 5.30.

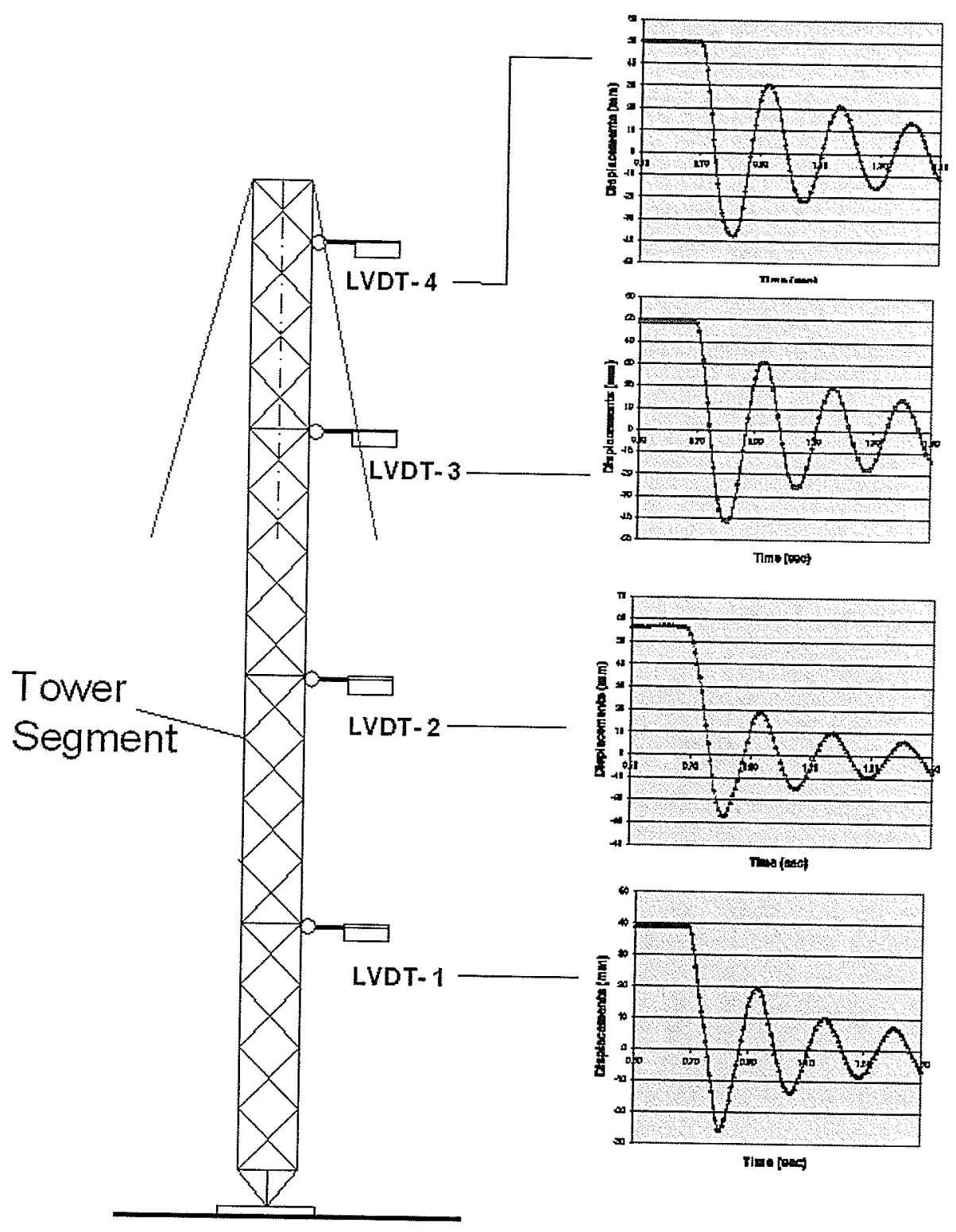

Fig. 5.30 Vibration along tower Test-16

For validating the single degree of freedom model for damped vibration, only the readings from the LVDT-4 located at the top of the tower segment were used. 
The displacements along the tower height for three full cycles of vibrations for Test-16 are presented in Fig. 5.31.

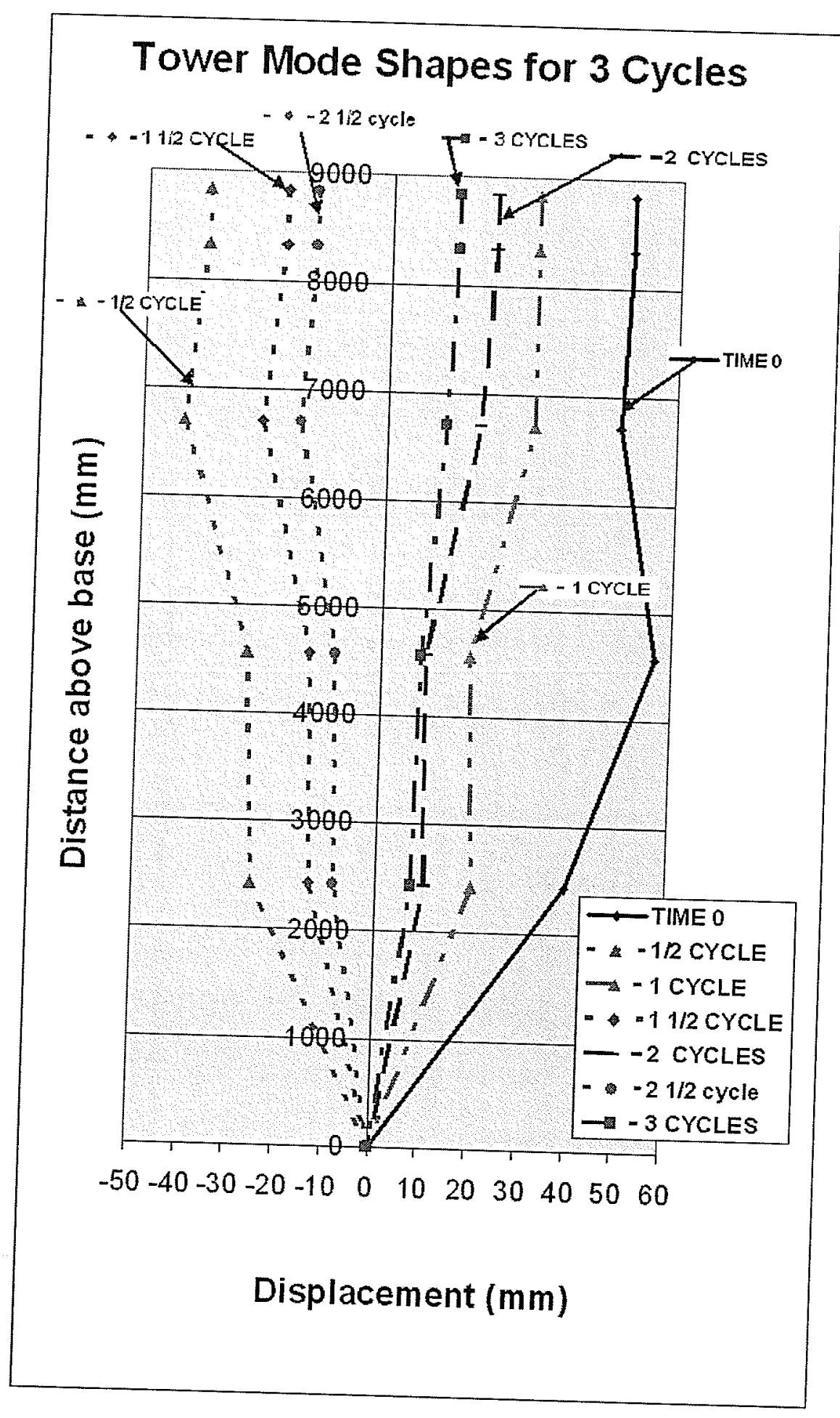

Fig. 5.31 Mode shapes for 3 full cycles Test-16 
The kinetic energy stored in the tower at time $t=0$ was dissipated by the attached cables and after three full cycles, the mid height section came to a rest position from a maximum of $56.63 \mathrm{~mm}$ (2.23 in) displacement to $8.42 \mathrm{~mm}$ (0.33 in), as shown in Fig. 5.31.

\subsection{Theoretical Background of the Dynamic Analysis}

The tested tower segment was allowed to vibrate freely in one plane and was modelled as a single degree of freedom system. The tower, disturbed from its equilibrium position, vibrated freely at a natural frequency which was unique for that single degree of freedom. A 3-D mechanical model of the tested tower segment is shown on Fig. 5.32.

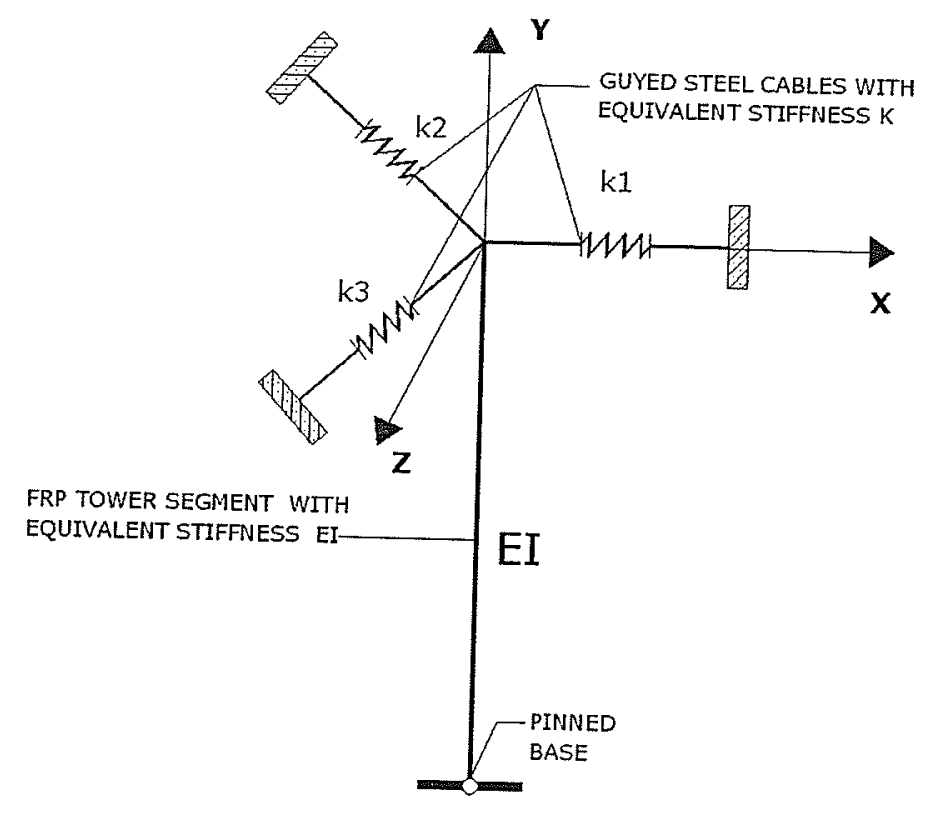

Fig. 5.32 3-D mechanical model of tested tower segment

In this model the FRP tower segment is represented as an elastic beam with stiffness $E I$, and cables are being represented as elastic springs with a spring 
constant $k$. The tower is connected to the base by a pinned connection and at the top by set of three cables. Because the applied load and the LVDT's were directed in the $X Y$ plane, the 3-D model was replaced with 2-D model with the addition of damper with a damping constant $c$ to simulate an energy dissipation mechanism, as shown in Fig. 5.33.

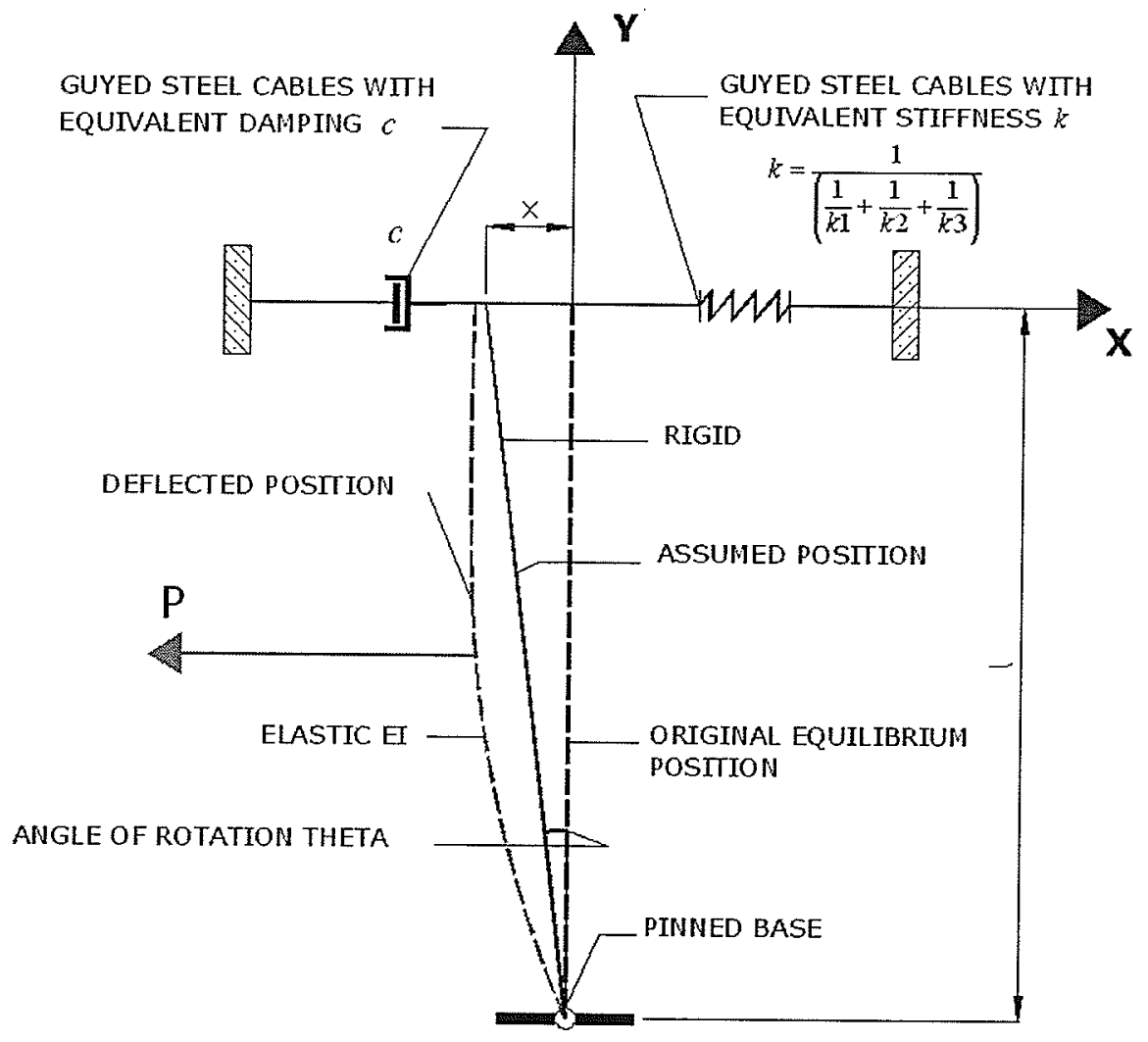

Fig. 5.33 2-D mechanical model of tested tower segment

To further simplify the model, the elastic column was replaced with a rigid one having a uniformly distributed mass $m$ over the column length $l$ (inclined position). Writing the angular momentum equilibrium about the pinned base, the general equation for natural frequency will be: 


$$
F_{I}+F_{D}+F_{S}=0
$$

where:

$F_{I}=\frac{m l^{2}}{3} \frac{d^{2} \theta}{d t^{2}} \rightarrow$ Inertia force

$F_{S}=k l x \rightarrow$ Spring force

$F_{D}=c l \frac{d x}{d t} \rightarrow$ Damping force

Therefore the equation of motion becomes:

$$
\frac{m l^{2}}{3} \frac{d^{2} \theta}{d t^{2}}+c l \frac{d x}{d t}+k l x=0
$$

But, $x=l \times \sin \theta$ and for small angles, $x=l \times \theta$ so by eliminating $\theta$ the equation of motion becomes:

$$
\begin{aligned}
& \frac{m}{3} \frac{d^{2} x}{d t^{2}}+c \frac{d x}{d t}+k x=0 \text { or } \\
& \frac{d^{2} x}{d t^{2}}+\frac{3 c}{m} \frac{d x}{d t}+\frac{3 k x}{m}=0
\end{aligned}
$$

Equations 5.3 and 5.4 represent second order differential equations of motion for the tower segment. Assuming a solution in the form $x(t)=C e^{s t}$ and substituting it in to Eq. 5.4, the auxiliary equation becomes:

$$
s^{2}+\frac{3 c s}{m}+\frac{3 k}{m}=0
$$

The roots of Eq. 6.5 are as follows: 


$$
s_{1,2}=\frac{1}{2}\left[-\frac{3 c}{m}+/-\sqrt{\left(\frac{3 c}{m}\right)^{2}-\frac{12 k}{m}}\right]
$$

Taking the quantity under root of Eq. 5.6 equal to zero yields:

$$
C_{c}=\frac{2}{3} m \sqrt{\frac{3 k}{m}}=\frac{2}{3} m \omega_{n}
$$

Equation 5.7 describes the critical damping constants for a system.

The natural circular frequency ${ }^{5}$ for the system is given by Eq. 5.8 below.

$$
\omega_{n}=\sqrt{\frac{3 k}{m}}
$$

The damping ratio or factor for the system can be expressed as:

$$
\zeta=\frac{c}{C_{c}}=\frac{3 c}{2 \sqrt{3 k m}}=\frac{\sqrt{3} c}{2 \sqrt{k m}}
$$

While the damped frequency of oscillation can be expressed as:

$$
\omega_{d}=\sqrt{1-\zeta^{2}} \times \omega_{n}=\sqrt{\frac{3 k}{m}-\left(\frac{3 c}{2 m}\right)^{2}}
$$

The values of the damping ratio $\zeta$, calculated from the test results, is a major component for solving the linearized equation of motion (Tedesco, et al. 1999) for the system in terms of $x$. The damping factor is necessary to calculate the system's natural frequencies.

${ }^{5}$ Natural frequency of the tower segment was alternatively calculated using the "Generalized single degree of freedom system approach". The natural frequency obtained was lower than that reported in the Thesis because, the top of the tested tower segment was constrained by 3 guy cables. 


\subsection{Calculation of Dynamic Properties from Test Data}

From the analysis of the data from Test -16 , shown in Fig. 5.26 a one second interval of the deflection recorded by LVDT4, placed at the top of tower segment was analysed, as shown in Fig. 5.34. Knowing that the rate of sampling for the data acquisition system was set to 128 readings per second, the time interval between four full cycles of vibration was calculated as $4 T_{d}=0.9297 \mathrm{sec}$, as shown in Fig. 5.34.

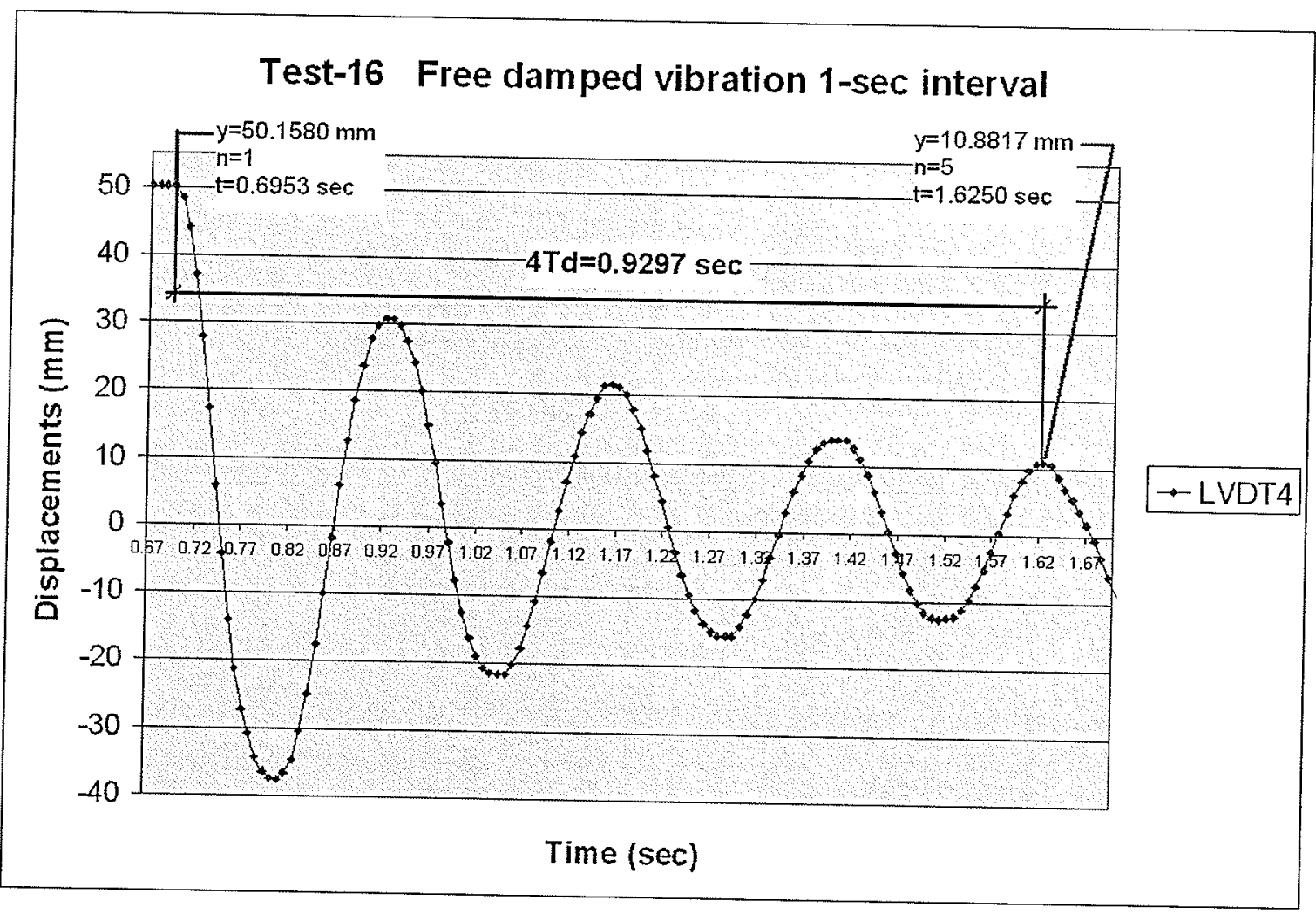

Fig. 5.34 1-sec interval for LVDT4, Test-16

From this unique property of the vibrating tower segment, several dynamic properties including the damped period $T_{d}$, the damped natural frequencies $f_{d}$, 
the logarithmic decrement $\delta$, and the damping factor $\zeta$ could be calculated. These properties are as follows:

$$
\begin{aligned}
& T_{d}=\frac{0.9297}{4}=0.232425 \mathrm{sec} \\
& f_{d}=\frac{1}{T_{d}}=4.302463 \mathrm{~Hz} \\
& \delta=\frac{1}{n} \ln \left(\frac{X_{i}}{X_{i+n}}\right)=\frac{1}{4} \ln \left(\frac{50.1580}{10.8817}\right)=0.3820 \\
& \zeta=\frac{\delta}{\sqrt{(2 \pi)^{2}+\delta^{2}}}=0.0607<1 \Rightarrow \text { underdamped system }
\end{aligned}
$$

The natural circular frequency and the circular frequency of the tower segment can be calculated from the following equation:

$$
\omega_{n}=\frac{\omega_{d}}{\sqrt{1-\zeta^{2}}}=\frac{2 \pi f_{d}}{\sqrt{1-\zeta^{2}}}
$$

After related substitutions, the natural circular frequency and the natural frequency of the tower segment was calculated as:

$$
\begin{aligned}
& \omega_{n}=\frac{2 \pi f_{d}}{\sqrt{1-\zeta^{2}}}=\frac{2 \times \pi \times 4.302463}{\sqrt{1-0.0607^{2}}}=27.083112 \frac{\mathrm{rad}}{\mathrm{s}} \\
& f_{n}=\frac{1}{T}=\frac{\omega_{n}}{2 \times \pi}=\frac{27.083345}{2 \times \pi}=4.310448 \mathrm{~Hz}
\end{aligned}
$$

In the assumed model, the equivalent elastic spring constant $k$ of all cables has to be known since the lateral stiffness of the tower does not contribute to the 


\section{Discussions of results}

equivalent stiffness of the system. This is due to the fact that the bottom of the tower is free to rotate in the direction of applied load. The mass of the tower $m$ was estimated from the masses of individual sections to be $98.38 \mathrm{~kg}(216.89 \mathrm{lb})$. In terms of dynamic units the mass is :

$$
m=98.38 \frac{N s^{2}}{m}
$$

The value of the equivalent spring constant for the supporting springs can be calculated from Eq. 5.18, which was directly modified from Eq. 5.8, as follows:

$$
k=\frac{\omega_{n}^{2} m}{3}=\frac{27.0833^{2} \times 0.0984}{3}=23.9063 \frac{\mathrm{kN}}{\mathrm{m}}
$$

Therefore, the system critical damping factor can be obtained from Eq. 5.7 as,

$$
C_{c}=\frac{2 \sqrt{3 \mathrm{~km}}}{3}=\frac{2 \times \sqrt{3 \times 23.9063 \times 0.0984}}{3}=1.7708 \frac{\mathrm{kN} \mathrm{s}}{\mathrm{m}}
$$

The system damping coefficient can be obtained from Eq. 5.9 as,

$$
c=\zeta \times C_{c}=0.0607 \times 1.7708=0.10745 \frac{\mathrm{kN} \mathrm{s}}{\mathrm{m}}
$$

Therefore, the damping natural frequency is calculated from Eq. 5.10.

$$
\omega_{d}=\sqrt{1-\zeta^{2}} \times \omega_{n}=\sqrt{\frac{3 k}{m}-\left(\frac{3 c}{2 m}\right)^{2}}=26.9908 \frac{\mathrm{rad}}{\mathrm{s}}
$$

The dynamic properties of the tower are listed in Table 5.1.

The undamped natural frequency of the tower segment, computed as $4.31 \mathrm{~Hz}$ was obtained for the cable configuration used in the lab. As discussed earlier, the natural frequency depends on the cable pretension and the cable axial stiffness. By increasing the cable pretension, the tower lateral vibration decreased, causing 
in turn, the natural frequency of vibration to increase. The value of natural frequency obtained from test data is compared to results from the FE analysis findings included in sections 3.6.6.2 and 3.6.6.4.

Table 5. 1 Dynamic Properties of Tower Segment

\begin{tabular}{|l|c|}
\hline \multicolumn{1}{|c|}{ Property } & Value \\
\hline Damped period, $T_{d}(\mathrm{~s})$ & 0.2324 \\
\hline Damped natural frequency, $f_{d}(\mathrm{~Hz})$ & 4.3025 \\
\hline Damped circular frequency, $\omega_{d}(\mathrm{rad} / \mathrm{s})$ & 26.9907 \\
\hline Logarithmic decrement, $\delta$ & 0.3820 \\
\hline Damping factor, $\zeta$ & 0.0607 \\
\hline Critical damping constant, $C_{c}\left(\frac{k N \mathrm{~s}}{m}\right)$ & 1.7708 \\
\hline System damping coefficient, $c\left(\frac{k N \mathrm{~s}}{m}\right)$ & 0.1075 \\
\hline Undamped circular frequency, $\omega_{n}(\mathrm{rad} / \mathrm{s})$ & 27.0831 \\
\hline Undamped natural frequency, $f_{n}(\mathrm{~Hz})$ & 4.3104 \\
\hline Equivalent spring stiffness $(k N / m)$ & 23.9063 \\
\hline Tower segment mass,$m\left(\frac{N s^{2}}{m}\right)$ & 98.38 \\
\hline
\end{tabular}

*Note: Tower stiffness calculated based on the segment deflection at mid-height $(X=56.6 \mathrm{~mm})$, where the point load was applied. 


\subsection{COMPARISON of FEM Model and Test Deflection under Service Loads}

Comparison of the deflected shape of the $8.53 \mathrm{~m}(28 \mathrm{ft})$ tower segment shown in Fig. 5.35 under service loading obtained from the FEM analysis and test data from dynamic analysis at time 0 , as indicated in Fig. 7.31, at four locations along the tower was undertaken. The results from ANSYS are plotted along with the experimental data in Fig. 5.35. The results show that there is a very close correlation between test data and FEM findings. This gives validity to the theoretical model developed.

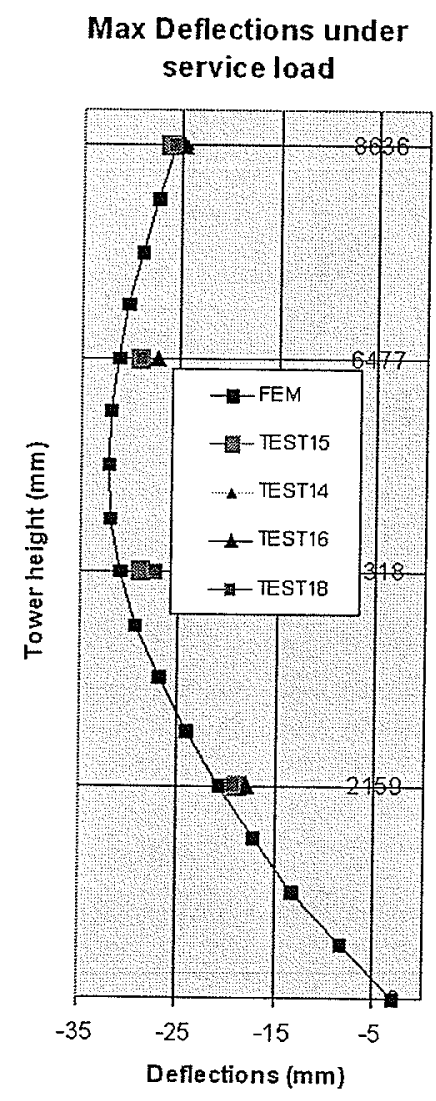

Fig. 5.35 Comparison of FEM model and Test deflection under service loads 
CHAPTER 6

\title{
RECOMMENDATIONS FOR THE DESIGN OF
}

\author{
COMPOSITE TOWERS
}




\subsection{General}

The effect of fibre volume fraction on mechanical properties of composite material used for fabrication of latticed tower segment as well as strength failure evaluation of the FRP tower were investigated and are discussed in this Chapter. Also, a prediction of the maximum compressive loads based on the Euler formula was undertaken.

\subsection{Effect of Fibre Volume Fraction on Mechanical properties of FRP Towers}

The fabricated FRP tower segments consisted of unidirectional fibres lamina; hence properties of unidirectional lamina were used in the analysis. The properties of lamina constituencies are provided in Table 6.1.

Table 6.1 Properties of constituencies for unidirectional lamina (Burachynsky, 2006)

\begin{tabular}{|l|c|c|}
\hline \multicolumn{1}{|c|}{ Property } & E-glass & $\begin{array}{c}\text { West System } \\
\text { 105/205EpoxyResin } \\
\text { /Hardener }\end{array}$ \\
\hline Tensile Modulus GPa (psi) & $72.4\left(1.05 \times 10^{7}\right)$ & $2.81\left(4.08 \times 10^{5}\right)$ \\
\hline Poisson's ratio & 0.27 & 0.3 \\
\hline Tensile strength GPa (psi) & $2.4\left(3.48 \times 10^{5}\right)$ & $0.054\left(7.85 \times 10^{3}\right)$ \\
\hline Shear Modulus GPa (psi) & $30\left(4.35 \times 10^{6}\right)$ & $1.38\left(2.00 \times 10^{5}\right)$ \\
\hline Density g/mm^3 (lb/in^3) & $0.0025(0.092)$ & $0.0016(0.059)$ \\
\hline
\end{tabular}


According to industry standards for unidirectional lamina, the typical content of fibre volume fraction (Kaw, 1997) ranges between 50 to $70 \%$, as shown in Table 6.2. By using the industrial filament winding process, the highest fibre volume fractions for unidirectional lamina is around $70 \%$.

Table 6.2 Typical fibre volume fractions (Kaw, 1997)

\begin{tabular}{|c|c|c|}
\hline $\begin{array}{c}\text { Reinforcement } \\
\text { Form }\end{array}$ & $\begin{array}{c}\text { Possible range of fibre } \\
\text { volume fractions (\%) }\end{array}$ & $\begin{array}{c}\text { Typical value for fibre } \\
\text { volume fraction (\%) }\end{array}$ \\
\hline unidirectional & $\mathbf{5 0 - 7 0}$ & $\mathbf{6 5}$ \\
\hline woven & $35-55$ & 45 \\
\hline random mat & $10-30$ & 20 \\
\hline
\end{tabular}

Conservatively, the typical value for fibre volume fraction of unidirectional reinforced composites can be taken as $V_{f}=65 \%$. Using the rule of mixture, given by Eq. 3.1 in Chapter-3, the modulus of elasticity in the fibre direction (tensile modulus) for a range of fibre volume fractions was computed and is shown and shown in Fig. 6.1. 


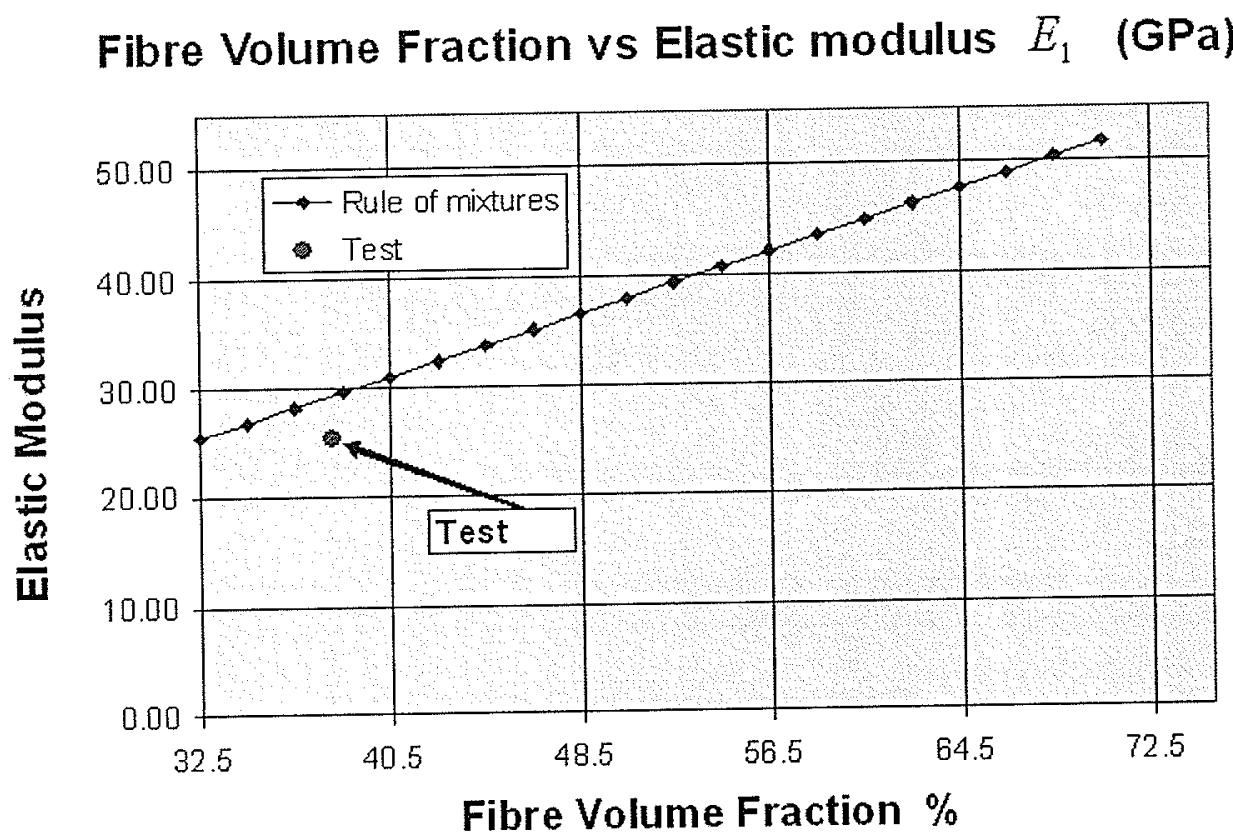

Fig. 6.1 Modulus of elasticity in fibre direction

The elastic modulus in the fibre direction is shown in Fig. 6.1 as a function of the fibre volume fraction. The test tag indicates the value of particular mechanical properties, in this case, elastic modulus used in fabrication and testing of tower segment. The test was performed separately by Ungkurapinan (2005) and Burachynsky (2006).

Using the inverse rule of mixture, given by Eqs. 3.3, 3.4 and 3.5 in Chapter-3, the tensile modulus in the direction perpendicular to the fibres was calculated and is shown in Fig. 6.2. The results indicate that the three methods give quite different results. The test data fit well the rule of mixture curve. The Major Poisson's ratio, the In -Plane Shear Modulus and Composite Density curves shown in Figs. 6.3, 6.4 and 6.5 , respectively, as a function of the Fibre Volume Fraction. 
Fibre Volume Fraction vs Elastic modulus $E_{2}$ (GPa)

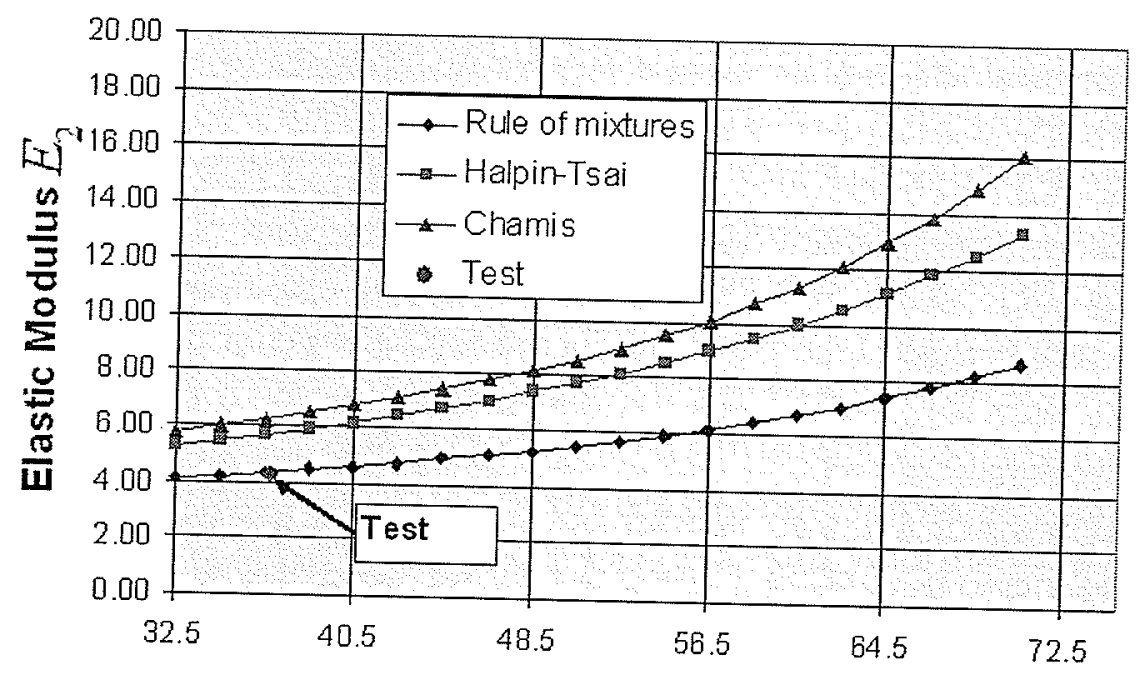

Fibre Volume Fraction \%

Fig. 6.2 Modulus of elasticity in the direction perpendicular to the fibres

Fibre Volume Fraction vs Major Poisson's ratio

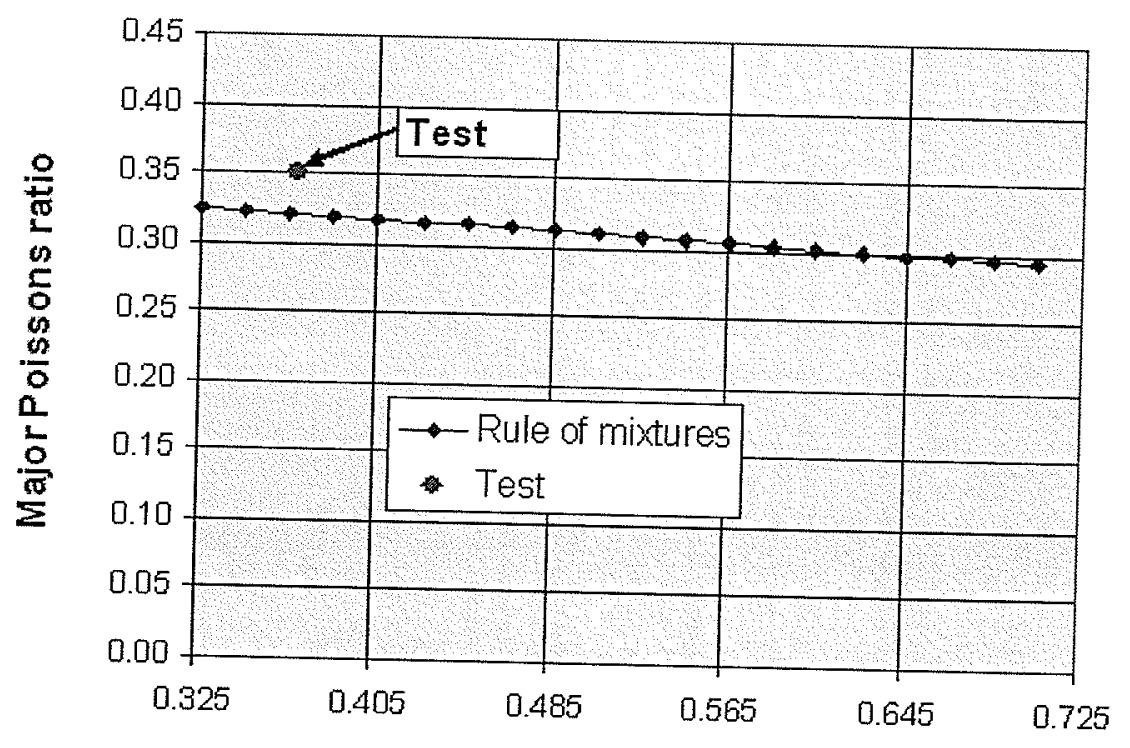

Fibre Volume Fraction \%

Fig. 6.3 Major Poisson's ratio 
Fibre Volume Fraction vs In Plane Shear Modulus

$G_{12}$ (Gpa)

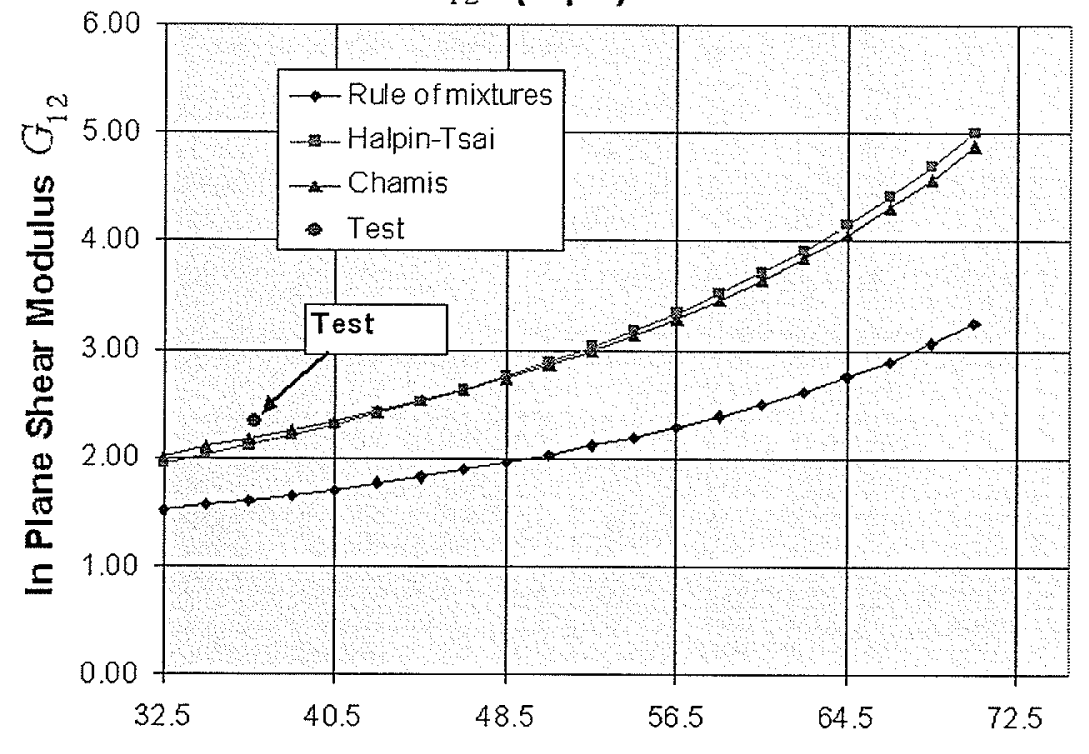

Fibre Volume Fraction \%

Fig. 6.4 In Plane Shear Modulus

Fibre Volume Fraction vs Composite Density $\mathrm{g} / \mathrm{mm}^{3}$

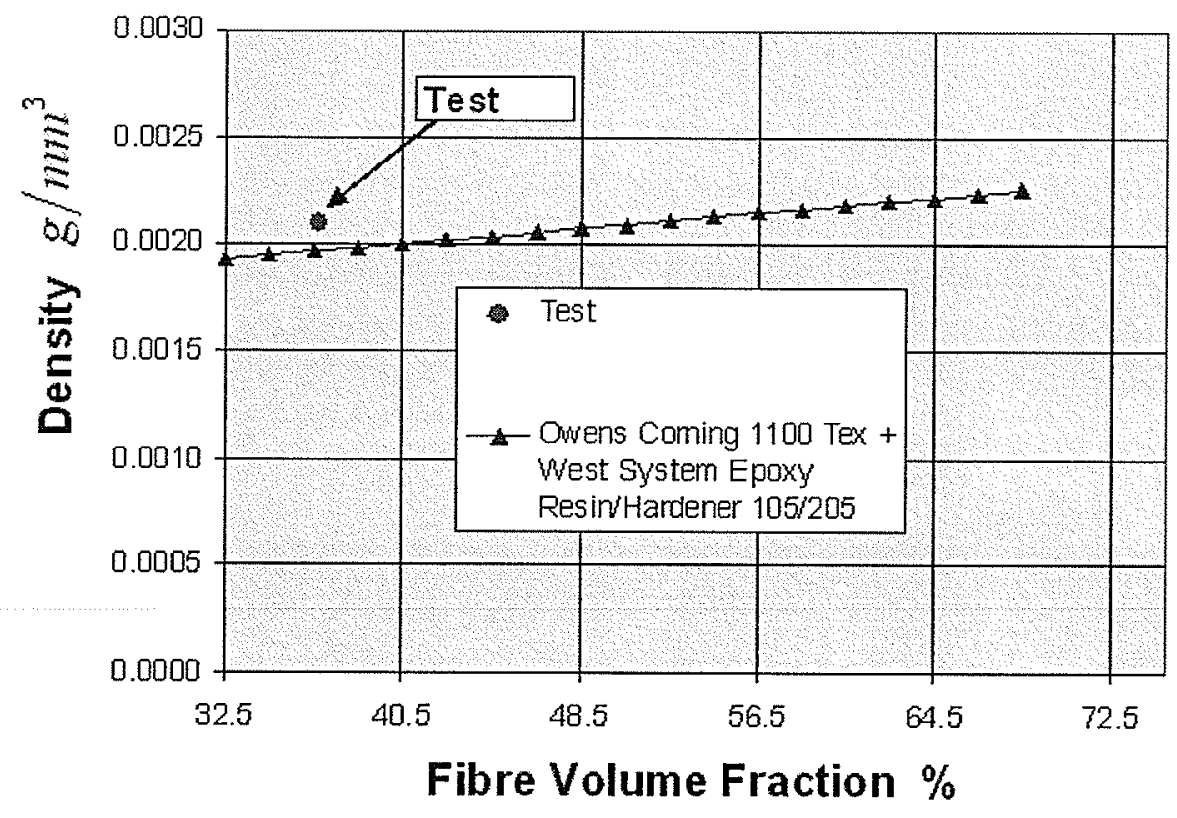

Fig. 6.5 Composite Density 
The mechanical properties constants for the recommended maximum fibre volume fraction of $V_{f}=65 \%$ are listed in Table 6.3.

Table 6.3 Mechanical properties for unidirectional lamina

\begin{tabular}{|c|c|c|}
\hline & $\begin{array}{c}\text { Used in the original } \\
\text { FEM analysis } \\
\text { at } V_{f}=36.8 \%\end{array}$ & $\begin{array}{c}\text { Values at } \\
V_{f}=65 \%\end{array}$ \\
\hline$E_{1}=G P a(p s i)$ & $25.44\left(3.69 \times 10^{6}\right)$ & $47.71\left(6.92 \times 10^{6}\right)$ \\
\hline$E_{2}=G P a(p s i)$ & $4.24\left(0.615 \times 10^{6}\right)$ & $7.38\left(1.07 \times 10^{6}\right)$ \\
\hline$v_{12}$ & 0.35 & 0.3 \\
\hline$G_{12}=G P a(p s i)$ & $2.76\left(0.4 \times 10^{6}\right)$ & $4.15\left(6.03 \times 10^{5}\right)$ \\
\hline$\rho=g / m^{3}\left(\mathrm{lb} / \mathrm{in}^{3}\right)$ & $0.0021(0.076)$ & $0.0022(0.08)$ \\
\hline
\end{tabular}

The behaviour of the FRP tower was re-evaluated using the new set of mechanical properties and the FE ANSYS 8.1 program. The deflections of the tower with prestressed and not prestressed cables are shown in Fig. 6.6. The results indicate that the increase in fibre volume fraction to a maximum value of $65 \%$ reduces the tip deflection by $15.54 \mathrm{~mm}(0.612 \mathrm{in})$ or $7.5 \%$ of the tower when the cables are not prestressed and by $14.41 \mathrm{~mm}(0.567 \mathrm{in})$ or $7.0 \%$ in the tower when the cables are prestressed. At the same time, the mass of the tower increases by a negligible amount of $19 \mathrm{~kg}(42 \mathrm{lb})$. Therefore, increasing the volume of fibres results in an increase in the stiffness of the tower mast and reduces lateral deflections. The extra cost associated with an increase in volume 
fraction must be taken into consideration in order to make this process economically viable. The current cost of E-glass fibres varies between $\$ 2$ to $\$ 4$ dollars per $\mathrm{kg}$, depending on the manufacturer.

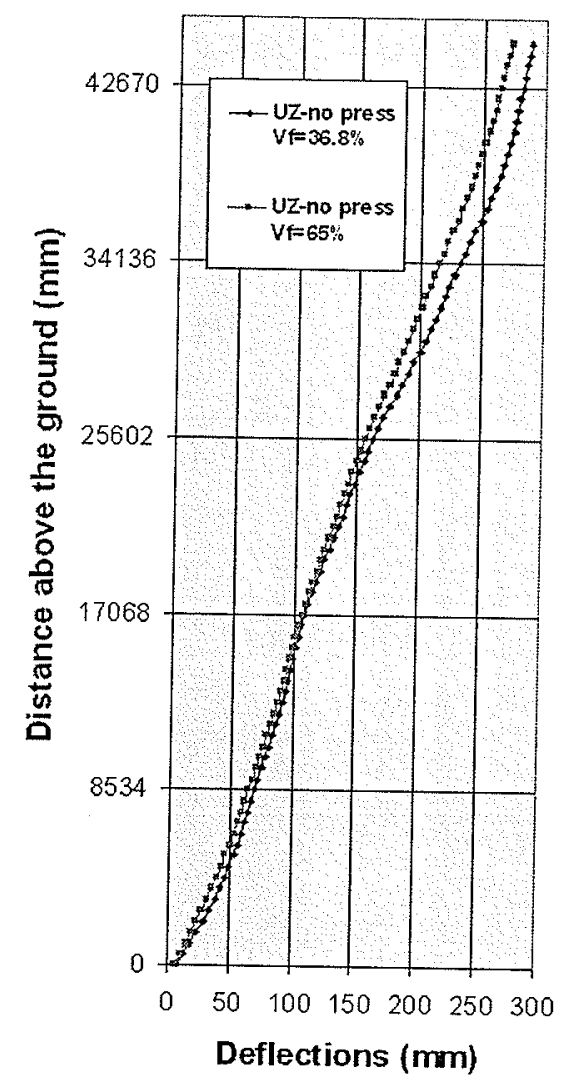

(a) Deflections with no prestress in cables

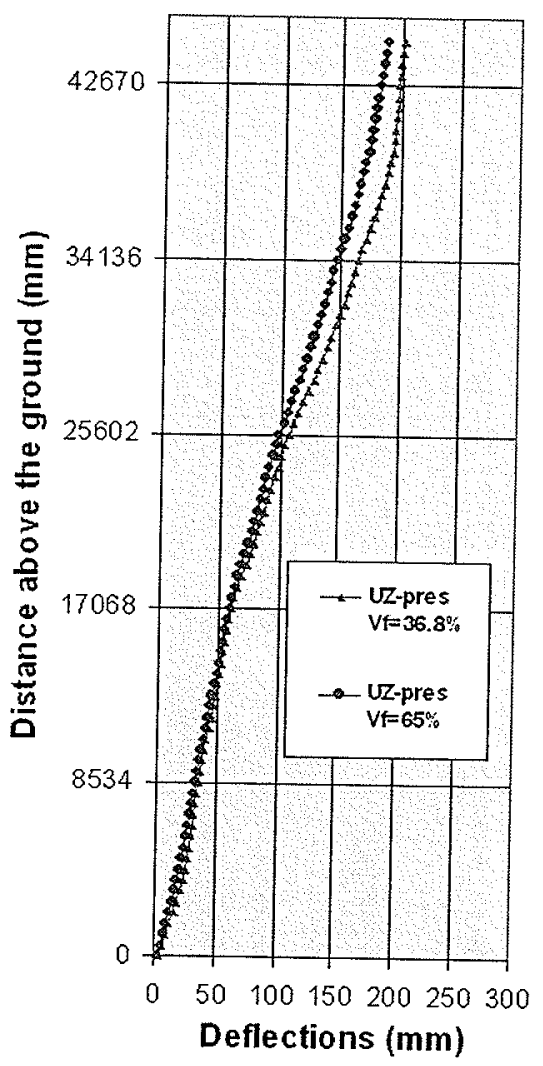

(b) Deflections with prestress in cables

Fig. 6.6 Tower deflections

Therefore the increase of tower mass by $19 \mathrm{~kg}$ will increase the cost of these fibres to $\$ 38$ to $\$ 76$ dollars for a tower segment ${ }^{6}$. This increase in cost is small, making the option of increasing the fibre volume fraction economically sound. A deflection and cost comparison between a full scale FRP tower and an

\footnotetext{
${ }^{6}$ The cost of tower segment prototype including the design, material and labour was

$\$ 2,000.00$. This price does not include manufacturing of collapsible mandrel.
} 
equivalent steel tower was included in Appendix-B. The conclusion was that the average cost of materials required for construction of a FRP tower is lower than the cost for an equivalent steel tower.

\subsection{Strength Failure Evaluation of the FRP Tower}

Based on the Failure Theories for unidirectional lamina outlined in Chapter-3, there are five strength parameters associated with two material axes, one parallel to fibres and one perpendicular: tension and compression in the axis parallel to fibres; tension and compression in the axis perpendicular to fibres; and, shear strength of a unidirectional lamina. The material properties used in the analysis of the FRP tower were obtained from test data presented by Burachynsky (2006) and Ungkurapinan (2005) and are listed in Table 6.4.

Table 6.4 Ultimate strength parameters

\begin{tabular}{|l|c|}
\hline Material Properties & Values \\
\hline Longitudinal Tensile $\left(F_{1}^{t u}\right)$ & $610.2 \mathrm{MPa}(88.5 \mathrm{ksi})$ \\
\hline Longitudinal compressive $\left(F_{1}^{c u}\right)$ & $324.67 \mathrm{MPa}(49.7 \mathrm{ksi})$ \\
\hline Transverse tensile $\left(F_{2}^{t u}\right)$ & $12.29 \mathrm{MPa}(1.78 \mathrm{ksi})$ \\
\hline Transverse compressive $\left(F_{2}^{c t}\right)$ & $69.64 \mathrm{MPa} \quad(10.1 \mathrm{ksi})$ \\
\hline In-plane shear $\left(F^{s u}\right)$ & $37.23 \mathrm{MPa} \quad(5.41 \mathrm{ksi})$ \\
\hline
\end{tabular}


From the four theories discussed in Chapter-3 only two, the Maximum Stress Failure theory and the Tsai-Wu interactive failure theory were used in this thesis to evaluate the strength of the tower composite members. The Maximum Stress Failure theory does not account for the interaction between the stress components acting along the principal axis. A failure envelope for this theory, based on the ultimate strength parameters listed in Table 6.4 is shown in Fig. 6.7. To be able to account for the interaction between stress components under the general state of plane stress with unequal tensile and compressive strengths, the Tsai-Wu criterion, outlined in Section 3.4.8.4 was used. Using the properties given by Eq. 3.22, the failure envelope was constructed and is shown in Fig. 6.7 .

\section{Maximum Stress Failure Theory + Tsai-Wu Theory}

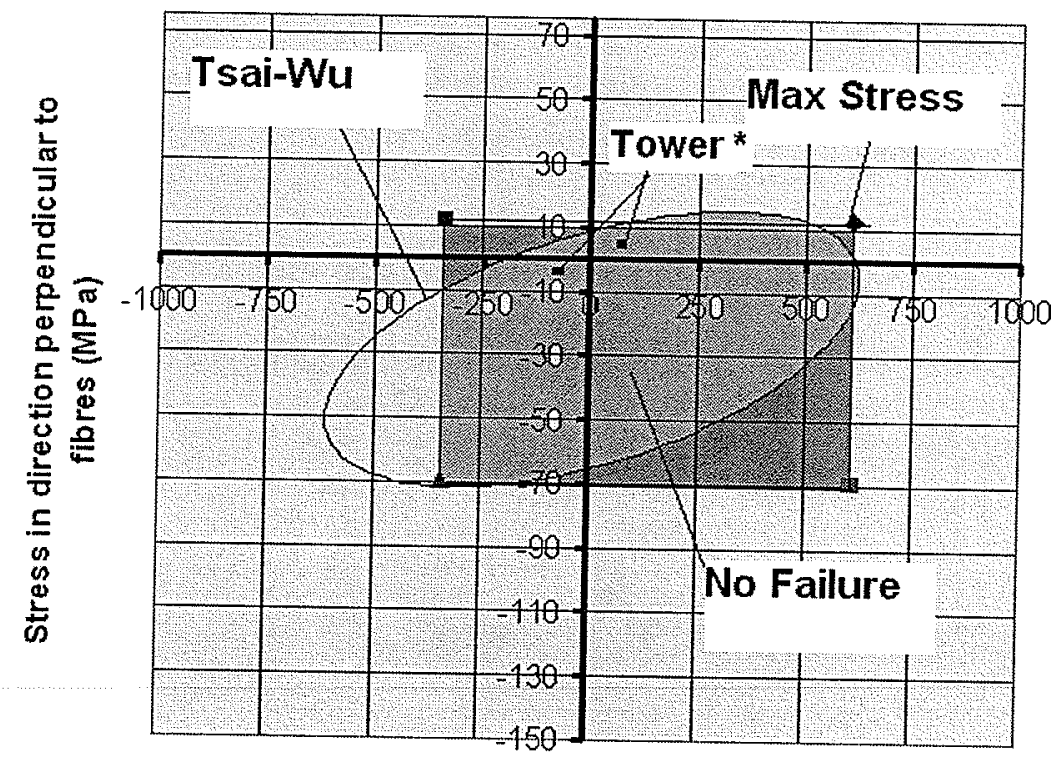

Stress in direction paralell to fibres (MPa)

* Tower maximum stresses (75.83 MPa, 5.96 MPa) and (-68.22 MPa, -5.96 MPa)

Fig. 6.7 Failure envelope based on Maximum Stress and Tsai-Wu Theories 
As indicated in Fig. 6.7, the "no failure zone" shows the area of safe stress components for FRP tower. Thus, the positive maximum tensile stress is limited to $+12.29 \mathrm{MPa}(+1.78 \mathrm{ksi})$ in the direction perpendicular to the fibres and the negative maximum compressive stress is limited to $-69.64 \mathrm{MPa}(-10.1 \mathrm{ksi})$ in the same direction. In the direction parallel to fibres the maximum positive stress is limited to $610.2 \mathrm{MPa}(88.5 \mathrm{ksi})$ and maximum compressive stress is limited to $-342.67 \mathrm{MPa}(-49.7 \mathrm{ksi})$. From the numerical analysis of the full scale tower outlined in Chapter 3 , the maximum stresses under the most critical load cases were listed in Table 6.5. Incorporating the values of the most unfavourable combinations of negative and positive stresses listed in Table 6.5 and

Table 6.5 Maximum tower stresses from the static FEM analysis under Load Case- $1^{*}$ and Load Case-2**

\begin{tabular}{|c|c|c|}
\hline \multirow{2}{*}{ Tower Stress component } & \multicolumn{2}{|c|}{ Value } \\
\cline { 2 - 3 } & (MPa) & (ksi) \\
\hline Maximum longitudinal stress under Load Case-1 $\left(\sigma_{1}\right)$ & $-68.22 / / 72.77$ & $-9.89 /+10.55$ \\
Maximum longitudinal stress under Load Case-2 $\left(\sigma_{1}\right)$ & $-61.42 / 75.83$ & $-10.27 /+10.99$ \\
\hline Maximum transverse stress under Load Case-1 $\left(\sigma_{2}\right)$ & $-5.96 /+5.96$ & $-0.86 /+0.86$ \\
Maximum transverse stress under Load Case-2 $\left(\sigma_{2}\right)$ & $-4.58 /+4.99$ & $-0.64 /+0.73$ \\
\hline In plane shear stress under Load Case- $1\left(\tau_{12}\right)$ & $-4.58 /+5.69$ & $-0.66 /+0.83$ \\
In plane shear stress under Load Case-2 $\left(\tau_{12}\right)$ & $-4.88 /+5.57$ & $-0.71 /+0.81$ \\
\hline
\end{tabular}


material properties listed in Table 6.4 into the Tsai-Wu equation (Eq.3.22) yielded the value 0.393 . This value is well below unity. Therefore, the FRP tower is safe from failure with a large margin of safety for static loadings. It is important to point out that tower members are carrying the load in the most favourable axial direction. The transverse and shear stresses which are trying to pull the fibres apart, are relatively small. Due to high longitudinal loading and small cross sections of tower mast members, failure may occur due to geometric instability (buckling) rather than of the material failure. This possible mode of failure is discussed below.

\subsection{Buckling of Unidirectional Lamina}

Since the maximum compressive stresses occur in the vertical chords of the tower, the compressive strength of the unidirectional lamina plays a critical role in the tower design.

The most important development in the area of predicting the failure mechanism of composites under compressive stresses is the micromechanical model formulated by Rosen (1964), who states that the failure mode is one of fibre microbuckling resisted by the matrix. Fibre microbuckling is defined as fibre instability followed by decreased capability of the fibres to carry load, with the final result being matrix failure by overstressing (Kaw, 1997). The model used by Rosen (1964) to develop his theory assumes that the fibres can be idealized as 2D slabs of thickness $h$, as shown in Fig. 6.8. 


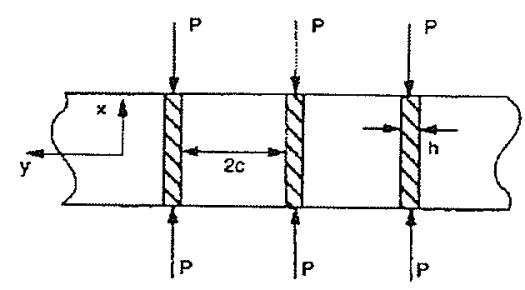

Fig. 6.8 Fibre-buckling model (Rosen,1964)

The fibres are equally spaced and are separated by a matrix slab of thickness $2 c$, where $2 \mathrm{c}$ represents the space between fibres taken by matrix, and $\mathrm{h}$ indicate the thickness of single fibre. The compressive load $P$ is applied vertically to initially straight fibres. Elastic buckling occurs in two distinctive modes:

The first, called extension mode, assumes that the fibres and the matrix exhibit anti-phase deformations, as shown in Fig. 6.9. The second mode, called shear buckling mode, assumes that the fibre and the matrix exhibit in-phase deformation (same deformed shape), as shown in Fig. 6.10.
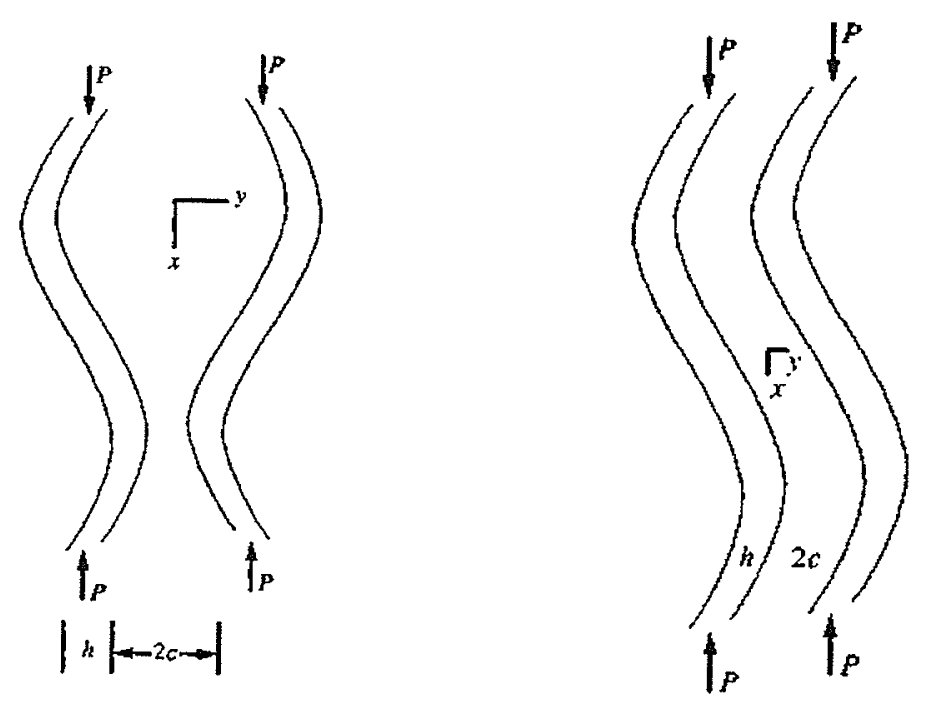

Fig. 6.9 Extension mode (Kaw, 1997) Fig. 6.10 Shearing mode (Kaw, 1997) 


\section{Recommendations for the Design of Composite Towers}

Using the energy approach, Rosen (1964) calculated the critical buckling force $P$ of the fibre in extension mode in terms of fibre volume fraction as:

$$
P=2 h \sqrt{\frac{V_{f} E_{m} E_{f}}{3\left(1-V_{f}\right)}}
$$

where:

$h=$ width of the fibre

$V_{f}=$ fibre volume fraction

$E_{m}=$ matrix elastic modulus

$E_{f}=$ fibre elastic modulus

Associated with this critical buckling load, is the critical stress for the lamina, expressed as:

$$
\sigma=2 V_{f} \sqrt{\frac{V_{f} E_{m} E_{f}}{3\left(1-V_{f}\right)}}
$$

According to the shear buckling mode, the critical buckling load is given by

$$
P=h\left[\frac{G_{m}}{V_{f}\left(1-V_{f}\right)}+\frac{\pi^{2} E_{f}}{12}\left(\frac{n h}{L}\right)^{2}\right]
$$

where:

$n=$ integer

$L=$ length of fibre

$G_{m}=$ shear modulus of matrix

The second term in the square brackets is much smaller than the first, and therefore, can be neglected. Thus, 


$$
P=h\left[\frac{G_{m}}{V_{f}\left(1-V_{f}\right)}\right]
$$

The critical stress according to the shear buckling mode is given as,

$$
\sigma=\frac{P}{h}=\frac{G_{m}}{V_{f} V_{m}}
$$

The critical stress according to the two modes of failure, the extension and shear buckling modes, are as follows:

Extension mode of failure: $\sigma_{C R E}=2 V_{f} \sqrt{\frac{V_{f} E_{m} E_{f}}{3 V_{m}}}$

Shear mode of failure $\quad \sigma_{C R B}=\frac{G_{m}}{V_{f} V_{m}}$

To be able to investigate the relation between fibre volume fraction and critical buckling stresses in extension and shear modes the critical buckling stresses given by equations 6.6 and 6.7 were plotted in Fig. 6.11 .

\section{Critical buckling stress for extension and shear modes}

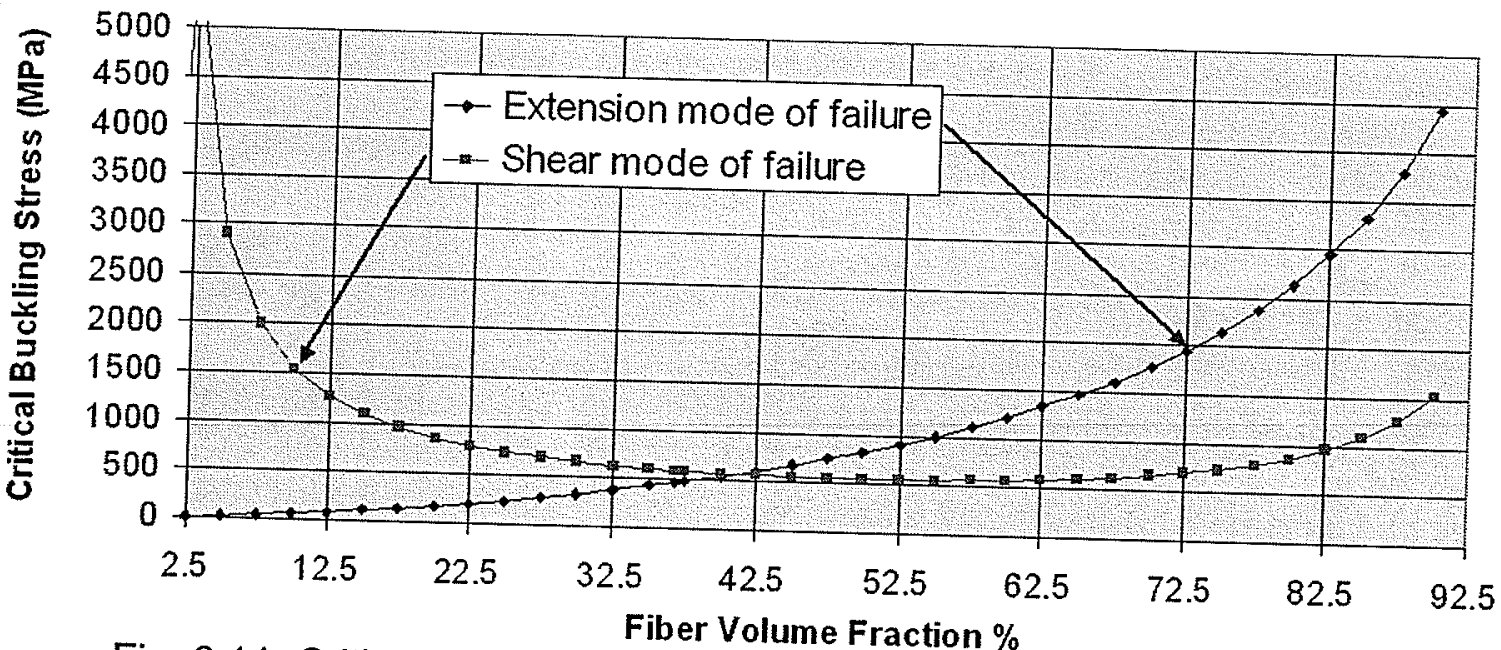

Fig. 6.11 Critical buckling stress for extension and shear modes of failure 
The results shown in Fig. 6.11 indicate that the extension mode of failure is more critical for higher fibre volume fractions while the shear mode governs the failure in low fibre volume fractions. For the value of fibre volume fraction of $36.8 \%$ the critical buckling stress, according to the extension mode, is $462.6 \mathrm{MPa}(67.1 \mathrm{ksi})$ while according to the shear mode of failure it is $592.9 \mathrm{MPa}$ (86 ksi). Both of these values are much higher than the compressive stress of $58.54 \mathrm{MPa}(8.49$ ksi) observed during testing and reported on page 193.

\subsection{Prediction of Maximum Compressive Load Based on Euler Formula}

Based on the Euler's formula for slender elastic columns, the critical buckling load of the slender column is equal to:

$$
P_{E}=\frac{\pi^{2} E I}{(k L)^{2}}
$$

where, $k$ is the effective length factor which depends on the type of supports.

The failure associated with this force involves sudden lateral deflections without deformation of the cross section. The effect of the shear deformation on the buckling load is taken into account by dividing $P_{E}$ by $\left(1+\frac{P_{E}}{G A}\right)$, where $G$ is the shear modulus and $A$ is the cross sectional area of the member. Based on the geometry of the tower chord shown in Fig. 6.12, and assuming pin-pin boundary conditions $(k=1.0)$ for each the slenderness ratio $\lambda=\frac{k \times L_{e}}{r}$ was calculated as 
$\lambda=83 . L_{e}$ was assumed to be $457 \mathrm{~mm}(18 \mathrm{in})$ and $r=5.4991 \mathrm{~mm}(0.2165 \mathrm{in})$, based on the dimensions shown in Fig. 6.12, and on the basis of a slenderness ratio $\lambda=83$, the critical Euler buckling load for the one leg of chord member, shown in Fig. 6.12, was calculated using Eq. 6.8. The results are shown in Table 6.6. A modulus of elasticity in the direction parallel to fibres of $E_{1}=25.44 \mathrm{GPa}=\left(3.69 \times 10^{6} \mathrm{psi}\right)$ and the moment of Inertia of $E_{1}=1.09748 \times 10^{4} \mathrm{~mm}^{4}=\left(0.0264 \mathrm{in}^{4}\right)$ were used in the calculations. The critical stress was obtained by dividing the Euler buckling load by the cross sectional area of a single leg $A=363 \mathrm{~mm}^{2}\left(0.5625 \mathrm{in}^{2}\right)$.

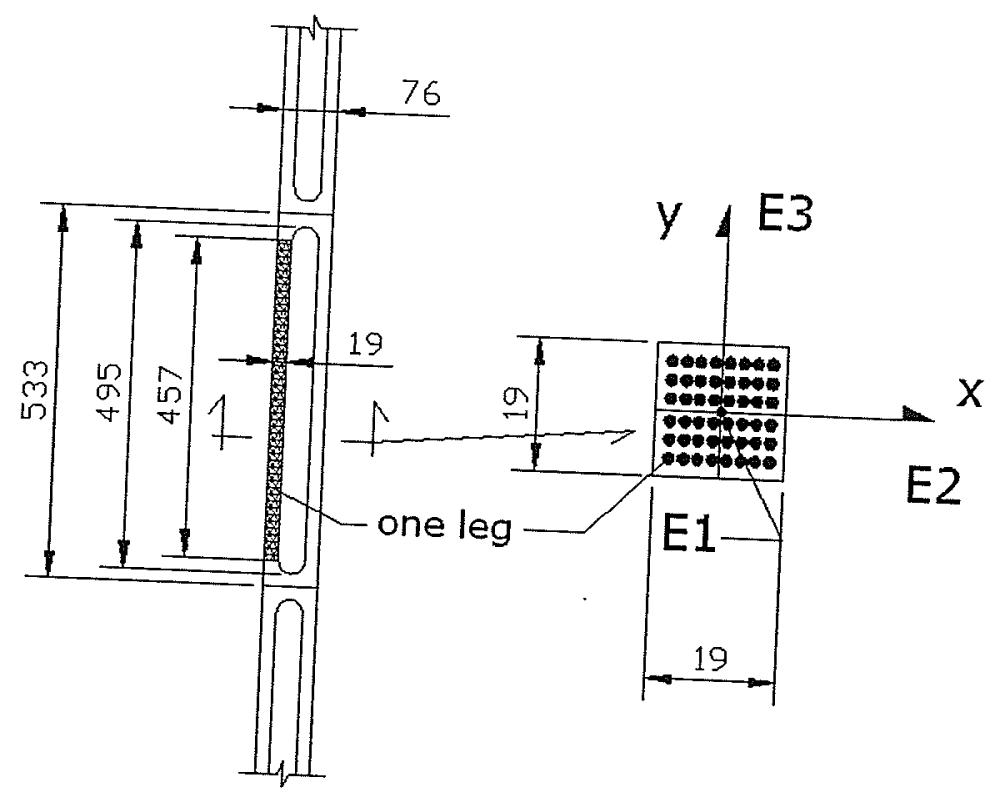

Fig. 6.12 Tower chord geometry for Euler Load calculations (units are in $\mathrm{mm}$ ) 
Table 6.6 Euler load and critical stresses for a single leg in the tower chord

\begin{tabular}{|l|l|l|}
\hline Euler buckling load* & Critical stress & $\begin{array}{c}\text { Critical stress with shear } \\
\text { deformation }\end{array}$ \\
\hline $13.18 \mathrm{kN}(2.96 \mathrm{kip})$ & $36.33 \mathrm{MPa}(5.27 \mathrm{ksi})$ & $35.50 \mathrm{MPa}(5.15 \mathrm{ksi})$ \\
\hline
\end{tabular}

* based on fibre volume fraction of $36.8 \%$

The effect of shear was taken into account using a value for in-plane shear modulus $G_{12}=2.758 \mathrm{GPa}\left(0.4 \times 10^{6} \mathrm{psi}\right)$ and an area of single leg as $A=363 \mathrm{~mm}^{2}\left(0.5625 \mathrm{in}^{2}\right)$. The critical stress, taking into account shear deformation is shown in Table 6.6.

Using the maximum value for the compressive stress of $-35.50 \mathrm{MPa}(-5.15 \mathrm{ksi})$ for a single leg, the FRP tower chord is $2 x-35.50 \mathrm{Mpa}(-5.15 \mathrm{ksi})=-71.00 \mathrm{MPa}$ $(-10.30 \mathrm{ksi})$. This value is higher than the maximum compressive stress of -68.22 MPa (-9.89 ksi) the chord would be subjected to, under the loading described in Chapter-3, paragraph 3.6.3.2.3.

However, the value of the critical Euler stress for tower chords equal to -71.00 $\mathrm{MPa}(-9.89 \mathrm{ksi})$ is lower that the maximum combined compressive stress -78.63 MPa (-11.4 ksi) obtained from dynamic analysis in paragraph 3.6.8.1.

Because of that, the tower bottom segment must have its chords cross sectional areas increased. 


\section{CHAPTER 7}

\section{SUMMARY AND CONCLUSIONS}




\subsection{Summary and conclusions}

A composite guyed latticed tower was investigated in this study. Both theoretical and experimental work was carried out. Latticed tower sections were designed by a research team and were fabricated by Cormorant Composites of Winnipeg using the filament winding process and a collapsible mandrel. They were later tested under static and dynamic loading. Glass fibre (1100 TEX) and epoxy resin (105/2005) supplied by West System were used to fabricate the tower sections. The experimental program was carried out in two stages. In the first stage, an

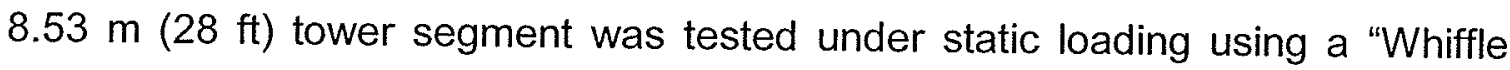
Tree" arrangement. The uniformly distributed loading was applied to the tower specimen through a system of point loads resembling wind loading acting at the bottom section of a $45 \mathrm{~m}$ (147 ft) full scale tower. The data collected consisted of deflections along the span of the tower in the direction of the applied load; strains at several critical locations; and, loads at their points of applications. In the second stage of the experimental program the tower specimen was tested under dynamic loading. The vibration data were collected using three accelerometers and linear motions transducers.

The ANSYS 8.1 finite element program was used to simulate the behaviour of the tested tower segment as well as the behaviour of the $45 \mathrm{~m}(147 \mathrm{ft})$ tower. The chord members along the three corners of the tower, as well as all bracing members, were modelled using BEAM4 elements from the ANSYS elements library. The guy cables were modelled using COMBIN14 elements. 
The guy cables in the full scale tower were modelled using Link10 tension only elements. All tower members were modelled with material properties obtained through unidirectional coupons tests conducted by Ungkurapinan (2005) and Burachynsky (2006). The theoretical models were compared to and verified with experimental data. Good agreement between numerical findings and test data was achieved suggesting the accuracy and validity of the theoretical models.

The numerical models verified by experiments were used for the design of the guyed tower prototype. Maximum tip deflections under service loading with and without prestress were obtained. Also maximum combined stresses in the vertical chord members and in the horizontal and vertical braces for two distinctive load cases were obtained theoretically. The stresses were compared to maximum strengths obtained from test data. The dynamic analysis using the patch load method, recommended by the CSA-S37-01 Standard, was implemented. The results of the tower response to dynamic wind fluctuation were obtained using both simple and detailed scaling procedure and then compared to the response under static wind loading. A comparative analysis involving a full scale $45 \mathrm{~m}$ (147 $\mathrm{ft}$ ) steel tower was also performed. Based on experimental and numerical results the following conclusions were drawn: 
Conclusions from the static testing and analysis of the FRP tower segment:

- The theoretical deflections of an $8.53 \mathrm{~m}(28 \mathrm{ft})$ tower segment and an equivalent section of a full scale tower compare well, proving the validity of the developed model.

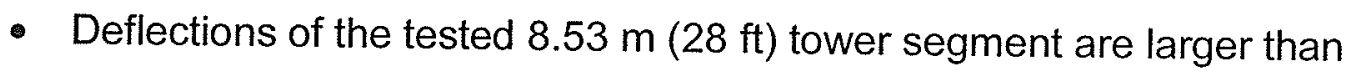
those obtained from numerical modelling due to observed slip in the connections.

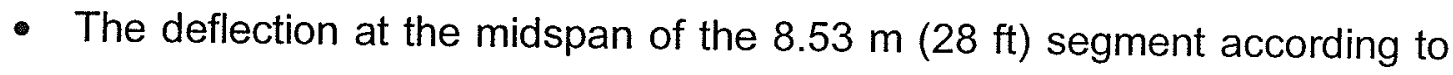
the FE model was $29.55 \mathrm{~mm}$ (1.16 in) under a factored loading of 5.14 $\mathrm{kN}$ (1156 lbs) and $10.39 \mathrm{~mm}$ (0.41 in) under a service loading of $2.62 \mathrm{kN}$ (589.92 lbs). These deflections correspond to $L / 288$ and $L / 821$, respectively, where $L$ is referred as a length of the tower segment.

- The maximum stresses for tension and compression recorded at the base of the tower segment are $36.61 \mathrm{MPa}(5.31 \mathrm{ksi})$ and $58.54 \mathrm{MPa}(8.49 \mathrm{ksi})$. These are $6 \%$ and $17 \%$ of the maximum tensile and compressive capacity of the composite material from which they were made. 
Conclusions from the dynamic testing and analysis of the FRP tower segment:

- The natural vibration of the $8.53 \mathrm{~m}(28 \mathrm{ft})$ tower segment tested in the upright position closely resemble one determined through the FE modal and harmonic analysis.

- The undamped natural frequency of the vibrating tower segment was calculated as $4.31 \mathrm{~Hz}$.

- The first flexural natural frequency of vibration of the $45 \mathrm{~m}(147 \mathrm{ft})$ tower is $0.219 \mathrm{~Hz}$ and is lower than the natural frequency of the tested FRP tower segment $4.3104 \mathrm{~Hz}$ by the factor of 20 .

- There is a very close correlation between the deflected shape of the tower segment based on test data and that obtained through the FEA proving validity of the Gust Factor Method.

- The dynamic analysis of the full scale tower using the Patch Load Method, recommended by CSA-S37-01, indicates that by using the detailed scaling the Patch Load Method gives similar results to the Gust Factor Method. 


\section{Conclusions from the FE static analysis of FRP $45 \mathrm{~m}$ (147 ft) tower:}

- By introducing an equal prestress of $2.76 \mathrm{MPa}$ (400 psi) to all cables, the tower tip deflection can be reduced by $14.4 \%$ if no antenna is present and by $11 \%$ if an antenna is attached.

- The maximum factored guy force with $10 \%$ guy prestress equivalent to 1.78 $\mathrm{kN}(400 \mathrm{lb})$ is equal to $17.37 \mathrm{kN}$ (3.9 kips), which is just under the breaking strength of $17.78 \mathrm{kN}$ (3.99 kips) of the guy cables.

- The highest combined stress from static analysis for both load Cases 1 (load normal to a side) and Case 2 (load parallel to a side) is $-68.22 \mathrm{MPa}$ (-9894.6 psi) and does not govern the design of tower.

- The maximum compressive buckling strength of tower chords, based on a fibre volume fraction of $36.8 \%$, is $-71.00 \mathrm{MPa}(-10.30 \mathrm{ksi})$ and is higher than the experimental maximum compressive stress of $-58.8 \mathrm{MPa}(-8.49 \mathrm{ksi})$.

\section{Conclusions from the FEM dynamic analysis of FRP $45 \mathrm{~m}(147 \mathrm{ft})$ tower:}

On the basis of the results from the dynamic analysis of the tower with fibre volume fraction of $36.8 \%$, the tower must be designed for a maximum combined compressive stress equal to $-78.63 \mathrm{MPa}(-11.4 \mathrm{ksi})$. This value is higher than maximum compressive buckling strength of the tower chords of $-71.00 \mathrm{MPa}$ 
$(-10.30 \mathrm{ksi})$ but much lower than the ultimate longitudinal compressive strength of lamina equal to $-324.67 \mathrm{MPa}(49.7 \mathrm{ksi})$. To increase the buckling strength of the tower bottom chords, it is recommended that the chords of the bottom segment have its cross sectional area increased.

\subsection{Recommendation for future research}

The research presented in this thesis for the development of composite guyed latticed towers is the first of its kind. The innovative concept of filament winding using the space truss arrangement and a collapsible mandrel presents another alternative for lattice technology in the composites industry. The next stage of this research program will include the fabrication of a $5867 \mathrm{~mm}(19.25 \mathrm{ft})$ tower sections for the construction of an $82 \mathrm{~m}(269.5 \mathrm{ft})$ FRP tower. The process of filament winding will be fully automated using a programmable filament winding machine. Although several aspects of the composite lattice tower were investigated, there are still a number of areas of research that must be carried out in order to produce economically viable guyed composite towers.

These include,

- Investigation of connections between tower sections to produce towers capable of taking variety of static and dynamic stresses under actual environmental conditions.

- Investigation of the guyed cables as the affect the overall dynamic performance of the tower. 
- Further testing of tower segments to evaluate the maximum compressive buckling strength of the tower chords.

- Investigation of the effect of environmental conditions, like moisture, UV light and temperature on the tower performance.

- Study of snow and ice accumulation on tower and cables should be conducted to verify the CSA-S37-01 provisions.

- Evaluation of the effect of an increased fibre volume fraction on tower stiffness and compressive strength trough testing.

- Investigation of the FRP tower under cycling loading to assess the fatigue strength of the connection between tower segments.

- Examination of appropriate tower coatings to prevent moisture and UV penetration in tower members.

- Investigation of composite guy anchors to eliminate galvanic corrosion.

- Investigation of structural optimization of the FRP tower from the point of view of manufacturing, transportation and assembly. 


\section{REFERENCES:}

ANSYS, 2004, "ANSYS User's Manual Ver. 8.1," Swanson Analysis Systems, Inc., Houston.

ASTM Standards D3039/D3039M, Standard Test Methods for Tensile Properties of Polymer Matrix Composite Materials, 2005

ASTM Standards D3410/D3410M-03, Standard Test Methods for Compressive Properties of Polymer Matrix Composite Materials with Unsupported Gage Section by Shear Loading, 2005

ASTM Standards D5379/D5379M-05, Standard Test Methods for Shear Properties of Polymer Composite Materials by V-Notched Beam Method, 2005

Bedford Reinforced Plastics Manual, 2007, 264 Reynoldsdale Road Bedford PA 15522-7401 USA.

Burachynsky, V.I., 2006, "Filament Winding of Long Tapered Tubes," Ph.D.

Dissertation, University of Manitoba, Canada.

Chen, W.F., 1997, "Handbook of Structural Engineering," CRC Press, Boca Raton, FL.

CSA-S-16.1-94, 1995, "Handbook of Steel Construction," Sixth edition, Canadian Institute of Steel Construction, Willowdale, Ontario. 
CSA Standard S37-01, 2001, "Antennas, Towers and Antenna-Supporting Structures," Canadian Standard Association, Rexdale, Ontario.

Cohen, E., and Perrin, H.,1957 a., "Design of Multi-Level Guyed Towers: Wind Loading," Journal of the Structural Division, ASCE, Vol. 83, No.1355, pp.1-29.

Cohen, E., and Perrin, H.,1957 b.,"Design of Multi-Level Guyed Towers: Wind loading," Journal of the Structural Division, ASCE, Vol. 83 No.1356, pp. 1-29.

Composite Tower Solutions Inc.,(CTS) , 2008, Available at: http://compositetower.com/

EIA/TIA Standard, TIA-222-F, 2003, "Structural Standards for Steel Antenna Towers and Antenna Supporting Structures," Arlington, Virginia.

Daniel, I.M. and Ishai, O.,1994, "Engineering Mechanics of Composite Materials," Oxford University Press, New York, N.Y.

Davenport, A. G. and Sparling, B. F.,1992, "Dynamic Gust Response Factors for Guyed Towers," Journal of Wind Engineering and Industrial Aerodynamics, Vol. 44, pp. 2237-2248.

Dean, D.L.,1961, "Static and Dynamic Analysis of Guy Cables," Journal of Structural Division, ASCE, Vol. No.ST1, pp.1-21.

Ekhande, S. G. , Madagula, M. K. S.,1998, "Geometric Non-Linear Analysis of Three-Dimensional Guyed Towers," Computers \& Structures, Vol. 29, No 5, pp. 801-806. 
Gesrtoft, P. and Davenport, A.G., 1986, “A Simplified Method for Dynamic Analysis of Guyed Mast," Journal of Wind Engineering and Industrial Aerodynamics, Vol. 23, pp. 487-499.

Goldberg, J.E., and Meyers, V.J.,1965, “A Study of Guyed Towers,” Journal of Structural Division, ASCE, Vol. 91 pp. 57-76.

Goldberg, J.E., and Gaunt, T.J.,1973, "Stability of Guyed Towers," Journal of Structural Division, ASCE, Vol. 99, 741-756.

Hopkins, D.A. and Chamis, C.C.,1988, "A Unique set of Micromechanics Equations for High Temperature Metal Matrix Composite," STM STP 964, American Society for Testing and Materials, Philadelphia, PA pp. 159-176.

Hull, F.H.,1962, "Stability Analysis of Multi-Level Guyed Towers," Journal of the Structural Division, ASCE, Vol. 88, pp. 61-80.

Issa, R.A., and Avent, R.R.,1991, "Microcomputer Analysis of Guyed Towers as Lattices," ASCE , Journal of Structural Engineering, Vol.117, No.4, pp. 1238-1256.

Kahla, N.,1993, "Static and Dynamic Analysis of Guyed Towers," PhD Dissertation, University of Wisconsin, Madison.

Kaw, A. K.,1997, “Mechanics of Composite Materials,” CRC Press, Boca Raton, New York. 
Madugula, M.K.S., Wahba, Y.M.F., Monforton, G.R., 1998, "Dynamic Response of Guyed Masts," Engineering Structures, Vol. 20, No. 12, pp.1097-1101.

Miklofsky, H.A., and Abegg, M.G.,1966, "Design of Guyed Towers by Interaction Diagrams," Journal of the Structural Division, ASCE, Vol.92, pp. 245-256.

Murphy, J., 1988, "The Reinforced Plastics Handbook," Second Edition, Elsevier Advanced Technology, Oxford.

National Building Code of Canada, 2005, "National Research Council of Canada, Canadian Structural Design Manual, Supplement No.4," Ottawa, Canada.

Nello Corporation, Catalog, 2006, P.O. Box 376 Nappanee, IN 46550.

Odley, E.G., 1966, "Analysis of High Guyed Towers," Journal of the Structural Division, ASCE, Vol. 92, pp.169-195.

Peters, S.T., Humphrey W.D. and Floral R.F.,1991, "Filament WindingComposite Structure Fabrication," published by SAMPE, Covina, California.

Peyrot, A.H., and Goulois, A.M.,1978, "Analysis of Flexible Transmission Lines," ASCE , Journal of Structural Division, Vol.104 (5), pp. 763-779

Peyrot, A.H. and Goulois, A.M., 1979, "Analysis of Cable Structures," Computers \& Structures, Vol. 10, No. 5, pp. 805-813. 
Przybyla, L., 2008, "IsoTruss Grid Structures", Available at:

http://www.techtransfer.byu.edu/AvailableTechnologies/ltemDetail.aspx?itemld=81

Rosen, B.W., 1964, "Mechanics of Composite Strengthening-Fiber Composite Materials," Chapter3, American Society of Metals Seminar, Metal Parks, Ohio, pp. 37-75.

Rosenthal, F. and Skop, R. A., 1980, "Guyed Towers under Arbitrary Loads," Journal of the Structural Division, ASCE, Vol. 106(3), pp. 679-692.

Rowe, R.S., 1958, "Amplification of Stress and Displacement in Guyed Towers," Journal of Structural Division, ASCE, No.ST6, pp. 1821-1-1821-20.

Sparling, B.F. and Davenport A.G.,1998, "Three-Dimensional Dynamic Response of Guyed Towers to Wind Turbulence," Canadian Journal of Civil Engineering, Vol.25, pp. 512-525.

Sparling, B.F., 1995, "The Dynamic behaviour of guys and guyed masts in turbulent winds", PhD Thesis University of Western Ontario, London, Canada. SPI, 2008, "The Society of the Plastic Industry, The Plastic Industry Trade Association," 1667 K ST NW, Suite 1000, Washington DC 20006.

Swanson, R.S.,1997, "Introduction to Design and Analysis with Advanced Composite Materials," Prentice Hall, Upper Saddle River, New Jersey 07458. 
Tedesco, J., McDougal, W.,1999, "Structural Dynamics Theory and Applications," Addison-Wesley Longman, Inc., Menlo Park, California.

Tsai, S.W., and Wu, E.M., 1971, "A General Theory of Strength for Anisotropic Materials," Journal of Composite Materials, Vol. 5, pp.58-80

Ungkurapinan, N., 2005, "The Development of Composite Wind Turbine Towers," Dissertation, University of Manitoba, Canada.

Williamson, R.A., and Margolin, M.N.,1966, "Shear Effect in Design of Guyed Towers," Journal of Structural Division, ASCE, Vol.92, pp. 213-233.

Williamson, R.A., 1973, "Stability study of Guyed Towers under Ice Loads," Journal of Structural Division, ASCE Vol. ST12, pp. 2391-2408. 


\section{APPENDIX-A ANSYS INPUT FILES}




\section{A.1 INPUT FILE FOR $8.53 \mathrm{~m}(28 \mathrm{ft})$ FRP TOWER EGMENT}

! ANSYS command file to perform 3D Frame analysis of 4 section tower segment ! Cables modelled using LINK10 elements

!

/PREP7

ITITLE,ANALYSIS OF 4-SECTION FRP TOWER (28 FEET LONG)-TOWER-CABLES NO INITIAL PRESTRESS
$\mathrm{K}, \quad 1,0.000000,-6.347000,10.99100$
$\mathrm{K}, \quad 2,0.000000,-6.347000,-10.99100$
$\mathrm{K}, \quad 3,0.000000, \quad 12.69100,0.000000$
$\mathrm{K}, \quad 4,21.00000, \quad 12.69100,0.000000$
$\mathrm{K}, \quad 5,31.50000, \quad 3.172000,5.495500$
K, $\quad 6,21.00000,-6.347000,10.99100$
$\mathrm{K}, \quad 7,10.50000, \quad 3.172000,5.495500$
$\mathrm{K}, \quad 8,10.50000,-6.347000,0.000000$
$\mathrm{K}, \quad 9,10.50000, \quad 3.172000,-5.495500$
$\mathrm{K}, 10,31.50000,-6.347000,0.000000$
$\mathrm{K}, \quad 11,21.00000,-6.347000,-10.99100$
$\mathrm{K}, \quad 12,31.50000, \quad 3.172000,-5.495500$
$\mathrm{K}, 13,42.00000,12.69100,0.000000$
$\mathrm{K}, \quad 14,52.50000,3.172000,5.495500$
$\mathrm{K}, \quad 15,42.00000,-6.347000,10.99100$
$\mathrm{K}, \quad 16,52.50000,-6.347000,0.000000$
$\mathrm{K}, \quad 17,42.00000, \quad-6.347000,-10.99100$
$\mathrm{K}, \quad 18,52.50000, \quad 3.172000,-5.495500$
$\mathrm{K}, \quad 19,63.00000,12.69100,0.000000$
K, $20,73.50000, \quad 3.172000,5.495500$
K, 21, 63.00000, $-6.347000,10.99100$
$\mathrm{K}, \quad 22,73.50000,-6.347000,0.000000$
K, 23,63.00000, $-6.347000,-10.99100$
$\mathrm{K}, 24,73.50000, \quad 3.172000,-5.495500$
$\mathrm{K}, \quad 25,105.0000,12.69100,0.000000$
$\mathrm{K}, \quad 26,115.5000, \quad 3.172000,5.495500$
$\mathrm{K}, \quad 27,105.0000,-6.347000,10.99100$
$\mathrm{K}, \quad 28,115.5000,-6.347000,0.000000$
$\mathrm{K}, \quad 29,84.00000, \quad 12.69100,0.000000$
$\mathrm{K}, \quad 30,94.50000, \quad 3.172000,5.495500$
$\mathrm{K}, \quad 31,105.0000,-6.347000,-10.99100$
$\mathrm{K}, \quad 32,84.00000, \quad-6.347000,10.99100$
$\mathrm{K}, \quad 33,115.5000, \quad 3.172000,-5.495500$
$\mathrm{K}, \quad 34,94.50000, \quad-6.347000,0.000000$
$\mathrm{K}, \quad 35,84.00000,-6.347000,-10.99100$
K, 36, 126.0000, $12.69100,0.000000$
$\mathrm{K}, \quad 37,136.5000, \quad 3.172000,5.495500$
$\mathrm{K}, \quad 38,94.50000, \quad 3.172000,-5.495500$
$\mathrm{K}, \quad 39,126.0000,-6.347000,10.99100$
$\mathrm{K}, 40,136.5000,-6.347000,0.000000$
$\mathrm{K}, \quad 41, \quad 126.0000,-6.347000,-10.99100$
$\mathrm{K}, \quad 42, \quad 136.5000, \quad 3.172000,-5.495500$
$\mathrm{K}, 43,147.0000,12.69100,0.000000$ 


$\begin{array}{llll}\mathrm{K}, & 44,157.5000, & 3.172000,5.495500 \\ \mathrm{~K}, & 45,147.0000, & -6.347000,10.99100 \\ \mathrm{~K}, & 46,157.5000, & -6.347000,0.000000 \\ \mathrm{~K}, & 47,147.0000, & -6.347000,-10.99100 \\ \mathrm{~K}, & 48, & 157.5000, & 3.172000,-5.495500 \\ \mathrm{~K}, & 49,189.0000, & 12.69100,0.000000 \\ \mathrm{~K}, & 50,199.5000, & 3.172000,5.495500 \\ \mathrm{~K}, & 51,189.0000, & -6.347000,10.99100 \\ \mathrm{~K}, & 52,199.5000, & -6.347000,0.000000 \\ \mathrm{~K}, & 53,168.0000, & 12.69100,0.000000 \\ \mathrm{~K}, & 54,178.5000, & 3.172000,5.495500 \\ \mathrm{~K}, & 55,189.0000, & -6.347000,-10.99100 \\ \mathrm{~K}, & 56,168.0000, & 3.172000,10.99100 \\ \mathrm{~K}, & 58,178.5000, & -6.347000,0.000000 \\ \mathrm{~K}, & 59, & 168.0000, & -6.347000,-10.99100 \\ \mathrm{~K}, & 60, & 210.0000, & 12.69100,0.000000\end{array}$
L, $\quad 4,5$
L, 6,5
L, $\quad 6,10$
L, 3,7
L, 11,10
L, 1,7
L, 11,12
L, 1,8
L, $\quad 4,12$
L, $\quad 2,8$
L, 13,14
L, $\quad 2,9$
L, 15,14
L, 3,9
L, 15,16
L, 17,16
L, 17,18
L, 13,18
L, 19,20
L, 21,20
L, $21, \quad 22$
L, 23,22
L, 23, 24
L, 19,24
L, 3,4
L, 4,13
L, 13,19
L, $\quad 1,6$
L, $6, \quad 15$
L, 15,21
L, 7,4
L, 7,6
L, 5,13
L, 5,15
L, 14,19
L, 14,21
L, 2, 11
L, 11,17 
L, 17,23

L, 10,17

L, $\quad 9, \quad 11$

L, 9,4

L, 8,11

L, 8,6

L, $12, \quad 17$

L, 12,13

L, 10,15

L, 18,23

L, 18,19

L, 16,23

L, 16,21

LGEN,4,ALL,,,84

!ELEVATION=84"
L,23,70
L, 19,64
L,21,67
L,24,70
L,24,64
L,20,64
L,20,67
L,22,67
L,22,70
!HORIZONTAL BRACE
L,67,64
L,64,70
L,70,67

!ELEVATION=168"

$L, 78,88$

$\mathrm{L}, 82,94$

$\mathrm{L}, 80,91$

$\mathrm{L}, 79,88$

L, 79,91

$L, 83,94$

$\mathrm{L}, 83,88$

L,81,94

L, 81,91

!HORIZONTAL BRACE

L,88,94

L, 94,91

$L, 91,88$

!ELEVATION=252"

$\mathrm{L}, 106,118$

$\mathrm{L}, 102,112$

$\mathrm{L}, 104,115$

L, 107,118 


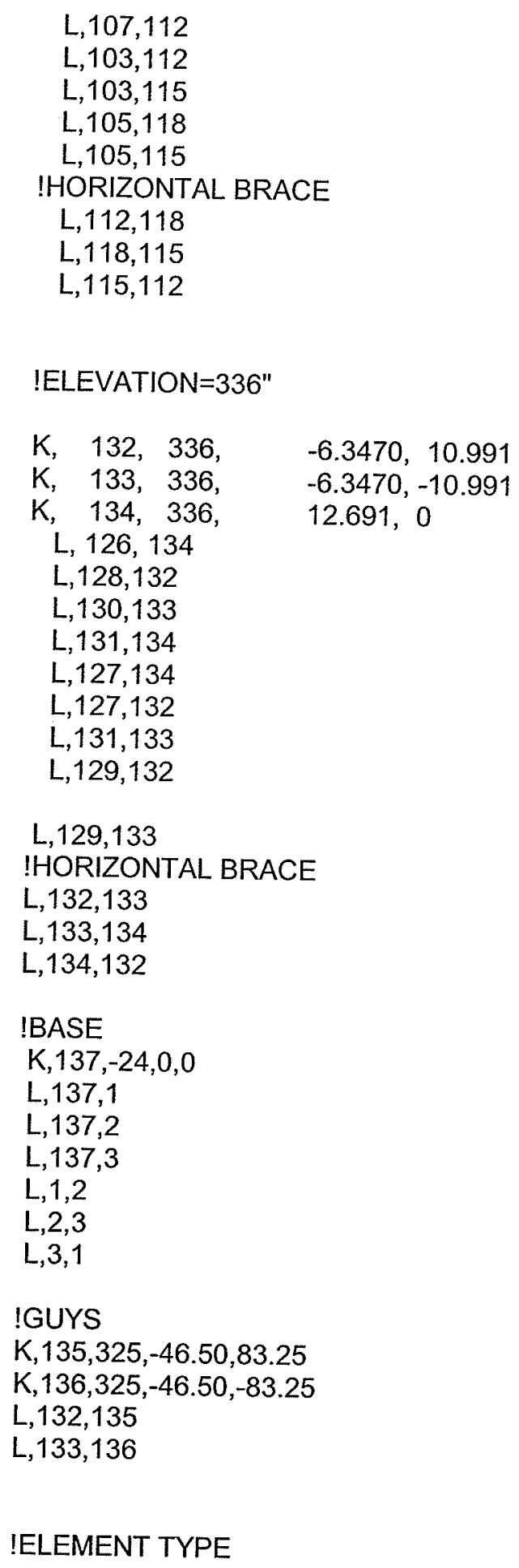

!ELEMENT TYPE

IREAL CONSTANT VARIATION TO ACCOUNT FOR ROTATION OF LOVAL CS TO GLOBAL CS

\section{ET,1,BEAM4}

IPROPERTIES OF VERTICAL COLUMNS 
!R, 1,3.0,3.9374,1.0,2,3,!AREA $=3 \mathrm{IN}^{\wedge} 2$

IR, $1,1.5,1.9686,0.125,1,3,-120$ !THETA $=-120$

$R, 1,1.125,1.4766,0.0527,0.75,3,-120$ !THETA=-120 !COLUMNN-1,REAL CONSTANT-1 ! $A R E A=1.125, I Z Z=1.4766, I Y Y=0.0527, T K Z=0.75, T K Y=3, T H E T A=-120$

ET, 1,BEAM4

IPROPERTIES OF VERTICAL COLUMNS

!R,2,3.0,3.9374,1.0,2,3,!AREA=3 IN^2

$\mathrm{R}, 2,1.125,1.4766,0.0527,0.75,3,-60$ !THETA=-60 !COLUMNN-2,REAL CONSTANT-2 IAREA $=1.125, I Z Z=1.4766, \quad M Y=0.0527, T K Z=0.75, T K Y=3$, THETA $=-60$

ET, 1,BEAM4

IPROPERTIES OF VERTICAL COLUMNS

!R,3,3.0,3.9374, 1.0,2,3, AREA $=3 \mathrm{IN}^{\wedge} 2$

R,3,1.125,1.4766,0.0527,0.75,3,-90 !THETA=-90 !COLUMNN-3,REAL CONSTANT-3

!AREA $=1.125, I Z Z=1.4766, I Y Y=0.0527, T K Z=0.75, T K Y=3$, THETA=-90

!PROPERTIES OF CROSS-BRACINGS

$\mathrm{R}, 4,0.25,0.0052,0.0052,0.5,0.5$, !REAL CONSTANT-4

!PROPRTIES OF HORIZ BRACINGS

$\mathrm{R}, 5,0.500,0.0104,0.0417,1.0,0.5,90$ !REAL CONSTANT-5

! AREA $=0.5, \mathrm{IZZ}=0.0104, \mathrm{IYY}=0.0417, \mathrm{TKZ}=1, \mathrm{TKY}=0.5, \mathrm{THETA}=90$

IPROPRTIES OF GUY CABLES

!ET,2,COMBIN14 ! Element type 2

IR,6,373.34 ! NO INITIAL PRESTRESS

!SPRING CONSTANT $=373.34$

ET,2,LINK10,,0, 


\section{R,6,0.0285,0! NO INITIAL PRESTRESS \\ !R,6,0.0285,0.00048397! INITIAL STRAIN FROM 400LB PRESTRESS ON 3/16"GUY CABLE !REAL CONSTANT-6 \\ !R,6,0.035,0.00039406 !INITIAL STRAIN FROM 400LB PRESTRESS ON 1/4" GUY CABLE \\ !AREA $=0.0285$, ISTRN $=0$ FOR NO PRESTRESS}

!ORTHOTROPIC MATRIAL PROPERTIES-TOWER

MP,EX,1,3.69e6 !LB/IN^2 !MATERIAL TYPE-1

$\mathrm{MP}, \mathrm{EY}, 1,0.615 \mathrm{e} 6 \mathrm{!LB} / \mathrm{IN}^{\wedge} 2$

$M P, E Z, 1,0.615 \mathrm{e} 6 ! \mathrm{LB} / \mathrm{IN}^{\wedge} 2$

$M P, G X Y, 1,0.4 \mathrm{e} 6 ! \mathrm{LB} / \mathrm{IN}^{\wedge} 2$

$\mathrm{MP}, \mathrm{GYZ}, 1,0.4 \mathrm{e} 6 ! \mathrm{LB} / \mathrm{IN}^{\wedge} 2$

$\mathrm{MP}, \mathrm{GXZ}, 1,0.4 \mathrm{e} 6 ! \mathrm{LB} / \mathrm{IN}^{\wedge} 2$

$M P, P R X Y, 1,0.35$

MP,PRYZ, 1,0.06

MP,PRXZ,1,0.35

MP,DENS, $1,0.076$ !LB/IN^3

!ISOTROPIC MATRIAL PROPERTIES-GUYS

MP,EX,2,29E6 IMATERIAL TYPE-2

$M P, P R X Y, 2,0.3$

MP,DENS, $2,0.284$ !LB/IN^3

!ISOTROPIC MATRIAL PROPERTIES-BASE

MP,EX,3,29E6 IMATERIAL TYPE-3

$M P, P R X Y, 3,0.3$

MP,DENS,3,0.284!LB/IN^3

ET,3,PIPE16 ! EIEMENT TYPE = PIPE 16

KEYOPT, 1,6,1 ! changed option to give the extra force and mom output!*

$\mathrm{R}, 7,3,0.1875$, ! Real Constant=7, Material=3, Outside Diameter, Wall thickness!*

LSEL,ALL

LATT, 1,4,1 !MAT-1,REAL-4,TYPE-1 !CROSS-BRACING

LSEL,ALL

LSEL,S,LOC,Y,12.691 !COLUMN-3

LATT, $1,3,1$

LSEL,ALL

LSEL,S,LOC,Z,10,991 !COLUMN-1

LATT $, 1,1,1$

LSEL,ALL 
LSEL,S,LOC,Z,-10.991 !COLUMN-2

LATT, $1,2,1$

LSEL,ALL

!GUY CABLES

LSEL,S,LINE, ,259

LATT, $2,6,2$

LSEL,ALL

LSEL,S,LINE, ,260

LATT, 2,6,2

LSEL,ALL

!HORIZ BRACING

LSEL,S,LOC,X,84 !HORIZ-BRACING

LATT, $1,5,1$

LSEL,ALL

LSEL,S,LOC,X,168 !HORIZ-BRACING

LATT $, 1,5,1$

LSEL,ALL

LSEL,S,LOC,X,252 !HORIZ-BRACING

LATT, $1,5,1$

LSEL,ALL

LSEL,S,LOC,X,336 !HORIZ-BRACING

LATT, $1,5,1$

LSEL,ALL

LSEL,S,LOC,X,-24,0

LSEL,R,LINE, ,253,255, 1

LATT, $3,7,3$

LSEL,ALL

LSEL,S,LOC,X,0,0

LSEL,R,LINE,,256,258, 1

LATT, $3,7,3$

LSEL,ALL

LESIZE,ALL, ,1

LMESH,ALL

!

!

FINISH !FINISH PREPROCESSOR

!

ISOLU !ENTER SOLUTION PHASE 


\section{!APPLY CONSTRAINS}

!"BOUNDARY CNDITIONS

DK,137,UX,0

DK, 137,UY,0

DK, 137,UZ,0

DK, 135,UX,0

DK, 135,UY,0

DK, 135,UZ,0

DK, 136,UX,0

DK, 136,UY,0

DK, 136,UZ,0

!DEFINE FORCES ON KEYPOINTS

! POINT LOADINGS ON PANELS

!CASE-1
$A=73.74$ !DISTANCE $21 "$
$\mathrm{B}=73.74$ !DISTANCE 63"
$C=73.74$ !DISTANCE $105^{\prime \prime}$
$\mathrm{D}=73.74$ ! DISTANCE 147"
$E=73.74$ !DISTANCE $189^{\prime \prime}$
$F=73.74$ !DISTANCE 231"
$\mathrm{G}=73.74$ !DISTANCE 273"
$H=73.74$ !DISTANCE $315^{\prime \prime}$

ICASE-1

$F K, 4, F Y, A / 3$

$F K, 6, F Y, A / 3$

$F K, 11, F Y, A / 3$

FK,19,FY,A/3

$\mathrm{FK}, 21, \mathrm{FY}, \mathrm{A} / 3$

$F K, 23, F Y, A / 3$

$F K, 57, F Y, A / 3$

$\mathrm{FK}, 62, \mathrm{FY}, \mathrm{A} / 3$

$\mathrm{FK}, 66, \mathrm{FY}, \mathrm{A} / 3$

$\mathrm{FK}, 78, \mathrm{FY}, \mathrm{A} / 3$

$\mathrm{FK}, 80, \mathrm{FY}, \mathrm{A} / 3$

$\mathrm{FK}, 82, \mathrm{FY}, \mathrm{A} / 3$

$\mathrm{FK}, 84, \mathrm{FY}, \mathrm{A} / 3$

$\mathrm{FK}, 86, \mathrm{FY}, \mathrm{A} / 3$ 
$\mathrm{FK}, 90, \mathrm{FY}, \mathrm{A} / 3$

$F K, 102, F Y, A / 3$

FK, 104,FY,A/3

$F K, 106, F Y, A / 3$

FK, 110,FY,A/3

$F K, 108, F Y, A / 3$

$F K, 114, F Y, A / 3$

$\mathrm{FK}, 126, \mathrm{FY}, \mathrm{A} / 3$

$F K, 128, F Y, A / 3$

$F K, 130, F Y, A / 3$

!EXTRA FORCE ON THE END

!FK, 132,FY,117.226

!FK, 133,FY,117.226

!FK, 134,FY, 117.226

IPBC,U,1

LPLOT,ALL

ACEL,, 1 !GRAVITY IN Y-DIRECTION

!/OUTPUT,'MASS','txt','C:IMay92005ISTATIC GRAVITY',, 0

/PBC,F,1

!!!

!!!

!!!

ISOLU

ANTYPE,STATIC

NLGEOM,ON !NON LINEAR GEOMETRY ANALYSIS ACTIVATED

AUTOTS,ON !AUTO TIME STEPPING

NSUBST,10,1000,1 !SETS SIZE OF FIRST SUBSTEP TO 1/10 OF TOTAL LOAD, MAX

SUBST.1000

OUTRES,ALL,ALL

SOLVE

FINISH

/POST1

PRRSOL,F

!AXIAL,STRESS 


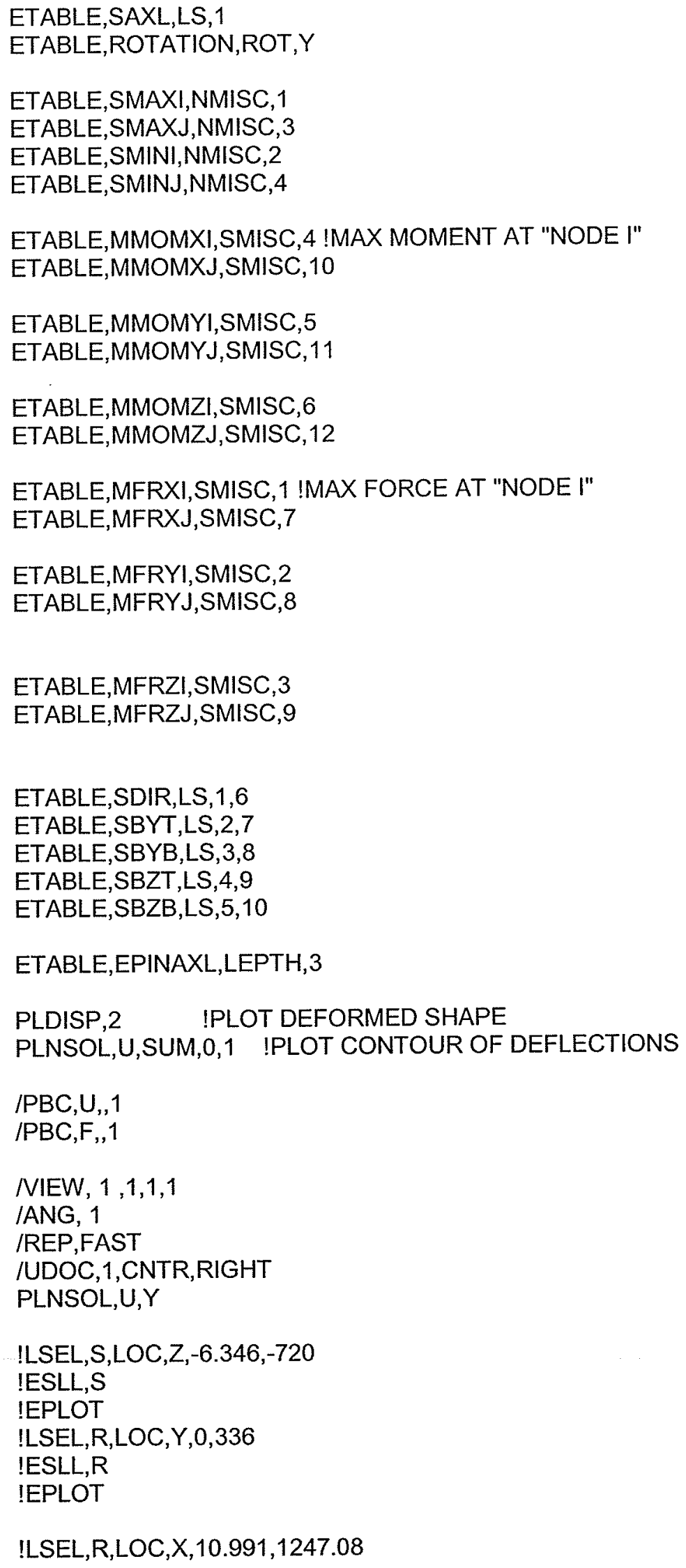




\section{Appendix-A}

!ESLL,R

!ESEL,R,ELEM , 28,1254

!/AUTO, 1

!/PBC,ALL, ,0

!/REP

!/PSYMB,CS, 1

!/PBC,ALL, ,0

!/REP 


\section{A.2 INPUT FILE FOR $45 \mathrm{~m}(147 \mathrm{ft})$ FRP TOWER}

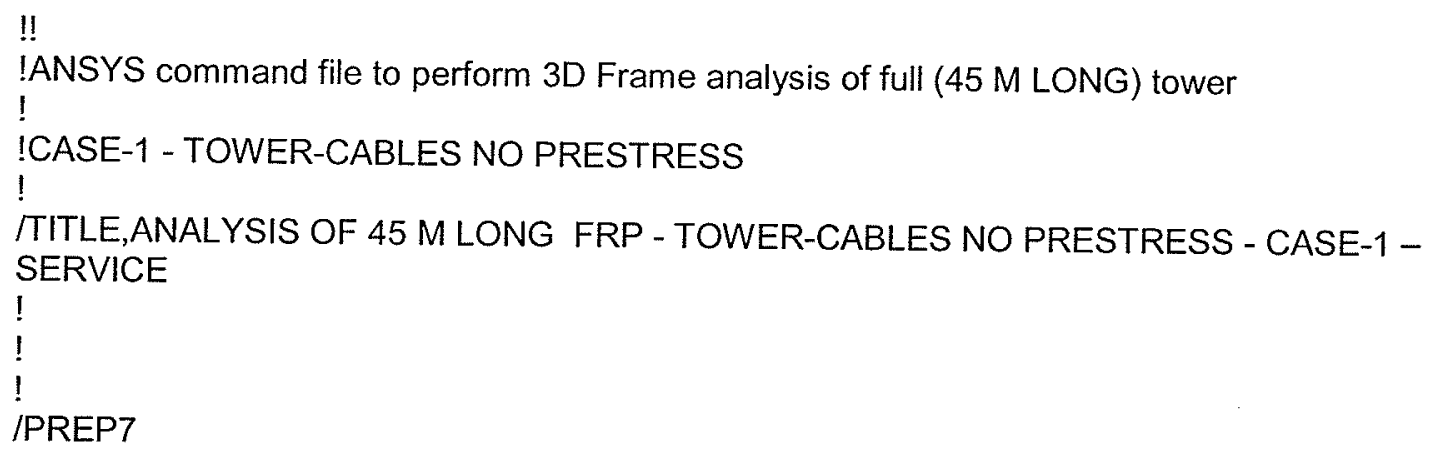




$\begin{array}{llll}\mathrm{K}, & 39,10.99100, & 126.0000, & -6.347000 \\ \mathrm{~K}, & 40,0.000000, & 136.5000, & -6.347000 \\ & & & \\ \mathrm{~K} & 41,-10.99100, & 126.0000, & -6.347000 \\ \mathrm{~K}, & 42,-5.495500, & 136.5000, & 3.172000 \\ \mathrm{~K}, & 43,0.000000, & 147.0000, & 12.69100 \\ \mathrm{~K}, & 44,5.495500, & 157.5000, & 3.172000 \\ \mathrm{~K}, & 45,10.99100, & 147.0000, & -6.347000 \\ \mathrm{~K}, & 46,0.000000, & 157.5000, & -6.347000 \\ \mathrm{~K}, & 47,-10.99100, & 147.0000, & -6.347000 \\ \mathrm{~K}, & 48,-5.495500, & 157.5000, & 3.172000 \\ \mathrm{~K}, & 49,0.000000, & 189.0000, & 12.69100 \\ \mathrm{~K}, & 50,5.495500, & 199.5000, & 3.172000 \\ \mathrm{~K}, & 51,10.99100, & 189.0000, & -6.347000 \\ \mathrm{~K}, & 52,0.000000, & 199.5000, & -6.347000 \\ \mathrm{~K}, & 53,0.000000, & 168.0000, & 12.69100 \\ \mathrm{~K}, & 54,5.495500, & 178.5000, & 3.172000 \\ \mathrm{~K}, & 55,-10.99100, & 189.0000, & -6.347000 \\ \mathrm{~K}, & 56,10.99100, & 168.0000, & 3.172000 \\ \mathrm{~K}, & 58,0.000000, & 178.5000, & -6.347000 \\ \mathrm{~K}, & 59,-10.99100, & 168.0000, & -6.347000 \\ \mathrm{~K}, & 60,0.000000, & 210.0000, & 12.69100\end{array}$

L, 4,5

L, 6,5

L, 6,10

L, 3,7

L, 11,10

L, 1,7

L, $\quad 11,12$

L, 1,8

L, $\quad 4,12$

L, 2,8

L, 13,14

L, $\quad 2,9$

L, 15,14

L, 3,9

L, 15,16

L, 17,16

L, 17,18

L, 13, 18

L, 19,20

L, $\quad 21,20$

L, $21, \quad 22$

L, 23,22

L, 23,24

L, 19,24

L, $3, \quad 4$

L, $\quad 4, \quad 13$

L, 13,19

L, 1,6

L, 6,15 
L, 15,21

L, 7,4

L, 7,6

L, 5,13

L, $5, \quad 15$

L, 14,19

L, $14, \quad 21$

L, $2, \quad 11$

L, 11,17

L, 17,23

L, 10,17

L, $\quad 9, \quad 11$

L, 9,4

L, 8,11

L, 8,6

L, 12,17

L, 12,13

L, 10,15

L, 18,23

L, 18,19

L, 16,23

L, 16,21

LGEN,4,ALL , ,,84

!ELEVATION=84"

$L, 23,70$

L, 19,64

L,21,67

$\mathrm{L}, 24,70$

$\mathrm{L}, 24,64$

L,20,64

L, 20,67

L,22,67

$\mathrm{L}, 22,70$

!ELEVATION=168"
L,78,88
$L, 82,94$
L,80,91
L, 79,88
L,79,91
$\mathrm{L}, 83,94$
L, 83,88
$\mathrm{L}, 81,94$
L,81,91
!ELEVATION=252"
L, 106,118
L, 102,112
L, 104, 115
L, 107,118
L, 107,112
$\mathrm{L}, 103,112$
L, 103,115
L, 105,118 


\footnotetext{
$\mathrm{L}, 105,115$

IHORIZONTAL BRACES

L, 64,67

$L, 67,70$

$L, 70,64$

$\mathrm{L}, 88,91$

$\mathrm{L}, 91,94$

L, 94,88

$\mathrm{L}, 112,115$

L, 115,118

$L, 118,112$

LGEN,5,ALL,,,,336

LGEN, $2,1,51,,, 1680$

!ELEVATION=336"

$L, 130,142$

$\mathrm{L}, 126,136$

$\mathrm{L}, 128,139$

$\mathrm{L}, 131,142$

L, 131,136

$L, 127,136$

$L, 127,139$

$\mathrm{L}, 129,139$

L, 129,142

!ELEVATION=672"

$L, 226,238$

L,222,232

L,224,235

$\mathrm{L}, 227,238$

$\mathrm{L}, 227,232$

$L, 223,232$

$\mathrm{L}, 223,235$

L, 225,235

$L, 225,238$

!ELEVATION=1008"

L,322,334

L, 318,328

L, 320,331

$L, 323,334$

L, 323,328

L, 319,328

$L, 319,331$

$\mathrm{L}, 321,331$

L, 321,334

!ELEVATION=1344"

L, 416,427

$\mathrm{L}, 414,424$

$\mathrm{L}, 418,430$

$\mathrm{L}, 415,427$

$\mathrm{L}, 415,424$

L, 417,427

$\mathrm{L}, 417,430$

$L, 419,430$

$L, 419,424$

!ELEVATION=1680"

L,514,526

L, 510,520
} 


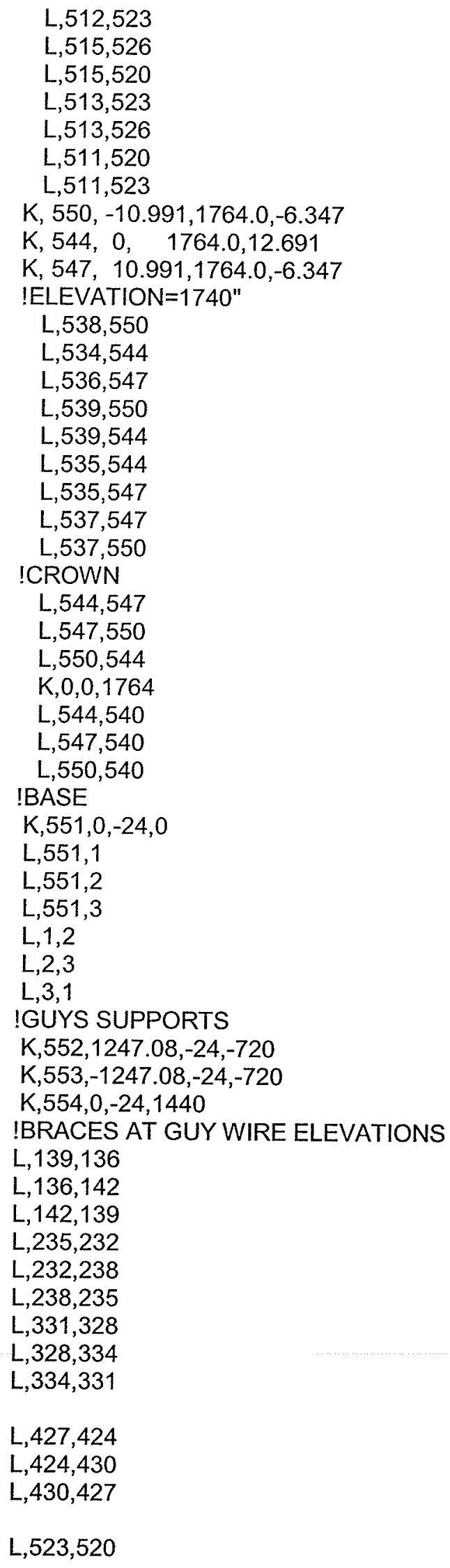


IGUY WIRES

!EL.336"

L,552,139

L, 553,142

L,554, 136

!EL.672"

L, 554,232

L, 552,235

$L, 553,238$

!EL.1008"

L, 552,331

L, 554,328

$L, 553,334$

!EL.1344"

L, 552,427

$L, 554,424$

$L, 553,430$

!EL.1680"

L, 552,523

L, 554,520

L,553,526

!ELEMENT TYPE GLOBAL CS

IREAL CONSTANT VARIATION TO ACCOUNT FOR ROTATION OF LOVAL CS TO

ET,1,BEAM4

!PROPERTIES OF VERTICAL COLUMNS

$! R, 1,3.0,3 \cdot 9374,1 \cdot 0,2,3, !$ AREA $=3 \mathrm{IN}^{\wedge} 2$

IR,1,1.5,1.9686,0.125,1,3,-120 !THETA=-120

$\mathrm{R}, 1,1.125,1.4766,0.0527,0.75,3,-120$ !THETA=-120 !COLUMNN-1,REAL CONSTANT-1

!AREA $=1.125, I Z Z=1.4766, I Y Y=0.0527, T K Z=0.75, T K Y=3, T H E T A=-120$

\section{ET, 1,BEAM4}

IPROPERTIES OF VERTICAL COLUMNS

!R,2,3.0,3.9374,1.0,2,3,!AREA $=3$ IN^$^{\wedge}$

$\mathrm{R}, 2,1.125,1.4766,0.0527,0.75,3,-60$ !THETA=-60 !COLUMNN-2,REAL CONSTANT-2 
!AREA $=1.125, \mathrm{IZZ}=1.4766, \mathrm{I} Y=0.0527, \mathrm{TKZ}=0.75, \mathrm{TKY}=3, \mathrm{THETA}=-60$

\section{ET,1,BEAM4}

IPROPERTIES OF VERTICAL COLUMNS

!R,3,3.0,3.9374,1.0,2,3,!AREA $=3 \mathrm{IN}^{\wedge} 2$

$\mathrm{R}, 3,1.125,1.4766,0.0527,0.75,3,-90$ !THETA=-90 !COLUMNN-3,REAL CONSTANT-3 ! AREA = 1.125, IZZ =1.4766, IYY=0.0527, TKZ=0.75, TKY=3, THETA=-90

!PROPERTIES OF CROSS-BRACINGS

$\mathrm{R}, 4,0.25,0.0052,0.0052,0.5,0.5$, !REAL CONSTANT-4

!PROPRTIES OF HORIZ BRACINGS

$R, 5,0.500,0.0104,0.0417,1.0,0.5,90$ !REAL CONSTANT-5

!AREA $=0.5, \mathrm{IZZ}=0.0104, \mathrm{IYY}=0.0417, \mathrm{TKZ}=1, \mathrm{TKY}=0.5, \mathrm{THETA}=90$

!PROPRTIES OF GUY CABLES

ET,2,LINK10,0,

R,6,0.0285,0 !NO INITIAL PRESTRESS ON 3/16"GUY CABLE !REAL CONSTANT-6 !

IR,6,0.0285,0.00048397 !INITIAL STRAIN FROM 400LB PRESTRESS ON 3/16"GUY CABLE !REAL CONSTANT-6

!R,6,0.035,0.00039406 !INITIAL STRAIN FROM 400LB PRESTRESS ON 1/4" GUY CABLE

!ORTHOTROPIC MATRIAL PROPERTIES-TOWER

MP,EX,1,3.69e6 !LB/IN^2 !MATERIAL TYPE-1

MP,EY, $1,0.615 \mathrm{e} 6$ !LB/IN^2

$\mathrm{MP}, \mathrm{EZ}, 1,0.615 \mathrm{e} 6$ !LB/IN^2

$M P, G X Y, 1,0.4 \mathrm{e} 6 ! \mathrm{LB} / \mathrm{IN}^{\wedge} 2$

MP,GYZ,1,0.4e6 !LB/IN^2

$M P, G X Z, 1,0.4 \mathrm{e} 6 ! \mathrm{LB} / \mathrm{IN}^{\wedge} 2$

MP,PRXY, $1,0.35$

MP,PRYZ, 1,0.06

$M P, P R X Z, 1,0.35$

MP,DENS, $1,0.076$ !LB/IN^3 


\section{!ISOTROPIC MATRIAL PROPERTIES-GUYS}

MP,EX,2,29E6 IMATERIAL TYPE-2

$M P, P R X Y, 2,0.3$

MP,DENS,2,0.284 !LB/IN^3

!ISOTROPIC MATRIAL PROPERTIES-BASE

MP,EX,3,29E6 IMATERIAL TYPE-3

MP,PRXY,3,0.3

MP,DENS,3,0.284!LB/IN^3

ET,3,PIPE16 ! EIEMENT TYPE = PIPE 16

KEYOPT, 1,6,1 ! changed option to give the extra force and mom output!*

$\mathrm{R}, 7,3,0.1875$,! Real Constant=7, Material=3, Outside Diameter, Wall thickness! ${ }^{*}$

\section{LSEL,ALL}

LATT,1,4,1 !MAT-1,REAL-4,TYPE-1 !CROSS-BRACING

LSEL,ALL

LSEL,S,LOC,Z,12.691 !COLUMN-3

LATT $, 1,3,1$

LSEL,ALL

LSEL,S,LOC,X,10,991!COLUMN-1

LATT $, 1,1,1$

LSEL,ALL

LSEL,S,LOC,X,-10.991 !COLUMN-2

LATT $, 1,2,1$

LSEL,ALL !HORIZ-BRACING

LSEL,S,LOC, Y,336

LATT, $1,5,1$

LSEL,ALL

!GUY CABLES

LSEL,S,LINE, ,1345

LATT, 2,6,2

LSEL,ALL

LSEL,S,LINE,, 1342

LATT, 2,6,2

LSEL,ALL

LSEL,S,LINE, , 1339

LATT, 2,6,2

LSEL,ALL

LSEL,S,LINE, , 1337

LATT, 2,6,2 


\author{
LSEL,ALL \\ LSEL,S,LINE,,1333 \\ LATT, $2,6,2$ \\ LSEL,ALL \\ LSEL,S,LINE,, 1346 \\ LATT, 2,6,2 \\ LSEL,ALL \\ LSEL,S,LINE, 1343 \\ LATT, 2,6,2 \\ LSEL,ALL \\ LSEL,S,LINE, 1340 \\ LATT, 2,6,2 \\ LSEL,ALL \\ LSEL,S,LINE,, 1336 \\ LATT, 2,6,2 \\ LSEL,ALL \\ LSEL,S,LINE,,1335 \\ LATT, 2,6,2 \\ LSEL,ALL \\ LSEL,S,LINE, , 1347 \\ LATT, $2,6,2$ \\ LSEL,ALL \\ LSEL,S,LINE, 1344 \\ LATT, 2,6,2 \\ LSEL,ALL \\ LSEL,S,LINE, , 1341 \\ LATT, $2,6,2$ \\ LSEL,ALL \\ LSEL,S,LINE,,1338 \\ LATT, 2,6,2 \\ LSEL,ALL \\ LSEL,S,LINE, 1334 \\ LATT, 2,6,2 \\ LSEL,ALL
}

!HORIZ BRACING

LSEL,S,LOC,Y,672

LATT, 1,5,1

LSEL,ALL

LSEL,S,LOC,Y,1008

LATT, $1,5,1$

LSEL,ALL

LSEL,S,LOC,Y, 1344

LSEL,R,LINE, , 1327,1329,1, LATT, $1,5,1$

LSEL,ALL

LSEL,S,LOC,Y,1680

LSEL,R,LINE,,1330,1332,1,

LATT, $1,5,1$ 


\author{
LSEL,ALL \\ LSEL,S,LOC, Y,84 \\ LATT, $1,5,1$ \\ LSEL,ALL \\ LSEL,S,LOC,Y,168 \\ LATT, 1,5,1 \\ LSEL,ALL \\ LSEL,S,LOC,Y,252 \\ LATT, 1,5,1 \\ LSEL,ALL \\ LSEL,S,LOC,Y,420 \\ LATT, 1,5,1 \\ LSEL,ALL \\ LSEL,S,LOC,Y,504 \\ LATT, $1,5,1$ \\ LSEL,ALL \\ LSEL,S,LOC,Y,588 \\ LATT, 1,5,1 \\ LSEL,ALL \\ LSEL,S,LOC,Y,756 \\ LATT, $1,5,1$ \\ LSEL,ALL \\ LSEL, S,LOC, Y,840 \\ LATT, $1,5,1$ \\ LSEL,ALL \\ LSEL,S,LOC, Y,924 \\ LATT, 1,5,1 \\ LSEL,ALL \\ LSEL,S,LOC,Y,1092 \\ LSEL,R,LINE, ,952,954,1 \\ LATT, 1,5,1 \\ LSEL,ALL \\ LSEL,S,LOC,Y,1176 \\ LSEL,R,LINE, ,955,957,1 \\ LATT, 1,5,1 \\ LSEL,ALL \\ LSEL,S,LOC,Y,1260 \\ LSEL,R,LINE, $958,960,1$ \\ LATT, 1,5,1 \\ LSEL,ALL \\ LSEL,S,LOC,Y,1428 \\ LSEL,R,LINE, ,1192,1194,1 \\ LATT, $1,5,1$
}


LSEL,ALL

LSEL,S,LOC,Y,1512

LSEL,R,LINE, ,1195,1197,1

LATT, $1,5,1$

LSEL,ALL

LSEL,S,LOC, Y,1596

LSEL,R,LINE,,1198,1200,1

LATT, $1,5,1$

LSEL,ALL

LSEL,S,LOC,Y,1764

LSEL,R,LINE, , 1306,1308,1

LATT, $1,5,1$

LSEL,ALL

LSEL,S,LOC,Y,-24,0

LSEL,R,LINE, ,1312,1314,1

LATT, 3, 7,3

LSEL,ALL

LESIZE,ALL, ,, 1

LMESH,ALL

!

!

FINISH !FINISH PREPROCESSOR

!

ISOLU !ENTER SOLUTION PHASE

!APPLY CONSTRAINS

!*BOUNDARY CNDITIONS

DK,552,UX,0

DK, 552,UY,0

$\mathrm{DK}, 552, \mathrm{UZ}, 0$

DK,553,UX,0

DK, 553,UY,0

DK, 553,UZ, 0

DK, 554,UX,0

DK, 554,UY,0

DK, 554,UZ,0

DK,551,UX,0

DK, $551, U Y, 0$

DK,551,UZ,0

/PBC,U,1

LPLOT,ALL

IDEFINE FORCES ON KEYPOINTS 


\section{! POINT LOADINGS ON PANELS \\ $A=15.64$ !ELEV.0"-84" \\ $B=17.97$ !ELEV.84"-168" \\ $\mathrm{C}=19.49$ !ELEV.168"-252" \\ $D=20.64$ !ELEV.252"-336" \\ $E=21.58$ !ELEV.336"-420" \\ $F=22.38$ !ELEV.420"-506" \\ $\mathrm{G}=23.09$ !ELEV.506"-588" \\ $H=23.71$ !ELEV.588"-672" \\ $\mathrm{I}=24.28$ !ELEV.672"-756" \\ $\mathrm{J}=24.79$ !ELEV.756"-840" \\ $\mathrm{K} 1=25.27$ !ELEV.840"-924" \\ L1=25.71 !ELEV.924"-1008" \\ $M=26.13$ !ELEV.1008"-1092" \\ $\mathrm{N}=26.52$ !ELEV.1092"-1176" \\ $\mathrm{O}=26.89$ !ELEV.1176"-1260" \\ $\mathrm{P}=27.24$ !ELEV.1260"-1344" \\ $\mathrm{Q}=27.57$ !ELEV.1344"-1428" \\ $\mathrm{R}=27.88$ !ELEV.1428"-1512" \\ $\mathrm{S}=28.18$ !ELEV.1512"-1586" \\ $\mathrm{T}=28.48$ !ELEV.1596"-1680" \\ $\mathrm{U}=28.76$ !ELEV.1680"-1764"}

!CASE-1 SERVICE - (95 KM/HOUR--- WIND ONLY)

!CASE-2 FACTORED - $\left(1.5^{\star}(95 \mathrm{KM} / \mathrm{HOUR}---\right.$ WIND ONLY $\left.)\right)$

! $\mathrm{A}=23.46$ !ELEV.0"-84"

! $\mathrm{B}=26.95$ !ELEV.84"-168"

!C=29.23 !ELEV. 168"-252"

!D=30.96 !ELEV.252"-336"

! $=32.37$ !ELEV. $336^{\prime \prime}-420^{\prime \prime}$

IF=33.58 !ELEV.420"-506"

! $\mathrm{G}=34.63$ !ELEV.506"-588"

!H=35.57 !ELEV.588"-672"

$! \mid=36.41$ !ELEV.672"-756"

!J=37.19 !ELEV.756"-840"

!K1 $=37.90$ !ELEV. $840 "-924 "$

!L1=38.57 !ELEV.924"-1008"

!M=39.19 !ELEV.1008"-1092"

!N=39.78 !ELEV.1092"-1176"

$! O=40.33$ !ELEV.1176"-1260"

!P=40.85 !ELEV.1260"-1344"

! $Q=41.35$ !ELEV.1344"-1428"

! $R=41.83$ !ELEV.1428"-1512"

IS $=42.28$ !ELEV.1512"-1586"

!T=42.72 !ELEV.1596"-1680"

!U=43.14 !ELEV.1680"-1764"

ICASE-3 SERVICE - (25 MM ICE AND 95 KM/HOUR WIND ) 


$$
\begin{aligned}
& \text { !A=29.35 !ELEV.0"-84" } \\
& \text { ! } \mathrm{B}=33.72 \text { !ELEV.84"-168" } \\
& \text { !C }=36.57 \text { !ELEV. 168"-252" } \\
& \text { !D }=38.73 \text { !ELEV.252"-336" } \\
& \text { ! } E=40.50 \text { !ELEV.336"-420" } \\
& \text { ! } \mathrm{F}=42.00 \text { !ELEV.420"-506" } \\
& \text { ! } \mathrm{G}=43.32 \text { !ELEV.506"-588" } \\
& \text { ! } \mathrm{H}=44.49 \text { !ELEV.588"-672" } \\
& \text { !I=45.55 !ELEV.672"-756" } \\
& \text { !J }=46.52 \text { !ELEV.756"-840" } \\
& \text { !K1=47.42 !ELEV.840"-924" } \\
& \text { !L1=48.25 !ELEV.924"-1008" } \\
& \text { ! } M=49.03 \text { !ELEV.1008"-1092" } \\
& \text { !N=49.76 !ELEV.1092"-1176" } \\
& ! O=50.45 \text { !ELEV.1176"-1260" } \\
& \text { IP=51.11 !ELEV.1260"-1344" } \\
& ! Q=51.73 \text { !ELEV.1344"-1428" } \\
& \text { ! } R=52.32 \text { !ELEV.1428"-1512" } \\
& \text { !S=52.89 !ELEV.1512"-1586" } \\
& \text { !T=53.44 !ELEV.1596"-1680" } \\
& \text { !U=53.96 !ELEV.1680"-1764" }
\end{aligned}
$$

!CASE-4 FACTORED- $1.5^{\star}$ (25 MM ICE AND $95 \mathrm{KM} / \mathrm{HOUR}$ WIND)

!A=44.03 !ELEV.0"-84"

! $\mathrm{B}=50.58$ !ELEV.84"-168"

$! C=54.85$ !ELEV.168"-252"

!D=58.10 !ELEV.252"-336"

! $=60.75$ !ELEV.336"-420"

! $F=63.00$ !ELEV.420"-506"

!G=64.98 !ELEV.506"-588"

!H=66.74 !ELEV.588"-672"

!I=68.33 !ELEV.672"-756"

! $\mathrm{J}=69.78$ !ELEV.756"-840"

!K1=71.12 !ELEV.840"-924"

!L1=72.37 !ELEV.924"-1008"

! $M=73.54$ !ELEV.1008"-1092"

! $\mathrm{N}=74.64$ !ELEV.1092"-1176"

!O=75.68 !ELEV.1176"-1260"

IP=76.66 !ELEV.1260"-1344"

!Q=77.59 !ELEV.1344"-1428"

! $R=78.49$ !ELEV.1428"-1512"

IS $=79.34$ !ELEV.1512"-1586"

$! T=80.16$ !ELEV.1596"-1680"

!U=80.94 !ELEV.1680"-1764"

!ELEV.0"-84" -"A"

$F K, 1, F Z, A$

$F K, 2, F Z, A$

$F K, 6, F Z, A$

$F K, 11, F Z, A$ 
FK, 15,FZ,A

$F K, 17, F Z, A$

$F K, 21, F Z, A$

$F K, 23, F Z, A$

!ELEV.84"-168" -"B"

$F K, 70, F Z, B$

FK,67,FZ,B

$\mathrm{FK}, 66, \mathrm{FZ}, \mathrm{B}$

FK,62,FZ,B

$\mathrm{FK}, 76, \mathrm{FZ}, \mathrm{B}$

$\mathrm{FK}, 74, \mathrm{FZ}, \mathrm{B}$

$F K, 82, F Z, B$

$F K, 80, F Z, B$

!ELEV.168"-252" -"C"

FK,91,FZ,C

FK, 94,FZ,C

$F K, 86, F Z, C$

$F K, 90, F Z, C$

FK,98,FZ,C

$F K, 100, F Z, C$

FK, 104,FZ,C

FK, 106,FZ,C

!ELEV.252"-336"-"D"

FK,115,FZ,D

FK, 118,FZ,D

$F K, 110, F Z, D$

FK, 114,FZ,D

FK,122,FZ,D

FK, 124,FZ,D

FK, 128,FZ,D

FK, 130,FZ,D

!ELEV.336"-420" -"E"

FK, 139,FZ,E

FK, 142,FZ,E

FK,134,FZ,E

FK, 138,FZ,E

FK, 146,FZ,E

FK, 148,FZ,E

FK, 152,FZ,E

FK, 154,FZ,E

!ELEV.420"-506"-"F"

FK,163,FZ,F

$F K, 166, F Z, F$

FK, 158,FZ,F

FK, 162,FZ,F 
FK,170,FZ,F

$F K, 172, F Z, F$

FK, 176,FZ,F

FK, 178,FZ,F

!ELEV.506"-588"-"G"

FK,187,FZ,G

$F K, 190, F Z, G$

$F K, 182, F Z, G$

FK,186,FZ,G

FK, 194,FZ,G

FK,196,FZ,G

$F K, 200, F Z, G$

FK,202,FZ,G

!ELEV.588"-672"-"H"

$\mathrm{FK}, 211, \mathrm{FZ}, \mathrm{H}$

$F K, 214, F Z, H$

$F K, 206, F Z, H$

FK,210,FZ,H

FK,218,FZ,H

FK, 220,FZ,H

$\mathrm{FK}, 224, \mathrm{FZ}, \mathrm{H}$

$F K, 226, F Z, H$

!ELEV.672"-756"-"|"

$F K, 235, F Z, I$

$F K, 238, F Z$,I

$F K, 230, F Z$,I

$F K, 234, F Z, I$

$F K, 242, F Z, I$

$F K, 244, F Z$,I

$F K, 248, F Z$,I

$F K, 250, F Z, I$

!ELEV.756"-840"-"J"

$F K, 259, F Z, J$

FK,262,FZ,J

FK,254,FZ,J

FK,258,FZ,J

$F K, 266, F Z, J$

$F K, 268, F Z, J$

$\mathrm{FK}, 272, \mathrm{FZ}, \mathrm{J}$

FK,274,FZ,J

!ELEV.840"-924"-"K1"

$F K, 283, F Z, K 1$

$F K, 286, F Z, K 1$

$F K, 278, F Z, K 1$

$F K, 282, F Z, K 1$

$F K, 290, F Z, K 1$ 


\footnotetext{
$\mathrm{FK}, 292, \mathrm{FZ}, \mathrm{K} 1$

$F K, 296, F Z, K 1$

$F K, 298, F Z, K 1$

!ELEV.924"-1008"-"L1"

FK,307,FZ,L1

FK,310,FZ,L1

$F K, 302, F Z, L 1$

FK,306,FZ,L1

FK,314,FZ,L1

FK,316,FZ,L1

FK,320,FZ,L1

FK,322,FZ,L1

!ELEV.1008"-1092"-"M"

FK,331,FZ,M

FK,334,FZ,M

FK,326,FZ,M

$F K, 330, F Z, M$

FK,338,FZ,M

$F K, 340, F Z, M$

FK,344,FZ,M

FK,346,FZ,M

!ELEV.1092"-1176" -"N"

$F K, 355, F Z, N$

$F K, 358, F Z, N$

$F K, 350, F Z, N$

FK,354,FZ,N

$\mathrm{FK}, 362, \mathrm{FZ}, \mathrm{N}$

$F K, 364, F Z, N$

FK,368,FZ,N

$F K, 370, F Z, N$

!ELEV.1176"-1260"-"O"

FK, 379,FZ,O

$\mathrm{FK}, 382, \mathrm{FZ}, \mathrm{O}$

$F K, 374, F Z, O$

FK,378,FZ,O

FK,386,FZ,O

FK,388,FZ,O

$F K, 392, F Z, O$

FK,394,FZ,O

!ELEV.1260"-1344"-"P"

FK,403,FZ,P

FK, 406,FZ,P

FK, 398,FZ,P

$\mathrm{FK}, 402, \mathrm{FZ}, \mathrm{P}$

$F K, 410, F Z, P$

FK,412,FZ,P
} 
FK,416,FZ,P

$F K, 418, F Z, P$

!ELEV.1344"-1428"-"Q"

$F K, 427, F Z, Q$

$F K, 430, F Z, Q$

$F K, 422, F Z, Q$

$F K, 426, F Z, Q$

$F K, 434, F Z, Q$

$\mathrm{FK}, 436, \mathrm{FZ}, \mathrm{Q}$

$F K, 440, F Z, Q$

FK,442,FZ,Q

!ELEV.1428"-1512" -"R"

FK,451,FZ,R

FK,454,FZ,R

$F K, 446, F Z, R$

$F K, 450, F Z, R$

FK,458,FZ,R

FK,460,FZ,R

$F K, 464, F Z, R$

FK,466,FZ,R

!ELEV.1512"-1586"-"S"

$\mathrm{FK}, 475, \mathrm{FZ}, \mathrm{S}$

FK,478,FZ,S

$\mathrm{FK}, 470, \mathrm{FZ}, \mathrm{S}$

$\mathrm{FK}, 474, \mathrm{FZ}, \mathrm{S}$

FK, 482,FZ,S

FK,484,FZ,S

FK,488,FZ,S

FK,490,FZ,S

!ELEV.1596"-1680"-"T"

FK,499,FZ,T

FK,502,FZ,T

FK,494,FZ,T

FK,498,FZ,T

FK,506,FZ,T

FK,508,FZ,T

FK,512,FZ,T

FK,514,FZ,T

!ELEV.1680"-1764"-"U"

FK,523,FZ,U

$F K, 526, F Z, U$

$F K, 518, F Z, U$

$F K, 522, F Z, U$

$F K, 530, F Z, U$

$F K, 532, F Z, U$

$F K, 536, F Z, U$ 
FK,538,FZ,U

FK, 547,FZ,U

FK, 550,FZ,U

ACEL,, 1 !GRAVITY IN Y-DIRECTION

!/OUTPUT,'MASS','txt','C:IMay92005ISTATIC GRAVITY',, 0

$/ \mathrm{PBC}, \mathrm{F}_{, 1}, 1$

!!!

!!!

!!!

ISOLU

ANTYPE,STATIC

NLGEOM,ON INON LINEAR GEOMETRY ANALYSIS ACTIVATED

AUTOTS,ON IAUTO TIME STEPPING

SUBST. 1000

OUTRES,ALL,ALL

SOLVE

FINISH

IPOST1

PRRSOL,F

!AXIAL,STRESS

ETABLE,SAXL,LS, 1

ETABLE,ROTATION,ROT,Y

ETABLE,SMAXI,NMISC, 1

ETABLE,SMAXJ,NMISC, 3

ETABLE,SMINI,NMISC,2

ETABLE,SMINJ,NMISC, 4

ETABLE,MMOMXI,SMISC,4 !MAX MOMENT AT "NODE I"

ETABLE,MMOMXJ,SMISC, 10

ETABLE,MMOMYI,SMISC,5

ETABLE,MMOMYJ,SMISC, 11

ETABLE,MMOMZI,SMISC,6

ETABLE,MMOMZJ,SMISC,12

ETABLE,MFRXI,SMISC, 1 !MAX FORCE AT "NODE I"

ETABLE,MFRXJ,SMISC, 7

ETABLE,MFRYI,SMISC,2

ETABLE,MFRYJ,SMISC,8 
ETABLE,MFRZI,SMISC, 3

ETABLE,MFRZJ,SMISC,9

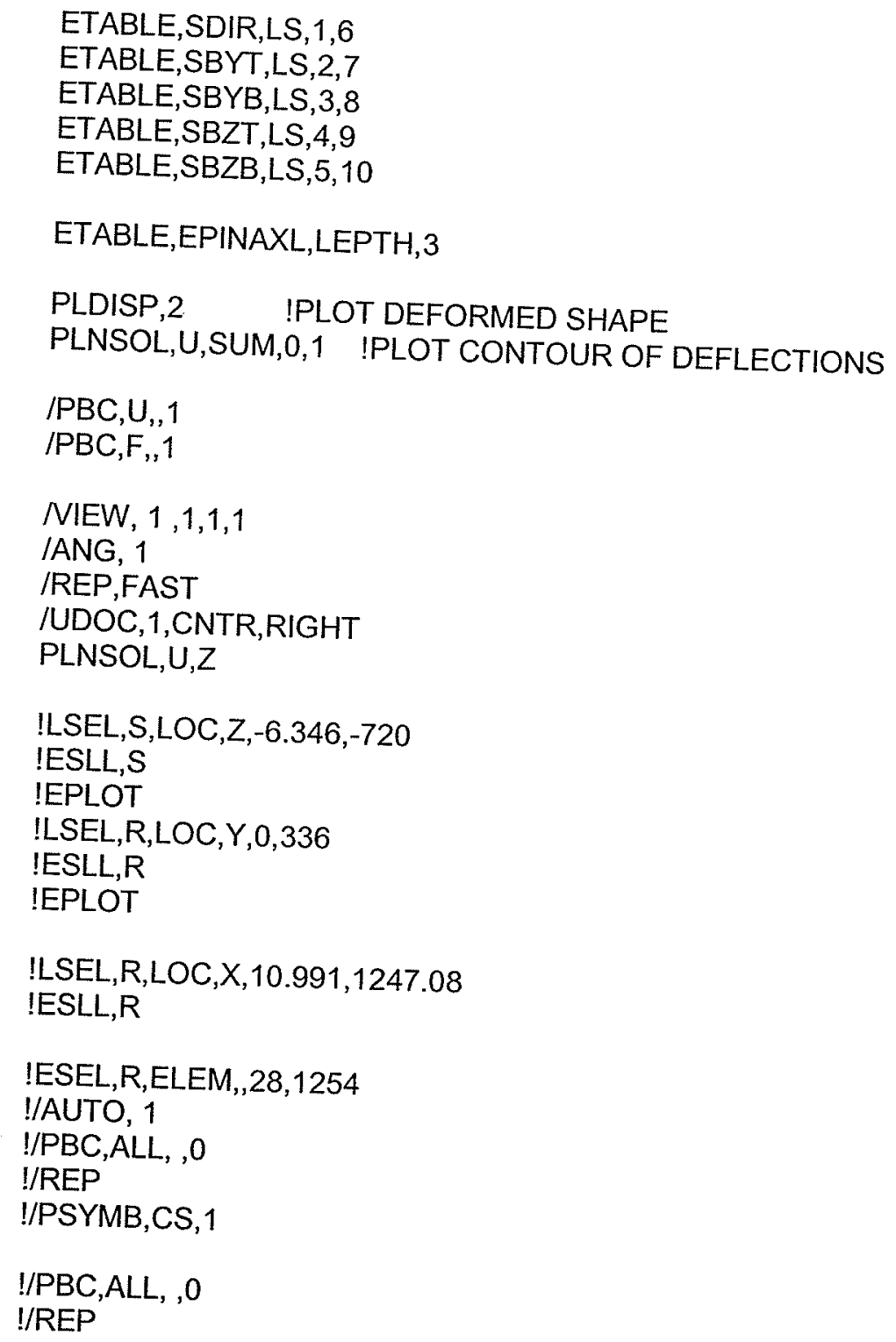




\section{APPENDIX-B}

FEM MODELING OF STEEL TOWER 


\section{B.3 Finite Element Modelling of a Steel Tower}

In order to evaluate the cost associated with the construction of an FRP tower, a comparison between an FRP and a Steel tower was undertaken. A new FE model of $45 \mathrm{~m}$ (147 ft ) tower was assembled based on the cross sectional properties shown in Fig. B.3.1. the same member arrangement as for FRP tower was used. Schifflerized angles ( $90^{\circ}$ hot-rolled equal leg angles bent to $60^{\circ}$ ) $\mathrm{L} 76 \mathrm{x}$ $76 \times 4.8$ were chosen for the main chord members of the steel tower. The vertical and diagonal bracing members were assumed to be $25 \times 25 \times 3.2$ standard angles. The procedure for wind loading calculation was outlined in Section 3.5.2.

However, the tributary areas of the typical panel configuration were revised, as shown in Fig. B.3.2. the results are shown in Table A.3.1.

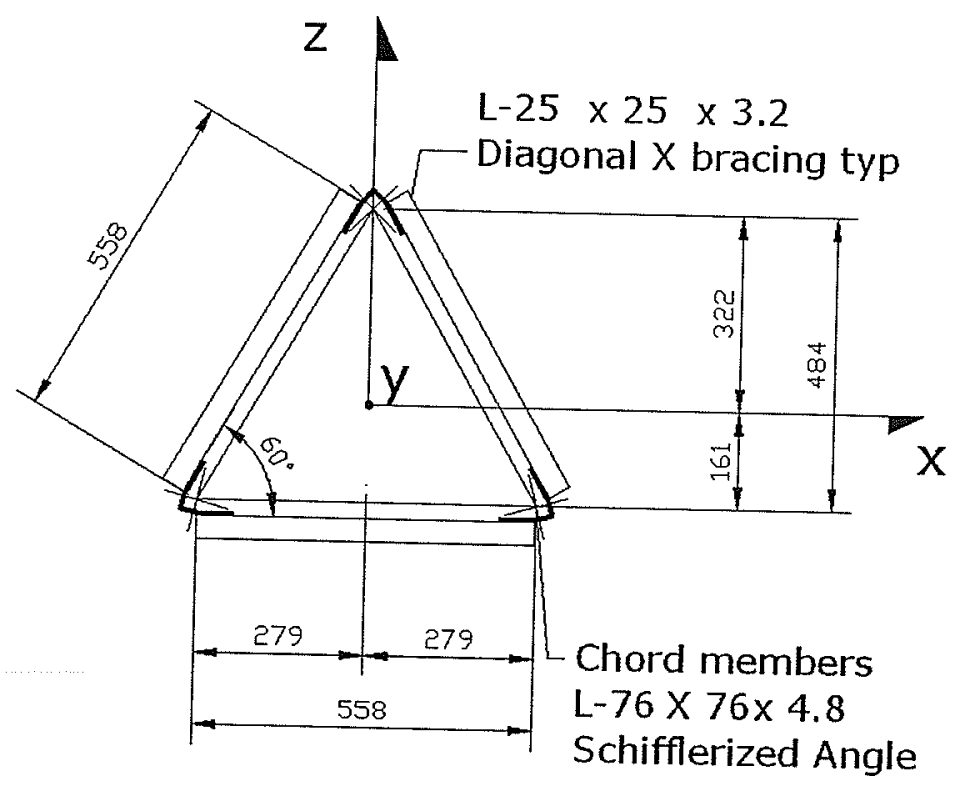

Fig. B.3 1 Steel tower cross section (all dimensions in $\mathrm{mm}$ ) 


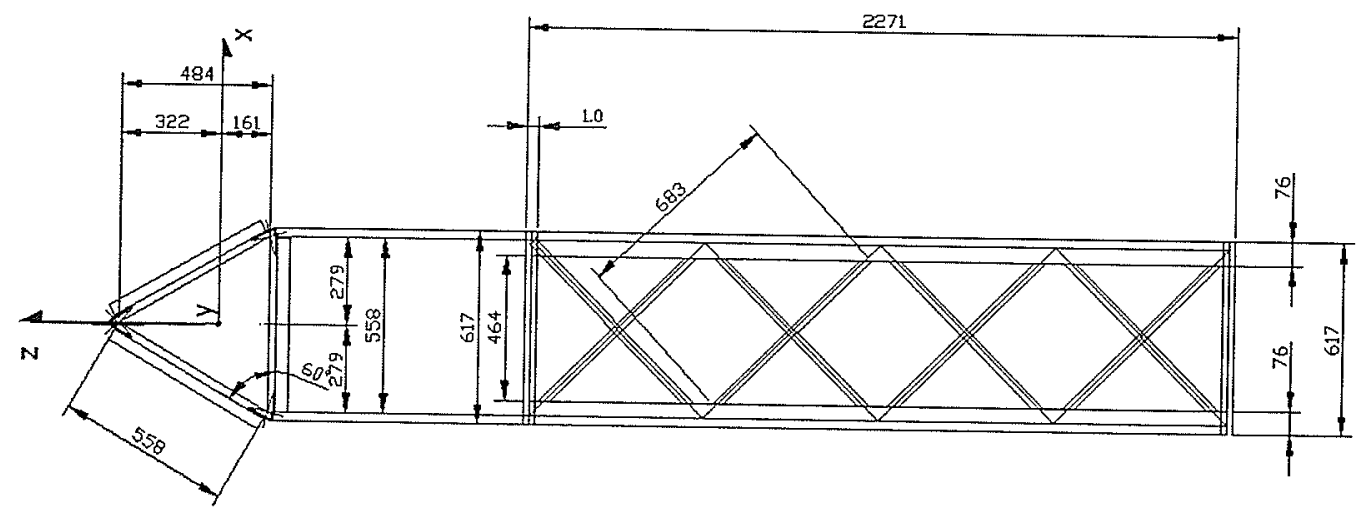

Fig. B.3 2 Steel tower typical panel (all dimensions in $\mathrm{mm}$ )

The size of the chord members was based on the minimum angle size available in the industry which can be bent to $60 \mathrm{deg}$. For horizontal and vertical bracing members, the minimum size available was also selected. 
Table B.3 1 Typical loading per node for steel tower

\begin{tabular}{|c|c|c|c|}
\hline \multicolumn{4}{|c|}{ Steel tower wind loadings } \\
\hline \multirow[b]{2}{*}{$\begin{array}{l}\text { Distance above the } \\
\text { base }(\mathrm{mm})\end{array}$} & \multirow{2}{*}{$\begin{array}{l}\text { P per } \\
\text { panel } \\
\text { (N) }\end{array}$} & \multirow{2}{*}{$\begin{array}{l}\text { UNFACTORED } \\
\begin{array}{c}\text { P per node } \\
(\mathbf{N})\end{array}\end{array}$} & \multirow{2}{*}{$\begin{array}{l}\text { FACTORED } \\
\begin{array}{c}\text { P per node } \\
\text { (N) }\end{array}\end{array}$} \\
\hline & & & \\
\hline $42672-44806$ & 1314.67 & 164.32 & 246.52 \\
\hline $40538-42672$ & 1301.91 & 162.76 & 244.12 \\
\hline $38405-40538$ & 1288.61 & 161.07 & 241.63 \\
\hline $36271-38405$ & 1274.77 & 159.34 & 239.00 \\
\hline $34138-36271$ & 1260.27 & 157.56 & 236.29 \\
\hline $32004-34138$ & 1245.10 & 155.64 & 233.44 \\
\hline $29870-32004$ & 1229.13 & 153.64 & 230.46 \\
\hline $27737-29870$ & 1212.27 & 151.55 & 227.30 \\
\hline $25603-27737$ & 1194.44 & 149.33 & 223.97 \\
\hline $23470-25603$ & 1175.49 & 146.92 & 220.41 \\
\hline $21336-23470$ & 1155.20 & 144.39 & 216.58 \\
\hline $19202-21336$ & 1133.36 & 141.68 & 212.49 \\
\hline 17069-19202 & 1109.74 & 138.74 & 208.09 \\
\hline $14935-17069$ & 1083.90 & 135.49 & 203.24 \\
\hline $12802-14935$ & 1055.34 & 131.93 & 197.86 \\
\hline $10668-12802$ & 1023.31 & 127.93 & 191.85 \\
\hline $8534-10668$ & 986.66 & 123.35 & 185.00 \\
\hline $6401-8534$ & 943.60 & 117.97 & 176.91 \\
\hline $4267-6401$ & 890.85 & 111.34 & 167.03 \\
\hline $2134-4267$ & 821.45 & 102.66 & 154.04 \\
\hline $0-2134$ & 715.10 & 89.41 & 134.07 \\
\hline
\end{tabular}

Using ANSYS 8.1 (ANSYS, 2004) the deflections for the $45 \mathrm{~m}$ (147 ft) steel tower were obtained and are shown in Fig. B.3.3. The deflections for an FRP tower of the same height are shown in Fig. B.3.4. 


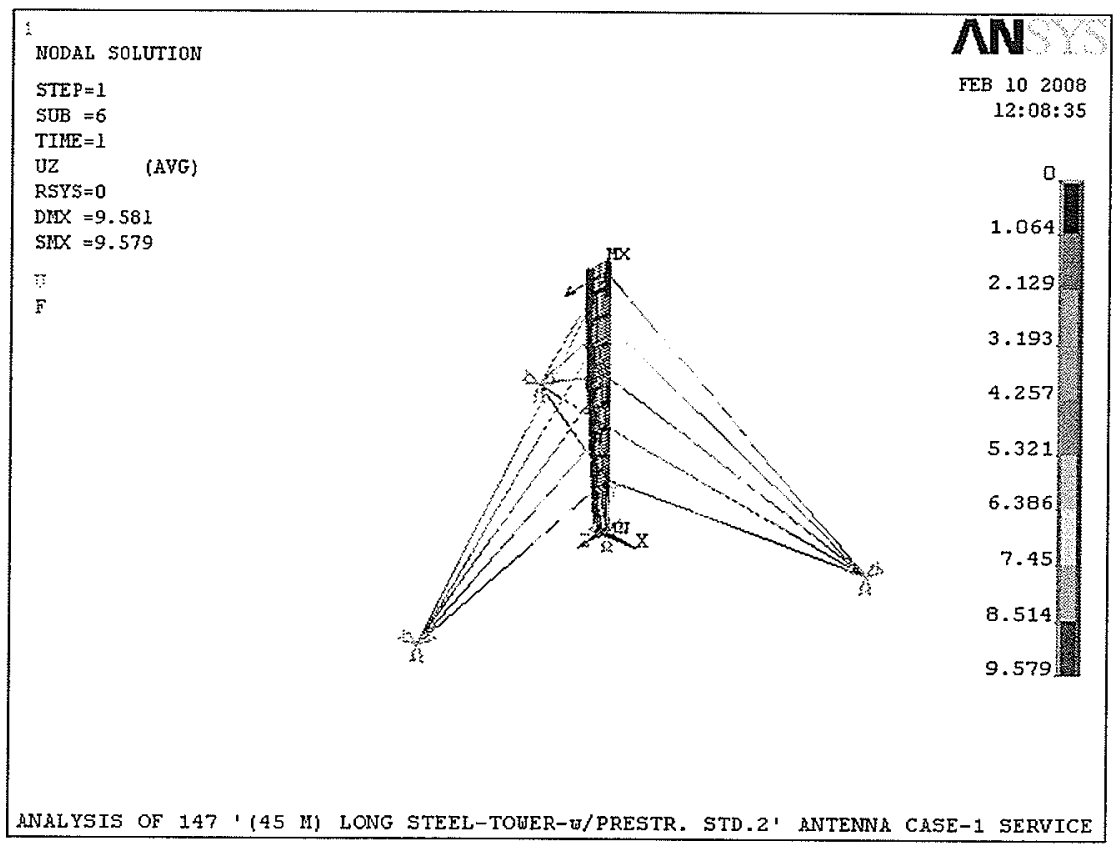

Fig. B.3 3 Maximum deflection of Steel tower (units are in inches)

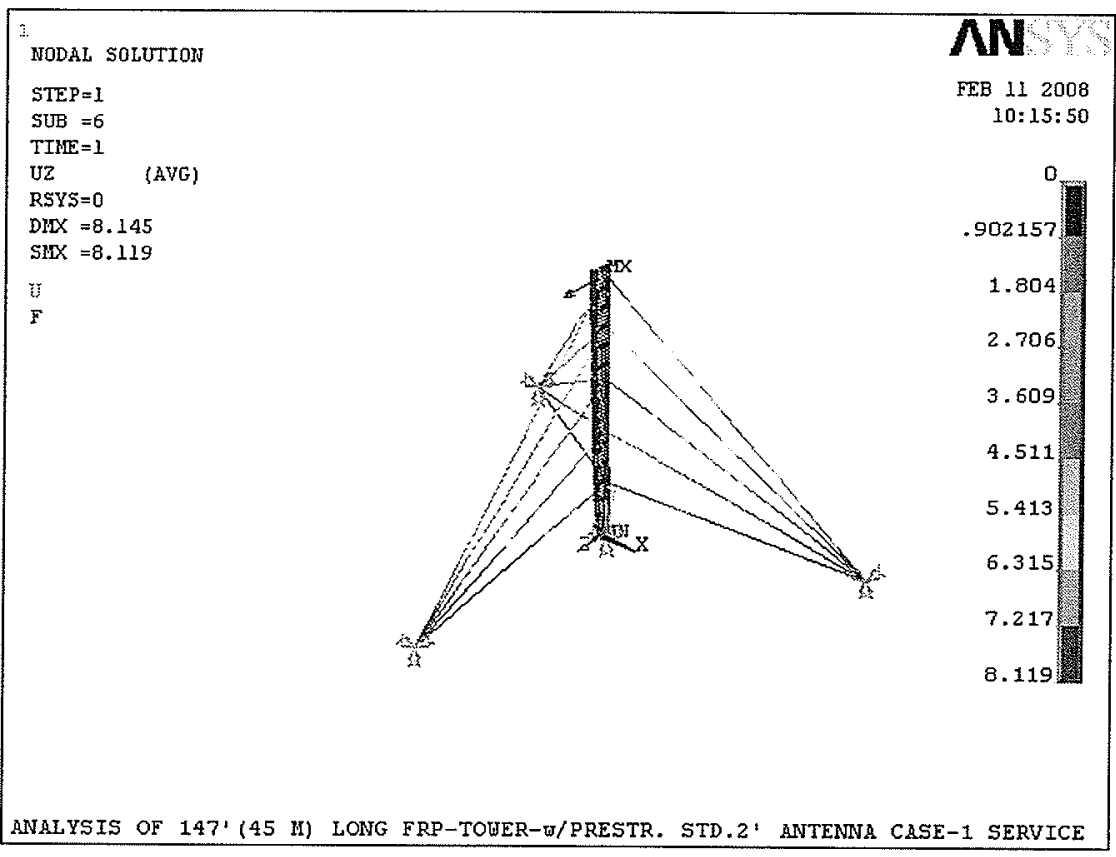

Fig. B.3 4 Maximum deflection of FRP tower (units are in inches) The deflections of both the Steel and FRP tower under the same loading conditions along the height are shown in in Fig. B.3.5. 


\section{DEFELCTION COMPARISON \\ FRP VS STEEL TOWER}

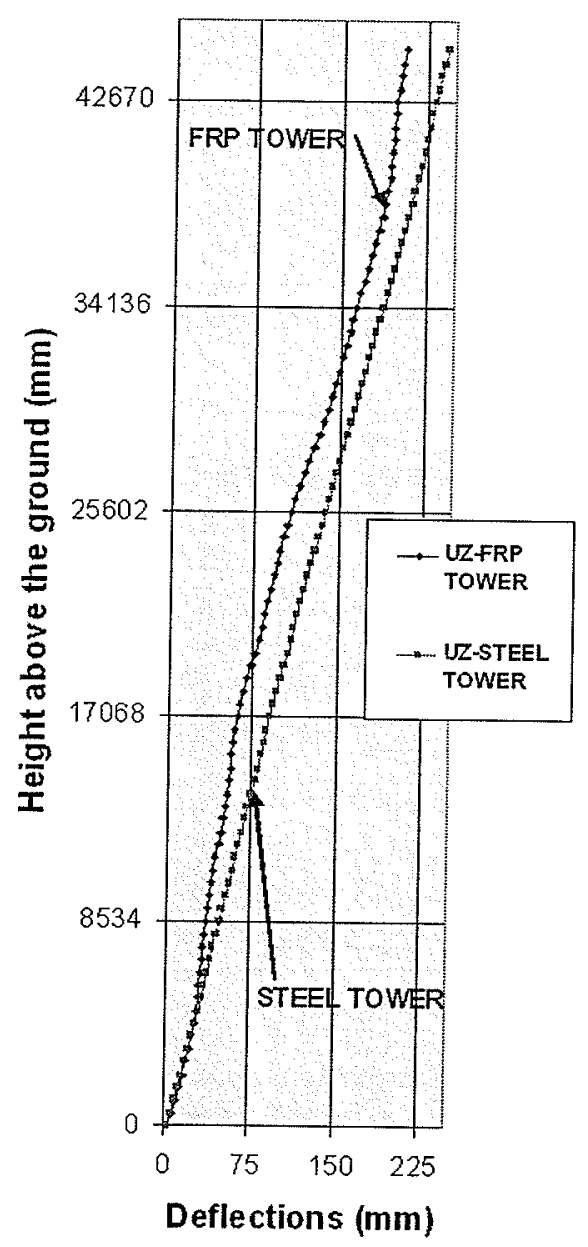

Fig. B.3 5 Deflection comparison between Steel and FRP towers

The maximum deflection at the tip of FRP tower uz is equal to $206.88 \mathrm{~mm}(8.14$ in) and is smaller than the tip deflection of steel tower, which is $243.61 \mathrm{~mm}(9.59$ in). Although the modulus of elasticity of the FRP material is $1 / 3$ of the modulus of elasticity of the steel, the steel tower exhibited larger deflections.

The difference in deflections may be attributed to the difference in the effective drag area $C_{d f} \times A_{f}$, where $C_{d f}$ is the drag factor of flat members and $A_{f}$ is the 
area of flat members. For the steel tower $C_{d f} \times A_{f}=1.18$, while for FRP tower, $C_{d f} \times A_{f}=0.84$. The masses of the two towers are listed in Table B.3.2.

The total mass of the tower depends on the tower length as shown in Fig. B.3.6.

Table B.3 2 Mass comparison FRP vs steel tower

\begin{tabular}{|c|c|c|}
\hline ITEM & FRP-Tower & STEEL Tower \\
\hline Tower & $361.58(\mathrm{~kg})$ & $1239.54(\mathrm{~kg})$ \\
\hline
\end{tabular}

Mast Total Mass $(\mathrm{kg})$

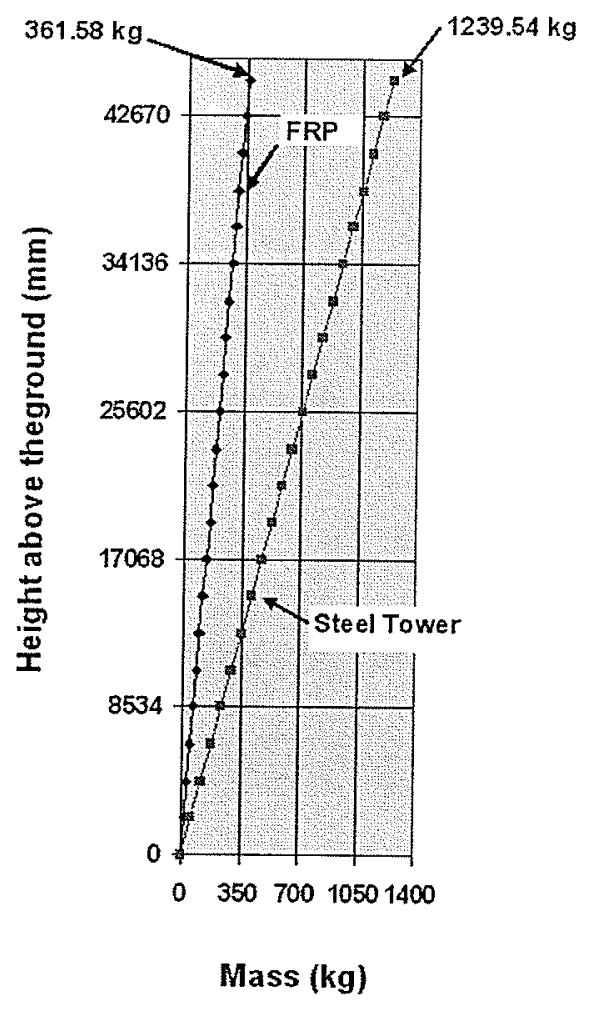

Fig. B.3 6 Total tower mass

These results showed that the steel tower made from the smallest available sections, having the same geometry as an FRP tower is $343 \%$ heavier than an 
FRP tower. Furthermore, the FRP tower performs better under wind loading due to smaller drag profile. In determining the total mass, the mass of the connections was not included. The average cost of glass fibre ranges between $\$ 2$ and $\$ 4$ dollars per $\mathrm{kg}$, the average cost of epoxy ranges between $\$ 6$ to $\$ 8$ dollars per $\mathrm{kg}$ and the average cost of structural steel is between $\$ 1.5$ and $\$ 2$ dollars per $\mathrm{kg}$. Table B.3.3 shows the comparison of the cost of the materials only required to produce the prototype tower. It can be seen that the FRP tower cost is lower than the steel tower. This FRP cost advantage can be further increased by increasing the fibre volume fraction.

Taking into account the need for corrosion protection and maintenance as well as the cost of transportation and erection, steel towers seem to be more expensive than the FRP towers.

Table B.3 3 Cost comparison FRP vs steel tower

\begin{tabular}{|c|c|c|}
\hline ITEM & FRP-Tower* & STEEL Tower \\
\hline Tower & $\$ 1638-\$ 2361$ & $\$ 1859-\$ 2479$ \\
\hline
\end{tabular}

*Note : based on $36.9 \%$ fibre volume fraction 